Florida International University

FIU Digital Commons

$10-22-2018$

\title{
Electrochemical Behaviors of the Electrodes for Proton Conducting Intermediate Temperature Solid Oxide Fuel Cells (IT- SOFC)
}

Shichen Sun

ssun006@fiu.edu

Follow this and additional works at: https://digitalcommons.fiu.edu/etd

Part of the Ceramic Materials Commons, and the Energy Systems Commons

\section{Recommended Citation}

Sun, Shichen, "Electrochemical Behaviors of the Electrodes for Proton Conducting Intermediate Temperature Solid Oxide Fuel Cells (IT-SOFC)" (2018). FIU Electronic Theses and Dissertations. 3915. https://digitalcommons.fiu.edu/etd/3915

This work is brought to you for free and open access by the University Graduate School at FIU Digital Commons. It has been accepted for inclusion in FIU Electronic Theses and Dissertations by an authorized administrator of FIU Digital Commons. For more information, please contact dcc@fiu.edu. 


\title{
FLORIDA INTERNATIONAL UNIVERSITY
}

\author{
Miami, Florida
}

\section{ELECTROCHEMICAL BEHAVIORS OF THE ELECTRODES FOR PROTON CONDUCTING INTERMEDIATE TEMPERATURE SOLID OXIDE FUEL CELLS (IT-SOFC)}

A dissertation submitted in partial fulfillment of the requirements for the degree of DOCTOR OF PHILOSOPHY

in

MATERIALS SCIENCE AND ENGINEERING

by

Shichen Sun

2018 
To: Dean John L. Volakis

College of Engineering and Computing

This dissertation, written by Shichen Sun and, entitled Electrochemical Behaviors of the Electrodes for Proton Conducting Intermediate Temperature Solid Oxide Fuel Cells (ITSOFC), having been approved in respect to style and intellectual content, is referred to you for judgment.

We have read this thesis and recommend that it be approved.

$\begin{array}{r}\hline \text { Arvind Agarwal } \\ \hline \text { Norman Munroe } \\ \hline \text { Yu Zhong } \\ \hline \text { Anil Virkar } \\ \hline \text { Zhe Cheng, Major Professor }\end{array}$

Date of Defense: Oct 22, 2018

The dissertation of Shichen Sun is approved.

Dean John L. Volakis College of Engineering and Computing

Andrés G. Gil Vice President for Research and Economic Development and Dean of the University Graduate School

Florida International University, 2018 


\section{DEDICATION}

I dedicate this thesis to my parents, Yafen Wang and Yaobo Sun and my girlfriend, Xiuyuan Yang for their consistent support and patience along all these years. 


\section{ACKNOWLEDGMENTS}

I would like to express my deepest gratitude to my adviser Dr. Zhe Cheng for his continuous support, guidance and encouragement during the project. Working with him has been a constant learning experience for me. Also, I would like to extend my appreciation to Dr. Arvind Agarwal, Dr. Norman Munroe, Dr. Yu Zhong and Dr. Anvil Virkar for serving as my committee members and providing insightful suggestions and guidance throughout the course of this research.

I like to take this opportunity and thank the support of Advanced Materials Engineering Research (AMERI) and Center for Study of Matter at Extreme Conditions (CeSMEC) at FIU for providing facilities.

I am thankful to University Graduate School, FIU for supporting me through Dissertation Year Fellowship (DYF) awards. Last but not the least; I would like to thank my parents and my girlfriend for having faith in me and motivating me in pursuing my goal. 


\author{
ABSTRACT OF THE DISSERTATION \\ ELECTROCHEMICAL BEHAVIORS OF THE ELECTRODES FOR PROTON \\ CONDUCTING INTERMEDIATE TEMPERATURE SOLID OXIDE FUEL CELLS \\ (IT-SOFC) \\ by
}

Shichen Sun

Florida International University, 2018

Miami, Florida

Professor Zhe Cheng, Major Professor

Proton conducting intermediate temperature $\left(600^{\circ} \mathrm{C}-400^{\circ} \mathrm{C}\right)$ solid oxide fuel cells (ITSOFC) have many potential advantages for clean and efficient power generation from readily available hydrocarbon fuels. However, it still has many unsolved problems, especially on the anode where the fuel got oxidized and the cathode where oxygen got reduced.

In this study, for the anode, the effects of hydrogen sulfite $\left(\mathrm{H}_{2} \mathrm{~S}\right)$ and carbon dioxide $\left(\mathrm{CO}_{2}\right)$ as fuel contaminants were studied on the nickel $(\mathrm{Ni})$ based cermet anode of proton conducting IT-SOFC using proton conducting electrolyte of $\mathrm{BaZr}_{0.1} \mathrm{Ce}_{0.7} \mathrm{Y}_{0.1} \mathrm{Yb}_{0.1} \mathrm{O}_{3}$ (BZCYYb). Both low-ppm level $\mathrm{H}_{2} \mathrm{~S}$ and low-percentage level $\mathrm{CO}_{2}$ caused similar poisoning effects on the anode reaction. The $\mathrm{H}_{2} \mathrm{~S}$ poisoning effect was also found to be much less than on oxide-ion conducting SOFC, which is attributed to the absence of water 
evolution for the anode reaction in proton conducting SOFC. In addition, the $\mathrm{H}_{2} \mathrm{~S} / \mathrm{CO}_{2}$ poisoning mechanisms were investigated using X-ray diffraction, energy dispersive spectroscopy (EDS), Raman spectroscopy, and secondary ion mass spectroscopy (SIMS). For $\mathrm{H}_{2} \mathrm{~S}$, other than possible sulfur dissolution into BZCYYb, no bulk reaction was found, suggesting sulfur adsorption contributes to the reduced performance. For $\mathrm{CO}_{2}$, reaction with $\mathrm{BZCYYb}$ to form $\mathrm{BaCO}_{3}$ and $\mathrm{CeO}_{2}$ is identified and is believed to be the reason for the sudden worsening in $\mathrm{CO}_{2}$ poisoning as temperature drops below $\sim 550^{\circ} \mathrm{C}$.

For the cathode, several representative SOFC cathodes including silver (Ag), $\mathrm{La}_{0.6} \mathrm{Sr}_{0.4} \mathrm{Co}_{0.2} \mathrm{Fe}_{0.8} \mathrm{O}_{3-\delta}$ (LSCF), LSCF-BZCYYb composite, and $\mathrm{Ba}_{0.5} \mathrm{Sr}_{0.5} \mathrm{Co}_{0.8} \mathrm{Fe}_{0.2} \mathrm{O}_{3-\delta}$ (BSCF) were evaluated based on BZCYYb electrolyte. LSCF give similar high interfacial resistance as Ag, while LSCF-BZCYYb composite cathode shows lower interfacial resistance, suggesting LSCF behaves like pure electronic conductor cathode in this case. For BSCF, it shows smallest interfacial resistance and the charge transfer process appears to accelerate with the introduction of $\mathrm{H}_{2} \mathrm{O}$, while oxygen adsorption/transport seem to slow down due to adsorbed $\mathrm{H}_{2} \mathrm{O}$. Furthermore, $\mathrm{CO}_{2}$ was shown to cause poisoning on the $\mathrm{BSCF}$ cathode, yet the poisoning was significantly reduced with the co-presence of water. The results suggest that although BSCF seem to display mixed proton-electronic conduction, its strong affinity to $\mathrm{H}_{2} \mathrm{O}$ may inhibit the oxygen reduction reaction on the cathode and new cathode materials still need to be designed. 


\section{TABLE OF CONTENTS}

CHAPTER

PAGE

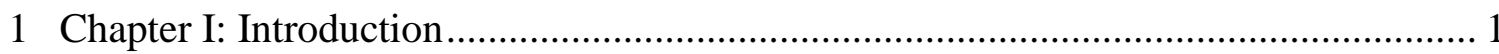

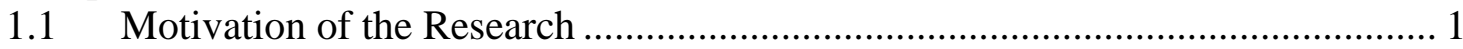

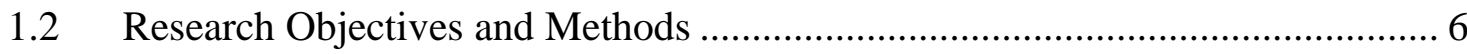

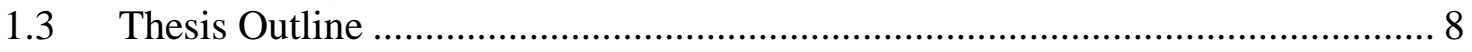

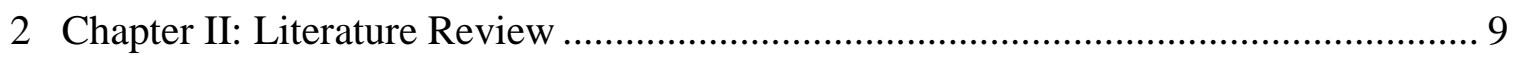

2.1 Proton Conducting Intermediate Temperature Solid Oxide Fuel Cells

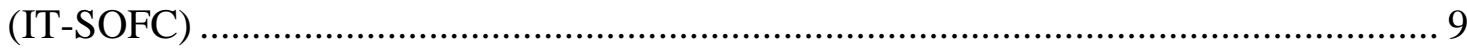

2.1.1 Components and Structure of SOFC...................................................... 9

2.1.2 From High Temperature SOFC (HT-SOFC) to Intermediate Temperature

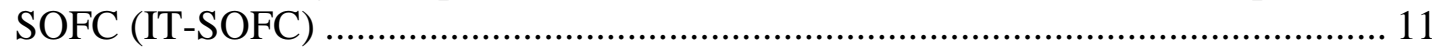

2.1.3 From Proton Conducting Ceramics to Proton Conducting IT-SOFC .......... 14

2.2 Anode for Proton Conducting IT-SOFC ......................................................... 18

2.2.1 Anode Reaction Process for Oxide Ion Conducting SOFC and Proton

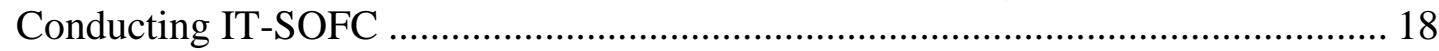

2.2.2 Anode $\mathrm{H}_{2} \mathrm{~S}$ Poisoning Effect on Oxide-ion Conducting SOFC and Proton

Conducting IT-SOFC ………………………………….................................... 21

2.2.3 Anode $\mathrm{CO}_{2}$ Poisoning Effect on Proton Conducting IT-SOFC ................... 32

2.3 Cathode for Proton Conducting IT-SOFC ...................................................... 39

2.3.1 Cathode Reaction Process for Oxide-ion Conducting SOFC versus Proton

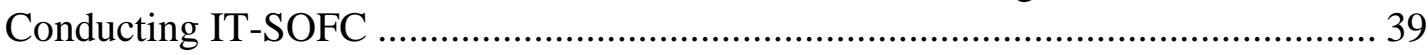

2.3.2 Different Cathodes on Proton Conducting IT-SOFC …………………...... 43

3 Chapter III: $\mathrm{H}_{2} \mathrm{~S}$ Poisoning Behavior for the Anode of Proton Conducting IT-SOFC 66

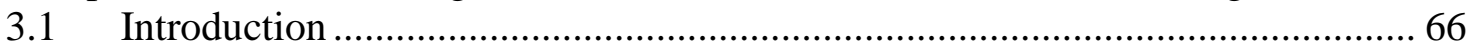

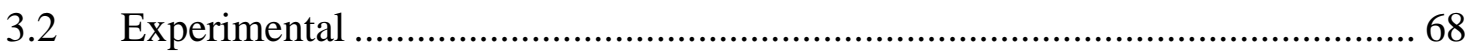

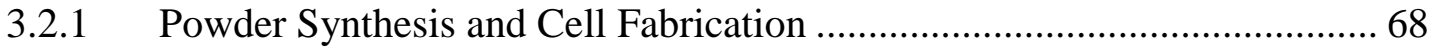

3.2.2 Testing of the Effects of $\mathrm{H}_{2} \mathrm{~S}$ on Electrochemical Cells ............................. 71

3.2.3 Stability Tests of Ni-BZCYYb Mixed Powders ......................................... 73

3.2.4 SIMS Analysis on Ni-BZCYYb Pellet after $\mathrm{H}_{2} \mathrm{~S}$ Exposure ....................... 74

$3.3 \quad$ Results ............................................................................................... 76

3.3.1 $\quad \mathrm{H}_{2} \mathrm{~S}$ Effect on Ni-BZCYYb/BZCYYb/LSCF Anode-supported PC-SFOC

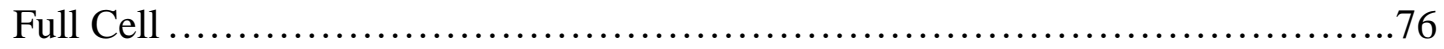

3.3.2 $\mathrm{H}_{2} \mathrm{~S}$ Effect on Ni-BZCYYb/BZCYYb/LSCF Electrolyte-supported PC-

SOFC Full Cell .............................................................................................. 79

3.3.3 $\mathrm{H}_{2} \mathrm{~S}$ Effect on Ni-BZCYYb/BZCYYb/Ni-BZCYYb Anode Symmetrical

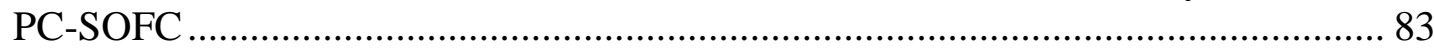

3.3.4 $\mathrm{H}_{2} \mathrm{~S}$ Effect on Ni-YSZ/YSZ/Ni-YSZ Anode Symmetrical OC-SOFC ....... 86

3.3.5 XRD and EDS Analysis on Ni-BZCYYb Powder Mixture after Exposure

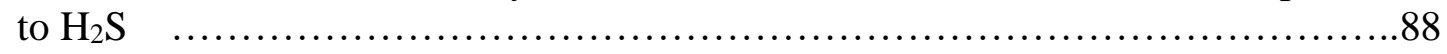

3.3.6 SIMS Analysis on Ni-BZCYYb Composite Pellet after Exposure to Lowppm Level $\mathrm{H}_{2} \mathrm{~S}$. 


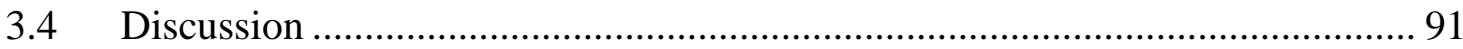

3.4.1 Electrochemical Behaviors of PC-SOFC against $\mathrm{H}_{2} \mathrm{~S}$ Poisoning ............... 91

3.4.2 Comparison of Electrochemical Behaviors of Anode Symmetrical PC-

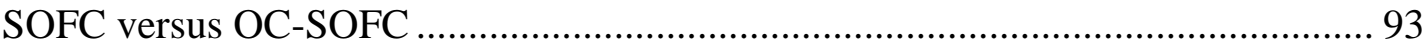

3.4.3 Analysis of the $\mathrm{H}_{2} \mathrm{~S}$ Effect on Ni-BZCYYb Mixture …………………..... 99

3.4.4 Proposed $\mathrm{H}_{2} \mathrm{~S}$ Poisoning Mechanism for the Anode Reaction Process of PC-SOFC

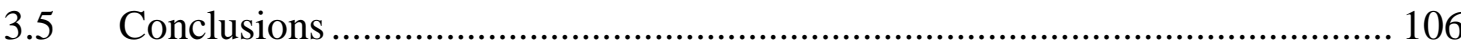

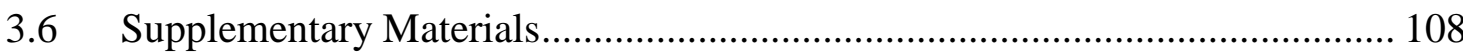

4 Chapter IV: $\mathrm{CO}_{2}$ Poisoning Behavior for the Anode of Proton Conducting IT-SOFC

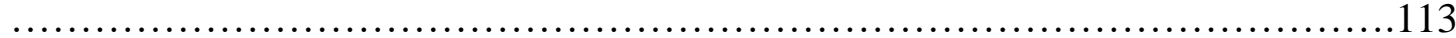

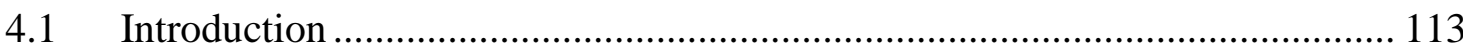

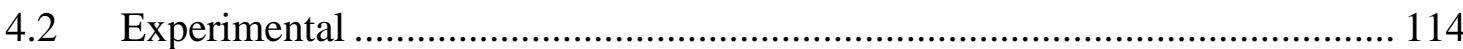

4.2.1 Powder Synthesis and Cell Fabrication ................................................... 114

4.2.2 Electrochemical Testing of the Effects of $\mathrm{CO}_{2}$ as Fuel Contaminants ..... 116

4.2.3 Stability Tests of Ni-BZCYYb Mixed Powders ………………………..... 117

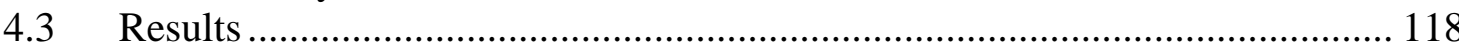

4.3.1 $\mathrm{CO}_{2}$ Poisoning of Ni-BZCYYb/BZCYYb /LSCF Anode-supported PC-

SOFC Full Cell ................................................................................... 118

4.3.2 $\quad \mathrm{CO}_{2}$ Poisoning of Ni-BZCYYb/BZCYYb/LSCF Electrolyte-supported

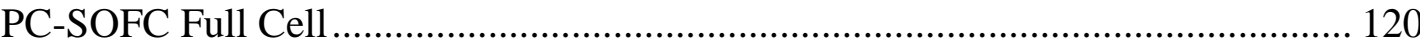

4.3.3 $\mathrm{CO}_{2}$ Poisoning of Ni-BZCYYb/BZCYYb/Ni-BZCYYb Anode

Symmetrical Cell ........................................................ 122

4.3.4 $\quad \mathrm{CO}_{2}$ Exposure Tests on Ni-BZCYYb Mixed Powders ............................. 123

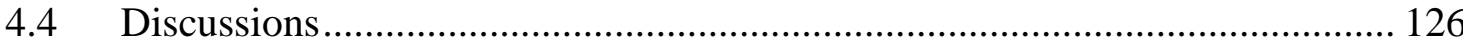

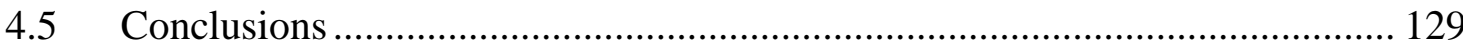

5 Chapter V: Electrochemical Behaviors of Ag, LSCF and BSCF as Cathode for Proton

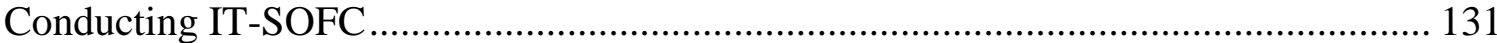

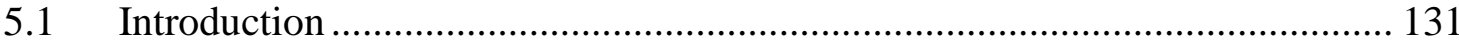

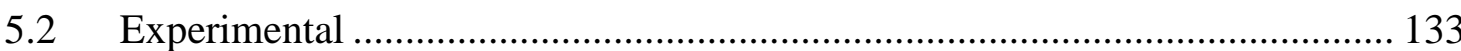

5.2.1 Powder Synthesis and Compatibility Test ................................................ 133

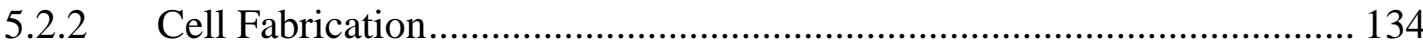

5.2.3 Electrochemical Impedance Spectroscopy (EIS) Measurement ................ 135

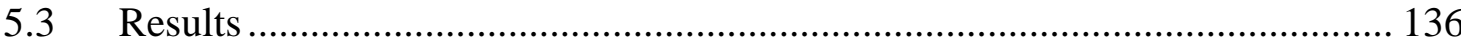

5.3.1 Stability, Compatibility, and Microstructure of the Electrodes ................. 136

5.3.2 Electrochemical Behavior of Different Dlectrodes under Various $p \mathrm{O}_{2}$ and

Moisture Content …………………………………….................................. 138

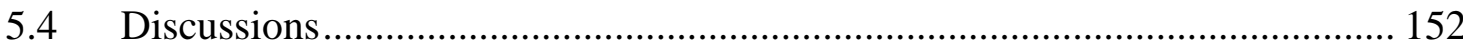

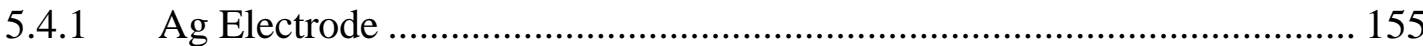

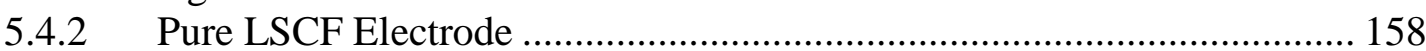

5.4.3 LSCF-BZCYYb Composite Electrode …………………………......... 160

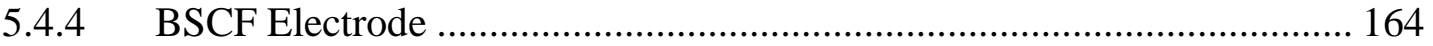

5.4.5 Electrochemical Behavior of BSCF Anode-supported Full Cell at $450^{\circ} \mathrm{C} 166$ 
6 Chapter VI: Effects of $\mathrm{H}_{2} \mathrm{O}$ and $\mathrm{CO}_{2}$ on Electrochemical Behaviors of BSCF Cathode

for Proton Conducting IT-SOFC ……………………..................................... 172

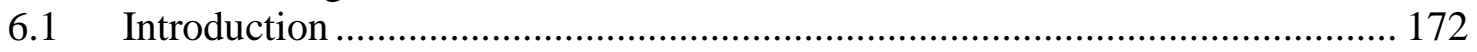

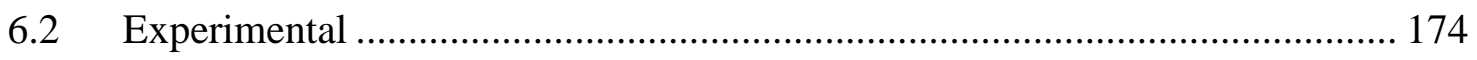

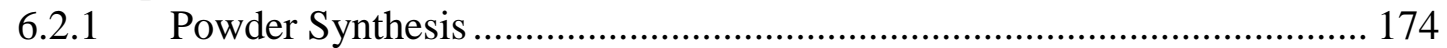

6.2.2 Chemical Compatibility and Stability Test.............................................. 175

6.2.3 BSCF/BZCYYb/BSCF Symmetrical Cells Fabrication ............................ 176

6.2.4 Electrochemical Impedance Spectroscopy (EIS) Measurements .............. 177

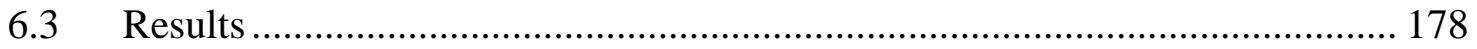

6.3.1 Compatibility and Stability of BSCF and BZCYYb in Various

Atmospheres .............................................................................................. 178

6.3.2 Effect of Moisture on BSCF Cathode Electrochemical Behavior ............. 180

6.3.3 Effect of $\mathrm{CO}_{2}$ on BSCF Cathode Electrochemical Behavior ..................... 185

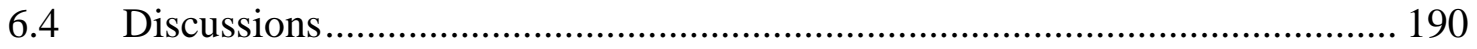

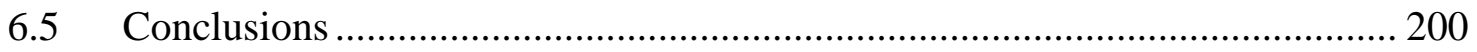

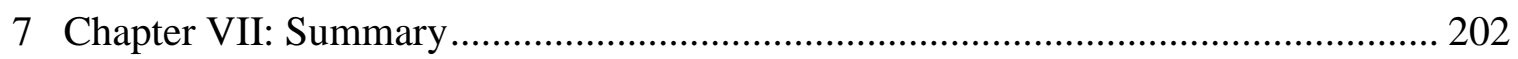

7.1 Anode for Proton Conducing IT-SOFC ………......................................... 202

7.2 Cathode for Proton Conducting IT-SOFC .................................................... 204

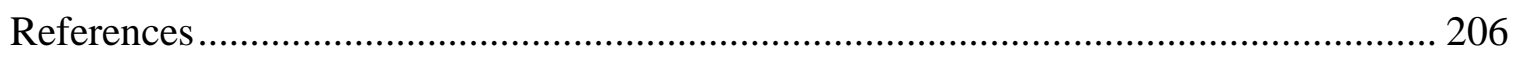

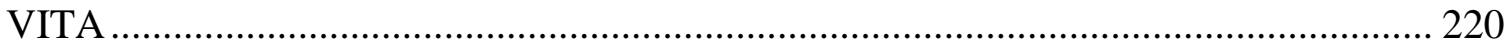




\section{LIST OF TABLES}

\section{TABLES}

PAGE

Table 3. 1 Summary of poisoning effect by low-ppm level $\mathrm{H}_{2} \mathrm{~S}$ on oxide-ion conducting SOFC and PC-SOFC in hydrogen-based fuel at $\sim 750{ }^{\circ} \mathrm{C}$. For electrolyte, YSZ stands for $8 \mathrm{~mol} \%$ yttria stabilized zirconia while $\mathrm{BZCYYb}$ stands for $\mathrm{BaZr}_{0.1} \mathrm{Ce}_{0.7} \mathrm{Y}_{0.1} \mathrm{Yb}_{0.1} \mathrm{O}_{3-\delta}$ proton conducting ceramic (PCC) electrolyte. $\Delta R_{\mathrm{O}}$ and $\Delta R_{\mathrm{ai}}$ are the observed relative increase in cell ohmic resistance and total electrode apparent interfacial resistance, respectively, measured under open circuit condition.

Table 5. 1 Elementary steps (and their reverse steps) of the oxygen electrode reaction for the reversible oxygen electrode reactions for ideal oxide-ion based SOFC (step $1,2,3,4)$ and ideal proton conducting SOFC (step 1,2,3',4',5). [157]

Table 6. 1 Elementary steps of the oxygen electrode reaction for BSCF electrode over BZCYYb electrolyte without the presence of $\mathrm{H}_{2} \mathrm{O}$ under ideal pure oxide ion conduction condition and under ideal, fully hydrated condition which only conduct proton and not oxide ion... 190

Table 6. 2 Relative change of Ohmic resistance $\mathrm{R}_{\mathrm{O}}$ and interface polarization resistance $\mathrm{R}_{\mathrm{p}}$ for the $\mathrm{BSCF} / \mathrm{BZCYYb} \mathrm{BSCF}$ cathode symmetrical cell after being poisoned by $1 \% \mathrm{CO}_{2}$ for 2 hours and the recovery by then removing $1 \% \mathrm{CO}_{2}$ for 24 hours in both dry and $3 \% \mathrm{H}_{2} \mathrm{O}$ humidified simulated air 


\section{LIST OF FIGURES}

\section{FIGURE}

PAGE

Figure 1. 1 Schematics showing (a) electrodes reaction route for a conventional oxide-ion conducting SOFC, and (b) electrodes reaction route for a proton conducting SOFC ....... 3

Figure 2. 1 Materials and related issues for SOFC. From Mahato et al. [9] .............10

Figure 2. 2 Ionic conductivities of $\mathrm{BZCYYb}, \mathrm{BaZr}_{0.1} \mathrm{Ce}_{0.7} \mathrm{Y}_{0.2} \mathrm{O}_{3-\delta}(\mathrm{BZCY})$, Gadolinium doped ceria (GDC), and YSZ as measured at $400^{\circ}$ to $750^{\circ} \mathrm{C}$ in wet oxygen (with $\sim 3$ vol $\left.\% \mathrm{H}_{2} \mathrm{O}\right)$. From Yang et al. [15]

Figure 2. 3 Proton incorporation and conduction mechanisms in conventional perovskite proton conductors (for example, Y-doped $\mathrm{BaZrO}_{3}$ ). From Zhou et al. [92]. 15

Figure 2. 4 Schematic diagram of the anodic reaction process for $\mathrm{H}_{2}$ electrochemical oxidation around the anode (Ni)/electrolyte (YSZ) interfaces for a conventional oxide-ion conducting SOFC. 18

Figure 2. 5 Schematics showing anode reaction steps for ideal pure PC-SOFC at intermediate temperature. Note that the anode reaction mechanism for PC-SOFC is greatly simplified and the exact process including the dominating pathway still needs to be studied. In addition, BZCYYb stands for the $\mathrm{BaZr}_{0.1} \mathrm{Ce}_{0.7} \mathrm{Y}_{0.1} \mathrm{Yb}_{0.1} \mathrm{O}_{3-\delta} \mathrm{PCC}$ electrolyte.

Figure 2. 6 Impedance spectra of the cell using heat-treated BCY20 with 0-10 ppm H2S and $80 \% \mathrm{H}_{2}$ at $800{ }^{\circ} \mathrm{C}$. The frequency range was $0.1-105 \mathrm{~Hz}$. From Tomita et al. [17] . 23

Figure 2. 7 Change in hydrogen permeation flux through Ni-BZCY hydrogen permeation membrane with the introduction of 30-60ppm $\mathrm{H}_{2} \mathrm{~S}$ in gas mixture of $\sim 1.5 \% \mathrm{H}_{2} \mathrm{O}+$ $58 \% \mathrm{~N}_{2}+40 \% \mathrm{H}_{2}$ at $700^{\circ} \mathrm{C}$. Adapted from Fang et al. [100] 25

Figure 2. 8 Sulfur poisoning and regeneration behavior of $\mathrm{Ni}-\mathrm{BZCY}$ in the feed gas $\left(\sim 1.5 \% \mathrm{H}_{2} \mathrm{O}+58 \% \mathrm{~N}_{2}+40 \% \mathrm{H}_{2}\right)$ containing $60 \mathrm{ppm} \mathrm{H}_{2} \mathrm{~S}$ at $700^{\circ} \mathrm{C}$ and $120 \mathrm{ppm} \mathrm{H}_{2} \mathrm{~S}$ at $900^{\circ} \mathrm{C}$. Adapted from Fang et al. [101].......

Figure 2. 9 XRD patterns of Ni-BZCY obtained from (A) a polished surface after sintering, (B) feed side surface after testing in $60 \mathrm{ppm} \mathrm{H}_{2} \mathrm{~S}$ at $700^{\circ} \mathrm{C}$. Secondary pahses are: $(\diamond) \mathrm{BZCY},(\bullet) \mathrm{Ni},(*) \mathrm{Ni3S} 2,(\mathrm{O})$ doped $\mathrm{CeO}_{2},(\Delta) \mathrm{BaS}$. Adapted with change from Fang et al. [100]

Figure 2. 10 Dependence of Gibbs free energy change for reaction (1) on $\mathrm{H}_{2} \mathrm{~S}$ concentrations with 0.015 atm $\mathrm{H}_{2} \mathrm{O}$ at $900{ }^{\circ} \mathrm{C}$. Temperature dependence of critical $\mathrm{H}_{2} \mathrm{~S}$ concentration for reaction (1) with 0.015 atm $\mathrm{H}_{2} \mathrm{O}$. Adapted from Fang et al. [101]...... 27

Figure 2. 11 (A) The change in cell voltage at $750^{\circ} \mathrm{C}$ for two cells with the configuration of Ni-BZCYYb/ BZCYYb/ BZCY-LSCF and Ni-BZCYYb/ SDC/ LSCF operated at $750^{\circ} \mathrm{C}$ under the constant current density of $700 \mathrm{~mA} / \mathrm{cm}^{2}$ as $10-50 \mathrm{ppm}$ of $\mathrm{H} 2 \mathrm{~S}$ was 
introduced to the 3\%humidified $\mathrm{H}_{2}$ fuel stream, (B and C) Impedance spectra measured under OCV conditions at $750^{\circ} \mathrm{C}$ for the Ni-BZCYYb/ SDC/ LSCF anode-supported full cell in both (B) dry $\mathrm{H}_{2}$ and dry $\mathrm{H}_{2}$ containing 20 ppm $\mathrm{H}_{2} \mathrm{~S}$ and (C) wet $\mathrm{H}_{2}$ and wet $\mathrm{H}_{2}$ containing 20ppm $\mathrm{H}_{2} \mathrm{~S}$. from Yang et al. (2009) [15].

Figure 2. 12 Impedance spectra of Ni-YSZ/YSZ/LSCF anode-supported full cells operated at a constant current density of 200,500 , and $800 \mathrm{~mA} / \mathrm{cm}^{2}$ before and after 1 ppm $\mathrm{H}_{2} \mathrm{~S}$ was introduced into the fuel at $750^{\circ} \mathrm{C}$. From Yang et al. [35]

Figure 2. 13 Performances of the Ni-YSZ/YSZ/LSCF anode supported full cells operated at $750 \mathrm{C}$ at a constant current density of 200 and $400 \mathrm{~mA} / \mathrm{cm}^{2}$ in hydrogen for the first $\sim 600 \mathrm{~h}$ and then in hydrogen with (a) 0.8-1.1 $\mathrm{ppm} \mathrm{H}_{2} \mathrm{~S}$, and (b) 10ppm $\mathrm{H}_{2} \mathrm{~S}$. From Yang et al. [35] 31

Figure 2. 14 Hydrogen flux through (a) Ni-BZCY6 and (b) Ni-BZCY8 membranes in wet feed gas $\left(40 \% \mathrm{H}_{2} / \mathrm{He}\right)$ containing different concentrations of $10-30 \% \mathrm{CO}_{2}$ at $900^{\circ} \mathrm{C}$. From Zuo et al. [105] 34

Figure 2. 15 Time dependence of hydrogen flux through Ni-BaZr $\mathrm{r}_{0.8 \mathrm{x}} \mathrm{Ce}_{\mathrm{x}} \mathrm{Y}_{0.2} \mathrm{O}_{3}(0.4 \leqslant \mathrm{x}$ $\leqslant 0.8$ ) membranes in a feed gas of wet $20 \% \mathrm{CO}_{2}$ (balance $40 \% \mathrm{H}_{2} / \mathrm{He}$ ) at $900{ }^{\circ} \mathrm{C}$. From Zuo et al. [106] 35

Figure 2. 16 Hydrogen permeation fluxes of the Ni-BZCYYb membrane (lower line) and absolute humidity in feed gas passing through the reactor (upper line). The feed gas consisted of $20 \% \mathrm{H}_{2}, 5-60 \% \mathrm{CO}_{2}$, and 75-20\% He. From Fang et al. [107] .................... 36

Figure 2. 17 Time dependence of hydrogen flux of the Ni-BZCYYb membrane in 20$60 \% \mathrm{H}_{2}$ balanced with $3 \% \mathrm{H}_{2} \mathrm{O}, 30 \% \mathrm{CO}_{2}$, and $47-7 \% \mathrm{He}$, respectively. From Fang et al. [108]

Figure 2. $18 \mathrm{XRD}$ patterns obtained from the fresh (a) and tested (b) Ni-BZCYYb membrane. p: $\mathrm{BZCYYb}$, h: hexagonal $\mathrm{BaCO}_{3}$, o- orthorhombic $\mathrm{BaCO}_{3}$, c: carbon, e: doped- $\mathrm{CeO}_{2}$, ?: unknown phase. From Fang et al. [108] ............................................... 38

Figure 2. 19 Raman spectrum obtained from feed side surface of Ni-BZCYYb membrane after exposure to wet $\mathrm{CO}_{2}$ and recovery without $\mathrm{CO}_{2}$. From Fang et al. [108] ................ 39

Figure 2. 20 Schematics showing the reaction species involved and the elementary steps for the cathode reactions for oxide-ion conducting SOFC when mixed ionic and electronic conducting material is used as cathode.

Figure 2. 21 Schematics showing the reaction species involved and the elementary steps for the cathode reactions for proton conducting IT-SOFC.

Figure 2. 22 Voltage-current and power density-current curves of $\mathrm{Pt} / \mathrm{SrCe}_{0.95} \mathrm{Yb}_{0.05} \mathrm{O}_{3}$ (SCYb)/ $\mathrm{Pt}$ full cell at temperature of $800-600^{\circ} \mathrm{C}$ in $3 \%$ humidified fuel $\left(10 \% \mathrm{H}_{2}\right.$ balanced by Ar) at anode and dry air at cathode. From Taherparvar et al. [128] 44 
Figure 2. 23 (a) Fuel cell performance for $\mathrm{Pt} / \mathrm{SCYb} / \mathrm{Pt}$ full cell with varying $\mathrm{pH}_{2} \mathrm{O}$ at the cathode at (a) $600{ }^{\circ} \mathrm{C}$ (b) $700^{\circ} \mathrm{C}$ and (c) $800^{\circ} \mathrm{C}$ with $3 \%$ humidified fuel consisted of $10 \%$ $\mathrm{H}_{2}+$ Ar. From Taherparvar et al. [128] 45

Figure 2. 24 SEM images of the morphology of the Pt electrode in $\mathrm{Pt} / \mathrm{SCYb} / \mathrm{Pt}$ cell. From Potter et al. [129]. 46

Figure 2. 25 Impedance spectra of $\mathrm{Pt} / \mathrm{SCYb} / \mathrm{Pt}$ cell at $350^{\circ} \mathrm{C}$ in (a) humidified air and (b) dry air Numerical labels indicate $\log 10$ of applied frequency. Adapted from Potter et al. [129].

Figure 2. $26 \mathrm{Ag}$ cathode surface with the initial particle of (A) 5nm, (B) 0.1um, and (C) 6-13 um after firing at $500^{\circ} \mathrm{C}$. From Akimune et al. [130] 48

Figure 2. 27 Power density of cell using ( $)$ Pt cathode, and $\mathrm{Ag}$ cathode fired at $500^{\circ} \mathrm{C}$ with initial particle size of $(\Delta) 5 \mathrm{~nm},(\diamond) 0.1 \mathrm{um}$, and $(\square)$ 6-13um, and $\mathrm{Ag}$ cathode fired at $700^{\circ} \mathrm{C}$ with initial particle size of $(\boldsymbol{\Delta}) 5 \mathrm{~nm},(\diamond) 0.1 \mathrm{um}$ and (ם) 6-13um. From Akimune et al. [130]

Figure 2. 28 Impedance spectra acquired in wet air at $600{ }^{\circ} \mathrm{C}$ for the (b) LSCF composite cathode with $10 \mathrm{YbBC}$ (weight ratio 1:1), and (d) and pure phase LSCF as cathode on YbBC electrolyte-supported cell. Adapted from Fabbri et al. [93] 50

Figure 2. 29 (a) I-V and I-P curves, and (b) impedance spectra for the Pt/BCY/Pt and $\mathrm{Pt} / \mathrm{BCY} / \mathrm{LSCF}-10 \mathrm{YbBC}$ cell tested at $700{ }^{\circ} \mathrm{C}$. Adapt from Fabbri et al. [93].... 51

Figure 2. 30 (a) I-V curves, (b) interfaical resistances, for BZCY-based anode-supported cells with BZCY-LSCF and LSCF cathodes and (c) impedance spectra of the cell with LSCF-BZCY composite cathode at various temperatures. From Yang et al. [121] ........ 52

Figure 2. 31 SEM morphologies of the cathodes surface fired at: (A) $950^{\circ} \mathrm{C}$ and (B) $1100^{\circ} \mathrm{C}$. From Lin et al. [72].

Figure 2. $32 \mathrm{I}-\mathrm{V}$ and I-P curves for the cell with BSCF cathode fired at (A) $950^{\circ} \mathrm{C}$, and (B) $1100{ }^{\circ} \mathrm{C}$ at various temperatures of $700-400^{\circ} \mathrm{C}$. From Lin et al. [72]...

Figure 2. 33 Thermal variation in dry air of a) the relative weight loss of hydrated $\mathrm{La}_{0.6} \mathrm{Sr}_{0.4} \mathrm{Fe}_{0.8} \mathrm{Co}_{0.2} \mathrm{O}_{3-\delta}$ and $\mathrm{Ba}_{0.5} \mathrm{Sr}_{0.5} \mathrm{Co}_{0.8} \mathrm{Fe}_{0.2} \mathrm{O}_{3-\delta}$ samples, b) the calculated amount of inserted water (in mol. per mol. of oxide). Adapted with modification from Grimaud et al. $[20]$

Figure 2. 34 SEM micrographs of (a) LSFC sintered at $1000^{\circ} \mathrm{C}$, (b) BSCF sintered at $1000^{\circ} \mathrm{C}$ (c) $\mathrm{BSCF}$ sintered at $1100^{\circ} \mathrm{C}$. Adapted from Grimaud et al. [20]. 57

Figure 2. 35 Impedance spectra of the cathode symmetrical cell with (a)LSCF and (b) $1000^{\circ} \mathrm{C}$ fired $\mathrm{BSCF}$ and (c) $1100^{\circ} \mathrm{C}$ fired $\mathrm{BSCF}$ in air containing 0.03 to 0.30 bar of $\mathrm{H}_{2} \mathrm{O}$ at $600^{\circ} \mathrm{C}$. (Note for $\mathrm{BSCF}$, the water response is different when it was fired at higher 
temperature probably due to the reaction/mutual diffusion between BSCF and BCY electrolyte). Adapted from Grimaud et al. [20]

Figure 2. 36 (a) I-V and I-P curves and (b) impedance spectra of the BSCF/

$\mathrm{BaZr}_{0.4} \mathrm{Ce}_{0.45} \mathrm{Y}_{0.15} \mathrm{O}_{3-\delta}(\mathrm{BZCY} 40) / \mathrm{Ni}-\mathrm{BZCY} 40$ cell with various $p \mathrm{O}_{2}$ at $\mathrm{BSCF}$ cathode side at $700^{\circ} \mathrm{C}$. [131].

Figure 2. 37 (a) I-V and I-P curves and (b) impedance spectra of the BSCF/ $\mathrm{BaZr}_{0.4} \mathrm{Ce}_{0.45} \mathrm{Y}_{0.15} \mathrm{O}_{3-\delta}(\mathrm{BZCY} 40) / \mathrm{Ni}-\mathrm{BZCY} 40$ cell with various $p \mathrm{H}_{2} \mathrm{O}$ at $\mathrm{BSCF}$ cathode side at $700^{\circ} \mathrm{C}$. From Lim et al. [131] .....

Figure 2. 38 ASR temperature dependence for BCFZ (with water and without water) vs.

LSCF. From Shang et al. [132]

Figure 2. 39 Performance of the as-prepared single cells under hydrogen/air at different temperatures. (a) Cell with BCFZ cathode; (b) cell with LSCF cathode. From Duan et al. [132]

Figure 2. 40 (A) I-V and power density of the BCFZY/BZCYYb/Ni-BZCYYb anodesupported cell at $600-350^{\circ} \mathrm{C}$ (B) a cross-sectional view of the cell after operation for over 1100 hours (inset figure is the high-magnification view of BCFZY0.1 cathode after 1100 hours operation). Adapted from Duan et al. [133] 65

Figure 3. 1 Impedance spectra for a Ni-BZCYYb/BZCYYb/LSCF-BZCYYb anode supported proton-conducting SOFC full cell at $750^{\circ} \mathrm{C}$ showing the effect of introducing 5 ppm $\mathrm{H}_{2} \mathrm{~S}$ as fuel contaminant to the dry $\mathrm{H}_{2}$ (UHP grade $\mathrm{H}_{2}$ with $p \mathrm{H}_{2} \mathrm{O} \approx 10$ ppm; same for all subsequent figures) and 3\% humidified $\mathrm{H}_{2}$ (i.e. $\sim 3 \% \mathrm{H}_{2} \mathrm{O}+97 \% \mathrm{H}_{2}$, labelled

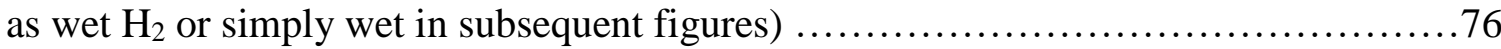

Figure 3. 2 Plots of cell voltage versus time for the Ni-BZCYYb/BZCYYb/LSCFBZCYYb anode-supported PC-SOFC full cell at $750^{\circ} \mathrm{C}$ when $5 \mathrm{ppm}$ of $\mathrm{H}_{2} \mathrm{~S}$ is introduced into and later removed from the fuel of (a) dry $\mathrm{H}_{2}\left(\mathrm{pH}_{2} \mathrm{O} \approx 10 \mathrm{ppm}\right)$ and (b) $3 \%$ humidified $\mathrm{H}_{2}$ 78

Figure 3. 3 Impedance spectra measured under open circuit condition for a $\mathrm{Ni}$ BZCYYb/BZCYYb/LSCF-BZCYYb electrolyte-supported PC-SOFC full cell at (a) $750^{\circ} \mathrm{C}$, (b) $650^{\circ} \mathrm{C}$, (c) $550^{\circ} \mathrm{C}$, and (d) $450^{\circ} \mathrm{C}$ showing the effect of introducing $3-10 \mathrm{ppm}$ (by volume) $\mathrm{H}_{2} \mathrm{~S}$ as fuel contaminant to the $\sim 3 \%$ wet $\mathrm{H}_{2}$.

Figure 3. 4 Impedance spectra for a Ni-BZCYYb/BZCYYb/LSCF-BZCYYb electrolytesupported PC-SOFC full cell operated with constant current of $5.5 \mathrm{~mA} / \mathrm{cm}^{2}$ at (a) $750^{\circ} \mathrm{C}$ and (b) $650^{\circ} \mathrm{C}$ showing the effect of introducing 3-10 $\mathrm{ppm}_{2} \mathrm{~S}$ as fuel contaminant to the wet $\mathrm{H}_{2}$..... 81

Figure 3. 5 Plots of cell voltage versus time under constant current for the NiBZCYYb/BZCYYb/LSCF-BZCYYb electrolyte-supported PC-SOFC full cell at (a) $750^{\circ} \mathrm{C}$, (b) $650^{\circ} \mathrm{C}$, (c) $550^{\circ} \mathrm{C}$, and (d) $450^{\circ} \mathrm{C}$ when $3-10 \mathrm{ppm}$ of $\mathrm{H}_{2} \mathrm{~S}$ is introduced into and later removed from the fuel of $3 \%$ humidified $\mathrm{H}_{2}$. 82 
Figure 3. 6 Plots showing change of cell impedance spectra for the $\mathrm{Ni}$ -

BZCYYb/BZCYYb/Ni-BZCYYb anode symmetrical PC-SOFC in fuels of dry $\mathrm{H}_{2}$ (a, c, e) and $\sim 3 \%$ humidified $\mathrm{H}_{2}(\mathrm{~b}, \mathrm{~d}, \mathrm{f})$ before and after the introduction of 3, 5, and $10 \mathrm{ppm}$ of $\mathrm{H}_{2} \mathrm{~S}$ at $750^{\circ} \mathrm{C}$ ( $\mathrm{a}$ and $\mathrm{b}$ ), $650^{\circ} \mathrm{C}$ (c and d), and $550^{\circ} \mathrm{C}$ (e and f), respectively. 86

Figure 3. 7 Impedance spectra for a Ni-YSZ/YSZ/Ni-YSZ anode symmetrical OC-SOFC at (a) $750^{\circ} \mathrm{C}$, (b) $650^{\circ} \mathrm{C}$, (c) $550^{\circ} \mathrm{C}$ showing the effect of introducing $10 \mathrm{ppm}_{2} \mathrm{~S}$ as fuel contaminant to the wet $\mathrm{H}_{2}$ (ohmic resistance subtracted).

Figure 3. 8 Impedance spectra for an Ni-BZCYYb/BZCYYb/Ni-BZCYYb anode symmetrical PC-SOFC at (a) $750^{\circ} \mathrm{C}$, (b) $650^{\circ} \mathrm{C}$, and (c) $550^{\circ} \mathrm{C}$ showing the effect of introducing $10 \mathrm{ppm} \mathrm{H}_{2} \mathrm{~S}$ as fuel contaminant to the wet $\mathrm{H}_{2}$ (ohimc resistance subtracted).

Figure 3. 9 XRD patterns for NiO-BZCYYb mixed powders after reduction in $\mathrm{H}_{2}$ at $750^{\circ} \mathrm{C}$ and then exposure tests at $550^{\circ} \mathrm{C}$ for 24 hours in pure $\mathrm{H}_{2}$ (as control sample) or fuel gas mixtures of dry $\mathrm{H}_{2}+10 \mathrm{ppm} \mathrm{H}_{2} \mathrm{~S} / \mathrm{H}_{2}$ or wet $\mathrm{H}_{2}+10 \mathrm{ppm} \mathrm{H}_{2} \mathrm{~S}$. These results prove that there is no observable bulk phase reaction between $\mathrm{Ni}$ and BZCYYb and $10 \mathrm{ppm}$ $\mathrm{H}_{2} \mathrm{~S}$ at $550^{\circ} \mathrm{C}$.

Figure 3. 10 Metallographic microscope image of the sintered and polished Ni-BZCYYb composite sample surface. The bright and dark regions correspond to the $\mathrm{Ni}$ and the $\mathrm{BZCYYb}$ phase, respectively.

Figure 3. 11 Representative SIMS mapping results showing the distributions of $\mathrm{Ni}, \mathrm{S}$, and Ba species (including their associated oxides) as the sample was sputtered down during the analysis.

Figure 3. 13 Comparison of activation energy (calculated from $550-750^{\circ} \mathrm{C}$ ) for ohmic resistance $\mathrm{R}_{\mathrm{O}}$, total apparent interfacial resistance $\mathrm{R}_{\mathrm{ai}}$, and the different electrode processes at high frequency $R_{H F}$, mid-frequency $R_{M F}$, and low frequency $R_{L F}$ in (a) dry $\mathrm{H}_{2}\left(\mathrm{pH}_{2} \mathrm{O} \approx 10 \mathrm{ppm}\right)$ and (b) $3 \%$ humidified $\mathrm{H}_{2}$ without and with 3,5 , and $10 \mathrm{ppm}_{2} \mathrm{~S}$ poison for the Ni-BZCYYb/BZCYYb/Ni-BZCYYb anode symmetrical PC-SOFC ...... 98

Figure 3. 14 Schematics showing anode reaction steps for both conventional oxide-ion conducting SOFC ( $a$ and $b$ ) and ideal pure PC-SOFC (c and d) before (a, c) and after (b, d) sulfur poisoning by low-ppm level $\mathrm{H}_{2} \mathrm{~S}$ at intermediate temperature. Note that the anode reaction mechanism for PC-SOFC is greatly simplified and the exact process including the dominating pathway still needs to be studied. In addition, BCZYYb stands for the $\mathrm{BaZr}_{0.1} \mathrm{Ce}_{0.7} \mathrm{Y}_{0.1} \mathrm{Yb}_{0.1} \mathrm{O}_{3-\delta}$ PCC electrolyte used in this study, while BZCYYbS stands for $\mathrm{BZCYYb}$ with sulfur incorporation into the oxygen sublattice to form $\mathrm{Ba}\left(\mathrm{Zr}_{0.1} \mathrm{Ce}_{0.7} \mathrm{Y}_{0.1} \mathrm{Y}_{0.1}\right) \mathrm{O}_{3-\delta-\mathrm{y}} \mathrm{S}_{\mathrm{y}}$ oxysulfide with $\mathrm{y}<<1$.

Figure 4. 1 (a) Plot of cell voltage versus time for the Ni-BZCYYb/BZCYYb/LSCFBZCYYb anode-supported proton-conducting SOFC full cell operated under constant current density of $125 \mathrm{~mA} / \mathrm{cm}^{2}$ showing the poisoning and recovery as caused by introducing $5 \% \mathrm{CO}_{2}$ to the $3 \%$ humidified $\mathrm{H}_{2}$ fuel and later remove it at $750^{\circ} \mathrm{C}$. (b) 
Impedance spectra for the Ni-BZCYYb/BZCYYb/LSCF anode-supported protonconducting SOFC full cell operated with $3 \%$ humidified $\mathrm{H}_{2}$ (labelled as "Wet $\mathrm{H}_{2}$ ") at $750^{\circ} \mathrm{C}$ under open circuit (OC) condition and constant cell voltage of $0.7 \mathrm{~V}$ showing the poisoning effect of $5 \% \mathrm{O}$

Figure 4. 2 Impedance spectra measured under open circuit condition for a $\mathrm{Ni}$ BZCYYb/BZCYYb/LSCF-BZCYYb electrolyte-supported proton-conducting SOFC (PC-SOFC) at (a) $750^{\circ} \mathrm{C}$, (b) $650^{\circ} \mathrm{C}$, (c) $550^{\circ} \mathrm{C}$, and showing the effect of introducing $5 \mathrm{vol} \% \mathrm{CO}_{2}$ as fuel contaminant to the dry $\mathrm{H}_{2}$.

Figure 4. 3 Impedance spectra showing the effect of introducing $5 \% \mathrm{CO}_{2}$ to dry $\mathrm{H}_{2}$ fuel on the Ni-BZCYYb/BZCYYb/Ni-BZCYYb anode symmetrical cell at (a) $750^{\circ} \mathrm{C}$, (b) $650^{\circ} \mathrm{C}$ and (c) $550^{\circ} \mathrm{C}$, respectively.

Figure 4. 4 (a) XRD patterns for $\mathrm{NiO}-\mathrm{BZCYYb}$ mixed powders after reduction in $\mathrm{H}_{2}$ at $750^{\circ} \mathrm{C}$, and exposure tests at $550^{\circ} \mathrm{C}$ for 24 hours to pure $\mathrm{H}_{2}$ (as control sample) and fuel gas mixtures of dry $\mathrm{H}_{2}+5 \% \mathrm{CO}_{2}$, wet $\mathrm{H}_{2}+5 \% \mathrm{CO}_{2}$, (b) Raman spectra for samples after exposure to fuel gas mixtures of dry $\mathrm{H}_{2}+5 \% \mathrm{CO}_{2}$, wet $\mathrm{H}_{2}+5 \% \mathrm{CO}_{2}$, and pure $\mathrm{H}_{2}$ (as control sample), respectively.

Figure 5. 1 XRD patterns of as-synthesized LSCF and BZCYYb powders and their mixtures after compatibility test of firing at $1000^{\circ} \mathrm{C}$ for 2 hours in air and the three different stability tests of exposing the fired LSCF-BZCYYb composite at $750^{\circ} \mathrm{C}$ for 24 hours in ambient air, pure $\mathrm{O}_{2}$, and $3 \%$ humidified air

Figure 5. 2 SEM images of the cross-section and the electrode surface of the fabricated $\mathrm{Ag} / \mathrm{BZCYYb} / \mathrm{Ag}$ (a and b), LSCF/BZCYYb/LSCF (c and d), LSCFBZCYYb/BZCYYb/LSCF- BZCYYb (e and f), and BSCF/BZCYYb/BSCF (g and h) cathode symmetrical cell, respectively.

Figure 5. 3 Impedance spectra for a $\mathrm{Ag} / \mathrm{BZCYYb} / \mathrm{Ag}$ symmetrical cell in dry simulated air $\left(20 \% \mathrm{O}_{2} / 80 \% \mathrm{~N}_{2}\right.$ with $<\sim 5 \mathrm{ppm} \mathrm{H}_{2} \mathrm{O}$ and $\left.\mathrm{CO}_{2}\right)$, pure oxygen, and simulated air humidified with $3 \% \mathrm{H}_{2} \mathrm{O}$ at (a) $650^{\circ} \mathrm{C}$, (b) $550^{\circ} \mathrm{C}$, and (c) $450^{\circ} \mathrm{C}$, respectively. 140

Figure 5. 4 Impedance spectra for a LSCF/BZCYYb/LSCF symmetrical cell in dry simulated air $\left(20 \% \mathrm{O}_{2} / 80 \% \mathrm{~N}_{2}\right.$ with $<\sim 5 \mathrm{ppm} \mathrm{H}_{2} \mathrm{O}$ and $\left.\mathrm{CO}_{2}\right)$, pure oxygen, and simulated air humidified with $3 \% \mathrm{H}_{2} \mathrm{O}$ at (a) $650^{\circ} \mathrm{C}$, (b) $550^{\circ} \mathrm{C}$, and (c) $450^{\circ} \mathrm{C}$, respectively....... 142

Figure 5. 5 Impedance spectra for a LSCF-BZCYYb/BZCYYb/LSCF-BZCYYb symmetrical cell in dry simulated air $\left(20 \% \mathrm{O}_{2} / 80 \% \mathrm{~N}_{2}\right.$ with $<\sim 5 \mathrm{ppm} \mathrm{H}_{2} \mathrm{O}$ and $\left.\mathrm{CO}_{2}\right)$ and pure oxygen at (a) $650^{\circ} \mathrm{C}$, (b) $550^{\circ} \mathrm{C}$, and (c) $450^{\circ} \mathrm{C}$, respectively.

Figure 5. 6 Impedance spectra for a LSCF-BZCYYb/BZCYYb/LSCF-BZCYYb symmetrical cell in dry simulated air $\left(20 \% \mathrm{O}_{2} / 80 \% \mathrm{~N}_{2}\right.$ with $<\sim 5 \mathrm{ppm} \mathrm{H}_{2} \mathrm{O}$ and $\left.\mathrm{CO}_{2}\right)$ versus simulated air humidified with various concentrations of moisture at (a) $650^{\circ} \mathrm{C}$, (b) $550^{\circ} \mathrm{C}$, and (c) $450^{\circ} \mathrm{C}$, respectively.... 146 
Figure 5. 7 Impedance spectra for a BSCF/BZCYYb/BSCF symmetrical cell in dry simulated air $\left(20 \% \mathrm{O}_{2} / 80 \% \mathrm{~N}_{2}\right.$ with $<\sim 5 \mathrm{ppm} \mathrm{H}_{2} \mathrm{O}$ and $\left.\mathrm{CO}_{2}\right)$ versus pure oxygen at (a) $650^{\circ} \mathrm{C}$, (b) $550^{\circ} \mathrm{C}$, (c) $450^{\circ} \mathrm{C}$, and (d) zoom-in of the impedance spectra at $450^{\circ} \mathrm{C}$ showing the high frequency (HF) part.

Figure 5. 8 Impedance spectra for a BSCF/BZCYYb/BSCF symmetrical cell in dry simulated air $\left(20 \% \mathrm{O}_{2} / 80 \% \mathrm{~N}_{2}\right.$ with $\left.<\sim 5 \mathrm{ppm} \mathrm{H}_{2} \mathrm{O}\right)$ versus simulated air with varying concentrations of moisture at (a) $650^{\circ} \mathrm{C}$, (b) $550^{\circ} \mathrm{C}$, (c) $450^{\circ} \mathrm{C}$, and (d) zoom-in of the impedance spectra at $450^{\circ} \mathrm{C}$ showing the high frequency (HF) part.

Figure 5. 9 Ohmic resistance subtracted impedance spectra for a BSCF/BZCYYb/BSCF symmetrical cell in dry simulated air $\left(20 \% \mathrm{O}_{2} / 80 \% \mathrm{~N}_{2}\right.$ with $\left.<\sim 5 \mathrm{ppm} \mathrm{H}_{2} \mathrm{O}\right)$ versus simulated air with various concentrations of moisture at (a) $650^{\circ} \mathrm{C}$, (b) $550^{\circ} \mathrm{C}$, and (c) $450^{\circ} \mathrm{C}$, respectively.

Figure 5. 10 Schematics showing the reaction species involved and the elementary steps (also refer to Table 5. 1) for the reversible oxygen electrode reactions for an ideal oxideion based SOFC with (a) Ag, (b) pure LSCF, (c) LSCF-BZCYYb composite, and (d) BSCF as the cathode (oxygen electrode) on BZCYYb electrolyte in a dry simulated air atmosphere.

Figure 5. 11 Schematics showing the reaction species involved and the elementary steps (also refer to Table 5. 1) for the reversible oxygen electrode reactions for an ideal protonconducting electrolyte based SOFC with (a) Ag, (b) pure LSCF, and (c) LSCF-BZCYYb composite, and (d) BSCF as the cathode (oxygen electrode) on proton conducting BZCYYb electrolyte in simulated air in a humidified atmosphere assuming full hydration for the electrolyte. 153

Figure 5. 12 Total apparent electrode interfacial resistance $\mathrm{R}_{\mathrm{ai}}$ in dry simulated air, pure oxygen and simulated air containing up to $20 \%$ moisture for LSCF-BZCYYb composite electrode symmetrical cells at temperatures from 650 to $450^{\circ} \mathrm{C}$. 163

Figure 5. 13 High frequency resistance $\mathrm{R}_{\mathrm{HF}}$ in dry simulated air, pure oxygen and simulated air containing up to $20 \%$ moisture for LSCF-BZCYYb composite electrode symmetrical cells at temperatures from 650 to $450^{\circ} \mathrm{C}$.

Figure 5. 14 Impedance spectra for a BSCF/BZCYYb/BSCF symmetrical cell in dry simulated air $\left(20 \% \mathrm{O}_{2} / 80 \% \mathrm{~N}_{2}\right.$ with $\left.<\sim 5 \mathrm{ppm} \mathrm{H}_{2} \mathrm{O}\right)$ and simulated air with $3 \% \mathrm{H} 2 \mathrm{O}$ versus $\mathrm{BSCF} / \mathrm{BZCYYb} / \mathrm{Ni}-\mathrm{BZCYYb}$ full cell at $450^{\circ} \mathrm{C}$

Figure 6. 1 XRD patterns of as synthesized BSCF and BZCYYb powders and their mixtures after different compatibility/stability tests. ....

Figure 6. 2 SEM image of cross-section of fabricated BSCF/BZCYYb/BSCF symmetrical cell. 
Figure 6. 3 Impedance spectra for a $\mathrm{BSCF} / \mathrm{BZCYYb} / \mathrm{BSCF}$ symmetrical cell in simulated air $\left(20 \% \mathrm{O}_{2} / 80 \% \mathrm{~N}_{2}\right.$ without $\mathrm{H}_{2} \mathrm{O}$ or $\left.\mathrm{CO}_{2}\right)$ versus simulated air humidified with various $\mathrm{pH}_{2} \mathrm{O}$ at (a) $650^{\circ} \mathrm{C}$, (b) $550^{\circ} \mathrm{C}$, and (c) $450^{\circ} \mathrm{C}$, respectively. 183

Figure 6. 4 Impedance spectra for $\mathrm{BSCF} / \mathrm{BZCYYb} / \mathrm{BSCF}$ symmetrical cell at $475^{\circ} \mathrm{C}$ in dry and wet (with various $\mathrm{pH}_{2} \mathrm{O}$ ) "simulated air" (a) the full impedance spectra, (b) zoom in to show the changes at the high frequency (HF) portion. 184

Figure 6. 5 Comparison of the impedance spectra for BSCF/BZCYYb/BSCF symmetrical cell at $450^{\circ} \mathrm{C}$ (a) entire impedance spectra comparing dry "simulated air" and dry pure $\mathrm{O}_{2}$ and zoom-in of the high frequency (HF) part, (b) zoom-in of pure $\mathrm{O}_{2}$ with different concentration of moisture at the high frequency (HF) part. 185

Figure 6. 6 Plots showing the change in impedance spectra for $\mathrm{BSCF} / \mathrm{BZCYYb/BSCF}$ symmetrical cell in dry "simulated air" $\left(20 \% \mathrm{O}_{2} / 80 \% \mathrm{~N}_{2}\right)$ before exposure to $\mathrm{CO}_{2}$, after exposure to $1 \% \mathrm{CO}_{2}$ for $2 \mathrm{~h}$, and after recovery (i.e., removal of $1 \% \mathrm{CO}_{2}$ ) for 24 hours at (a) $650^{\circ} \mathrm{C}$, (b) $550^{\circ} \mathrm{C}$ and (c) $450^{\circ} \mathrm{C}$, respectively. 187

Figure 6. 7 Impedance curve for BSCF/BZCYYb/BSCF symmetrical cell in humidified simulated air $\left(3 \% \mathrm{H}_{2} \mathrm{O} / 20 \% \mathrm{O}_{2} / 77 \% \mathrm{~N}_{2}\right.$ ) before exposure, after exposure to $1 \% \mathrm{CO}_{2}$ for 2 hours, and after recovery (i.e., removal of $1 \% \mathrm{CO}_{2}$ ) for 24 hours at (a) $650^{\circ} \mathrm{C}$, (b) $550^{\circ} \mathrm{C}$ and (c) $450^{\circ} \mathrm{C}$, respectively. 189

Figure 6. 8 Schematics showing the reaction species involved and the elementary steps (also refer to Table 5. 1) for the reversible oxygen electrode reaction for (a) ideal pure oxide-ion based SOFC and (b) ideal pure proton conducting SOFC.

Figure 6. 9 High frequency resistance $\mathrm{R}_{\mathrm{HF}}$ in dry simulated air versus that contains up to $20 \%$ moisture at temperatures from 500 to $400^{\circ} \mathrm{C}$ 198 


\section{Chapter I: Introduction}

\subsection{Motivation of the Research}

Solid oxide fuel cells (SOFC) are a type of electrochemical energy conversion devices that offer various advantages such as high overall combined heat and electrical efficiency (80$90 \%$ ), wide range of scales (100W-100MW) and high stack volumetric power density (10 $\left.\mathrm{W} / \mathrm{cm}^{3}\right)$ as well as high specific energy $(\sim 1 \mathrm{kWh} / \mathrm{kg})$ over conventional power generation systems. [1-10] However, several problems have been discovered for conventional SOFC based on oxide-ion conducting electrolyte, such as high degradation rate during long-term operation, and high cost for the sealing and interconnect materials. [3, 11, 12] These problems are mainly due to the high operating temperature (at or above $750^{\circ} \mathrm{C}$ ) for conventional oxide-ion conducting SOFC and have so far interfered with wide adoption of SOFC.

As a result, increasing interest has been drawn to intermediate temperature SOFC (ITSOFC), the type of SOFC that can operate at intermediate temperature range of $400^{\circ} \mathrm{C}$ to $600^{\circ} \mathrm{C}$ which is much lower than the operating temperature of conventional oxide-ion conducing SOFC. To achieve reduced operating temperature, proton conducting ceramics (PCC) are found to be promising electrolyte materials due to their high ionic conductivity at intermediate temperature compared to conventional oxide-ion conducting electrolyte materials. [11-15] For example, $\mathrm{BaZr}_{0.1} \mathrm{Ce}_{0.7} \mathrm{Y}_{0.1} \mathrm{Yb}_{0.1} \mathrm{O}_{3-\delta}(\mathrm{BZCYYb})$ which is one of the leading PCC, shows conductivity of $\sim 10^{-2} \Omega^{-1} \cdot \mathrm{cm}^{-1}$ at $450^{\circ} \mathrm{C}$ which is much higher than the conductivity of Yttria-stabilized zirconia (YSZ) $\left(\sim 2 * 10^{-4} \Omega^{-1} \cdot \mathrm{cm}^{-1}\right)$, which is the most 
widely used oxide-ion conducting electrolyte material for conventional SOFC. [15] However, the electrodes (anode and cathode) reaction mechanism have significantly changed as the electrolyte material changes from oxide-ion conductor (e.g. YSZ) to proton conductor, leading to many unsolved questions in the system of proton conducting ITSOFC.

For conventional SOFC based on oxide-ion conducting electrolyte, the structure typically consists of porous anode (typically a mixture of oxide-ion conducting oxides (e.g. YSZ) and metal catalyst (e.g. nickel (Ni)), dense solid oxide electrolyte (e.g. YSZ) and porous cathode (typically mixed oxide-ion and electron conducting oxides (e.g. $\left.\left.\mathrm{La}_{0.6} \mathrm{Sr}_{0.4} \mathrm{Co}_{0.2} \mathrm{Fe}_{0.8} \mathrm{O}_{3-\delta}(\mathrm{LSCF})\right)\right) .[4,7,11]$

On the anode side of conventional oxide-ion conducting SOFC, the reaction can be written as follows:

$\mathrm{H}_{2}+\mathrm{O}_{\mathrm{O}}^{\times}=\mathrm{H}_{2} \mathrm{O}+\mathrm{V}_{\mathrm{O}}^{*}+2 e^{-}$ Equation 1.1 As shown in Figure 1. 1 (a), the overall anode reaction pathway involves water evolution and is composed of several other elementary steps including (i) hydrogen $\left(\mathrm{H}_{2}\right)$ adsorption on the metal catalyst (e.g. Ni) surface, (ii) dissociation of hydrogen on the metal catalyst surface and diffusion of adsorbed dissociated hydrogen atoms over metal catalyst surface onto the triple-phase boundary (TPB), which is the region between the ion-conducting electrolyte phase (e.g. YSZ), the electron conducting metal phase (e.g. Ni), and the gas phase reaction sites, and (iii) charge transfer on the TPB, including creation of oxide ions (i.e. oxygen vacancies $\mathrm{V}_{\mathrm{O}}^{*}$ or the $\mathrm{O}^{2-}$ ), generation of water molecule and electrons, and (iv) desorption of water molecules from the TPB. 


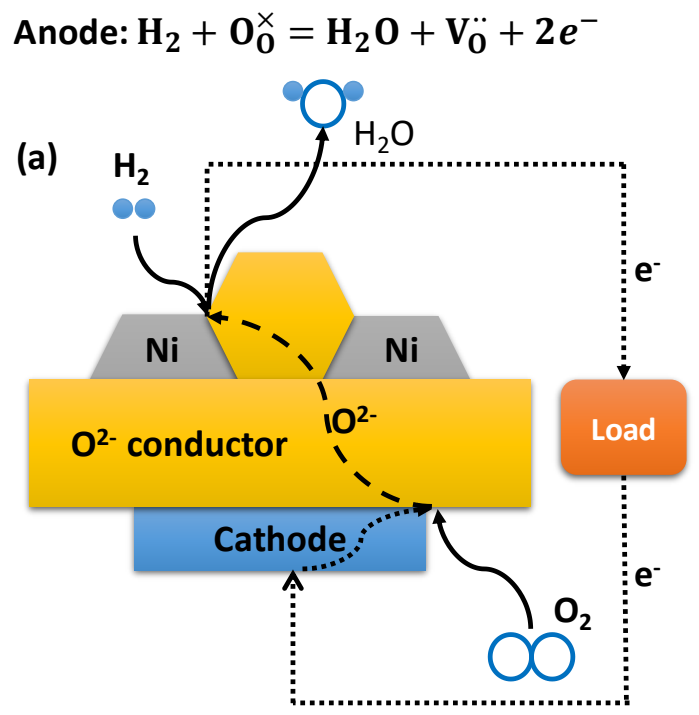

Cathode: $2 \mathrm{~V}_{0}^{\ddot{*}}+4 e^{-}+\mathrm{O}_{2}=20_{0}^{\times}$
Anode: $\mathrm{H}_{2}+2 \mathrm{O}_{\mathrm{O}}^{\times}=2(\mathrm{OH})_{0}^{\cdot}+2 e^{-}$

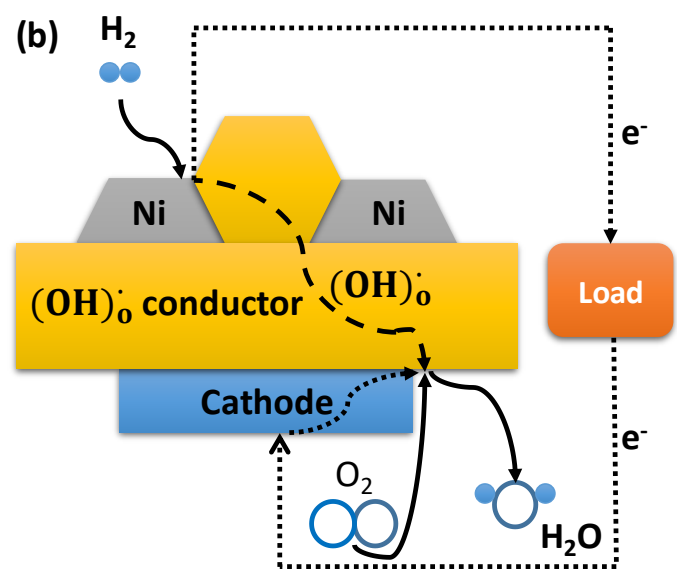

Cathode: $4(\mathrm{OH})_{0}^{\dot{j}}+4 e^{-}+\mathrm{O}_{2}=2 \mathrm{H}_{2} \mathrm{O}+4 \mathrm{O}_{0}^{\times}$

Figure 1. 1 Schematics showing (a) electrodes reaction route for a conventional oxide-ion conducting SOFC, and (b) electrodes reaction route for a proton conducting SOFC.

On the cathode side of conventional oxide-ion conducting SOFC, the overall reaction can be written as following:

$2 \mathrm{~V}_{\mathrm{O}}^{*}+4 e^{-}+\mathrm{O}_{2}=2 \mathrm{O}_{\mathrm{O}}^{\times}$

Equation 1.2

As shown in Figure 1. 1 (a), the overall reaction pathway in the cathode also consists of multiple elementary steps including (i) oxygen $\left(\mathrm{O}_{2}\right)$ adsorption on the cathode (e.g. LSCF) surface, (ii) dissociation of oxygen on the cathode surface and diffusion to the TPB of cathode; (iii) charge transfer including incorporation of dissociated oxygen and electrons and generation of lattice oxygen. 
In comparison, for the ideal reaction process in proton conducting IT-SOFC, the reaction route is different from that for conventional oxide-ion conducting SOFC as shown in Figure 1. 1 (b).

First and most importantly, the conducting species for proton conducting SOFC are protons $\left((\mathrm{OH})_{\mathrm{O}}^{\circ}\right)$ instead of oxide ions $\left(\mathrm{O}^{2-}\right)$ as in oxide-ion conducting SOFC. In this case, the overall anode reaction can be written as:

$\mathrm{H}_{2}+2 \mathrm{O}_{\mathrm{O}}^{\times}=2(\mathrm{OH})_{\mathrm{O}}^{\dot{2}}+2 e^{-}$

Equation 1.3

Such an anode reaction pathway consists of multiple elementary steps including (i) hydrogen adsorption, (ii) dissociation of adsorbed hydrogen and diffusion of dissociated hydrogen atoms to TPB, and (iii) charge transfer step involving the proton incorporation and generation of electrons in TPB region, without generation of water.

For the cathode reaction in proton conducting SOFC, it can be written as following:

$$
4(\mathrm{OH})_{\mathrm{O}}^{\dot{\gamma}}+4 e^{-}+\mathrm{O}_{2}=2 \mathrm{H}_{2} \mathrm{O}+4 \mathrm{O}_{\mathrm{O}}^{\times}
$$

Equation 1.4

Similarly, the overall cathode reaction pathway consists of several elementary steps as the following: (i) oxygen $\left(\mathrm{O}_{2}\right)$ adsorption on the cathode surface, (ii) dissociation of oxygen on the cathode surface and diffusion to the TPB of cathode, and (iii') charge transfer including the generation of water molecule near TPB and lattice oxygen remains and (iv') desorption of generated water on the TPB of cathode.

Even though there have been some studies on the reaction mechanisms for proton conducting IT-SOFC, various issues remain unsolved. 
For conventional oxide-ion conducting SOFC, the $\mathrm{Ni}$ metal catalyst is the only electrocatalytic active part for hydrogen oxidation in the anode reaction, i.e. step (i) $\mathrm{H}_{2}$ adsorption, (ii) $\mathrm{H}_{2}$ dissociation and surface diffusion and are believed to only happen on the metal catalyst surface (e.g. nickel Ni) while oxide-ion conductor (e.g. YSZ) participate only in step (iii) and (iv). On the other hand, previous studies seem to show certain electrocatalytic activity for PCC in hydrogen oxidation [16-19] as in proton conducting ITSOFC.

Besides that, considering the change in anode reaction process that no longer involve water evolution on the anode, how the anode for proton conducting IT-SOFC respond to different fuel contaminants such as $\mathrm{H}_{2} \mathrm{~S}$ and $\mathrm{CO}_{2}$ is still unknown.

On the other hand, for the cathode of proton conducting IT-SOFC, factors that limit the cathode reaction rate, such as material choice and cathode microstructure including grain size, are not well studied yet. Additionally, since $\mathrm{H}_{2} \mathrm{O}$ evolution is involved in the cathode reaction for proton conducting IT-SOFC, [20] understanding concerning the $\mathrm{H}_{2} \mathrm{O}$ effect on the cathode is required for further improving the cathode materials for proton conducting IT-SOFC. Besides that, $\mathrm{CO}_{2}$, which is generally not a concern for the cathode of conventional oxide-ion conducting SOFC, should be taken into consideration since PCC, which have high affinity to $\mathrm{CO}_{2}$ are involved in the cathode reaction for proton conducting IT-SOFC. [21-23]

Studying the issues outlined above is expected to generate new understandings and help optimize the anode and cathode for proton conducting IT-SOFC that operate at temperature down to $\sim 400^{\circ} \mathrm{C}$ would be designed. 


\subsection{Research Objectives and Methods}

The objectives of this research are to (i) characterize the electrochemical behaviors of the anode for proton conducting intermediate temperature $\left(\sim 400-750^{\circ} \mathrm{C}\right)$ solid oxide fuel cells (IT-SOFC) against low-ppm level $\mathrm{H}_{2} \mathrm{~S}$ and low-percentage level $\mathrm{CO}_{2}$, and develop new understanding about the underlying reaction mechanism including what role proton conducting ceramics (PCC) play in the anode reaction for proton conducting IT-SOFC (ii) characterize the electrochemical behaviors of several different types of cathode materials for proton conducting IT-SOFC including BSCF, Ag, LSCF and LSCF-BZCYYb facing different atmospheres (e.g. various $p \mathrm{H}_{2} \mathrm{O}, p \mathrm{O}_{2}$ and $\mathrm{CO}_{2}$ ) and design better cathode for proton conducting IT-SOFC based on the insight gained above.

In order to achieve the first objective, electrochemical experiments were carried out using low concertation fuel contaminants of $\mathrm{H}_{2} \mathrm{~S}$ and $\mathrm{CO}_{2}$ for proton conducting IT-SOFC.

In detail, $\mathrm{H}_{2} \mathrm{~S}$, which will cause severe poisoning on the anode for conventional oxideion conducting (e.g. Ni/YSZ mixture as anode) due to its strong adsorption on Ni surface with low concentration down to ppm(v)-level, [24-38] and $\mathrm{CO}_{2}$, which is believed to have strong adsorption on PCC surface while no affinity and reactivity to the Ni surface, [3942] were used to determine the electrocatalytic role of PCC in the anode reaction for proton conducting IT-SOFC.

The controlled poisoning experiments were carried out on anode-supported and electrolyte-supported full cells with the configuration of Ni-BZCYYb/BZCYYb/LSCF. Electrochemical behaviors of the anode for proton conducting IT-SOFC under typical 
operation conditions (e.g. temperature of $750-450^{\circ} \mathrm{C}$, atmosphere of $3 \% \mathrm{H}_{2} \mathrm{O}+\mathrm{H}_{2}$, etc.) were recorded using electrochemical impedance spectroscopy (EIS) and voltage monitoring under constant current. Furthermore, in order to study the reaction mechanism for the anode reaction without the complexity originated from the cathode and enlarge the poisoning effect on the anode, anode symmetrical cells with the configuration of $\mathrm{Ni}$ BZCYYb/BZCYYb/Ni-BZCYYb were used in this study. Besides that, conventional oxide-ion conducting anode symmetrical cell with the configuration of Ni-YSZ/YSZ/NiYSZ will be subjected to similar poisoning conditions for comparison purpose. Characterization techniques such as X-Ray diffraction (XRD), energy dispersive X-Ray spectroscopy (EDS) and secondary-ion mass spectroscopy (SIMS) are applied following the electrochemical response tests on the post-exposure anode or samples under similar reaction circumstances for achieving better understanding the fundamental interaction mechanism between fuel poisons $\left(\mathrm{H}_{2} \mathrm{~S}\right.$ and $\left.\mathrm{CO}_{2}\right)$ and the cermet anode for proton conducting IT-SOFC.

For the second task, cathode materials such as BSCF, Ag, LSCF, and LSCF-BZCYYb composite were studied using proton conducting cathode symmetrical cells based on BZCYYb electrolyte to eliminate possible influence from the anode. Such symmetrical cells were subjected to atmosphere with different $p \mathrm{H}_{2} \mathrm{O}, p \mathrm{O}_{2}$ and $p \mathrm{CO}_{2}$ in the of $750-450^{\circ} \mathrm{C}$. Electrochemical behaviors of various cathode symmetrical cells were recorded under these conditions and the results offer useful insights about the fundamental cathode reaction mechanism for the proton conducting IT-SOFC that are not available before. New cathode 
materials and microstructures for proton conducting IT-SOFC are also explored based on the insights gained above.

\subsection{Thesis Outline}

This dissertation is organized into 7 chapters. Chapter I provides a general introduction to proton conducting intermediate temperature solid oxide fuel cells (IT-SOFC) and some of the remaining challenges and the corresponding motivations for this sudy. Chapter II details the reason for adopting proton conducting IT-SOFC, followed by a review on the unsolved problems for the anode and cathode of proton conducting IT-SOFC and the need for our research. Chapter III and Chapter IV discusses the $\mathrm{H}_{2} \mathrm{~S}$ and $\mathrm{CO}_{2}$ poisoning effect on the anode of proton conducting IT-SOFC and their implications on the electrochemical catalytic role of proton conducting ceramics played in the anode reaction. Chapter V discusses the electrochemical responses of several different types of cathode materials to $\mathrm{H}_{2} \mathrm{O}$ vapor effect and their implications on understanding cathode reaction mechanism for proton conducting IT-SOFC. Chapter VI discusses the $\mathrm{H}_{2} \mathrm{O}$ and $\mathrm{CO}_{2}$ effect on the $\mathrm{Ba}_{0.5} \mathrm{Sr}_{0.5} \mathrm{Co}_{0.8} \mathrm{Fe}_{0.2} \mathrm{O}_{3}$ (BSCF) cathode for proton conducting IT-SOFC and the corresponding explanations. Summary of the major findings in this work and recommendations for future work are provided in Chapter VII. 


\section{Chapter II: Literature Review}

\subsection{Proton Conducting Intermediate Temperature Solid Oxide Fuel Cells (IT-SOFC)}

\subsubsection{Components and Structure of SOFC}

Solid oxide fuel cells are a type of energy conversion devices that produce electricity by combining the fuel (e.g. $\mathrm{H}_{2}$ ) and the oxidant (typically $\mathrm{O}_{2}$ in air) through electrochemical reactions. They have a solid electrolyte, which conducts oxide-ion or proton. $[1,2,4,7,8]$ As shown in Figure 2. 1, the dense electrolyte is located between the porous anode and the cathode, and the anode/electrolyte/cathode trilayer is typically referred to as a single cell or full cell. $[3,4,9,10,43,44]$ Fuel gas, typically $\mathrm{H}_{2}$, is fed to the anode, undergoes oxidation, and releases electrons to the external circuit. On the other hand, oxidant is fed to the cathode, undergoes reduction and accept the electrons from the external circuit. The electricity is produced by the electron flow from the anode to the cathode in the external circuit. 


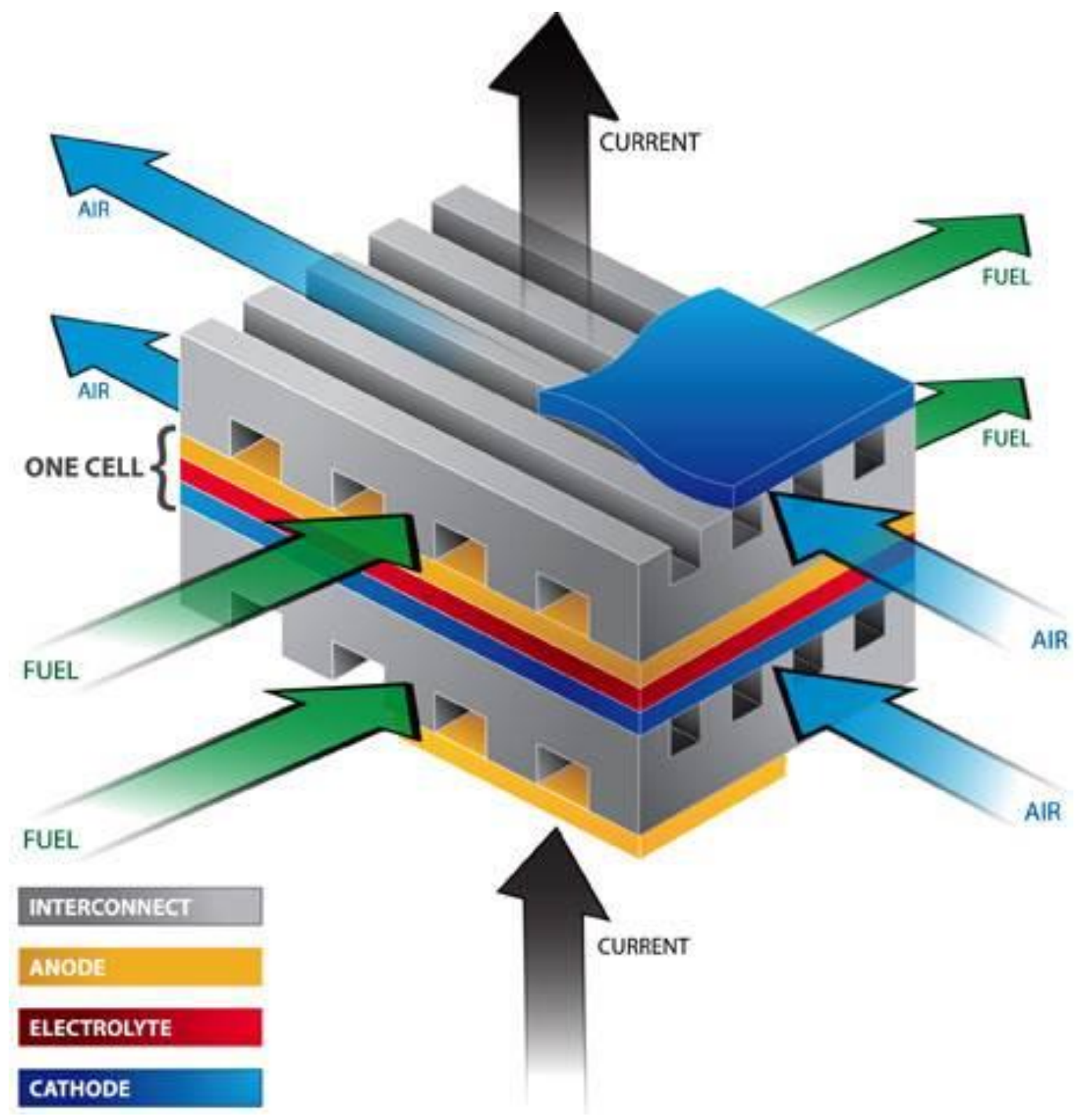

Figure 2. 1 Materials and related issues for SOFC. From Mahato et al. [9]

In an SOFC stack, single cells are connected in electrical series via a component called interconnect as shown in Figure 2. 1, which is typically doped lanthanum chromite or hightemperature metal alloys. [8, 45, 46] 


\subsubsection{From High Temperature SOFC (HT-SOFC) to Intermediate Temperature SOFC (IT-SOFC)}

So far, typical operating temperature for conventional SOFC is relatively high in the range from $1000^{\circ} \mathrm{C}$ to $700^{\circ} \mathrm{C}$, and they are called high-temperature SOFC (HT-SOFC).[11] These HT-SOFC are based on oxide-ion conducting electrolyte, for which the most commonly used is yttria-stabilized zirconia (YSZ) because of its adequate oxide-ion conductivity, and excellent stability in both oxidizing and reducing atmosphere. $[1,2,11,43,47-50]$ The oxide-ion conductivity for YSZ comes from its high concentration of oxygen vacancies, which are introduced when the $\mathrm{Zr}^{4+}$ cations in $\mathrm{ZrO}_{2}$ is replaced by $\mathrm{Y}^{3+}$ cations due to $\mathrm{Y}_{2} \mathrm{O}_{3}$ doping in $\mathrm{ZrO}_{2}$, as shown in equation 2.1. [47, 51-54]

$\mathrm{Y}_{2} \mathrm{O}_{3} \stackrel{\mathrm{ZrO}_{2}}{\longrightarrow} 2 \mathrm{Y}_{\mathrm{Zr}}^{\prime}+\mathrm{V}_{\mathrm{o}}+3 \mathrm{O}_{\mathrm{o}}^{\mathrm{X}}$ Equation 2. 1

For conventional oxide-ion conducting SOFC, Ni-YSZ cermet is widely used as the anode. $\mathrm{Ni}$, which serves as the electronic conductor and fuel (e.g. $\mathrm{H}_{2}$ ) oxidation electrocatalyst, is suitable for HT-SOFC operation due to its low cost (comparing with Co and noble metals), reasonable stability against oxidation in fuel mixture even with high $\mathrm{H}_{2} \mathrm{O}$ and $\mathrm{CO}_{2}$ concentration at high temperature of $\sim 1000^{\circ} \mathrm{C}$, [47, 55] as well as sufficient electronic conductivity and high electroactivity for fuel (e.g. $\mathrm{H}_{2}$ ) oxidation. The YSZ in the cermet anode provides mechanical support for the Ni particles, assures that the anode has similar thermal expansion coefficient (TEC) to other cell components, and inhibits $\mathrm{Ni}$ coarsening. [56, 57] In addition, the YSZ also serves as the oxide-ion conductor, which transports oxide-ion to the triple phase boundary of anode and expand the anode reaction 
zone. [58] YSZ has been considered to be not electrocatalytic active in fuel oxidation reaction. [47]

For the cathode of HT-SOFC, perovskite $\left(\mathrm{ABO}_{3}\right)$ structured oxides are commonly used. Many of them offer low cost, great oxide-ion conductivity, reasonable stability and compatibility, as well as similar thermal expansion coefficient as the electrolyte material (e.g. YSZ). $[56,59,60]$ Among those doped perovskite oxides cathodes, Strontium doped Lanthanum Manganite $\left(\mathrm{La}_{1-\mathrm{x}} \mathrm{Sr}_{\mathrm{x}}\right)_{1-\mathrm{y}} \mathrm{MnO}_{3-\delta}(\mathrm{LSM}),[48,61-66]$ Strontium and Iron codoped Lanthanum Cobaltite $\mathrm{La}_{1-\mathrm{x}} \mathrm{Sr}_{\mathrm{x}} \mathrm{Co}_{1-\mathrm{y}} \mathrm{Fe}_{\mathrm{y}} \mathrm{O}_{3-\delta}$ (LSCF) [67-69] and Strontium and Iron co-doped Barium Cobaltite $\mathrm{Ba}_{1-\mathrm{x}} \mathrm{Sr}_{\mathrm{x}} \mathrm{Co}_{1-\mathrm{y}} \mathrm{Fe}_{\mathrm{y}} \mathrm{O}_{3-\delta}$, [70-74] show high electrocatalytic activity for oxygen reduction, and high mixed ionic (oxide-ion) and electronic conductivity (MIEC).

The advantages of HT-SOFC comes from its high combined heat and power (CHP) efficiency ( >85\%), good modularity, fuel flexibility (meaning both pure $\mathrm{H}_{2}$ and many hydro-carbon fuels can be used), very low levels of $\mathrm{SO}_{\mathrm{x}}$ and $\mathrm{NO}_{\mathrm{x}}$ emissions as well as low noise during operation. $[3,5-7,11]$

However, there are still several major issues with the HT-SOFC that have limited the development and deployment of this technology associated with its high operating temperature. Among those issues, the most important ones are the high cost originated from the expensive sealing and interconnect materials that need to tolerate high temperature, high performance degradation rates due to unwanted reactions/diffusions at high temperature, as well as potential mechanical failure due to repeated thermal cycling. 
Thus, lowering the operating temperature of SOFC seems attractive, and possibly, necessary for their wider applications. This is because the lowered temperature is expected to slower the degradation due to slower diffusion and interactions between the components. The lower operating temperature may also enable the use of cheaper sealing and interconnect materials that are stable at $\sim 400-600^{\circ} \mathrm{C}$ (e.g. stainless steel or even graphite). Besides that, the reduced operating temperature could also enhance the durability during long-term thermal cycling due to less thermal stress and lower thermal mismatch. $[12,13$, 75]

However, for SOFC to operate at lower temperature in the range of $\sim 400-600^{\circ} \mathrm{C}$, the main challenges are related to high electrolyte resistivity and electrode polarization loss.[13] For common oxide-ion based electrolyte material in HT-SOFC, dramatic decrease in ionic conductivity was observed at intermediate temperature: For the example of YSZ elecrolyte, its ionic conductivity is only $\sim 10^{-4} \mathrm{ohm}^{-1} \mathrm{~cm}^{-1}$ at $450^{\circ} \mathrm{C}$ comparing with $\sim 10^{-2}$ $\mathrm{ohm}^{-1} \mathrm{~cm}^{-1}$ at $750^{\circ} \mathrm{C}$. [15] Therefore, in order to still use YSZ as the electrolyte at intermediate temperature, tremendously reduced YSZ thickness (by 10-100 times) is required to compensate for its low ionic conductivity. However, this may lead to significant decrease in durability and high cost (associated with $<1$ um thin-film deposition).

Alternatively, electrolyte material with higher ionic conductivity at intermediate temperature range could be adopted. For example, other oxide-ion conducting electrolytes such as gadolinium-doped ceria (GDC) shows higher ionic conductivity at reduced temperature. However, the ionic conductivities of those electrolyte materials are still not high enough, and for GDC the open circuit voltage (OCV) is low due to electronic leakage. 
Thus, electrolyte materials that have even higher ionic conductivity with lower electronic leakage are required.

\subsubsection{From Proton Conducting Ceramics to Proton Conducting IT-SOFC}

\subsubsection{Proton Conducting Ceramics: Conductivity and Stability}

Recently, proton conducting ceramics (PCC), mainly acceptor doped barium or strontium cerates or zirconates, [76-86] are found to be promising electrolyte materials for IT-SOFC due to their high ionic conductivities and low electronic leakage at intermediate temperature. For example, the ionic conductivity of $\mathrm{BaZr}_{0.1} \mathrm{Ce}_{0.7} \mathrm{Y}_{0.1} \mathrm{Yb}_{0.1} \mathrm{O}_{3-\delta}(\mathrm{BZCYYb})$ is $\sim 10^{-2} \mathrm{ohm}^{-1} \mathrm{~cm}^{-1}$ at $450^{\circ} \mathrm{C}$ as shown in Figure 2. 2, [15] which matches the conductivity of YSZ at $750^{\circ} \mathrm{C}$. The high ionic conductivity of PCC in principle allows much lower operation temperature of SOFC towards $450^{\circ} \mathrm{C}$. [15, 79, 82, 83, 85, 87-89]

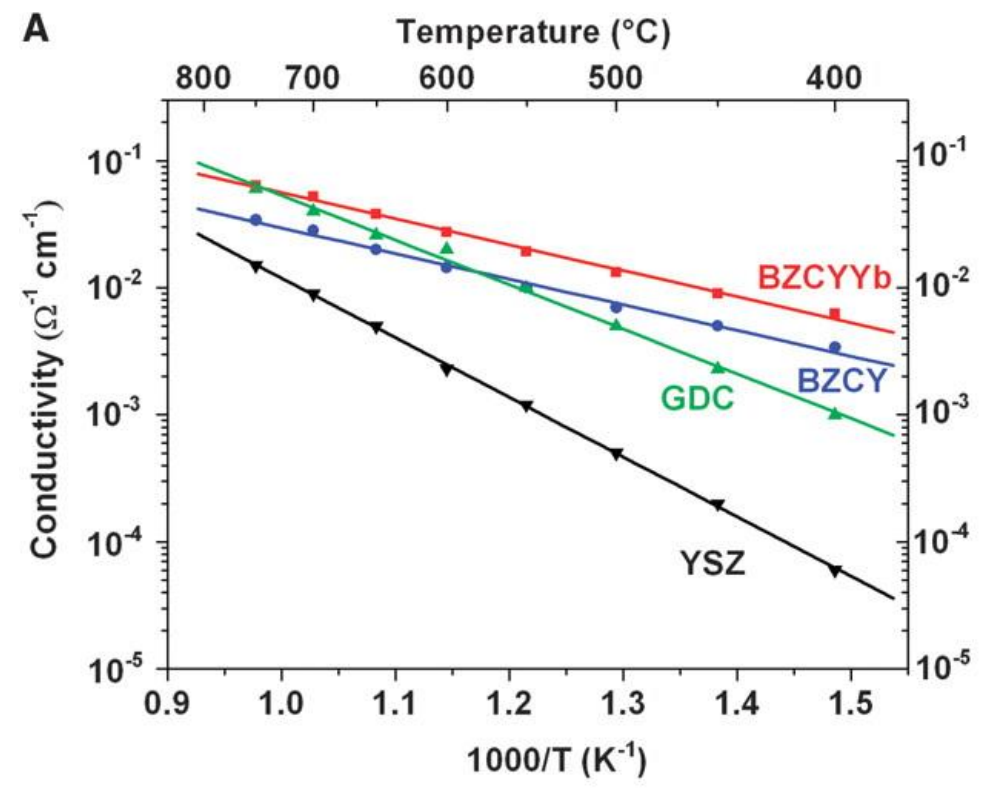


Figure 2. 2 Ionic conductivities of $\mathrm{BZCYYb}, \mathrm{BaZr}_{0.1} \mathrm{Ce}_{0.7} \mathrm{Y}_{0.2} \mathrm{O}_{3-\delta}(\mathrm{BZCY})$, Gadolinium doped ceria (GDC), and YSZ as measured at $400^{\circ}$ to $750^{\circ} \mathrm{C}$ in wet oxygen (with $\sim 3$ vol $\% \mathrm{H}_{2} \mathrm{O}$ ). From Yang et al. [15]

The high ionic conductivity for such PCC is mainly due to the conduction of proton $\left(\mathrm{H}_{\mathrm{i}}\right.$ or $\left.\mathrm{OH}_{\mathrm{O}}^{\circ}\right)$ instead of the oxide-ion $\left(\mathrm{V}_{\mathrm{o}}\right.$ or $\left.\mathrm{O}^{2-}\right)$, especially in atmospheres with high partial pressure of water and at temperature lower than $700^{\circ} \mathrm{C} .[15,88,90]$ Such proton conduction is based on the creation of proton defects from oxygen vacancies and water adsorbed from surrounding atmosphere, and the defect reaction can be written as following: [77]

$$
\mathrm{O}_{\mathrm{o}}^{\mathrm{X}}+\mathrm{V}_{\mathrm{o}}^{\ddot{2}}+\mathrm{H}_{2} \mathrm{O} \leftrightarrow 2 \mathrm{OH}_{\mathrm{O}} \text { or } \mathrm{V}_{\mathrm{o}}+\mathrm{H}_{2} \mathrm{O} \leftrightarrow \mathrm{OH}_{\mathrm{O}}+\mathrm{H}_{\mathrm{i}} \quad \text { Equation 2. } 1
$$

The proton can migrate or transfer from one lattice oxygen atom to a neighboring lattice oxygen, as illustrated in Figure 2. 3 below. [81, 91, 92]

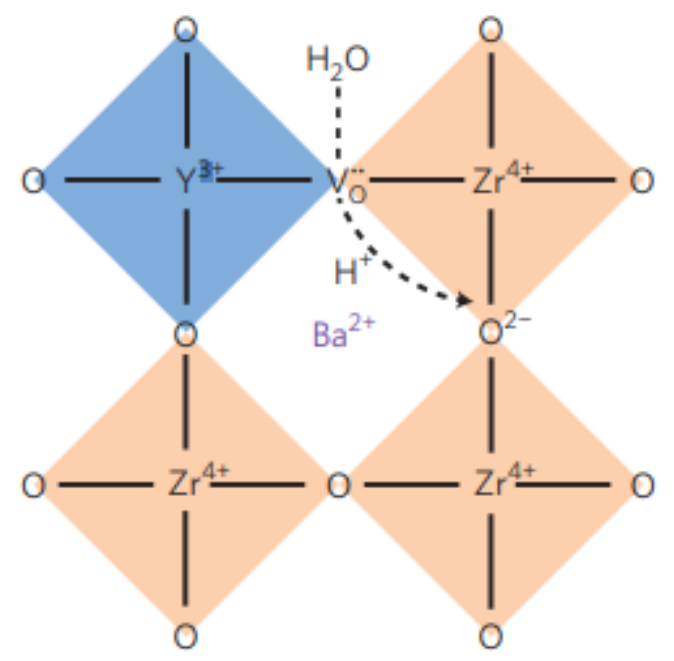

Figure 2. 3 Proton incorporation and conduction mechanisms in conventional perovskite proton conductors (for example, Y-doped $\mathrm{BaZrO}_{3}$ ). From Zhou et al. [92] 
It's worth mentioning that PCC may display both proton conductivity and oxide-ion conductivity, especially when the surrounding water partial pressure is low (e.g. $\mathrm{pH}_{2} \mathrm{O}<$ $\left.10^{-4}\right)$ or operation temperature is too high $\left(\mathrm{T}>700^{\circ} \mathrm{C}\right) .[76,77,90]$ However, proton conductivity is reported to dominate for PCC in humidified atmosphere with water concentration at or above $3 \%$ and at temperature significantly below $700^{\circ} \mathrm{C}$. The implication is that oxide-ion conductivity can be neglected, and PCC would demonstrate pure proton conduction under most IT-SOFC operation conditions $\left(\mathrm{T} \leq 600^{\circ} \mathrm{C}\right.$ with humidified fuel fed to the anode and ambient air containing $~ 2-3 \% \mathrm{H}_{2} \mathrm{O}$ fed to the cathode). $[76,77,80,88]$

The stability of PCC has been reported to depend on various factors. For example, PCC with high concentration of $\mathrm{Ce}$ are found to be reactive to high concentration of $\mathrm{CO}_{2} \cdot[41$, 79, 89]. Those with high $\mathrm{Zr}$ content show better stability against $\mathrm{CO}_{2}$ as well as $\mathrm{H}_{2} \mathrm{~S}$. [41] On the other hand, when $\mathrm{CO}_{2}$ concentration is low, the materials can be stable.

The compatibility between PCC and other cell components, mainly the electrodes also depends on specific materials and conditions. For the cathode, reaction involving the diffusion of $\mathrm{Ba}^{2+}$ from $\mathrm{BaCe}_{0.9} \mathrm{Y}_{0.1} \mathrm{O}_{2.95}$ to $\mathrm{Ba}_{0.5} \mathrm{Sr}_{0.5} \mathrm{Co}_{0.8} \mathrm{Fe}_{0.2} \mathrm{O}_{3-\delta}$ was observed for cofiring temperature above $950^{\circ} \mathrm{C}$. [72]

\subsubsection{Proton Conducting IT-SOFC}

When using proton conducing ceramics (PCC) as the electrolyte materials for ITSOFC, they are called proton conducting IT-SOFC. Typical proton conducting IT-SOFC 
also consists of three parts (anode/electrolyte/cathode) similar as oxide-ion conducting SOFC as mentioned in section 1.1.

Apart from the general advantages for conventional oxide-ion SOFC such as high efficiency, high power density and modularity as well as low emission, proton conducting IT-SOFC also possess a few unique benefits. For example, there is in principle no anodeside fuel dilution in proton conducting IT-SOFC because the water is generated on the cathode or air side during operation, which could increase fuel utilization. In addition, when hydrocarbon fuels (e.g. methane) are used, the co-production of electricity and highvalue hydro-carbons such as ethylene might be achieved. [93] Furthermore, $\mathrm{CO}_{2}$ capture and sequestration will also be much easier in proton conducting IT-SOFC because, as stated, $\mathrm{H}_{2} \mathrm{O}$ is generated in the cathode side and naturally separated from $\mathrm{CO}_{2}$. Additionally, recently studies suggest that proton conducting IT-SOFC may display enhanced resistance to fuel contaminants such as $\mathrm{H}_{2} \mathrm{~S}$. [12, 13, 75, 94]

Despite the advantages that proton conducting IT-SOFC offers, as stated in section 1.1 there are still many challenges and unknowns, especially about the anode and cathode reaction processes. The following sections will present some of the previous studies on the anode and cathode reaction processes for proton conducting IT-SOFC related to this study and when applicable, how they compare with conventional oxide-ion conducting SOFC. 


\subsection{Anode for Proton Conducting IT-SOFC}

\subsubsection{Anode Reaction Process for Oxide Ion Conducting SOFC and Proton Conducting IT-SOFC}

The anode materials for proton conducting IT-SOFC are similar to oxide-ion conducting SOFC: both are cermets consisting of metal catalyst (typically Ni) and ceramic electrolyte as the ion conductor (e.g., BZCYYb as PCC electrolyte versus YSZ as the oxide-ion conducting electrolyte). However, due to the change in the ionic species in the electrolyte there are significant differences in anode reaction processes between these two types of SOFC, which will be briefly reviewed below.

For the oxide-ion conducting SOFC, the overall anode reaction as described in section $1.1\left(\mathrm{O}_{\mathrm{o}}^{\mathrm{x}}+\mathrm{H}_{2}(\mathrm{~g}) \leftrightarrow \mathrm{V}_{\mathrm{o}}+\mathrm{H}_{2} \mathrm{O}+2 \mathrm{e}^{-}\right)$can be separated into several elementary steps as shown in Figure 2. 4. [95, 96]

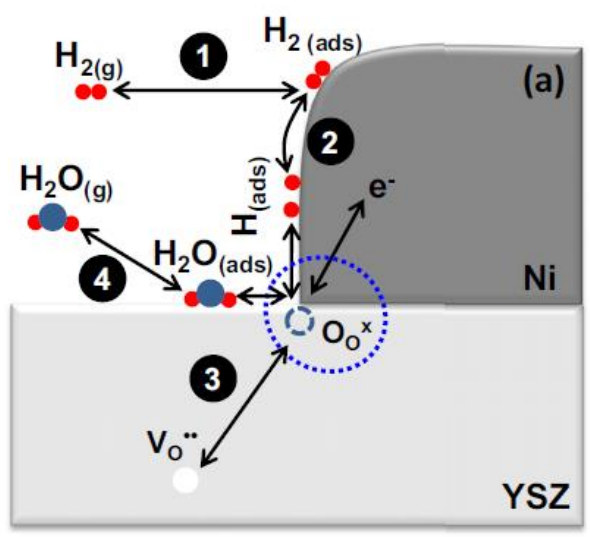

Figure 2. 4 Schematic diagram of the anodic reaction process for $\mathrm{H}_{2}$ electrochemical oxidation around the anode (Ni)/electrolyte (YSZ) interfaces for a conventional oxide-ion conducting SOFC. 
Specifically, step (1) represents the gas phase diffusion and adsorption of $\mathrm{H}_{2}$ that occur near the surface of the metal (e.g. Ni) catalyst, which can be written as Equation 2.4.

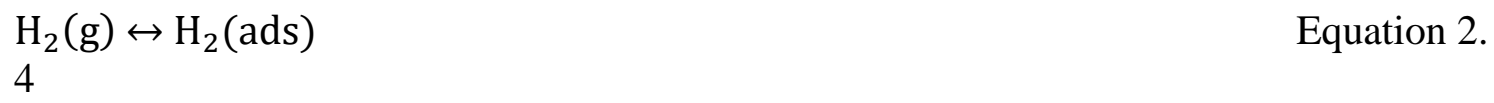

Equation 2.

4

Steps (2) is the dissociation of adsorbed $\mathrm{H}_{2}$ and the diffusion of dissociated hydrogen atoms onto triple phase boundary (TPB), which is believed to happen on the surface of the metal catalyst and can be written as:

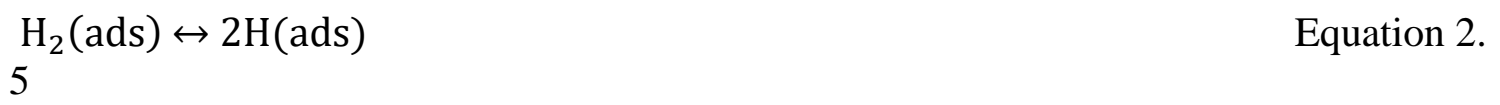

Steps (3) is the charge transfer step, which includes combining the adsorbed hydrogen atoms with the lattice oxygen in the oxide-ion conducting electrolyte (e.g. YSZ) to form $\mathrm{H}_{2} \mathrm{O}$ while generating oxygen vacancy and releasing electrons. [97, 98] This step can be written as:

$2 \mathrm{H}(\mathrm{ads})+\mathrm{O}_{\mathrm{O}}^{\mathrm{x}} \leftrightarrow \mathrm{V}_{\mathrm{O}}^{*}+\mathrm{H}_{2} \mathrm{O}(\mathrm{ads})+2 \mathrm{e}^{-} \quad$ Equation 2. 6

The last step (4) is the desorption of the water generated on the TPB of anode to the atmosphere, which can be written as:

$\mathrm{H}_{2} \mathrm{O}$ (ads) $\leftrightarrow \mathrm{H}_{2} \mathrm{O}(\mathrm{g})$ Equation 2. 7

In comparison, for proton conducting SOFC, especially when it is operated at intermediate temperature $\left(\leq \sim 600^{\circ} \mathrm{C}\right)$, the major carrier will be protons. [99] The overall anode reaction changes to $\mathrm{H}_{2}+2 \mathrm{O}_{\mathrm{O}}^{\mathrm{x}} \leftrightarrow 2(\mathrm{OH})_{\mathrm{O}}^{\dot{*}}+2 \mathrm{e}^{-}$. Similar to oxide-ion conducting SOFC, this reaction can still be separated into several elementary steps as shown in Figure 2. 5 . 


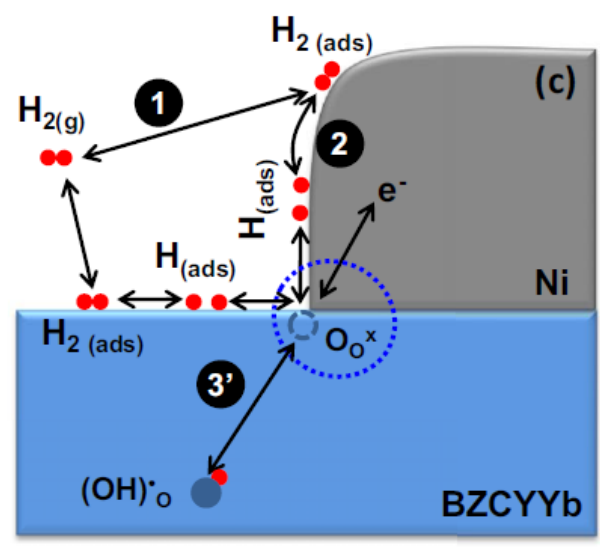

Figure 2. 5 Schematics showing anode reaction steps for ideal pure PC-SOFC at intermediate temperature. Note that the anode reaction mechanism for PC-SOFC is greatly simplified and the exact process including the dominating pathway still needs to be studied. In addition, BZCYYb stands for the $\mathrm{BaZr}_{0.1} \mathrm{Ce}_{0.7} \mathrm{Y}_{0.1} \mathrm{Yb}_{0.1} \mathrm{O}_{3-\delta} \mathrm{PCC}$ electrolyte.

Similar to oxide-ion conducting SOFC, step (1) and (2) are still hydrogen gas phase diffusion then adsorption and dissociation of adsorbed hydrogen then diffusion to TPB, respectively. However, in proton conducting SOFC, apart from Ni surface, these two steps might also occur over PCC surface as suggested from earlier studies. For example, power density of $\sim 100 \mathrm{~mW} / \mathrm{cm}^{2}$ was achieved by Hirabayashi et al. using $\mathrm{BaCe}_{0.76} \mathrm{Y}_{0.2} \mathrm{Pr}_{0.04} \mathrm{O}_{3-\delta}$ based proton conducting electrolyte-supported full cell without conventional anode. [16] In another study by Tomita et al., power density of $\sim 60 \mathrm{~mW} / \mathrm{cm}^{2}$ was achieved using anodeless $\mathrm{BaCe}_{0.8} \mathrm{Y}_{0.2} \mathrm{O}_{3-\delta}(\mathrm{BCY} 20)$ based electrolyte-supported cell. [17]

Step (3') is the anode charge transfer step for proton conducting IT-SOFC, which involves the incorporation of adsorbed hydrogen atoms into lattice oxygen to form proton defects (labeled as $(\mathrm{OH})_{\mathrm{O}}$ or $\mathrm{H}_{\mathrm{i}}$ ) and the release of electrons. This step can be written as: 
$\mathrm{H}($ ads $)+\mathrm{O}_{\mathrm{O}}^{\mathrm{x}} \leftrightarrow(\mathrm{OH})_{\mathrm{O}}^{\cdot}+\mathrm{e}^{-}$

Equation 2.

9

Step (3') is different from the anode charge transfer step in oxide-ion conducting SOFC in the sense that no water generation is involved, and the defects created are protons instead of oxygen vacancies.

Lastly, unlike the anode reaction in oxide-ion conducting SOFC, there will be no subsequent water desorption because no water is generated in the anode reaction for proton conducting IT-SOFC.

However, despite the knowledge gained on general anode reaction process for proton conducting IT-SOFC, very little is known about the effects of major fuel contaminants in hydro-carbon fuel (e.g. $\mathrm{H}_{2} \mathrm{~S}$ and $\mathrm{CO}_{2}$ ) on the anode reaction of proton conducting IT-SOFC. Because of the change in overall anode reaction process for proton conducting IT-SOFC compared to oxide-ion conducting SOFC, different responses to these fuel contaminants can be expected and are worth investigating. Such studies are important since in the near term, the primary fuel for proton conducting IT-SOFC will still be readily available hydrocarbon fuels instead of pure hydrogen.

\subsubsection{Anode $\mathrm{H}_{2} \mathrm{~S}$ Poisoning Effect on Oxide-ion Conducting SOFC and Proton Conducting IT-SOFC}

Among all fuel contaminants, $\mathrm{H}_{2} \mathrm{~S}$ is always encountered because it is either contained directly in the hydro-carbon fuels such as bio gas and natural gas or formed through the fuel reforming process during the operation. Since $\mathrm{Ni}$ is the metal catalyst in the cermet anode of proton conducting IT-SOFC (as well as oxide-ion conducting SOFC) and it is 
known to be very sensitive to $\mathrm{H}_{2} \mathrm{~S}$ poisoning, [24-38] studies focusing on the $\mathrm{H}_{2} \mathrm{~S}$ poisoning effect on the anode of proton conducting IT-SOFC will be needed.

For proton conducting IT-SOFC, as stated, very few studies have been carried out on the $\mathrm{H}_{2} \mathrm{~S}$ poisoning effect. On the other hand, hydrogen permeation membrane based on NiPCC cermet material shows great similarity to the anode of proton conducting IT-SOFC in terms of material (Ni-PCC), conducting species (proton) and operating atmosphere (reducing atmosphere containing $\mathrm{H}_{2}$ ). Thus, studies about the $\mathrm{H}_{2} \mathrm{~S}$ effect on hydrogen permeation membrane is expected to offer some insights for the $\mathrm{H}_{2} \mathrm{~S}$ effect on Ni-PCC cermet anode in proton conducting IT-SOFC and will be described as below. Thus, the following summarizes the existing studies on $\mathrm{H}_{2} \mathrm{~S}$ poisoning effect on both proton conducting IT-SOFC and hydrogen permeation membranes.

- Tomita et al. (2006) [17]

Tomita et al. were the first to report the $\mathrm{H}_{2} \mathrm{~S}$ effect on proton conducting SOFC. The authors studied the $\mathrm{H}_{2} \mathrm{~S}$ effect on the proton conducting cell with painted Pt cathode and BCY electrolyte with the thickness of $1 \mathrm{~mm}$, as well as Au current collector on the anode side (no other metal).

For such a cell, no change in impedance spectra was observed with the introduction of up to $10 \mathrm{ppm} \mathrm{H}_{2} \mathrm{~S}$ at $800^{\circ} \mathrm{C}$ as shown in Figure 2. 6. The authors attributed the high tolerance to $\mathrm{H}_{2} \mathrm{~S}$ to the Ce-rich phase on the surface of the heat-treated $\mathrm{BCY}$, which has low reactivity to $\mathrm{H}_{2} \mathrm{~S}$. 
(b)

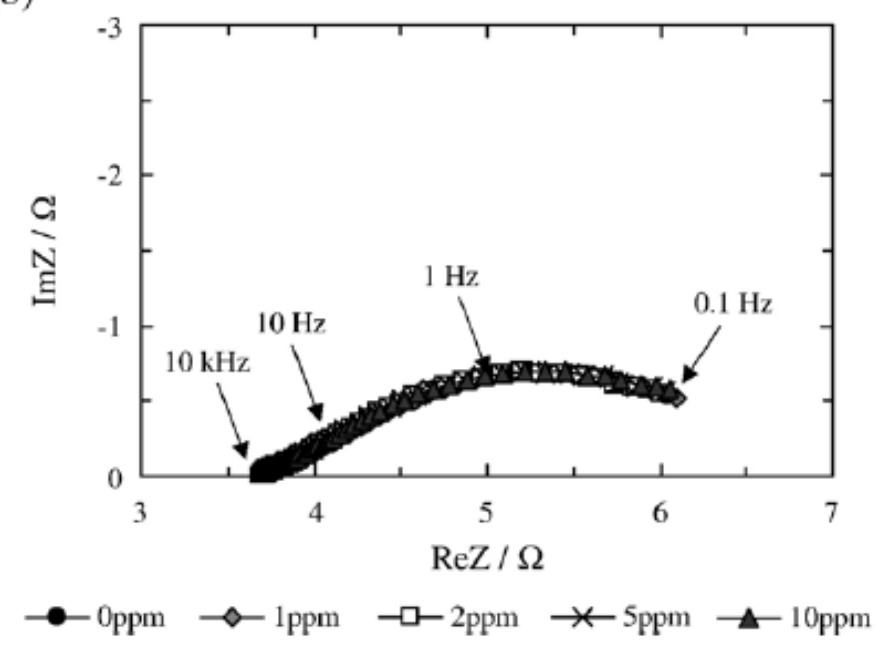

Figure 2. 6 Impedance spectra of the cell using heat-treated BCY20 with 0-10 ppm H2S and $80 \% \mathrm{H}_{2}$ at $800{ }^{\circ} \mathrm{C}$. The frequency range was $0.1-105 \mathrm{~Hz}$. From Tomita et al. [17]

However, there were many questions remain unsolved in this study. For example, such a cell lacks typical anode structure consisting of Ni and PCC for proton conducting ITSOFC and thus the knowledge gained in this study cannot be directly applied to proton conducting IT-SOFC. Secondly, the exact composition/structure for the BCY electrolyte was not clear. This is because the authors mentioned the BCY electrolyte was heat-treated in air at $1700^{\circ} \mathrm{C}$ for 10 hours before the cell fabrication presumably following the reaction 2.10 as described below:

$\mathrm{BaCe}_{0.2} \mathrm{Y}_{0.2} \mathrm{O}_{3-\delta} \rightarrow \mathrm{BaO}(\mathrm{g})+\mathrm{Ce}_{0.8} \mathrm{Y}_{0.2} \mathrm{O}_{1.9}$

However, since no phase characterization results for different parts of the cell was provided, the actual cell structure was doubtable given the complexity of the reactivity for the BCY system. [89] In addition, how the system will perform at $600-400^{\circ} \mathrm{C}$, which is the 
targeted operating temperature for proton conducting IT-SOFC, is not clear. Moreover, electrochemical measurements other than impedance spectroscopy such as discharge under constant current are also required for achieving solid understanding of the $\mathrm{H}_{2} \mathrm{~S}$ effect on the anode reaction for proton conducting IT-SOFC.

- $\quad$ Fang et al. $(2008,2009)[100,101]$

Fang et al. studied the $\mathrm{H}_{2} \mathrm{~S}$ poisoning effect on the $\mathrm{Ni}-\mathrm{BaZr}_{0.1} \mathrm{Ce}_{0.7} \mathrm{Y}_{0.2} \mathrm{O}_{3-\delta}(\mathrm{BZCY})$ hydrogen permeation membrane with the thickness of $\sim 0.5 \mathrm{~mm}$. As shown in Figure 2. 7 , at $700^{\circ} \mathrm{C}$, the hydrogen permeation flux quick decreased by about $20 \%$ when $30 \mathrm{ppm}$ of $\mathrm{H}_{2} \mathrm{~S}$ was first introduced to the feed gas consisting of $\sim 1.5 \% \mathrm{H}_{2} \mathrm{O}+58 \% \mathrm{~N}_{2}+40 \% \mathrm{H}_{2}$ and then slowly degraded until steady state. Further decrease of the hydrogen flux by about $10 \%$ was also observed with the increase of $\mathrm{H}_{2} \mathrm{~S}$ concentration to $60 \mathrm{ppm}$. In comparison, at higher temperature of $900^{\circ} \mathrm{C}$, almost no degradation in hydrogen flux with the introduction of 30-60ppm of $\mathrm{H}_{2} \mathrm{~S}$ in the feed gas was observed as shown in Figure 2. 8. On the other hand, when the $\mathrm{H}_{2} \mathrm{~S}$ concentration was further increased to $80-300 \mathrm{ppm}$, the decreases in hydrogen flux were much larger as shown in Figure 2.7 (b). 

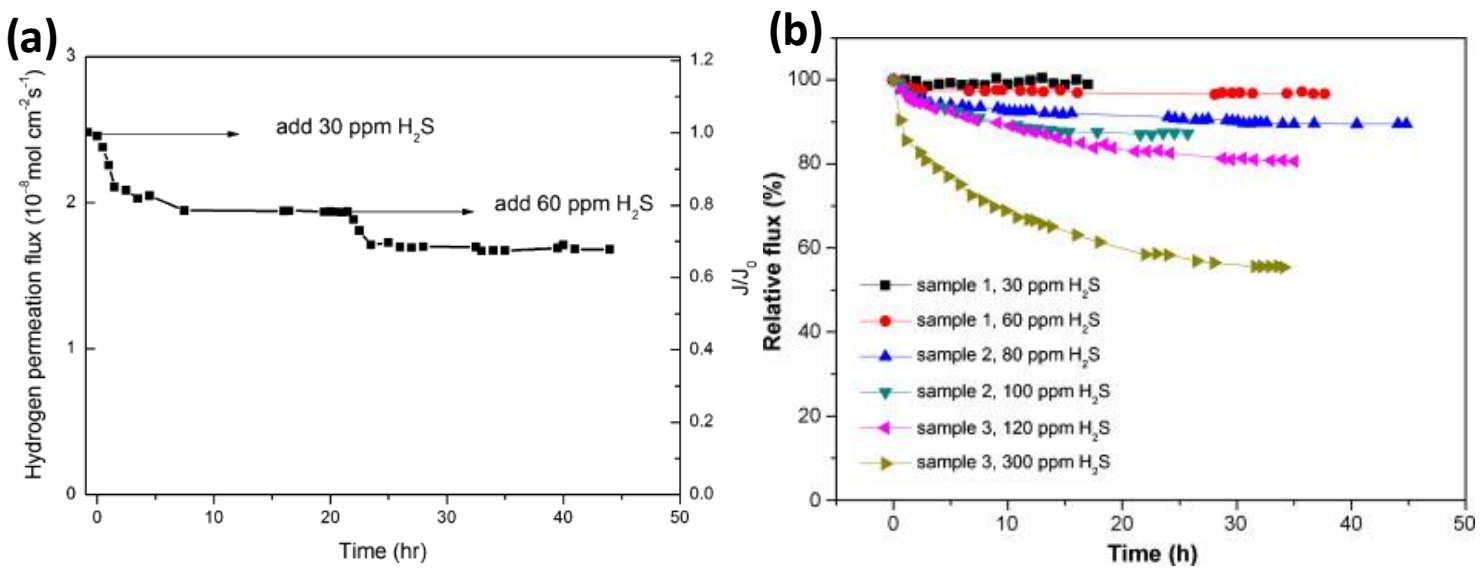

Figure 2. 7 Change in hydrogen permeation flux through Ni-BZCY hydrogen permeation membrane with the introduction of $30-60 \mathrm{ppm} \mathrm{H}_{2} \mathrm{~S}$ in gas mixture of $\sim 1.5 \% \mathrm{H}_{2} \mathrm{O}+$ $58 \% \mathrm{~N}_{2}+40 \% \mathrm{H}_{2}$ at $700^{\circ} \mathrm{C}$. Adapted from Fang et al. [100]

The authors also studied the regeneration behavior of the Ni-BZCY membrane after $\mathrm{H}_{2} \mathrm{~S}$ poisoning. As shown in Figure 2.8 (b), the hydrogen permeation flux largely recovered after the removal of $60 \mathrm{ppm}_{2} \mathrm{~S}$ from feed gas at $700^{\circ} \mathrm{C}$. At $900^{\circ} \mathrm{C}$, complete recovery was observed for the hydrogen flux after the removal of $120 \mathrm{ppm} \mathrm{H}_{2} \mathrm{~S}$.
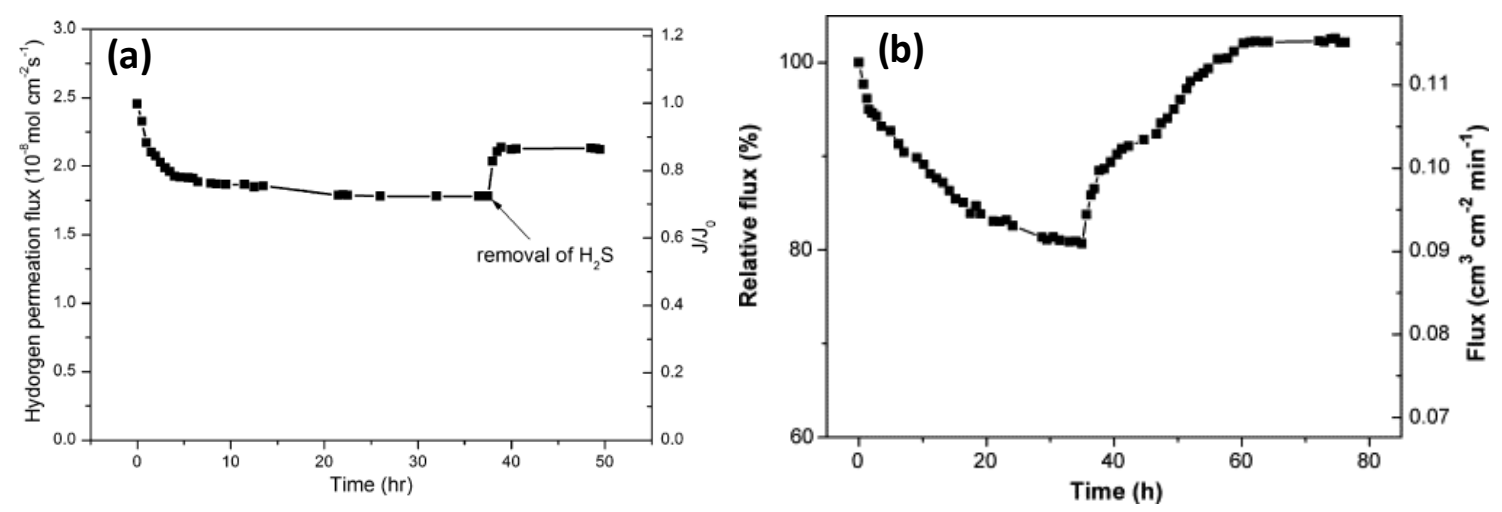

Figure 2. 8 Sulfur poisoning and regeneration behavior of $\mathrm{Ni}-\mathrm{BZCY}$ in the feed gas $\left(\sim 1.5 \% \mathrm{H}_{2} \mathrm{O}+58 \% \mathrm{~N}_{2}+40 \% \mathrm{H}_{2}\right)$ containing $60 \mathrm{ppm} \mathrm{H}_{2} \mathrm{~S}$ at $700^{\circ} \mathrm{C}$ and $120 \mathrm{ppm} \mathrm{H}_{2} \mathrm{~S}$ at $900^{\circ} \mathrm{C}$. Adapted from Fang et al. [101] 
Besides the hydrogen permeation measurements, XRD was used on the Ni-BZCY membrane before and after exposing to $\mathrm{H}_{2} \mathrm{~S}$ in the feed gas $\left(\sim 1.5 \% \mathrm{H}_{2} \mathrm{O}+58 \% \mathrm{~N}_{2}+40 \%\right.$ $\mathrm{H}_{2}$ ) as shown in Figure 2. 9. At $700^{\circ} \mathrm{C}$, very little amount of $\mathrm{Ni}_{3} \mathrm{~S}_{2}$, doped $\mathrm{CeO}_{2}$ and $\mathrm{BaS}$ were found in the post-exposure sample by $\mathrm{XRD}$, suggesting very limited reaction between the Ni-BZCY and $\mathrm{H}_{2} \mathrm{~S}$. [100, 102] EDX results indicated that around 5\% atomic ratio of sulfur species on the surface of BZCY. Because if all of the BZCY on the surface was transformed into $\mathrm{BaS}$ and doped $\mathrm{CeO}_{2}$, the sulfur content would be $\sim 20 \%$, this indicates the reaction between BZCY and $\mathrm{H}_{2} \mathrm{~S}$ was incomplete.
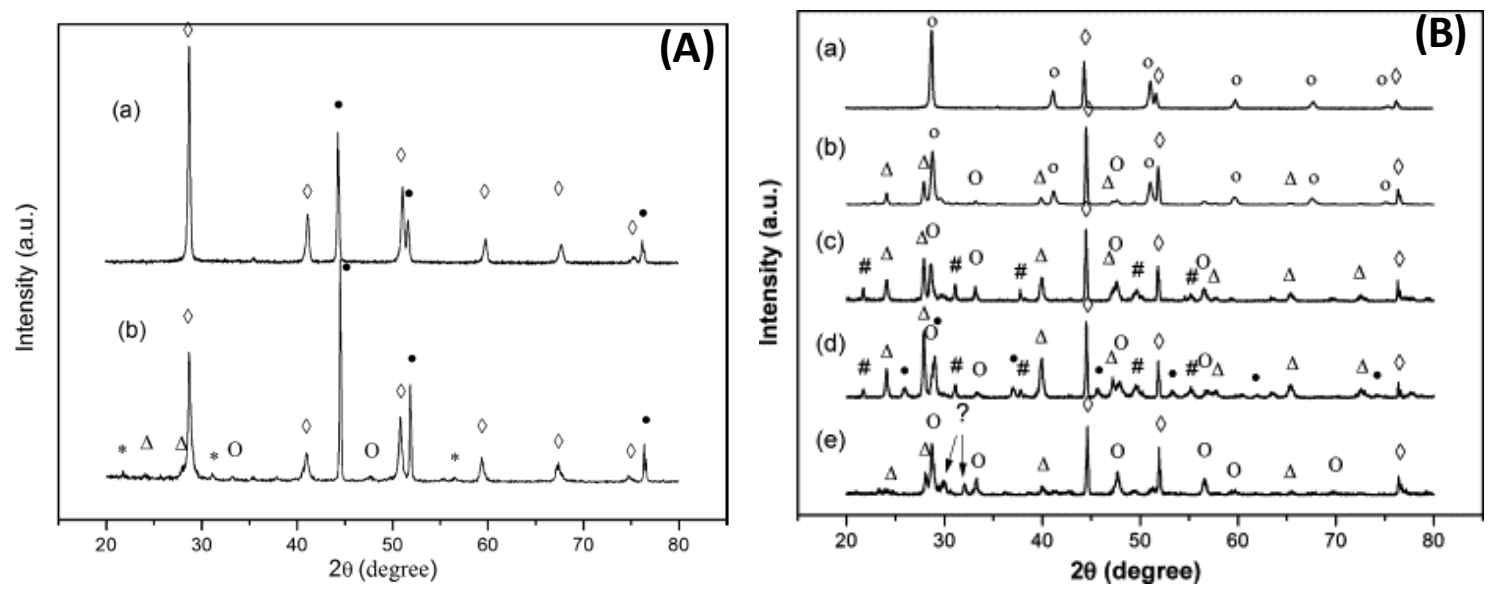

Figure 2. 9 XRD patterns of Ni-BZCY obtained from (A) a polished surface after sintering, (B) feed side surface after testing in $60 \mathrm{ppm} \mathrm{H}_{2} \mathrm{~S}$ at $700^{\circ} \mathrm{C}$. Secondary pahses are: $(\diamond) \mathrm{BZCY},(\bullet) \mathrm{Ni},(*) \mathrm{Ni} 3 \mathrm{~S} 2,(\mathrm{O})$ doped $\mathrm{CeO}_{2},(\Delta) \mathrm{BaS}$. Adapted with change from Fang et al. [100]

The authors attributed the $\mathrm{H}_{2} \mathrm{~S}$ poisoning effect on the Ni-BZCY membrane to the bulk phase reaction between $\mathrm{H}_{2} \mathrm{~S}$ and BZCY at high temperature of $\sim 900^{\circ} \mathrm{C}$. In fact, thermodynamic calculation was carried out in the study, and the results suggested the driving force for the reaction becomes larger as the change in Gibbs free energy gets 
more negative at lower temperature as shown in Figure 2. 10 (A). In addition, the dependence of the critical $\mathrm{H}_{2} \mathrm{~S}$ concentration for the reaction 2.11 also decreases as the temperature falls as shown in Figure 2. 10 (b). This indicates that the reaction is thermodynamically more favored at higher $\mathrm{H}_{2} \mathrm{~S}$ concentrations or lower temperatures.

$\mathrm{H}_{2} \mathrm{~S}(\mathrm{~g})+\mathrm{BaCeO}_{3}(\mathrm{~s})=\mathrm{H}_{2} \mathrm{O}(\mathrm{g})+\mathrm{BaS}(\mathrm{s})+\mathrm{CeO}_{2}(\mathrm{~s}) \quad$ Reaction 2.11
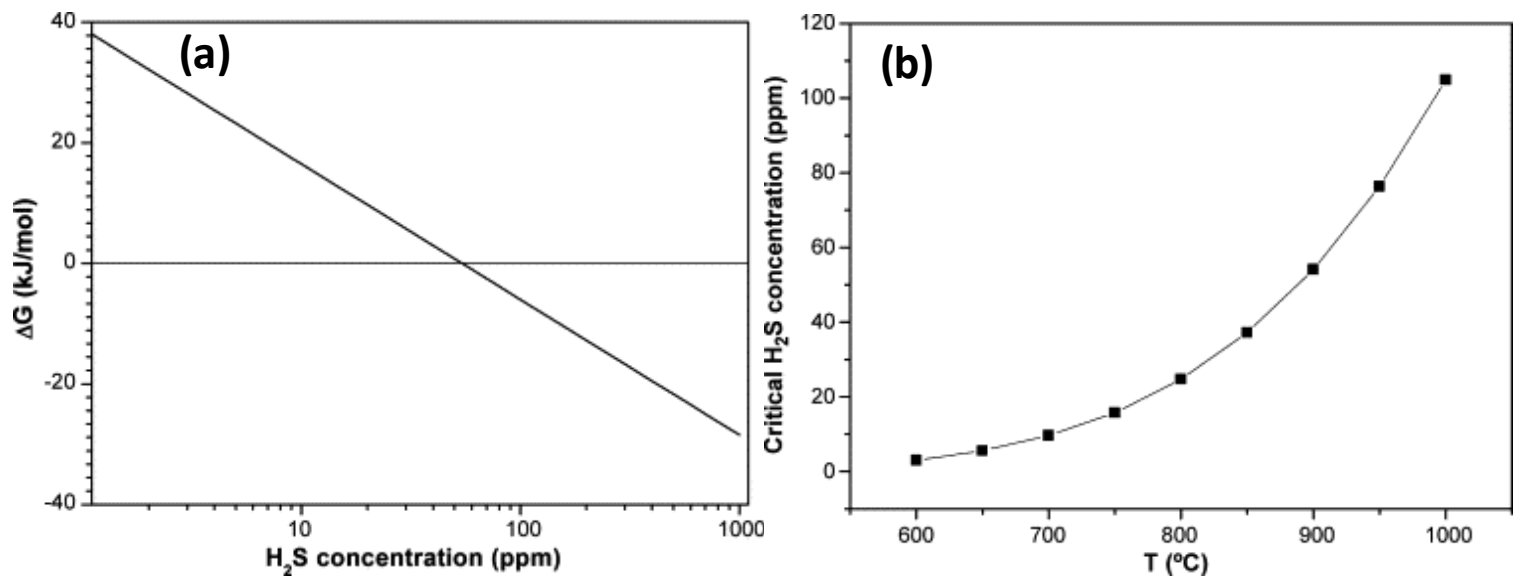

Figure 2. 10 Dependence of Gibbs free energy change for reaction (1) on $\mathrm{H}_{2} \mathrm{~S}$ concentrations with 0.015 atm $\mathrm{H}_{2} \mathrm{O}$ at $900{ }^{\circ} \mathrm{C}$. Temperature dependence of critical $\mathrm{H}_{2} \mathrm{~S}$ concentration for reaction (1) with 0.015 atm $\mathrm{H}_{2} \mathrm{O}$. Adapted from Fang et al. [101]

On the other hand, when the temperature was low of $\sim 700^{\circ} \mathrm{C}$, very little reaction was observed between the BZCY and $\mathrm{H}_{2} \mathrm{~S}$. Since the bulk reaction was thermodynamically more favorable at lower temperature, the limited reaction observed at $700^{\circ} \mathrm{C}$ was attributed to the slow kinetics such as slow diffusion. Thus, the poisoning effect of $\mathrm{H}_{2} \mathrm{~S}$ on $\mathrm{Ni}-\mathrm{BZCY}$ at $700^{\circ} \mathrm{C}$ was attributed by the authors to the adsorption of $\mathrm{H}_{2} \mathrm{~S}$ over $\mathrm{Ni}$ and BZCY surfaces. 
However, this study was carried out on Ni-BZCY hydrogen permeation membrane which has certain difference compared to the anode of proton conducting IT-SOFC. In addition, studies at even lower temperature of $600-400^{\circ} \mathrm{C}$ is still needed. Moreover, more sensitive surface characterization of Ni-PCC sample after exposing to $\mathrm{H}_{2} \mathrm{~S}$ is also required to achieve better understanding about the origin of the $\mathrm{H}_{2} \mathrm{~S}$ poisoning effect and the nature of interactions between sulfur and PCC such as BZCY.

- Yang et al. (2009) [15]

Yang et al. (2009) studied the influence of low-ppm level $\mathrm{H}_{2} \mathrm{~S}$ on the NiBZCYYb/BZCYYb/BZCY-LSCF anode-supported full cells. The observations are that at $750^{\circ} \mathrm{C}$ with a current density of $700 \mathrm{~mA} / \mathrm{cm}^{2}$, there are no change in cell voltages with the introduction of up to $30 \mathrm{ppm} \mathrm{H}_{2} \mathrm{~S}$ in $3 \%$ humidified (labeled as wet) $\mathrm{H}_{2}$ fuel for both cells at as shown in Figure 2. $11(\mathrm{~A})$.

Moreover, similar sulfur tolerance was observed for Ni-BZCYYb/SDC/LSCF anodesupported full cell and the impedance data showed no increase in interfacial resistance in 3\%humidified $\mathrm{H}_{2}$ containing 20ppm $\mathrm{H}_{2} \mathrm{~S}$ as shown in Figure 2. 11 (B). However, when the water was absent in the fuel stream, significant increase of $\sim 80 \%$ in interfacial resistance was observed for that cell with the introduction of $20 \mathrm{ppm} \mathrm{H}_{2} \mathrm{~S}$ into dry $\mathrm{H}_{2}$ as shown in Figure 2. $11(\mathrm{C})$.

The authors hypothesized water may adsorb on the BZCYYb surface to facilitate the oxidation of $\mathrm{H}_{2} \mathrm{~S}$ or elemental sulfur to $\mathrm{SO}_{2}$ at or near active sites, which can easily desorb. [103] 

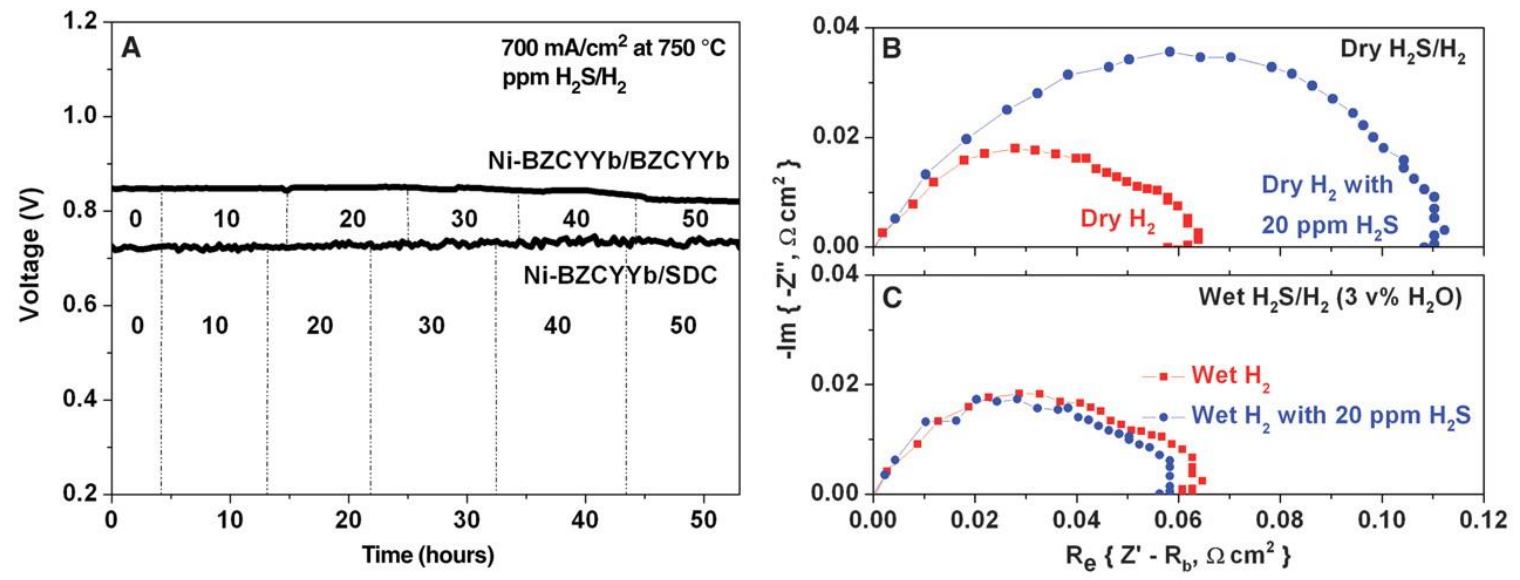

Figure 2. 11 (A) The change in cell voltage at $750^{\circ} \mathrm{C}$ for two cells with the configuration of Ni-BZCYYb/ BZCYYb/ BZCY-LSCF and Ni-BZCYYb/ SDC/ LSCF operated at $750^{\circ} \mathrm{C}$ under the constant current density of $700 \mathrm{~mA} / \mathrm{cm}^{2}$ as $10-50 \mathrm{ppm}$ of $\mathrm{H} 2 \mathrm{~S}$ was introduced to the $3 \%$ humidified $\mathrm{H}_{2}$ fuel stream, (B and $\mathrm{C}$ ) Impedance spectra measured under OCV conditions at $750^{\circ} \mathrm{C}$ for the Ni-BZCYYb/ SDC/ LSCF anode-supported full cell in both (B) dry $\mathrm{H}_{2}$ and dry $\mathrm{H}_{2}$ containing 20 ppm $\mathrm{H}_{2} \mathrm{~S}$ and (C) wet $\mathrm{H}_{2}$ and wet $\mathrm{H}_{2}$ containing 20ppm $\mathrm{H}_{2} \mathrm{~S}$. from Yang et al. (2009) [15]

However, no information about the impedance of the Ni-BZCYYb/BZCYYb/LSCF anode-supported full cell was showed. The response to low-ppm level $\mathrm{H}_{2} \mathrm{~S}$ for such cell at intermediate temperature of $400-600^{\circ} \mathrm{C}$ is still not clear. Moreover, two of the cells used in the study was based on thin electrolyte ( 20um) of SDC and YSZ, which may react with the BZCYYb in the anode and form proton conducting phases. [89]

For better understanding of the $\mathrm{H}_{2} \mathrm{~S}$ effect on the anode reaction of proton conducting IT-SOFC, it will be helpful to refer to the similar studies on $\mathrm{H}_{2} \mathrm{~S}$ effect of the conventional oxide-ion conducting SOFC, especially those operated at relatively low temperature $\left(\sim 750^{\circ} \mathrm{C}\right)$. This is because as stated before, despite the change in the anode reaction process, both the anode in proton conducting IT-SOFC and oxide-ion conducting SOFC contain Ni as metal catalyst and is sensitive to $\mathrm{H}_{2} \mathrm{~S}$. The similarity and also the difference between 
these two types of cells are expected to provide some insight for the $\mathrm{H}_{2} \mathrm{~S}$ poisoning effect on proton conducting IT-SOFC. Because the problem of $\mathrm{H}_{2} \mathrm{~S}$ poisoning for conventional oxide-ion conducting SOFC has been extensively studied and well documented, there are many available reviews, and will not be repeated here. Only one representative study at relevant temperature of $750^{\circ} \mathrm{C}$ by Yang et al. is given below as an example.

- $\quad$ Yang et al. (2010) [35]

Yang et al. studied the $\mathrm{H}_{2} \mathrm{~S}$ poisoning effect on the Ni-YSZ/YSZ/LSCF oxide-ion conducting anode-supported full cell. At $750^{\circ} \mathrm{C}$, increases in interfacial resistance of $\sim 40 \%$ $80 \%$ were observed with the introduction of $1 \mathrm{ppm} \mathrm{H}_{2} \mathrm{~S}$ into $\mathrm{H}_{2}$ fuel at different current density in the range of $800-200 \mathrm{~mA} / \mathrm{cm}^{2}$, as shown in Figure 2. 12.

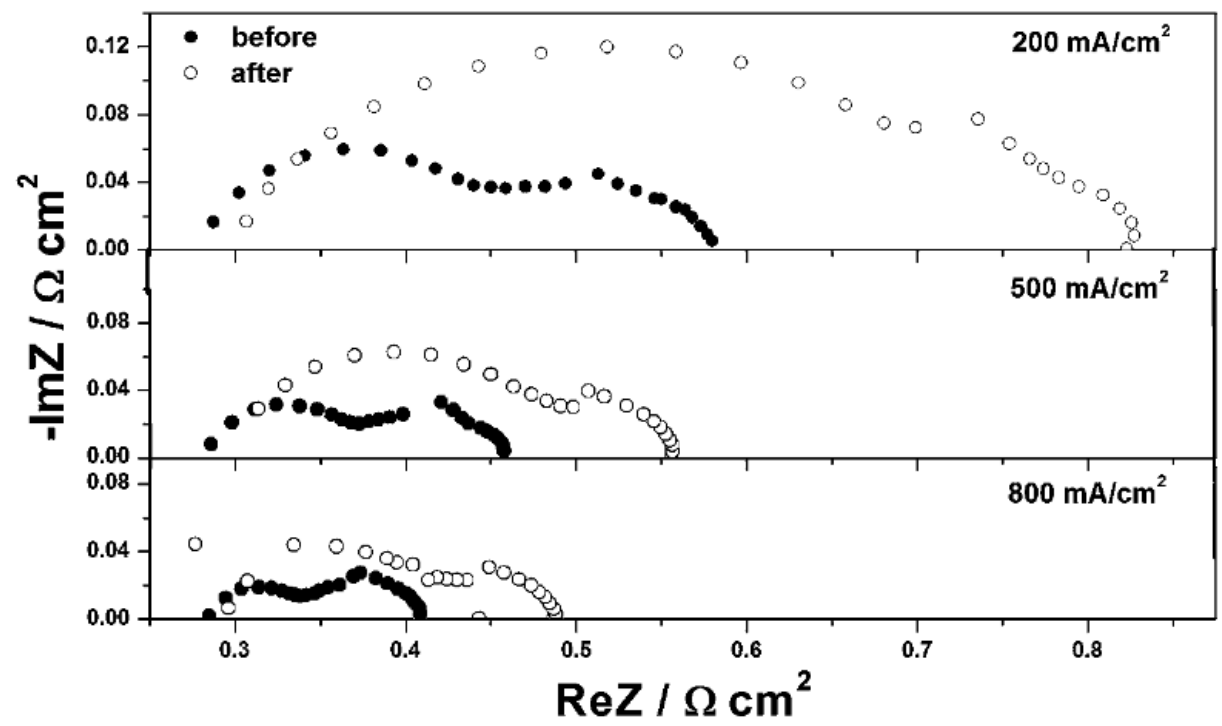


Figure 2. 12 Impedance spectra of Ni-YSZ/YSZ/LSCF anode-supported full cells operated at a constant current density of 200,500 , and $800 \mathrm{~mA} / \mathrm{cm}^{2}$ before and after 1 ppm $\mathrm{H}_{2} \mathrm{~S}$ was introduced into the fuel at $750^{\circ} \mathrm{C}$. From Yang et al. [35]

In addition, instant drops in the cell power output of $\sim 10-15 \%$ upon the exposure to 0.8-1.1 ppm $\mathrm{H}_{2} \mathrm{~S}$ in $\mathrm{H}_{2}$ at the current density of 200 and $400 \mathrm{~mA} / \mathrm{cm}^{2}$ was observed as shown in Figure 2. 13 (a). On the other hand, when $10 \mathrm{ppm}_{2} \mathrm{~S}$ was introduced to the $\mathrm{H}_{2}$ fuel at the current density of 200 and $400 \mathrm{~mA} / \mathrm{cm}^{2}$, slightly larger decreases were observed for the cell voltage as shown in Figure 2. 13 (b).
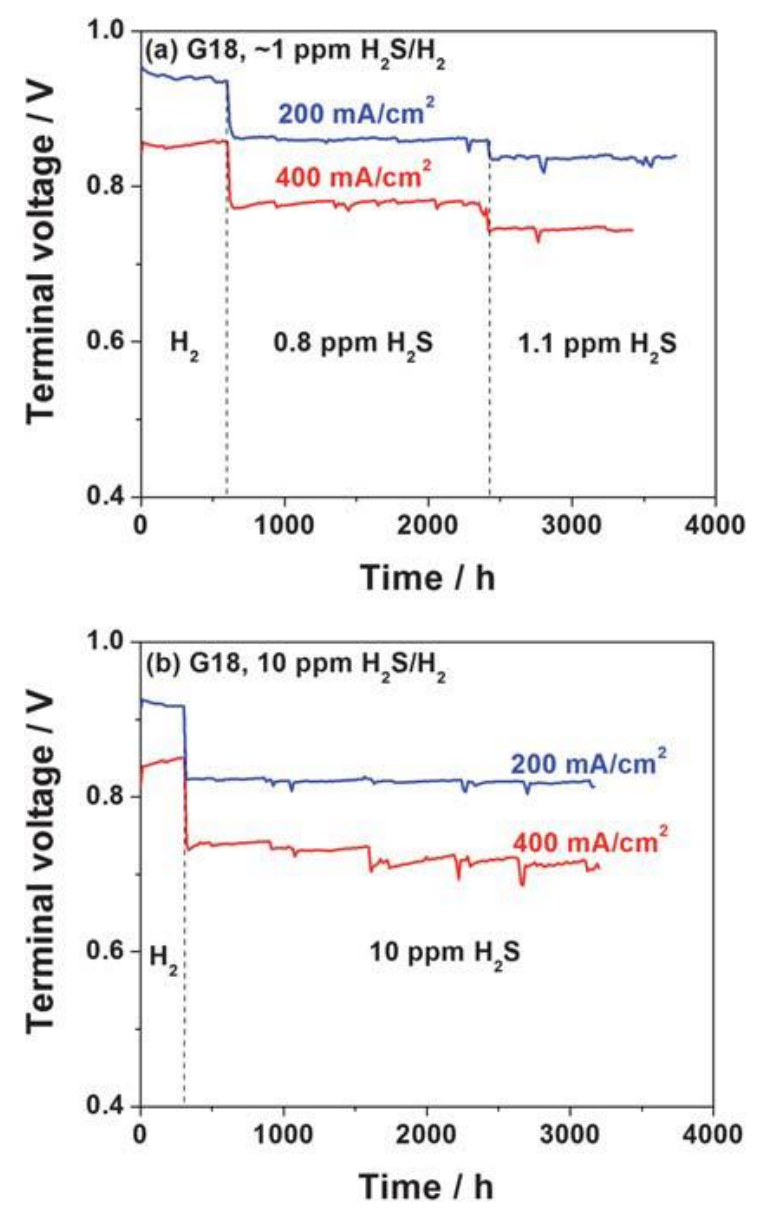

Figure 2. 13 Performances of the Ni-YSZ/YSZ/LSCF anode supported full cells operated at $750 \mathrm{C}$ at a constant current density of 200 and $400 \mathrm{~mA} / \mathrm{cm}^{2}$ in hydrogen for the first 
$\sim 600 \mathrm{~h}$ and then in hydrogen with (a) 0.8-1.1 $\mathrm{ppm} \mathrm{H}_{2} \mathrm{~S}$, and (b) 10ppm $\mathrm{H}_{2} \mathrm{~S}$. From Yang et al. [35]

In summary, even though there have been several studies reflecting the $\mathrm{H}_{2} \mathrm{~S}$ poisoning effect on the proton conducting electrode as mentioned above, most of these researches were carried out at relatively high temperature $\left(\geq 700^{\circ} \mathrm{C}\right)$. In addition, from the comparison, the $\mathrm{H}_{2} \mathrm{~S}$ poisoning on proton conducting IT-SOFC appears very different from conventional oxide-ion conducting SOFC, suggesting significant change in the poisoning process and the underlying mechanism. Thus, systematic studies focusing on $\mathrm{H}_{2} \mathrm{~S}$ poisoning of proton conducting IT-SOFC, especially at intermediate temperature of 400$600^{\circ} \mathrm{C}$ is required. Detailed investigation on the interaction between the $\mathrm{H}_{2} \mathrm{~S}$ and proton conducting cermet anode is also expected to help understand the fundamental poisoning mechanism.

\subsubsection{Anode $\mathrm{CO}_{2}$ Poisoning Effect on Proton Conducting IT-SOFC}

Unlike the widely-studied poisoning effect of $\mathrm{H}_{2} \mathrm{~S}$ on the anode reaction for SOFC, the $\mathrm{CO}_{2}$ effect has rarely been studied as $\mathrm{CO}_{2}$ typically is believed to be harmless for the anode reaction of conventional oxide-ion conducting SOFC. The chemisorption between the Ni catalyst and $\mathrm{CO}_{2}$ is thought to be insignificant in fuel atmosphere and there is no reaction between the conventional oxide-ion conductor of $\mathrm{YSZ}$ and $\mathrm{CO}_{2}$. [104]

On the other hand, certain extent of $\mathrm{CO}_{2}$ poisoning could be expected for the cermet anode of proton conducting IT-SOFC, which contains PCC that are known to be vulnerable 
to $\mathrm{CO}_{2}$. So far, there are numerous studies on the reactivity of proton conducting ceramics (PCC) electrolyte with $\mathrm{CO}_{2}$ as stated in section 2.1.3.1. [39-42] However, electrochemical behaviors of proton conducting IT-SOFC upon exposure to $\mathrm{CO}_{2}$ as an anode fuel contaminant are not clear.

Similar to $\mathrm{H}_{2} \mathrm{~S}$ poisoning effect, existing studies about the $\mathrm{CO}_{2}$ effect on Ni-PCC is mainly in the field of hydrogen permeation membrane and no study is available on proton conducting IT-SOFC. Nevertheless, due to the similarity between the hydrogen reaction for those two types of devices, these studies are expected to offer useful background information about the $\mathrm{CO}_{2}$ poisoning effect on the cermet anode for proton conducting ITSOFC and are described below.

- Zuo et al. $(2005,2006)[105,106]$

Zuo et al. studied the percentage-level $\mathrm{CO}_{2}$ poisoning effect on $\mathrm{Ni}-\mathrm{BaZr} 0.8-\mathrm{x} \mathrm{Ce}_{\mathrm{x}} \mathrm{Y}_{0.2} \mathrm{O}_{3}$ $(0.4 \leq \mathrm{x} \leq 0.8)$ membranes with the thickness of $\sim 0.5-0.75 \mathrm{~mm}$ at $900^{\circ} \mathrm{C}$. As shown in Figure 2. 14 (a), instant drops in hydrogen flux were observed for the Ni-BZCY6 ( $x=0.6)$ membrane with the introduction of $10-30 \% \mathrm{CO}_{2}$ into the wet feed gas of $40 \% \mathrm{H}_{2}$ balanced by He. The decrease in hydrogen flux is proportional to the concentration of $\mathrm{CO}_{2}$ in feed gas. The initial quick drops were followed by saturation after exposure to $\mathrm{CO}_{2}$ for $\sim 20$ hours under all concentrations. Similar poisoning effect was observed for Ni-BZCY8 $(x=0.8)$ membrane with the introduction of $10 \% \mathrm{CO}_{2}$ in feed gas as shown in Figure 2. 14 (b). However, as $\mathrm{CO}_{2}$ concentration further increased to $20 \%-30 \%$, much more severe poisoning effect was observed for Ni-BCY20 membrane with decrease of $\sim 80 \%-100 \%$ 
after more than 20 hours of exposure. This dramatic $\mathrm{CO}_{2}$ poisoning for $\mathrm{Ni}-\mathrm{BCY} 20$ membrane was attributed to the bulk phase reaction between $\mathrm{BCY} 20$ and $\mathrm{CO}_{2}$ with concentration $\geq 20 \%$ to form $\mathrm{BaCO}_{3}$.
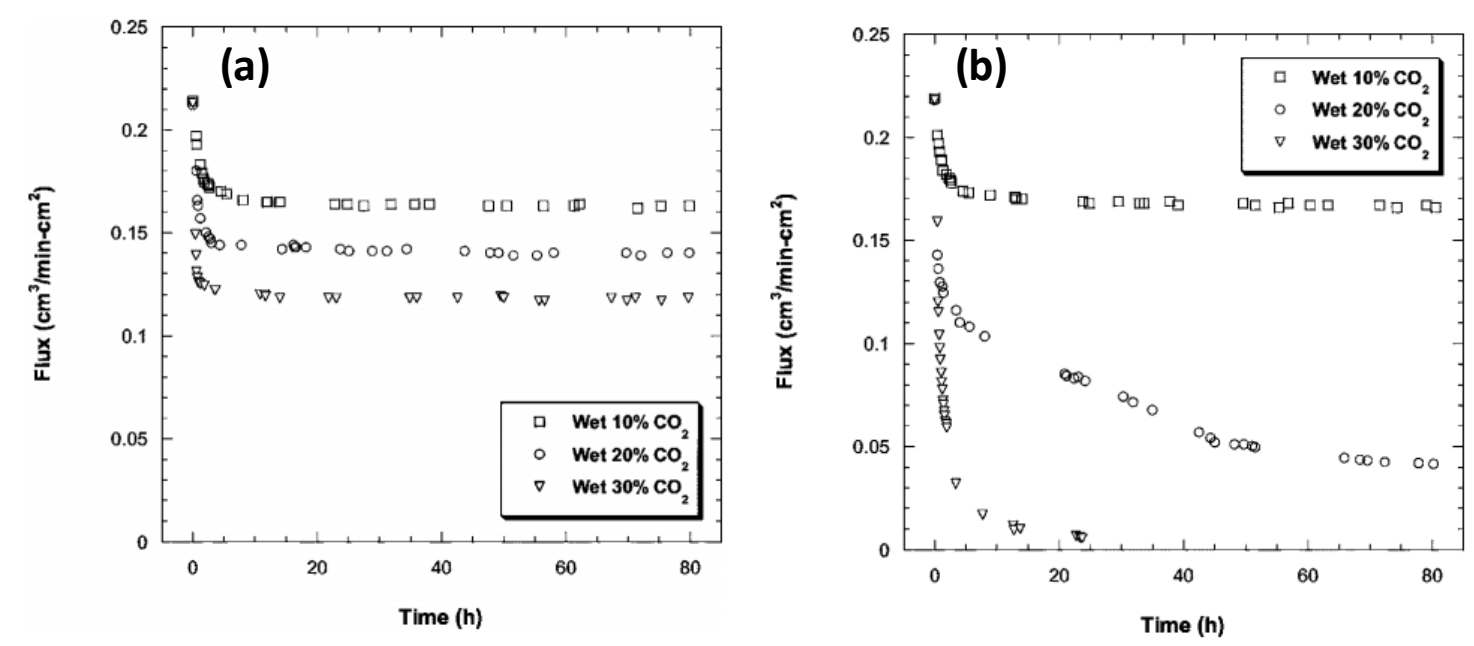

Figure 2. 14 Hydrogen flux through (a) Ni-BZCY6 and (b) Ni-BZCY8 membranes in wet feed gas $\left(40 \% \mathrm{H}_{2} / \mathrm{He}\right)$ containing different concentrations of $10-30 \% \mathrm{CO}_{2}$ at $900^{\circ} \mathrm{C}$. From Zuo et al. [105]

Zuo et al. also studied the influence of $\mathrm{Zr}$ doping concentration on the $\mathrm{CO}_{2}$ poisoning effect for hydrogen permeation through Ni-BZCY membranes as shown in Figure 2. 15. The relative drop in hydrogen permeation flux decreased with increasing $\mathrm{Zr}$ concentration, meaning the substitutional doping of $\mathrm{Zr}$ in Yttrium-doped barium cerate can significantly increase the stability against $\mathrm{CO}_{2}$ poisoning. 


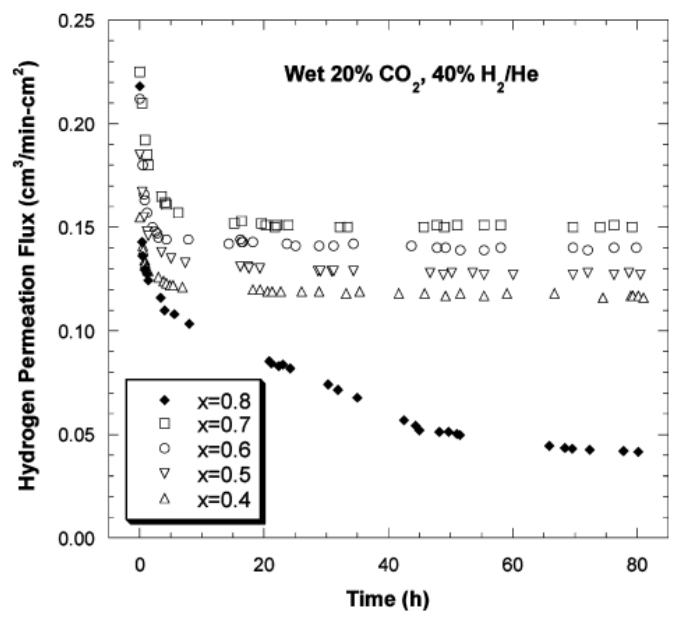

Figure 2. 15 Time dependence of hydrogen flux through $\mathrm{Ni}-\mathrm{BaZr}_{0.8-\mathrm{x}} \mathrm{Ce}_{\mathrm{x}} \mathrm{Y}_{0.2} \mathrm{O}_{3}(0.4 \leq \mathrm{x}$ $\leq 0.8$ ) membranes in a feed gas of wet $20 \% \mathrm{CO}_{2}$ (balance $40 \% \mathrm{H}_{2} / \mathrm{He}$ ) at $900{ }^{\circ} \mathrm{C}$. From Zuo et al. [106]

However, the origin of the observed $\mathrm{CO}_{2}$ poisoning had not been well illustrated using convincing experiments in this study. Moreover, no information was provided at testing temperature lower than $900^{\circ} \mathrm{C}$.

- $\quad$ Fang et al. $(2013,2014)[107,108]$

Fang et al. studied the $\mathrm{CO}_{2}$ poisoning effect on $\mathrm{Ni}-\mathrm{BZCYYb}$ as hydrogen permeation membrane with the thickness of $0.4 \mathrm{~mm}$ at $900^{\circ} \mathrm{C}$. When the feed gas contains no water, significant increases in hydrogen flux were observed with the introduction of $5-60 \% \mathrm{CO}_{2}$ into feed gas consisting of $20 \% \mathrm{H}_{2}+75-15 \%$ He as shown in Figure 2. 16. The authors attributed such enhanced hydrogen permeation to the co-presence of $\mathrm{CO}_{2}$ and $\mathrm{H}_{2}$ and the occurrence of reverse water-gas shift (RWGS) reaction as below: 
$\mathrm{H}_{2}(\mathrm{~g})+\mathrm{CO}_{2}(\mathrm{~g})=\mathrm{H}_{2} \mathrm{O}(\mathrm{g})+\mathrm{CO}(\mathrm{g})$

Reaction 2. 12

This was supported by the large increase in the moisture content with the introduction of $\mathrm{CO}_{2}$ into feed gas as also shown in Figure 2. 16.

The water generated from RWGS reaction was believed to increase the proton conductivity of the BZCYYb membrane and thus promoted the hydrogen permeation under these conditions.

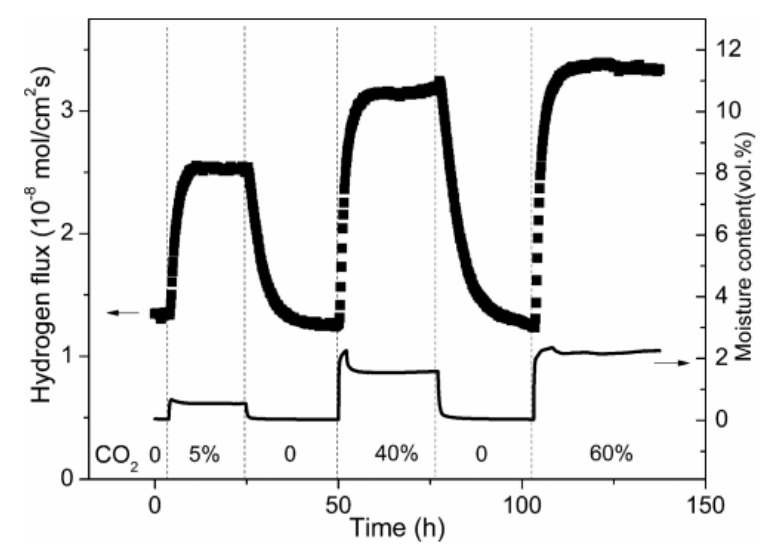

Figure 2. 16 Hydrogen permeation fluxes of the Ni-BZCYYb membrane (lower line) and absolute humidity in feed gas passing through the reactor (upper line). The feed gas consisted of $20 \% \mathrm{H}_{2}, 5-60 \% \mathrm{CO}_{2}$, and $75-20 \%$ He. From Fang et al. [107]

However, when the feed gas already contains $3 \% \mathrm{H}_{2} \mathrm{O}$, then the response of $\mathrm{Ni}-$ BZCYYb composite membrane to the introduction of $\mathrm{CO}_{2}$ was complex as shown in Figure 2. 17. When $30 \% \mathrm{CO}_{2}$ was introduced, initial increases in the hydrogen permeation fluxes were observed in all conditions. However, after the initial increases, subsequent behaviors depend on $\mathrm{H}_{2}$ concentration: when $\mathrm{H}_{2}$ was high at $60 \%$, similar enhancement in hydrogen flux was observed as the steady-state flow was higher than that prior to $\mathrm{CO}_{2}$ introduction; when $\mathrm{H}_{2}$ was low at $40 \%$ and $20 \%$, the steady-state fluxes 
were lower than those prior to $\mathrm{CO}_{2}$ introduction, indicating $\mathrm{CO}_{2}$ poisoning, which is consistent with earlier study by Zuo et al. [105, 106]

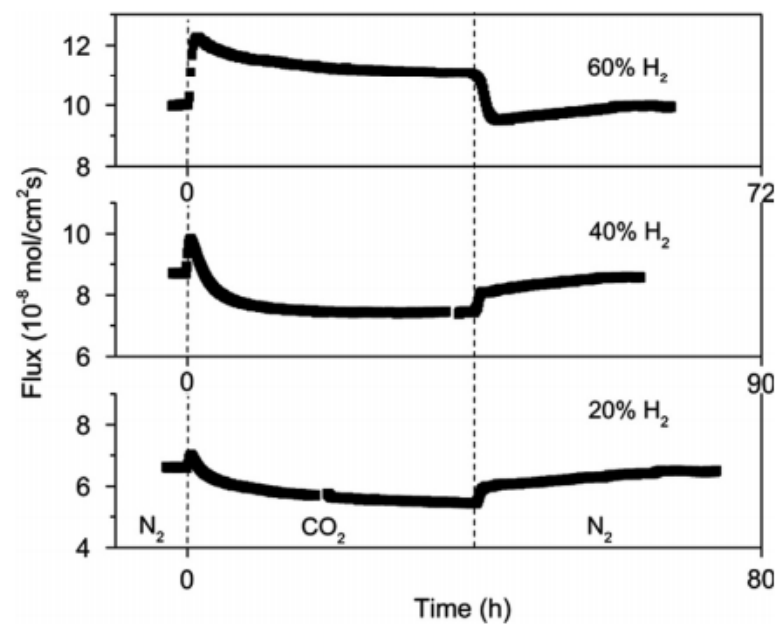

Figure 2. 17 Time dependence of hydrogen flux of the Ni-BZCYYb membrane in 20$60 \% \mathrm{H}_{2}$ balanced with $3 \% \mathrm{H}_{2} \mathrm{O}, 30 \% \mathrm{CO}_{2}$, and $47-7 \% \mathrm{He}$, respectively. From Fang et al. [108]

The degradation was attributed to the formation of secondary phases such as $\mathrm{BaCO}_{3}$, doped- $\mathrm{CeO}_{2}$, and carbon on the Ni-BZCYYb surface that inhibited the hydrogen flux which was confirmed by the XRD and Raman spectroscopy on the Ni-BZCYYb membrane after exposing to up to $60 \% \mathrm{CO}_{2}$ and recovering in wet $40 \% \mathrm{H}_{2}+\mathrm{N}_{2+} \mathrm{He}$ at $900^{\circ} \mathrm{C}$ for $912 \mathrm{~h}$ followed by fast cooling in the same atmosphere. As shown in Figure 2. 18 , secondary phases such as $\mathrm{BaCO}_{3}$, doped- $\mathrm{CeO}_{2}$, and carbon were detected by XRD for the sample. In addition, Raman spectroscopy also identified the existence of $\mathrm{BaCO}_{3}$, $\mathrm{CeO}_{2}$ or $\mathrm{BaCeO}_{3}$ and carbon, which correspond to the Raman peaks labeled as $\mathrm{CO}_{3}{ }^{2-}$ 
$\left(140,220,700\right.$ and $\left.1065 \mathrm{~cm}^{-1}\right)$, Ce-O $\left(478 \mathrm{~cm}^{-1}\right)$ or $\mathrm{Ce}-\mathrm{O}\left(353 \mathrm{~cm}^{-1}\right)$, and $\mathrm{C}(1353$ and $\left.1582 \mathrm{~cm}^{-1}\right)$, respectively in Figure 2. 20 .

The authors attributed the formation of these secondary phases to the reaction between the $\mathrm{CO}_{2}$ with $\mathrm{BZCYYb}$. The reason why $\mathrm{CO}_{2}$ showed poisoning effect in humidified feed gas is because the RWGS reaction was limited by the existing high $\mathrm{H}_{2} \mathrm{O}$ content, and the $\mathrm{CO}_{2}$ concentration would be higher than that in dry feed gas.

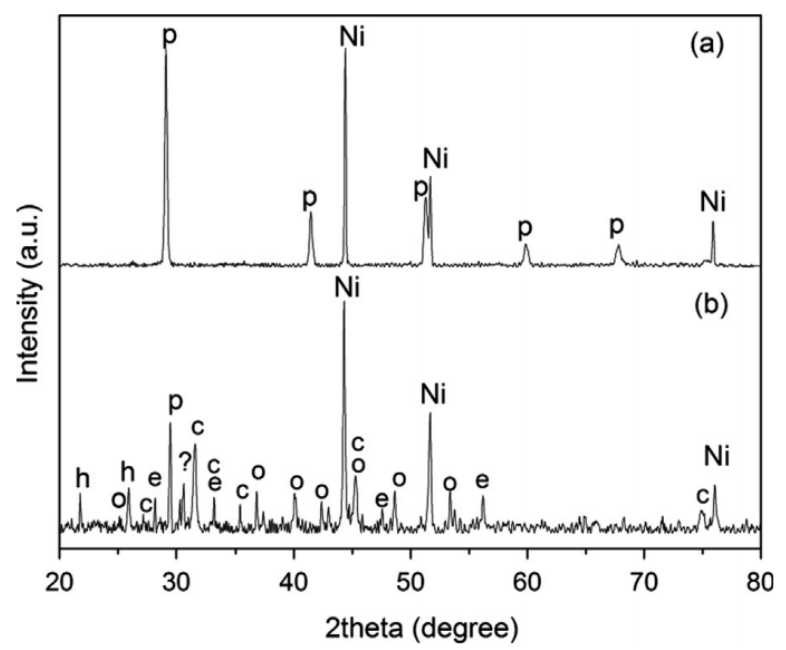

Figure 2. $18 \mathrm{XRD}$ patterns obtained from the fresh (a) and tested (b) Ni-BZCYYb membrane. p: $\mathrm{BZCYYb}$, h: hexagonal $\mathrm{BaCO}_{3}$, o- orthorhombic $\mathrm{BaCO}_{3}$, c: carbon, e: doped- $\mathrm{CeO}_{2}$, ?: unknown phase. From Fang et al. [108]

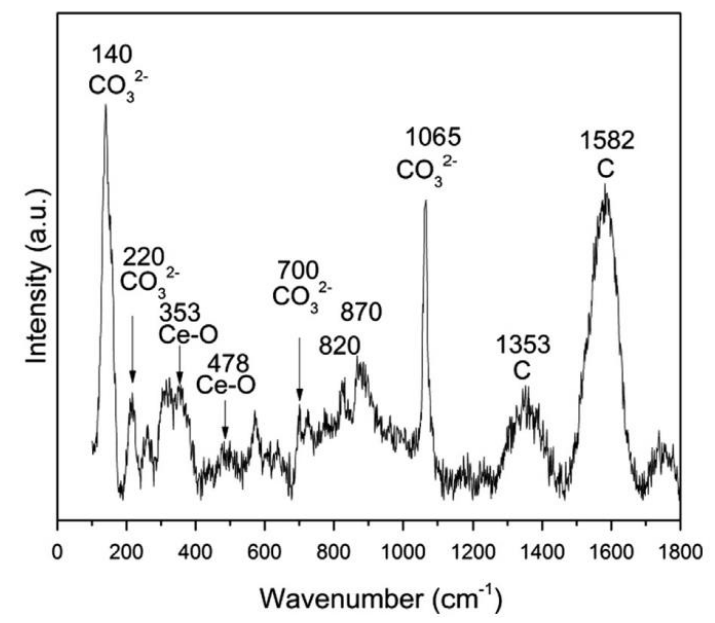


Figure 2. 19 Raman spectrum obtained from feed side surface of Ni-BZCYYb membrane after exposure to wet $\mathrm{CO}_{2}$ and recovery without $\mathrm{CO}_{2}$. From Fang et al. [108]

However, at intermediate temperature of $400-600^{\circ} \mathrm{C}$, since the RWGS reaction is thermodynamically unfavorable, how would the system will respond to $\mathrm{CO}_{2}$ effect is not clear. In addition, as stated, since the Ni-BZCYYb hydrogen permeation membrane is not an SOFC, how the knowledge gained in this study can be leveraged to proton conducting IT-SOFC is of interest.

\subsection{Cathode for Proton Conducting IT-SOFC}

\subsubsection{Cathode Reaction Process for Oxide-ion Conducting SOFC versus Proton Conducting IT-SOFC}

Similar to the anode reaction process, the cathode reaction process will also change according to the electrolyte material. For the conventional oxide-ion conducting SOFC, the

overall reaction of $\mathrm{O}_{2}+2 \mathrm{e}^{-}+2 \mathrm{~V}_{\mathrm{O}}^{*} \leftrightarrow 2 \mathrm{O}_{\mathrm{O}}^{\mathrm{x}}$, as mentioned in section 1.1 , can also be separated into several elementary steps as shown in Figure 2. 20 below. [109-119] 


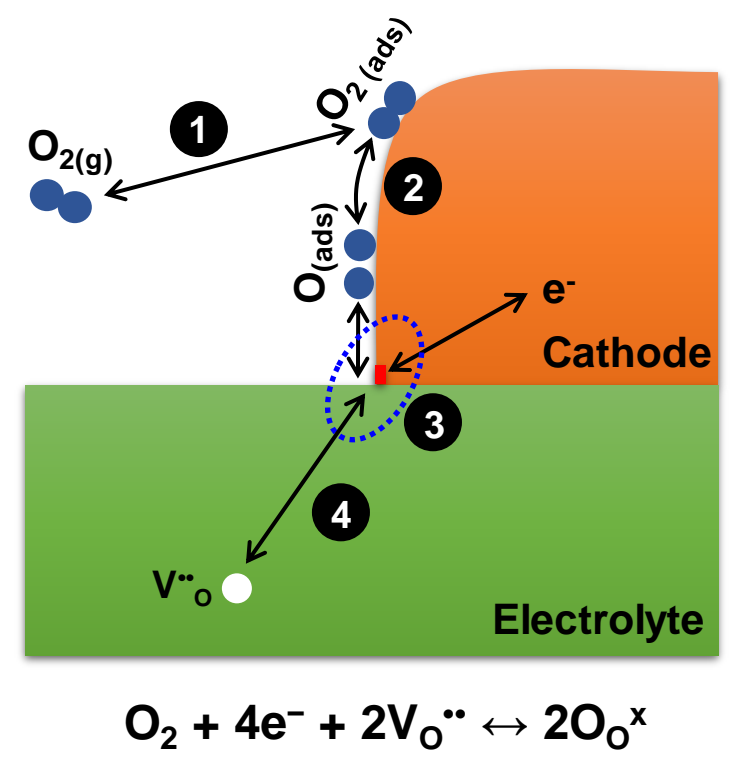

Figure 2. 20 Schematics showing the reaction species involved and the elementary steps for the cathode reactions for oxide-ion conducting SOFC when mixed ionic and electronic conducting material is used as cathode.

Step (1) is the oxygen adsorption reaction occurring on the surface of the cathode, which can be written as:

$\mathrm{O}_{2}(\mathrm{~g}) \leftrightarrow \mathrm{O}_{2}$ (ads)

Equation 2. 13

Step (2) is the dissociation of oxygen molecules into adsorbed oxygen atoms occurring on the surface of cathode, which can be written as:

$\mathrm{O}_{2}$ (ads) $\leftrightarrow 2 \mathrm{O}$ (ads)

Equation 2.

14

Step (3) represents the charge transfer step occurring over the cathode surface when mixed ionic-electronic conducting (MIEC) materials, such as LSCF and BSCF, are used as the cathode. [120] The dissociated oxygen atoms will accept electrons and incorporate into 
oxygen vacancies in the MIEC cathode and become lattice oxygen during this step, which can be written as:

$\mathrm{O}($ ads $)+2 \mathrm{e}^{-}+\mathrm{V}_{\mathrm{O}}^{*}($ cathode $) \leftrightarrow \mathrm{O}_{\mathrm{O}}^{\mathrm{x}}($ cathode $)$

Equation 2. 15

Step (4) represents the mass transfer step between the MIEC cathode and the electrolyte, which can be written as:

$\mathrm{V}_{\mathrm{O}}$ (cathode) $\leftrightarrow \mathrm{V}_{\mathrm{O}}^{*}$ (electrolyte $)$

16

Equation 2.

For the cathode reaction in the proton conducting IT-SOFC, due to the change of ionic species from oxide-ion to proton, the cathode reaction is through a different process of $\mathrm{O}_{2}+4 \mathrm{e}^{-}+4(\mathrm{OH})_{\mathrm{O}}^{\circ} \leftrightarrow 2 \mathrm{O}_{\mathrm{O}}^{\mathrm{x}}+2 \mathrm{H}_{2} \mathrm{O}$ as mentioned in section $1.1[20,118,121,122]$

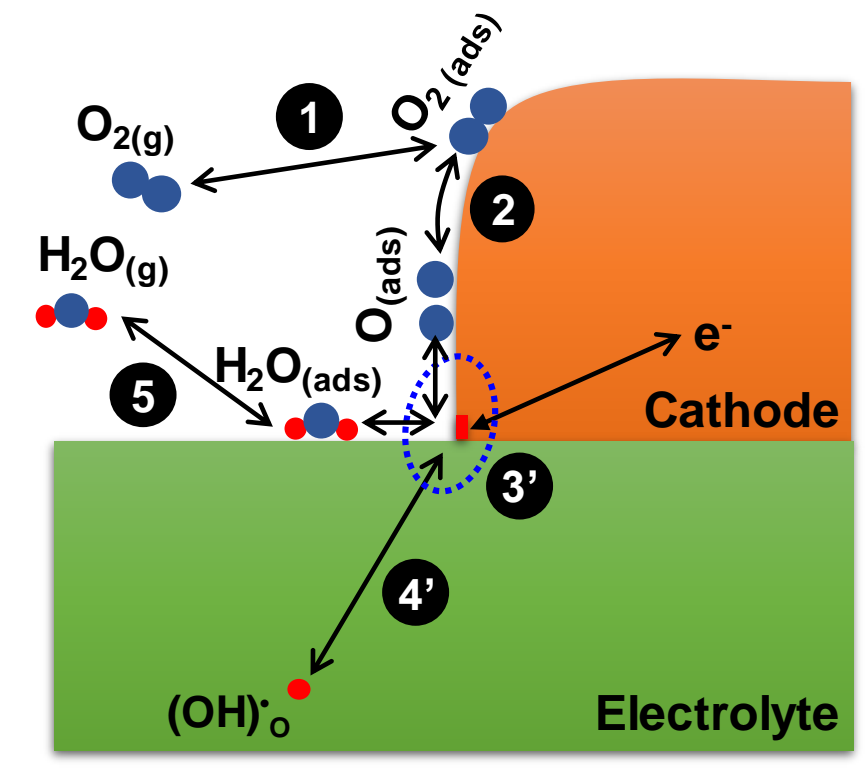

\section{$\mathrm{O}_{2}+4 \mathrm{e}^{-}+4(\mathrm{OH}) \mathrm{O}^{\cdot} \leftrightarrow 2 \mathrm{O}_{\mathrm{O}^{x}}+2 \mathrm{H}_{2} \mathrm{O}$}

Figure 2. 21 Schematics showing the reaction species involved and the elementary steps for the cathode reactions for proton conducting IT-SOFC. 
Similarly, this reaction process can also be divided into several elementary steps as shown in Figure 2. 21, including step (1) adsorption of oxygen molecules and (2) dissociation of adsorbed oxygen molecules into adsorbed oxygen atoms. Both steps are identical to the step (1) and (2) in the cathode reaction process for oxide-ion conducting SOFC.

On the other hand, the charge transfer step (3') would be different: It involves the combination of proton (or hydroxide group), electrons and adsorbed oxygen atoms to generate water on the TPB between cathode, electrolyte and atmosphere. This step can be written as:

$\mathrm{O}(\mathrm{ads})+2 \mathrm{e}^{-}+2(\mathrm{OH})_{\mathrm{O}}^{\circ}(\mathrm{TPB}) \leftrightarrow 2 \mathrm{O}_{\mathrm{O}}^{\mathrm{x}}(\mathrm{TPB})+\mathrm{H}_{2} \mathrm{O}$ (ads) $\quad$ Equation 2. 17

Step (4') is the mass transfer of proton from TPB of cathode through electrolyte, which can be written as:

$(\mathrm{OH})_{\mathrm{O}}^{\circ}($ electrolyte $) \leftrightarrow(\mathrm{OH})_{\mathrm{O}}^{\circ}(\mathrm{TPB})$ Equation 2. 18

Step (5) is the desorption of generated water from TPB of cathode, which can be written as:

$\mathrm{H}_{2} \mathrm{O}$ (ads) $\leftrightarrow \mathrm{H}_{2} \mathrm{O}(\mathrm{g})$ Equation 2. 19

The obvious difference between the cathode reaction process for the proton conducting IT-SOFC versus oxide-ion conducting SOFC suggests major change in the cathode material choice. However, no agreement has been reached on the most suitable cathode for proton conducting IT-SOFC, and the cathode reaction mechanism has not well studied yet. 
In the following section, some of the representative studies on the cathode materials adopted for proton conducting IT-SOFC were described.

\subsubsection{Different Cathodes on Proton Conducting IT-SOFC}

It has been well accepted that in intermediate-temperature $\mathrm{SOFC}$, oxygen reduction at the cathode is the main rate limiting factor to the performance of the whole system. $[61,114$, 123-125] Part of the reason is that the cathode materials are not optimized specifically for proton conducting IT-SOFC and thus high cathodic overpotential was observed. [119, 121, 125-127] Thus, previous studies are presented below in groups of pure electronic conductor, MIEC, and mixed electronic and protonic conductor.

\subsubsection{Electronic Conducting Cathode for Proton Conducting IT-SOFC}

Electronic conducting cathode, which typically is metal with great stability in oxidating atmosphere, has high electronic conductivity but negligible ionic conductivity. The most commonly used electronic conducting cathodes are silver $(\mathrm{Ag})$ and platinum $(\mathrm{Pt})$ metal. There were many studies about adopting the metal as the cathode for proton conducting IT-SOFC and some of the representatives were described below.

- Taherparvar et al. (2003) [128]

Taherparvar et al. studied the performance of the $\mathrm{Pt} / \mathrm{SrCe}_{0.95} \mathrm{Yb}_{0.05} \mathrm{O}_{3}(\mathrm{SCYb}) / \mathrm{Pt}$ proton conducting electrolyte-supported full cell at the temperature range of $800-600^{\circ} \mathrm{C}$ 
including the response to $\mathrm{H}_{2} \mathrm{O}$ on the Pt cathode. Power densities of only $\sim 8-2 \mathrm{~mW} / \mathrm{cm}^{2}$ were observed from $800-600^{\circ} \mathrm{C}$ for the cell as shown in Figure 2. 22, suggesting $\mathrm{Pt}$ is not an efficient electrode for proton conducting IT-SOFC.

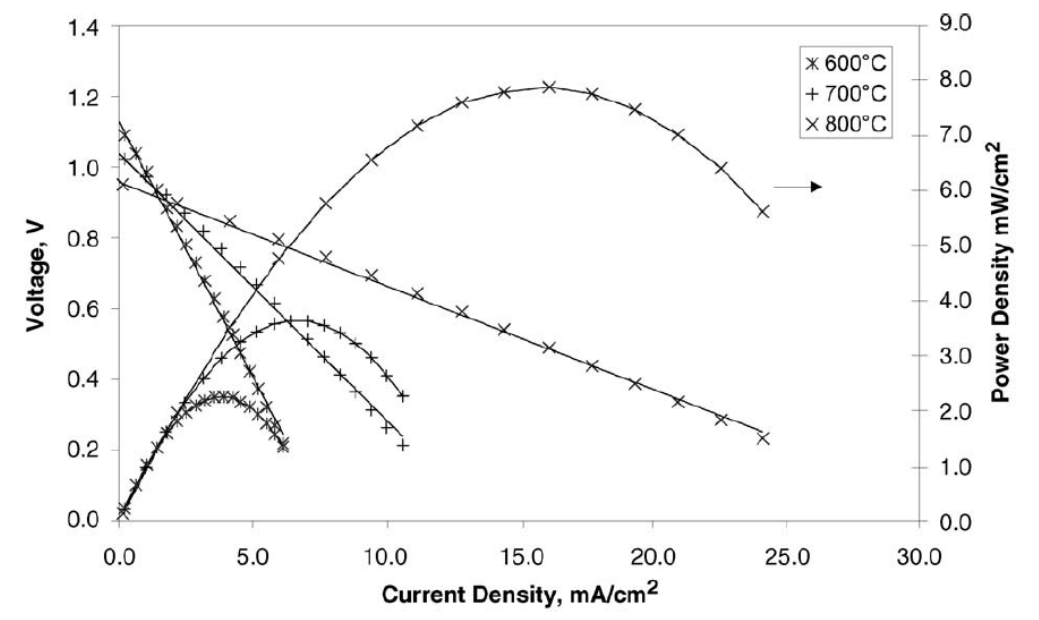

Figure 2. 22 Voltage-current and power density-current curves of $\mathrm{Pt} / \mathrm{SrCe}_{0.95} \mathrm{Yb}_{0.05} \mathrm{O}_{3}$ (SCYb)/ Pt full cell at temperature of $800-600^{\circ} \mathrm{C}$ in $3 \%$ humidified fuel $\left(10 \% \mathrm{H}_{2}\right.$ balanced by Ar) at anode and dry air at cathode. From Taherparvar et al. [128]

On the other hand, when 3-12\% moisture was introduced to the Pt cathode side of the cell, drops in both cell voltage and power density for the cell were observed at $800-600^{\circ} \mathrm{C}$ as shown in Figure 2. 23. 
(a)

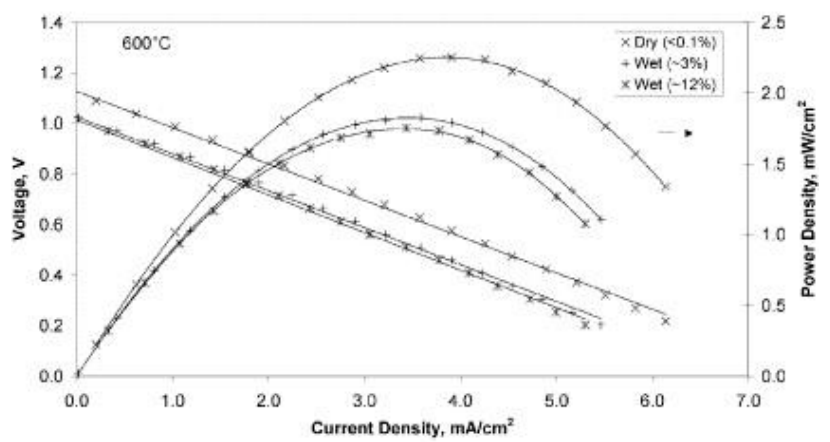

(b)

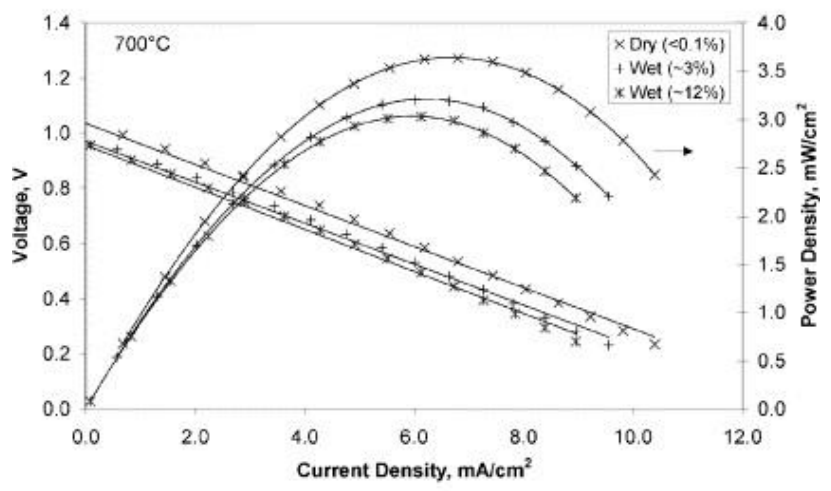

(c)

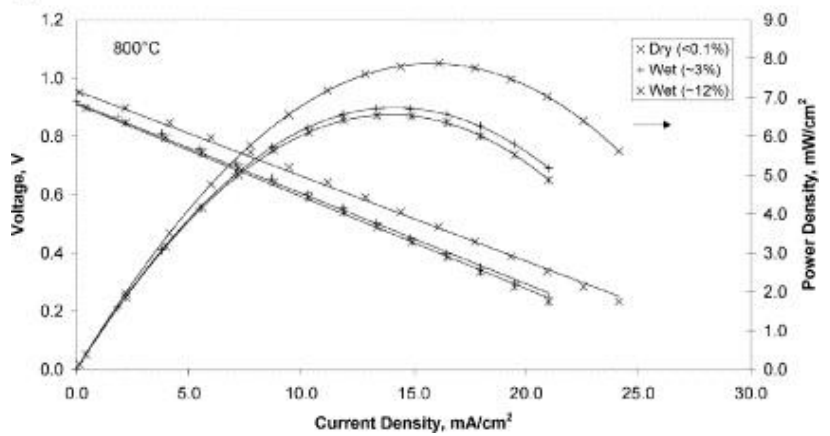

Figure 2. 23 (a) Fuel cell performance for $\mathrm{Pt} / \mathrm{SCYb} / \mathrm{Pt}$ full cell with varying $p \mathrm{H}_{2} \mathrm{O}$ at the cathode at (a) $600{ }^{\circ} \mathrm{C} \mathrm{(b)} 700^{\circ} \mathrm{C}$ and (c) $800^{\circ} \mathrm{C}$ with $3 \%$ humidified fuel consisted of $10 \%$ $\mathrm{H}_{2}+$ Ar. From Taherparvar et al. [128]

The authors hypothesized the $\mathrm{H}_{2} \mathrm{O}$ effect was due to the suppressed oxygen reduction reaction on the TPB of cathode by the hydration reaction between water and the SCYb electrolyte. 
However, the performance of $\mathrm{Pt} / \mathrm{SCYb} / \mathrm{Pt}$ is very low that the information gained in this study is hard to be leveraged for typical proton conducting IT-SOFC. In addition, more electrochemical measurements such as impedance spectroscopy would be needed for examining the humidification effect on metal cathode for proton conducting IT-SOFC.

- Potter et al. (2006) [129]

Potter et al. studied the microstructure and impedance spectra of $\mathrm{Pt} / \mathrm{SCY} / \mathrm{Pt}$ proton conducting cathode symmetrical cell at $350^{\circ} \mathrm{C}$. The authors found that the porosity of the Pt electrode in the cell was low and the grain size was small of $\sim 50-100 \mathrm{~nm}$ as shown in Figure 2. 24.

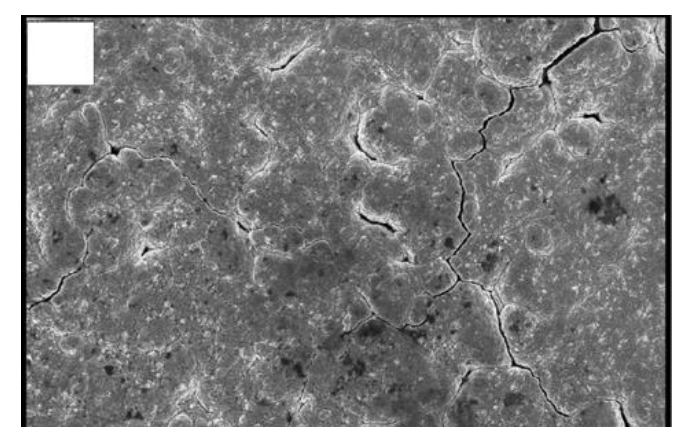

Figure 2. 24 SEM images of the morphology of the Pt electrode in Pt/ SCYb/ Pt cell. From Potter et al. [129]

The $\mathrm{H}_{2} \mathrm{O}$ effect on the Pt cathode was tested using impedance spectroscopy at $350^{\circ} \mathrm{C}$. Significant decrease in interfacial resistance was observed with the introduction of $\sim 3 \%$ $\mathrm{H}_{2} \mathrm{O}$ as show in Figure 2. 25. On the other hand, huge interfacial resistance larger than 10kohm was observed for the cell, suggesting Pt behaved as a very poor cathode on 
proton conducting SOFC based on SCYb electrolyte at $350^{\circ} \mathrm{C}$. The decrease in interfacial resistance with the introduction of moisture was not consistent with the observed decrease in power output by Taherparvar et al. [128]

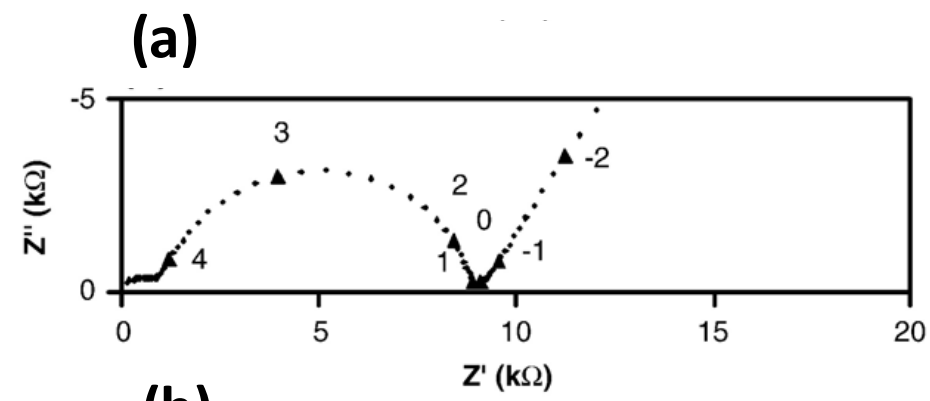

(b)

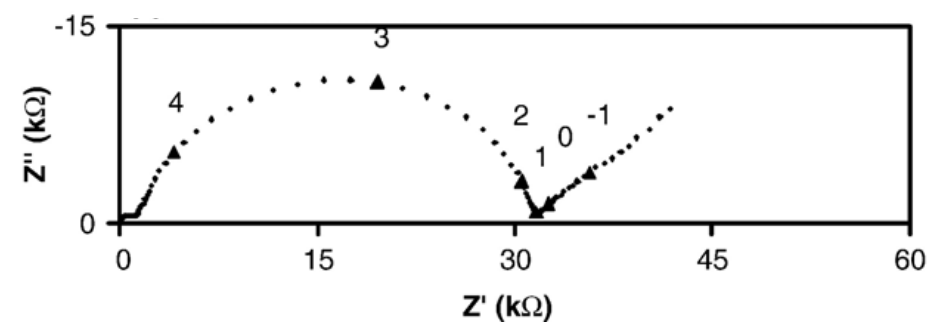

Figure 2. 25 Impedance spectra of $\mathrm{Pt} / \mathrm{SCYb} / \mathrm{Pt}$ cell at $350^{\circ} \mathrm{C}$ in (a) humidified air and (b) dry air Numerical labels indicate $\log 10$ of applied frequency. Adapted from Potter et al. [129]

However, no explanation was given on the origin of such $\mathrm{H}_{2} \mathrm{O}$ effect on the $\mathrm{Pt} / \mathrm{SCYb} /$ Pt cell. Moreover, the impedance loops provided were only at the temperature of $350^{\circ} \mathrm{C}$. Thus, testing at intermediate temperature of $600-400^{\circ} \mathrm{C}$ will be needed to achieve systematic understanding about the $\mathrm{H}_{2} \mathrm{O}$ effect on the proton conducting IT-SOFC with electronic conducting cathode. 
- Akimune et al. (2007) [130]

Akimune et al. studied the influence of cathode grain size on the cell performance using proton conducting electrolyte-supported full cell with the configuration of $\mathrm{Ag}$ cathode/ $\mathrm{BCY} / \mathrm{Pt}$ anode at the temperature range $500-300^{\circ} \mathrm{C}$. The grain size of the $\mathrm{Ag}$ cathode was modified by using several different types of Ag paste with various particle size $(5 \mathrm{~nm}, 0.1$ $\mu \mathrm{m}$ and 6 to $13 \mu \mathrm{m}$ ) as well as two different firing temperatures of $700^{\circ} \mathrm{C}$ and $500^{\circ} \mathrm{C}$. It was found that the final grain size of Ag cathode increases with initial particle size and firing temperature as shown in Figure 2. 26. For example, the smallest grain size of $\sim 0.85 \mathrm{um}$ was observed in the Ag cathode with the smallest initial particle size of $5 \mathrm{~nm}$ and lowest firing temperature of $500^{\circ} \mathrm{C}$.

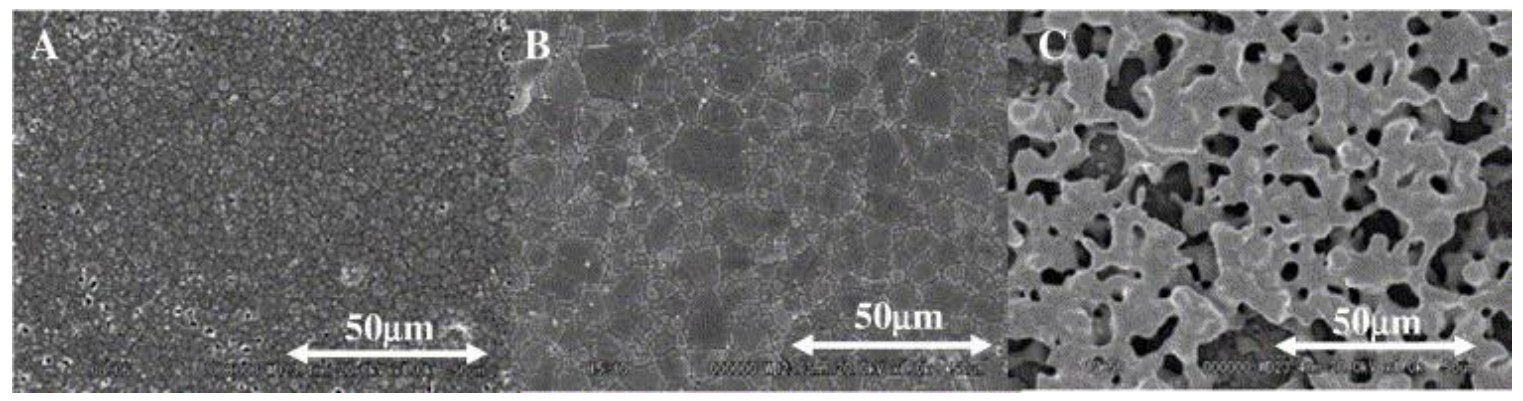

Figure 2. $26 \mathrm{Ag}$ cathode surface with the initial particle of (A) 5nm, (B) $0.1 \mathrm{um}$, and (C) 6-13 um after firing at $500^{\circ} \mathrm{C}$. From Akimune et al. [130]

It was found that the cell with smallest grain size of Ag cathode (smallest initial particle size, fired at $500^{\circ} \mathrm{C}$ ) delivered the best power density in the temperature range of 500$300^{\circ} \mathrm{C}(773 \mathrm{~K}-573 \mathrm{~K})$ as shown in Figure 2. 27. The enhanced performance of the cell was 
attributed to the relatively small gain size of $\mathrm{Ag}$ cathode that extends the number of TPB on the cathode.

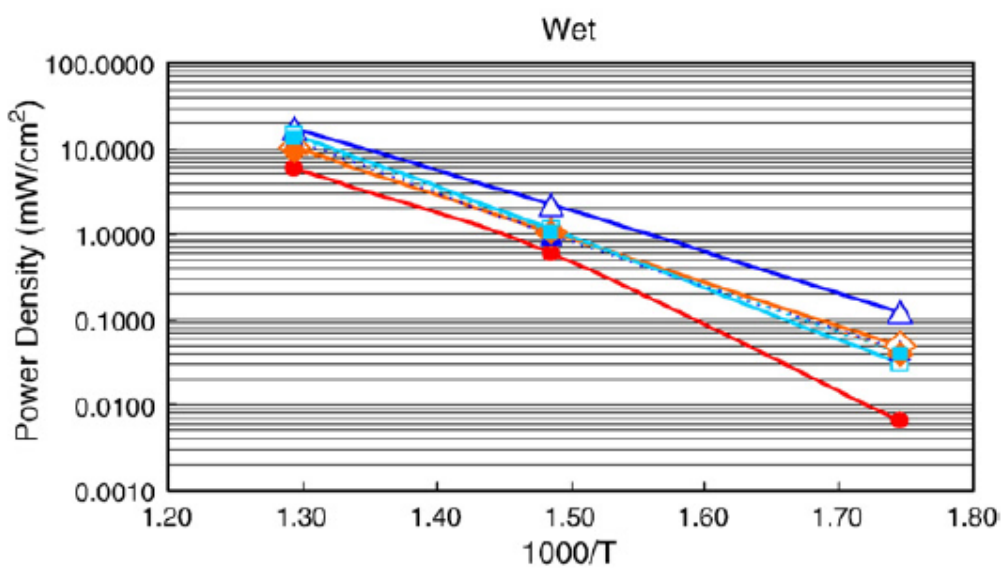

Figure 2. 27 Power density of cell using $(\bullet)$ Pt cathode, and $\mathrm{Ag}$ cathode fired at $500^{\circ} \mathrm{C}$ with initial particle size of $(\Delta) 5 \mathrm{~nm},(\diamond) 0.1 \mathrm{um}$, and $(\square)$ 6-13um, and Ag cathode fired at $700^{\circ} \mathrm{C}$ with initial particle size of $(\boldsymbol{\Delta})$ 5nm, ( $)$ 0.1 um and (a) 6-13um. From Akimune et al. [130]

However, the performance of $\mathrm{Ag} / \mathrm{BCY} / \mathrm{Pt}$ cell showed in this study was still too low to be leveraged.

\subsubsection{Mixed Ionic and Electronic Conducting (MIEC) and Mixed Electronic and Protonic Conducting Cathodes for Proton Conducting IT-SOFC}

Mixed ionic and electronic conducting (MIEC) cathode, which typically is doped perovskite materials, has high oxide-ionic and electronic conductivity. In the following, several representative studies using different cathode materials are described. Among those materials, the focus is on strontium and iron co-doped lanthanum cobaltite $\left(\mathrm{La}_{1-\mathrm{x}} \mathrm{Sr}_{\mathrm{x}} \mathrm{Co}_{1-}\right.$ 
$\left.{ }_{y} \mathrm{Fe}_{\mathrm{y}} \mathrm{O}_{3-\delta}(\mathrm{LSCF})\right)$ and barium cobaltite $\left(\mathrm{Ba}_{1-\mathrm{x}} \mathrm{Sr}_{\mathrm{x}} \mathrm{Co}_{1-\mathrm{y}} \mathrm{Fe}_{\mathrm{y}} \mathrm{O}_{3-\delta}(\mathrm{BSCF})\right)$, because both are regarded as the state-of-art MIEC cathodes for conventional oxide-ion conducting SOFC and have a good balance between chemical stability, thermal expansion and electrochemical activity.

- LSCF and LSCF related cathodes

Fabbri et al. (2009) studied LSCF and related composite cathodes for $\mathrm{BaCe}_{0.9} \mathrm{Yb}_{0.1} \mathrm{O}_{3-}$ $\delta(10 \mathrm{YbBC})$ based proton conducting electrolyte-supported full cells (thickness of $1 \mathrm{~mm}$ ) with the configuration of LSCF/10YbBC/Pt and LSCF-10YbBC/10YbBC/Pt. [93] The author found that the LSCF-10YbBC (1:1 weight ratio) composite cathode showed $~ 30 \%$ smaller interfacial resistance compared to the pure LSCF cathode on proton conducting IT$\mathrm{SOFC}$ at $600^{\circ} \mathrm{C}$ as shown in Figure 2. 28. The authors attributed the decrease in total interfacial resistance to the extended reaction zone, i.e. TPB area with the introduction of YbBC in the cathode.
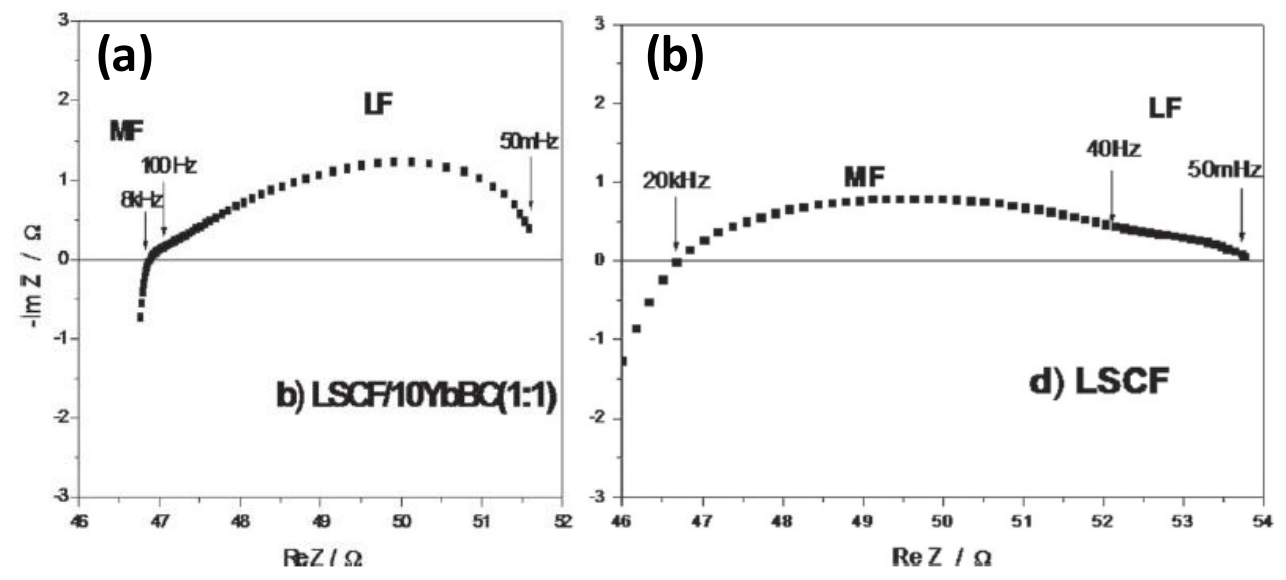

Figure 2. 28 Impedance spectra acquired in wet air at $600{ }^{\circ} \mathrm{C}$ for the (b) LSCF composite cathode with 10YbBC (weight ratio 1:1), and (d) and pure phase LSCF as cathode on YbBC electrolyte-supported cell. Adapted from Fabbri et al. [93] 
The authors also compared the I-V, I-P and impedance spectra for proton conducting cells with LSCF-10YbBC cathode versus $\mathrm{Pt}$ cathode (anode stays the same as $\mathrm{Pt}$ ) at $700^{\circ} \mathrm{C}$ as shown in Figure 2. 29. The cell with LSCF-10YbBC cathode showed higher power density and lower interfacial resistance compared to that with Pt cathode at $700^{\circ} \mathrm{C}$.
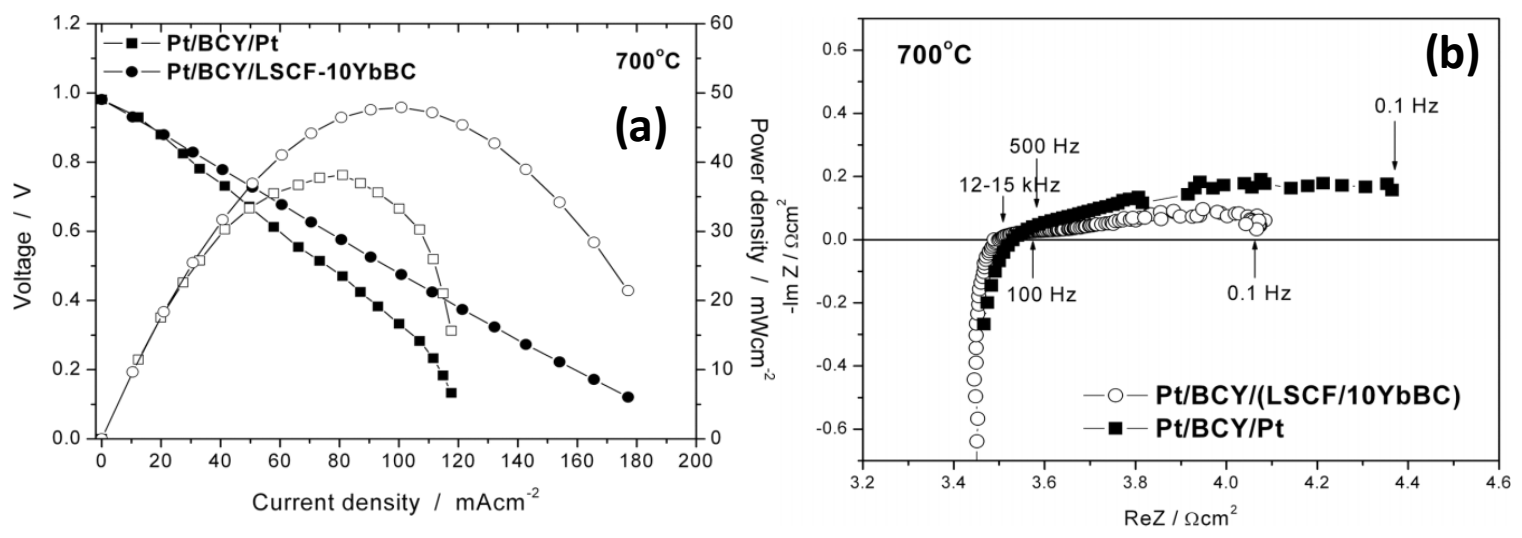

Figure 2. 29 (a) I-V and I-P curves, and (b) impedance spectra for the Pt/BCY/Pt and $\mathrm{Pt} / \mathrm{BCY} / \mathrm{LSCF}-10 \mathrm{YbBC}$ cell tested at $700{ }^{\circ} \mathrm{C}$. Adapt from Fabbri et al. [93]

Similarly, Yang et al. (2010) also compared the cell performance and impedance of $\mathrm{BaZr}_{0.1} \mathrm{Ce}_{0.7} \mathrm{Y}_{0.2} \mathrm{O}_{3-\delta}$ (BZCY) based anode-supported proton conducting SOFC (electrolyte thickness of $\sim 20$ um) with pure LSCF cathode versus LSCF-BZCY composite cathode at the temperature range of $750-550^{\circ} \mathrm{C}$. [121] As shown in Figure 2. 30, with the introduction of BZCY in LSCF cathode, increase in cell power density and decrease in interfacial resistance was observed at various temperatures. High maximum power density of $\sim 900 \mathrm{~mW} / \mathrm{cm}^{2}$ was achieved at $750^{\circ} \mathrm{C}$ in BZCY based proton conducting anode-supported 
cell with LSCF-BZCY composite cathode, suggesting LSCF-BZCY composite cathode is a good cathode for proton conducting IT-SOFC.
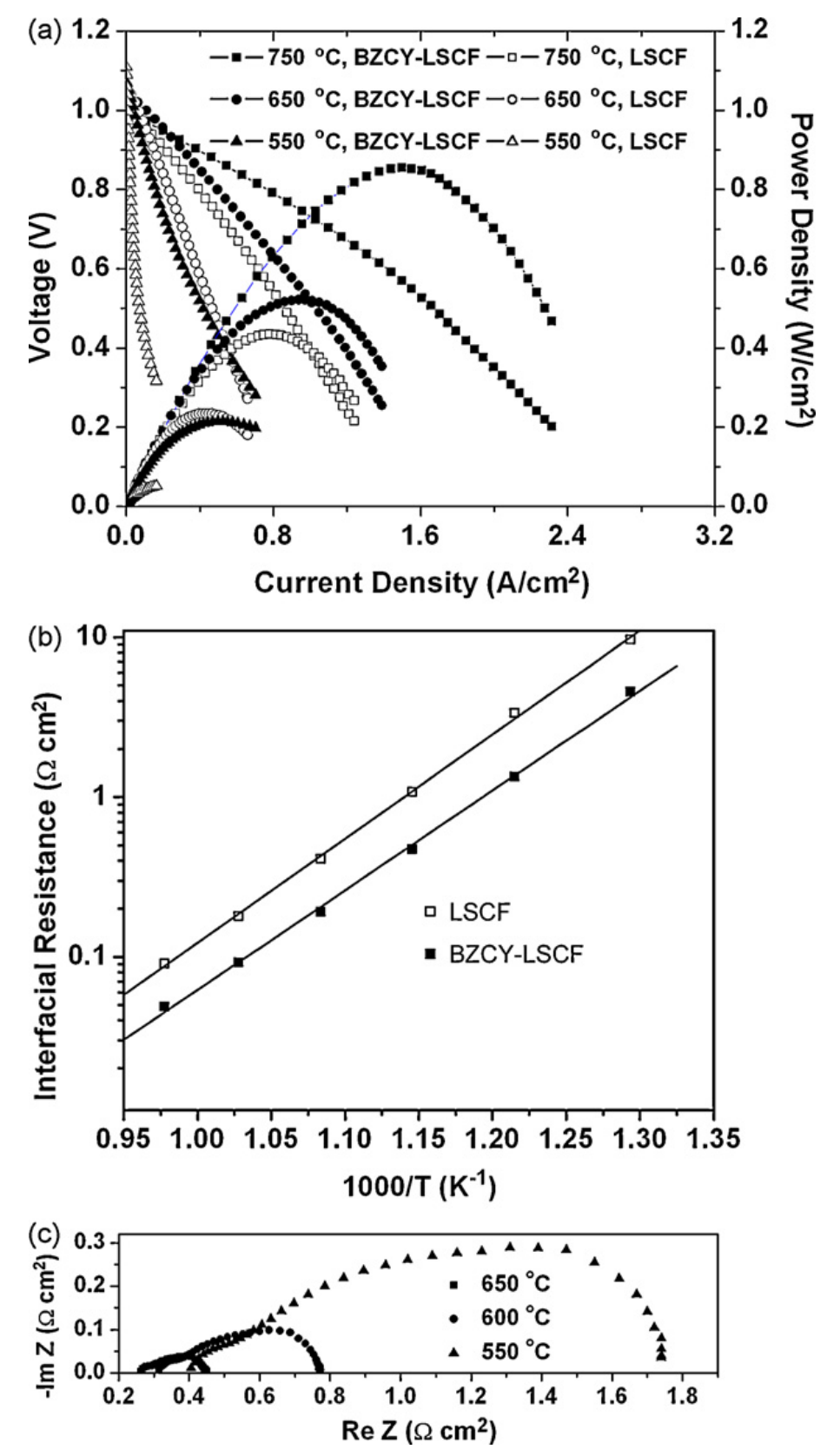

Figure 2. 30 (a) I-V curves, (b) interfaical resistances, for BZCY-based anode-supported cells with BZCY-LSCF and LSCF cathodes and (c) impedance spectra of the cell with LSCF-BZCY composite cathode at various temperatures. From Yang et al. [121] 
- $\quad$ BSCF cathode

Lin et al. (2008) studied the microstructure and performance of BSCF cathode for anodesupported proton conducting IT-SOFC with the configuration of $\mathrm{BSCF} / \mathrm{BaCe}_{0.9} \mathrm{Y}_{0.1} \mathrm{O}_{2.95}$ (BCY)/ Ni-BCY. [72] The influence of firing temperature on the BSCF cathode were examined using two different temperatures of $950^{\circ} \mathrm{C}$ and $1100^{\circ} \mathrm{C}$. It was found that the $\mathrm{BSCF}$ with lower firing temperature of $950^{\circ} \mathrm{C}$ showed slightly smaller grain size and higher porosity as shown in Figure 2. 31.

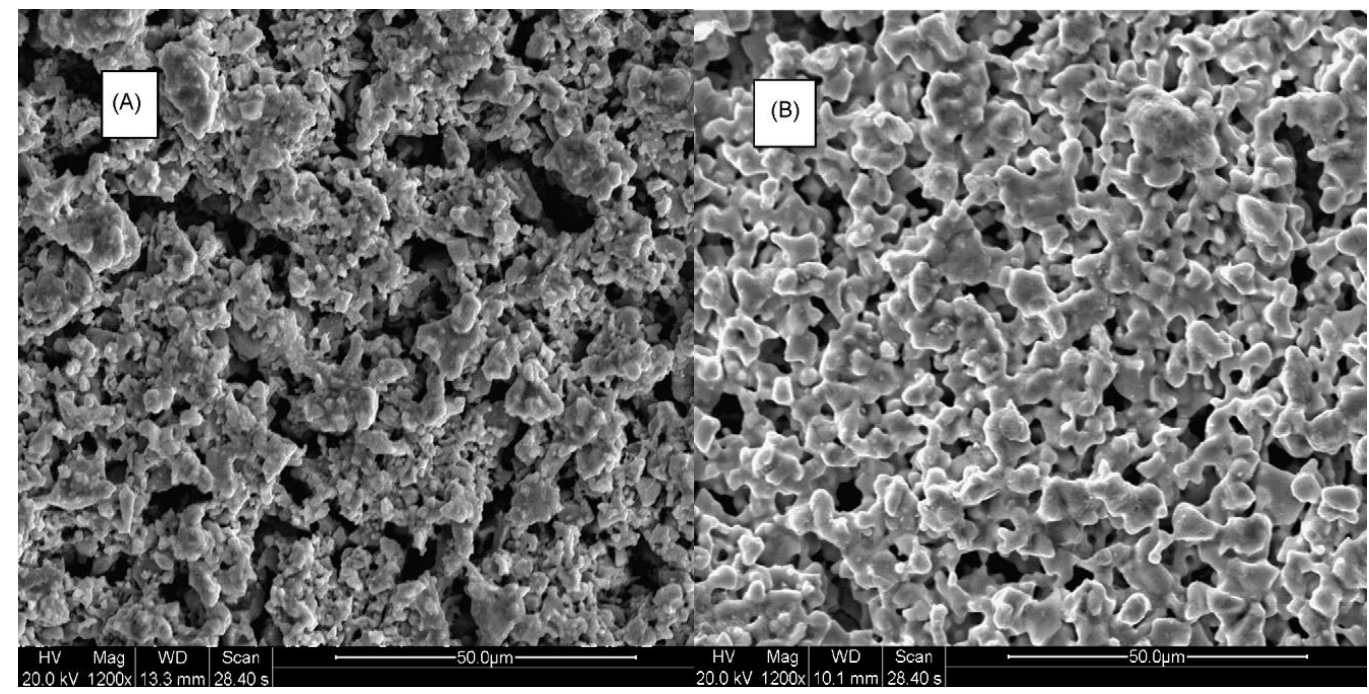

Figure 2. 31 SEM morphologies of the cathodes surface fired at: (A) $950^{\circ} \mathrm{C}$ and (B) $1100^{\circ} \mathrm{C}$. From Lin et al. [72]

In addition, the cell fired at $950^{\circ} \mathrm{C}$ showed better maximum power density (e.g $\sim 550 \mathrm{~mW} / \mathrm{cm}^{2}$ at $700^{\circ} \mathrm{C}$ and $\sim 130 \mathrm{~mW} / \mathrm{cm}^{2}$ at $400^{\circ} \mathrm{C}$ ), higher open circuit voltage and lower interfacial resistance (e.g. $\sim 0.15 \mathrm{ohm} \mathrm{cm}^{2}$ at $700^{\circ} \mathrm{C}$ ) in the temperature range of $700-400^{\circ} \mathrm{C}$ than the cell fired at $1100^{\circ} \mathrm{C}$ as shown in Figure 2. 32. The high power output 
suggests the BSCF is a good cathode for proton conducting IT-SOFC based on BCY electrolyte.
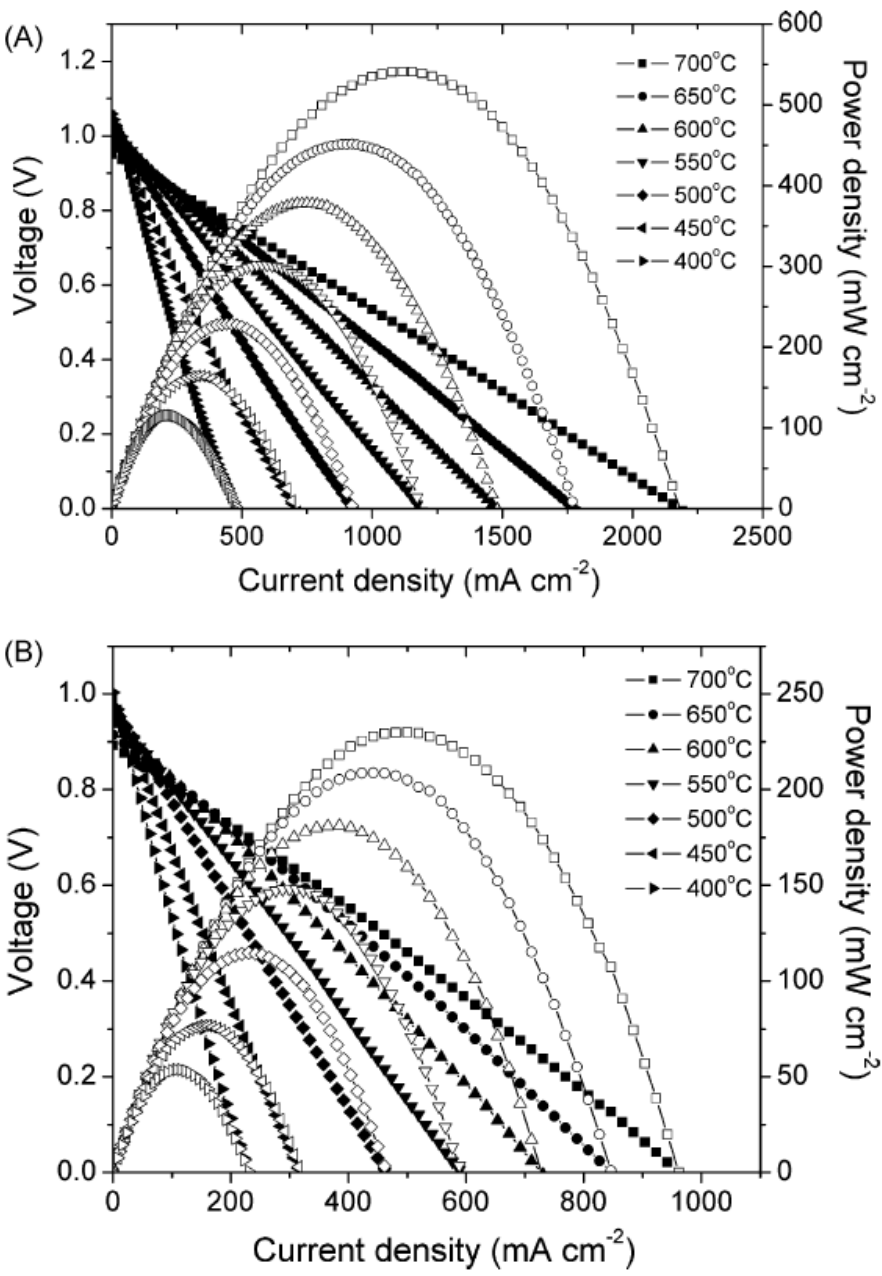

Figure 2. $32 \mathrm{I}-\mathrm{V}$ and I-P curves for the cell with $\mathrm{BSCF}$ cathode fired at (A) $950^{\circ} \mathrm{C}$, and (B) $1100{ }^{\circ} \mathrm{C}$ at various temperatures of $700-400^{\circ} \mathrm{C}$. From Lin et al. [72] 


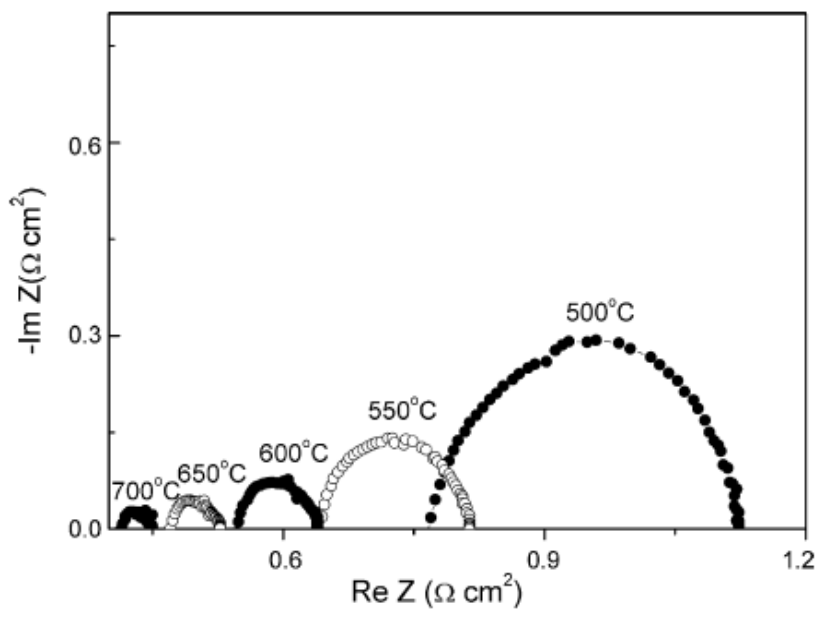

Fig. 8. EIS of the anode-supported fuel cell with $950^{\circ} \mathrm{C}$ fired $\mathrm{BSCF}$ cathode at various temperatures under OCV conditions. From Lin et al. [72]

Grimaud et al. (2012) studied the water uptake for BSCF and compared with LSCF using thermal gravimetric analysis (TGA). [20] The BSCF and LSCF powders were prehydrated in air containing $10 \% \mathrm{H}_{2} \mathrm{O}$ at $500^{\circ} \mathrm{C}$ for 12 hours followed by slow cooling in the same atmosphere before TGA measurement starting at room temperature towards $1000^{\circ} \mathrm{C}$ and then cool down to room temperature in dry air. (During the heating, weight loss come from both the oxygen loss and water loss, if any, while during the cooling, the weight gain is due to oxygen incorporation. The difference between heating and cooling gives the information about water content.) As shown in Figure 2. 33, the relative molar ratio of incorporated water to $\mathrm{BSCF}$ is $\sim 1: 10$, while it was negligible for LSCF, indicating that strong hydration reaction occurred in BSCF with possible proton conduction similar to typical PCC. 

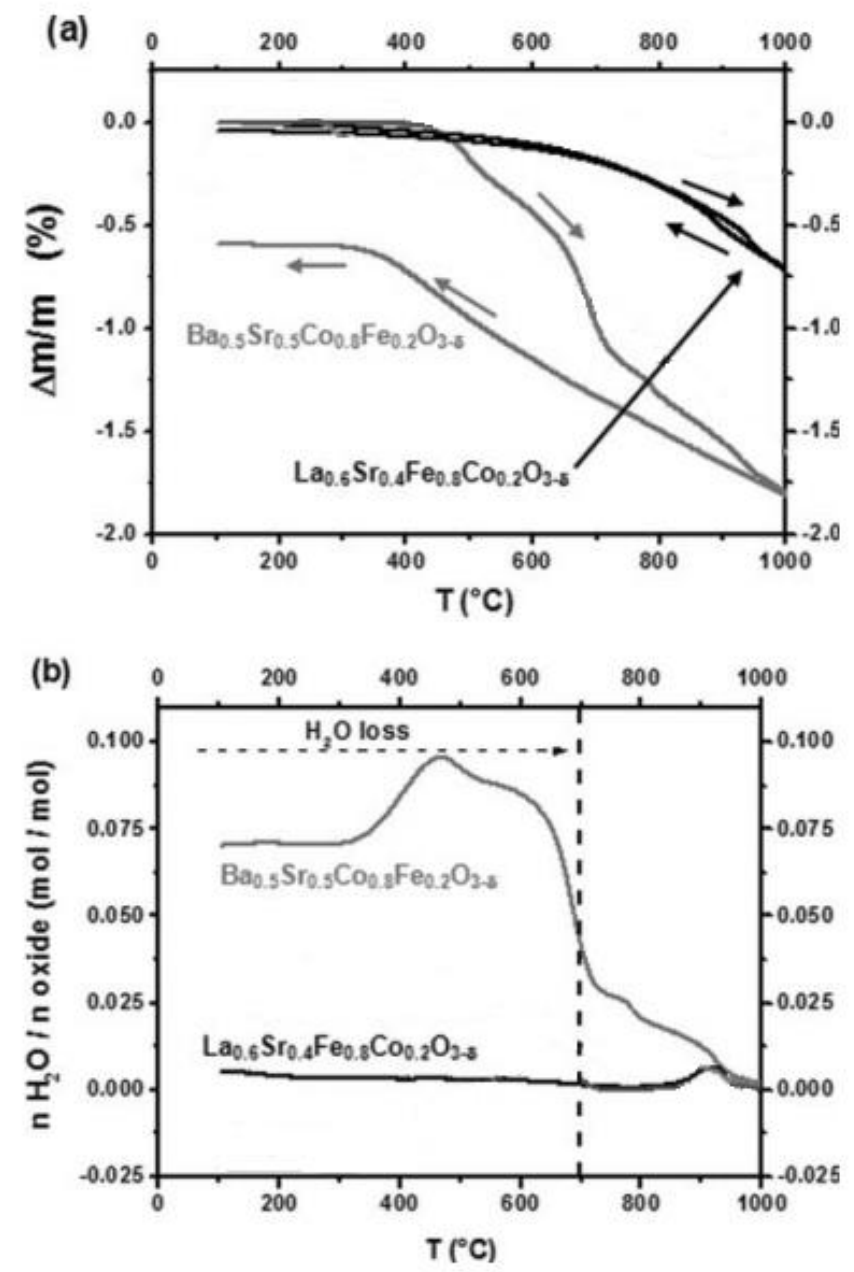

Figure 2. 33 Thermal variation in dry air of a) the relative weight loss of hydrated $\mathrm{La} 0.6 \mathrm{Sr}_{0.4} \mathrm{Fe}_{0.8} \mathrm{Co}_{0.2} \mathrm{O}_{3-\delta}$ and $\mathrm{Ba}_{0.5} \mathrm{Sr}_{0.5} \mathrm{Co}_{0.8} \mathrm{Fe}_{0.2} \mathrm{O}_{3-\delta}$ samples, b) the calculated amount of inserted water (in mol. per mol. of oxide). Adapted with modification from Grimaud et al. [20]

Moreover, the microstructure of BSCF cathode was compared with LSCF. As shown in Figure 2. 34, the BSCF cathode fired at $1000^{\circ} \mathrm{C}$ showed much larger grain size of $\sim 2-$ 10um compared to LSCF cathode of $\leq \sim 1$ um fired at same temperature. When BSCF cathode firing temperature was increased to $1100^{\circ} \mathrm{C}$, it got coarsen. 

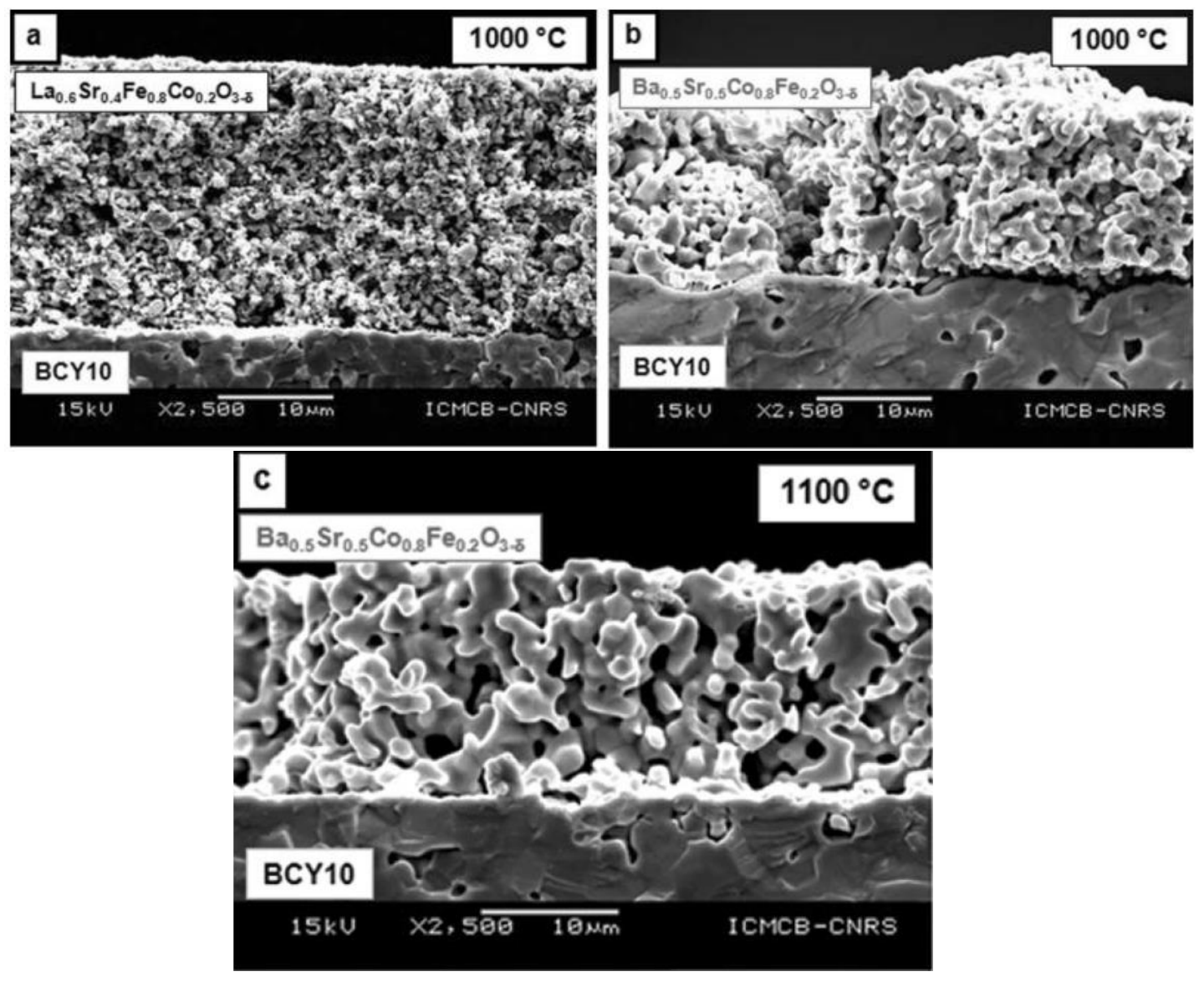

Figure 2. 34 SEM micrographs of (a) LSFC sintered at $1000^{\circ} \mathrm{C}$, (b) BSCF sintered at $1000^{\circ} \mathrm{C}$ (c) BSCF sintered at $1100^{\circ} \mathrm{C}$. Adapted from Grimaud et al. [20]

Furthermore, the electrochemical response of $\mathrm{BSCF}$ cathode to $\mathrm{H}_{2} \mathrm{O}$ was studied and compared with LSCF cathode using proton conducting cathode symmetrical cells based on $\mathrm{BaCe}_{0.9} \mathrm{Y}_{0.1} \mathrm{O}_{3-\delta}(\mathrm{BCY} 10)$ electrolyte with $p \mathrm{H}_{2} \mathrm{O}$ of $0.03-0.30$ bar at $600^{\circ} \mathrm{C}$. As shown in Fig 2.X, decrease in interfacial resistance for $1000^{\circ} \mathrm{C}$ fired $\mathrm{BSCF}$ cathode symmetrical cell with increasing $p \mathrm{H}_{2} \mathrm{O}$ from 0.03 bar to 0.30 bar was observed, while the opposite trend (increasing interfacial resistance with increasing $p \mathrm{H}_{2} \mathrm{O}$ ) was observed for LSCF cathode 
symmetrical cell. In addition, much smaller interfacial resistance of BSCF cathode symmetrical cells was observed compared to that for LSCF cell.
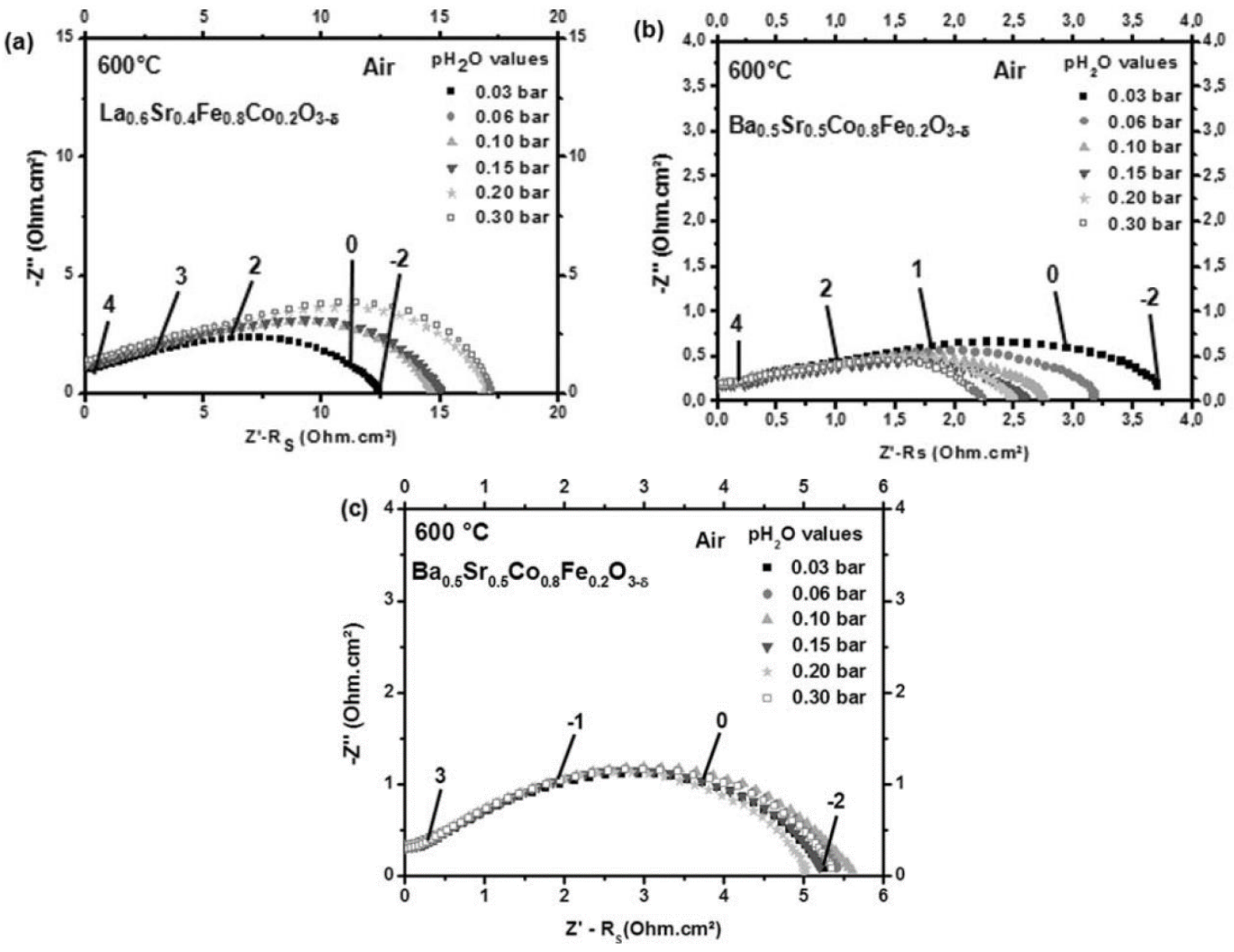

Figure 2. 35 Impedance spectra of the cathode symmetrical cell with (a)LSCF and (b) $1000^{\circ} \mathrm{C}$ fired BSCF and (c) $1100^{\circ} \mathrm{C}$ fired BSCF in air containing 0.03 to 0.30 bar of $\mathrm{H}_{2} \mathrm{O}$ at $600^{\circ} \mathrm{C}$. (Note for $\mathrm{BSCF}$, the water response is different when it was fired at higher temperature probably due to the reaction/mutual diffusion between BSCF and BCY electrolyte). Adapted from Grimaud et al. [20]

The decrease in cathode interfacial resistance for $1000^{\circ} \mathrm{C}$ fired $\mathrm{BSCF}$ cathode symmetrical cell with increasing $p \mathrm{H}_{2} \mathrm{O}$ was attributed by the authors to the acceleration of cathode reaction by the water insertion to the BSCF cathode. Such water insertion for BSCF was hypothesized to be similar to the hydration process in typical proton conducting 
ceramics and thus suggested that BSCF is a possible proton conductor. In comparison, LSCF, which showed negligible water uptake, was believed to be only an oxide-ion conductor. The cathode reaction was observed to slow down upon increasing water concentration, this was attributed to the water adsorption near TPB of cathode that blocked oxygen adsorption and transport.

On the other hand, it was noticed that when BSCF was fired at higher temperature of $1100^{\circ} \mathrm{C}$, the electrochemical response to water concentration seems to change: almost no decrease in interfacial resistance was observed with increasing $p \mathrm{H}_{2} \mathrm{O}$. Such behavior was attributed to the limited diffusion of water molecules inside the coarser cathode by the authors. However, another possibility is that there might be reaction or mutual diffusion between $\mathrm{BSCF}$ and $\mathrm{BZCYYb}$ at higher temperature of $1100^{\circ} \mathrm{C}$. [72]

Lim et al. (2016) studied the influence of $p \mathrm{O}_{2}$ and $p \mathrm{H}_{2} \mathrm{O}$ on BSCF cathode using proton conducting anode-supported full cell with the configuration of $\mathrm{BSCF} / \mathrm{BaZr} \mathrm{r}_{0.4} \mathrm{Ce}_{0.45} \mathrm{Y}_{0.15} \mathrm{O}_{3-}$ ${ }_{\delta}(\mathrm{BZCY} 40) / \mathrm{Ni}-\mathrm{BZCY} 40$ at $700^{\circ} \mathrm{C} .[131]$ The BSCF cathode was fired at $1100^{\circ} \mathrm{C}$ in this study. As shown in Figure 2. 36, the power output of the cell increased with increasing $p \mathrm{O}_{2}$, and both the bulk and interfacial resistance decreased with the increasing $p \mathrm{O}_{2}$ at cathode side. This was attributed to the accelerated oxygen reduction reaction in cathode. 

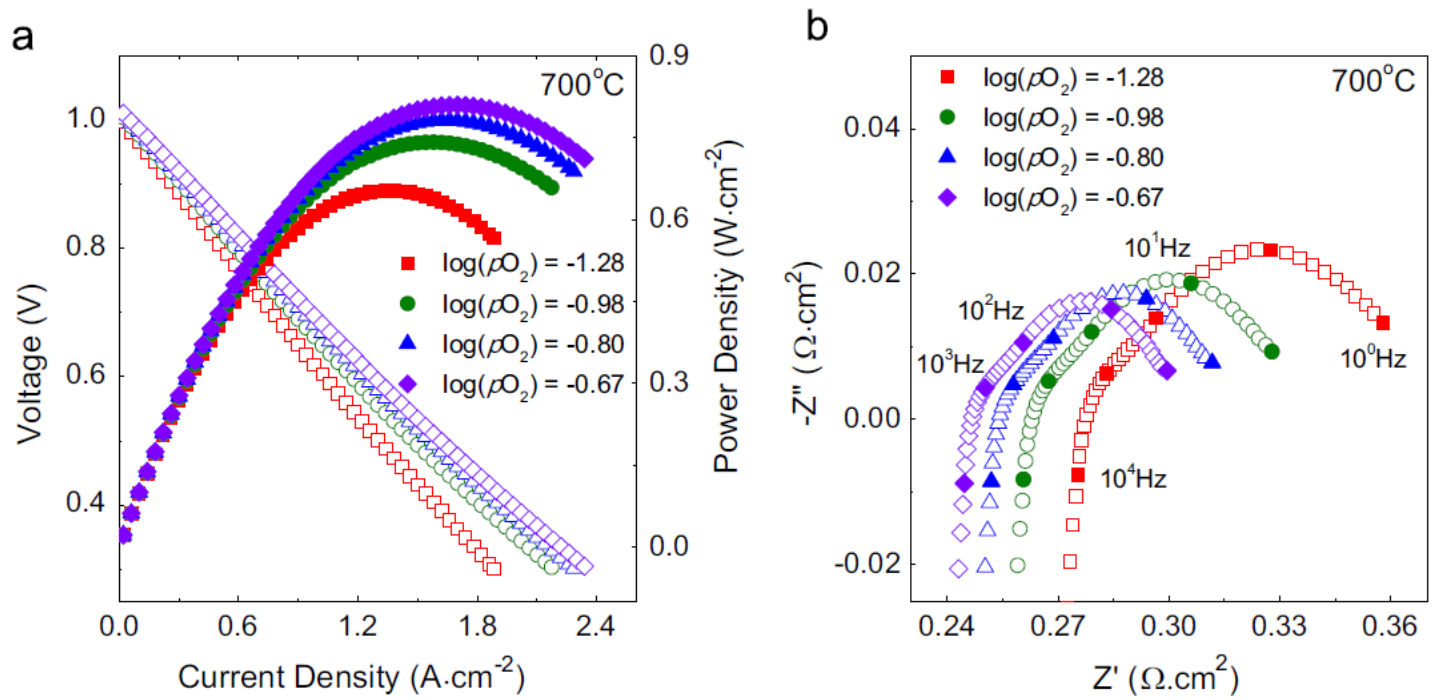

Figure 2. 36 (a) I-V and I-P curves and (b) impedance spectra of the BSCF/ $\mathrm{BaZr}_{0.4} \mathrm{Ce}_{0.45} \mathrm{Y}_{0.15} \mathrm{O}_{3-\delta}(\mathrm{BZCY} 40) / \mathrm{Ni}-\mathrm{BZCY} 40$ cell with various $p \mathrm{O}_{2}$ at $\mathrm{BSCF}$ cathode side at $700^{\circ} \mathrm{C} .[131]$

In addition, decreases in power density was observed for the cell with the introduction of $2.3 \% \mathrm{H}_{2} \mathrm{O}$ on cathode at $700^{\circ} \mathrm{C}$ as shown in Figure 2. 37 (a), which was consistent with the increase in interfacial resistance as shown in Figure 2. 37 (b). The decrease in open circuit voltage with the introduction of $\mathrm{H}_{2} \mathrm{O}$ was also observed. On the other hand, almost no further change in cell voltage, power density and interfacial resistance was observed when $p \mathrm{H}_{2} \mathrm{O}$ was increased from 0.023 atm to 0.054 atm, which was consistent with the observation in previous study by Grimaud et al. at $600^{\circ} \mathrm{C}$ using same $1100^{\circ} \mathrm{C}$ fired $\mathrm{BSCF}$ cathode. The decrease in cell performance with the introduction of water was attributed by the authors to the suppressed water release reaction ( $\left.\operatorname{step}\left(5^{\prime}\right)\right)$ and reduced cathode reaction sites with adsorbed water on TPB of cathode. It's noteworthy that high power density of 
$\sim 800 \mathrm{~mW} / \mathrm{cm}^{2}$ was achieved for the cell in dry atmosphere at $700^{\circ} \mathrm{C}$, which suggests that BSCF is a good cathode on proton conducting IT-SOFC, especially in dry condition.
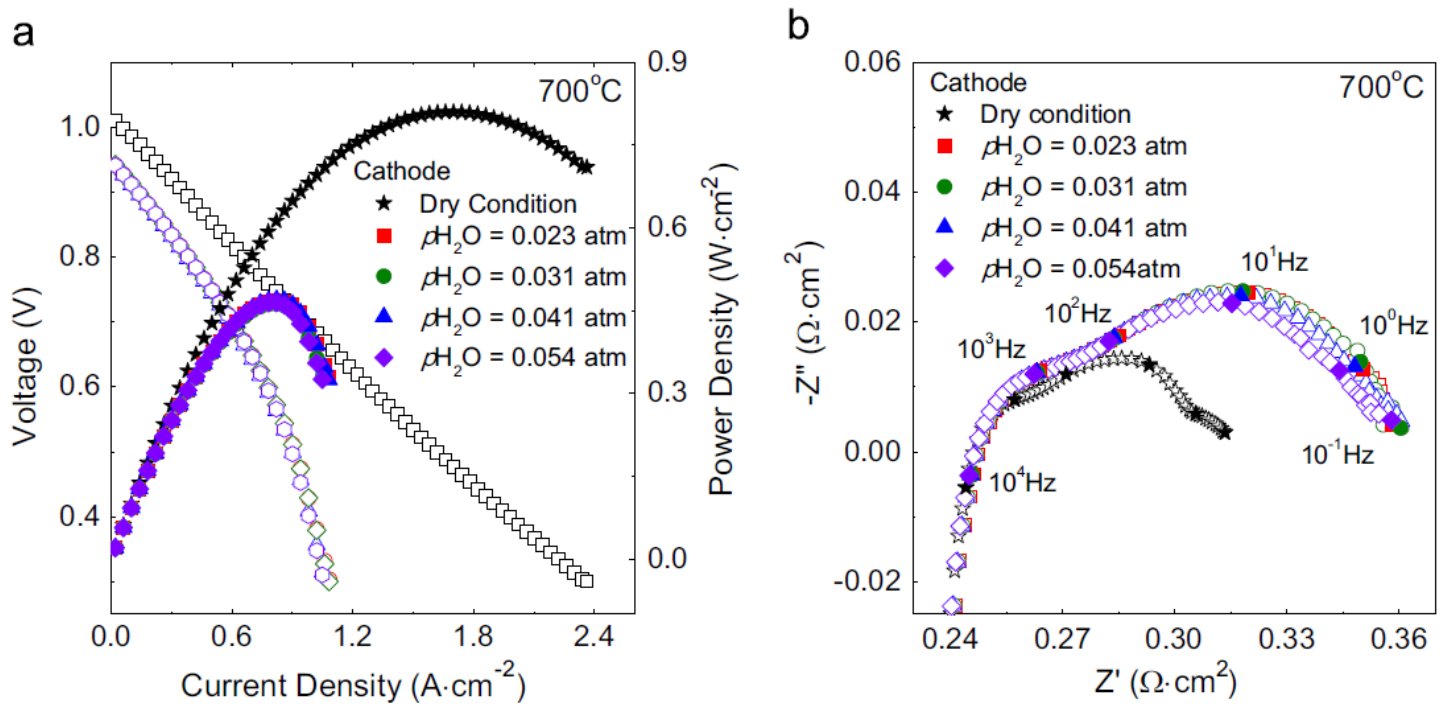

Figure 2. 37 (a) I-V and I-P curves and (b) impedance spectra of the BSCF/ $\mathrm{BaZr}_{0.4} \mathrm{Ce}_{0.45} \mathrm{Y}_{0.15} \mathrm{O}_{3-\delta}(\mathrm{BZCY} 40) / \mathrm{Ni}$ - BZCY40 cell with various $p \mathrm{H}_{2} \mathrm{O}$ at $\mathrm{BSCF}$ cathode side at $700^{\circ} \mathrm{C}$. From Lim et al. [131]

These studies suggest BSCF appears to be a good cathode on proton conducting ITSOFC and the $\mathrm{H}_{2} \mathrm{O}$ effect on the proton conducting cell with BSCF cathode is complicated and thus worth investigating, especially at temperature below $600^{\circ} \mathrm{C}$. In addition, $\mathrm{BSCF}$ is known to have affinity to $\mathrm{CO}_{2}$ and how it will be impacted by air containing $\mathrm{CO}_{2}$ in proton conducting IT-SOFC is worth studying. 
- Recent alternative cathodes

Additionally, some recent alternative cathodes, including transition-metal-doped derivative of the PCC (e.g. $\mathrm{BaZr}_{\mathrm{x}} \mathrm{Y}_{1-\mathrm{x}} \mathrm{O}_{3-\delta}(\mathrm{BZY})$ ), are believed to be mixed electronic and protonic conductive due to the existence of transition-metal cations ( $\mathrm{Co}$ and $\mathrm{Fe}$ ) dopants and protonic conductivity due to the original PCC material. Several representative studies are described below.

Shang et al. (2013) studied $\mathrm{BaCo}_{0.4} \mathrm{Fe}_{0.4} \mathrm{Zr}_{0.2} \mathrm{O}_{3-\delta}$ (BCFZ) as a possible mixed electronic and protonic conducting cathode using both proton conducting cathode symmetrical cell and anode-supported full cell based on BZCYYb electrolyte. [132] In addition, cells with LSCF cathode were adopted as the comparison. As shown in Figure 2. 38, the BCFZ cathode symmetrical cell showed the lowest interfacial resistances in air containing $3 \% \mathrm{H}_{2} \mathrm{O}$ at $650-400^{\circ} \mathrm{C}$ compared to the same cell in dry air and the LSCF cathode symmetrical cell. The reduced interfacial resistance of BCFZ cathode with the introduction of water was attributed to the enhancement in cathode conductivity with the introduced protonic conductivity from hydration reaction. 


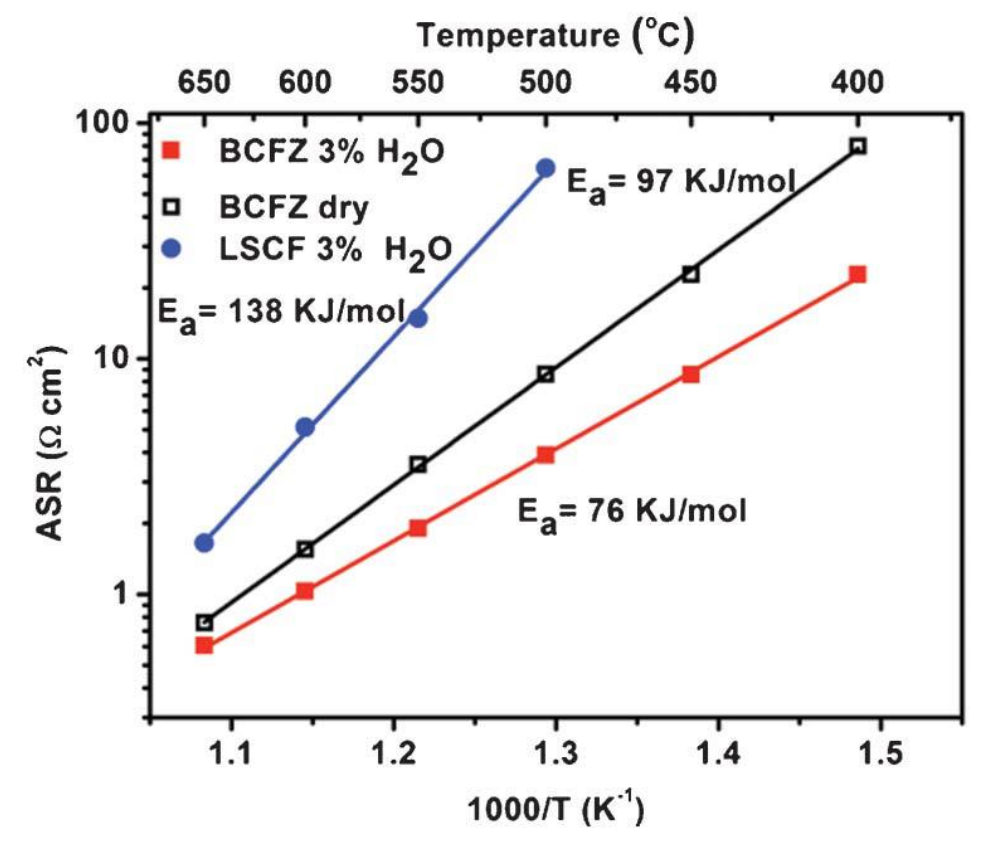

Figure 2. 38 ASR temperature dependence for BCFZ (with water and without water) vs. LSCF. From Shang et al. [132]

In addition, the power output of both BCFZ/ BZCYYb/ Ni-BZCYYb and LSCF/BZCYYb/Ni-BZCYYb proton conducting anode-supported cells were tested. The cell with BCFZ cathode showed much higher maximum power density compared to the cell with LSCF cathode as shown in Figure 2. 39. However, it's noteworthy that the power density of the cell with LSCF cathode in studies is much lower than the similar anodesupported full cell (with the configuration of LSCF/BZCY/Ni-BZCY) as mentioned above by Yang et al. 

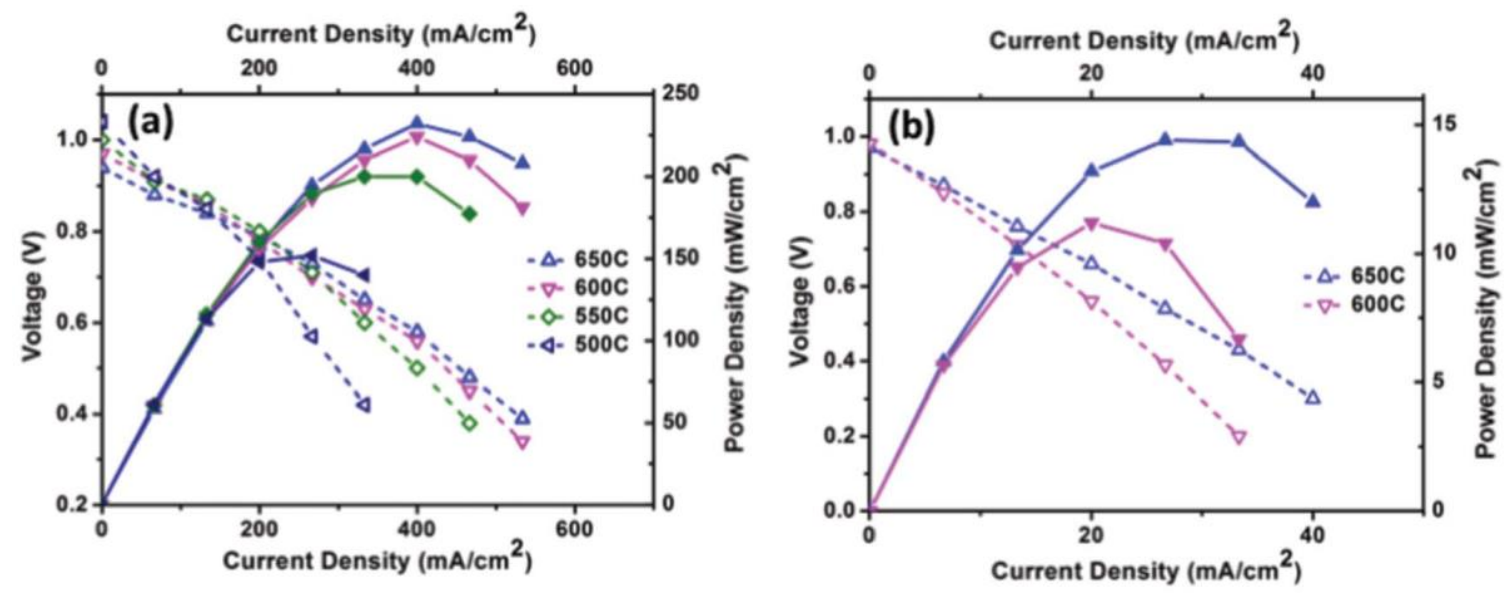

Figure 2. 39 Performance of the as-prepared single cells under hydrogen/air at different temperatures. (a) Cell with BCFZ cathode; (b) cell with LSCF cathode. From Duan et al. [132]

Duan et al. (2015) studied another cathode $\mathrm{BaCo}_{0.4} \mathrm{Fe}_{0.4} \mathrm{Zr}_{0.1} \mathrm{Y}_{0.1} \mathrm{O}_{3-\delta}$ (BCFZY) for proton conducting IT-SOFC based on BZCYYb electrolyte. [133] As shown in Figure 2. 40 , high power density of $\sim 650 \mathrm{~mW} / \mathrm{cm}^{2}$ was achieved at $600^{\circ} \mathrm{C}$, suggesting BCFZY is a good cathode on BZCYYb proton conducting IT-SOFC. In addition, very fine grain size of $\sim 100 \mathrm{~nm}$ was observed for the $900^{\circ} \mathrm{C}$ fire BCFZY cathode even after 1100 hours of operation. The great performance of the cell can be partially attributed to the fine microstate of the BCFZY cathode, which significantly increase the reaction sites on the cathode. 

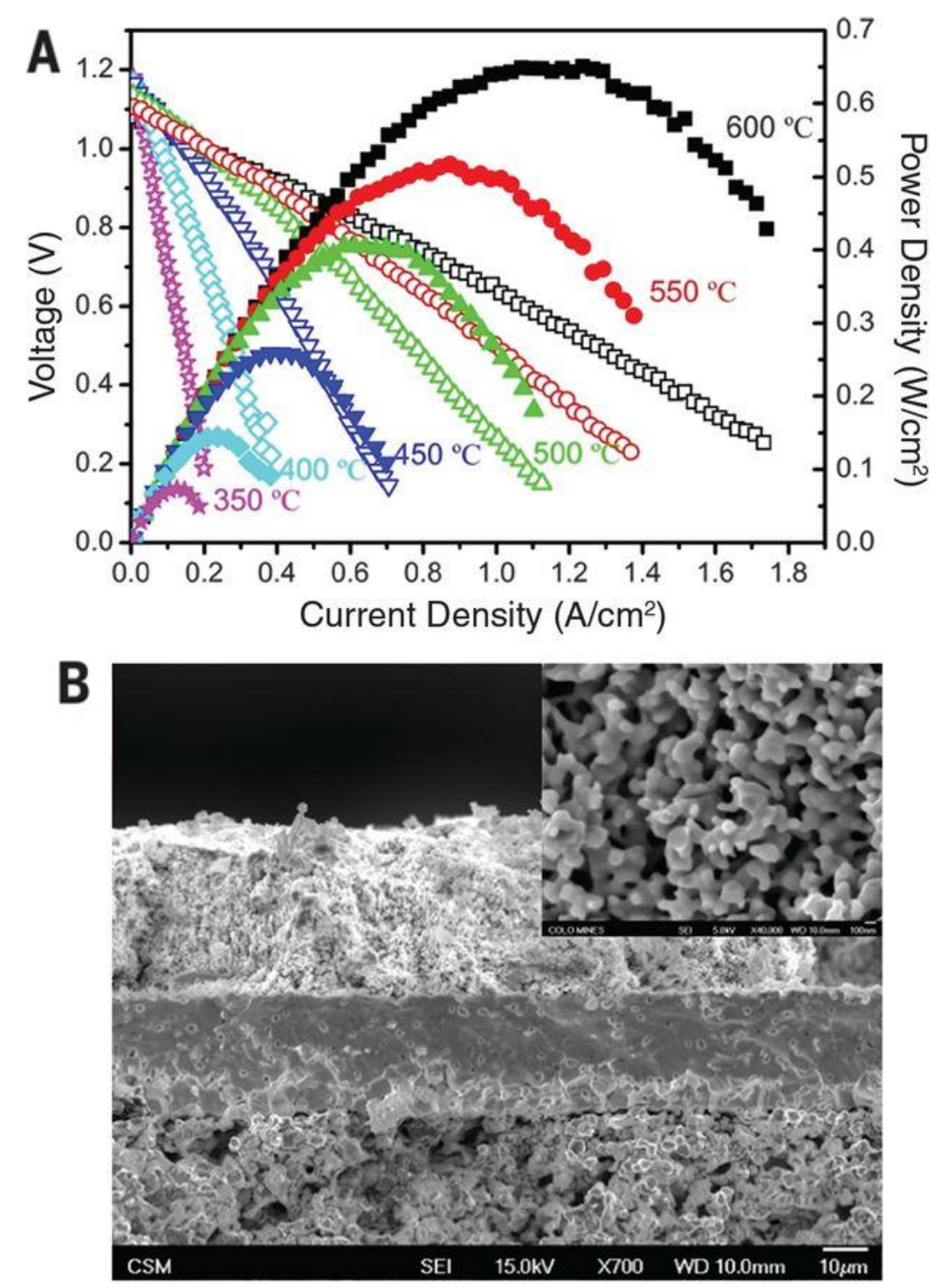

Figure 2. 40 (A) I-V and power density of the BCFZY/BZCYYb/Ni-BZCYYb anodesupported cell at $600-350^{\circ} \mathrm{C}$ (B) a cross-sectional view of the cell after operation for over 1100 hours (inset figure is the high-magnification view of BCFZY0.1 cathode after 1100 hours operation). Adapted from Duan et al. [133] 


\section{Chapter III: $\mathrm{H}_{2} \mathrm{~S}$ Poisoning Behavior for the Anode of Proton Conducting IT-SOFC}

This chapter details the study on the $\mathrm{H}_{2} \mathrm{~S}$ poisoning behavior for the anode of proton conducting IT-SOFC. This chapter is based on published paper by Shichen Sun, Osama Awadallah, and Zhe Cheng. Title of "Poisoning of Ni-based anode for proton conducting SOFC by $\mathrm{H} 2 \mathrm{~S}, \mathrm{CO} 2$, and $\mathrm{H} 2 \mathrm{O}$ as fuel contaminants." in Journal of Power Sources 378 (2018): 255-263 and published paper by Shichen Sun, and Zhe Cheng. Title of "H2S Poisoning of Proton Conducting Solid Oxide Fuel Cell and Comparison with Conventional Oxide-Ion Conducting Solid Oxide Fuel Cell." in Journal of The Electrochemical Society 165.10 (2018): F836-F844.

\subsection{Introduction}

Solid oxide fuel cell (SOFC) has shown great potential as an alternative power source due to its high energy conversion efficiency, high power density, and the ability to utilize readily available hydrocarbon fuels such as natural gas and coal gas, which are easier than pure hydrogen to transport and store in most areas. Recently intermediate temperature SOFC (IT-SOFC) has drawn growing attention due to higher overall thermodynamic efficiency and the possibility for lower cost and slower degradation from expanded choices of low-cost interconnect and sealing materials and reduced rate of corrosion and other unwanted reactions when the operating temperature is reduced from $\sim 750-1000^{\circ} \mathrm{C}$ for conventional SOFC to the range of $\sim 400-600^{\circ} \mathrm{C}$. $[12,13,134-136]$ 
Among various types of possible electrolyte materials for IT-SOFC, proton conducting ceramics (PCC), for example, $\mathrm{BaZr}_{0.1} \mathrm{Ce}_{0.7} \mathrm{Y}_{0.2-\mathrm{x}} \mathrm{Yb}_{\mathrm{x}} \mathrm{O}_{3-\delta}$ (BZCYYb), [15, 82, 84, 87-89] have become popular due to their high ionic conductivity at intermediate temperatures compared to conventional oxide-ion conducting electrolytes and the absence of anode-side fuel dilution. However, the change in anode reaction mechanism from oxide-ion conducting SOFC to proton conducting IT-SOFC has not been well studied yet. For example, previous studies have revealed that the anode for proton conducting IT-SOFC, which are based on cermet anodes consisting of Ni and PCC electrolyte material, seem to show better tolerance against poisoning by low parts-per-million (ppm)-level $\mathrm{H}_{2} \mathrm{~S}$ than conventional oxide-ion conducting SOFC. [15, 38, 100, 137] In particularly, for the cermet anode of conventional oxide-ion SOFC based on $\mathrm{Ni}$ and oxide-ion conducting electrolyte material (e.g. YSZ), the $\mathrm{H}_{2} \mathrm{~S}$ poisoning effect was severe: as little as 0.05 ppm-level of $\mathrm{H}_{2} \mathrm{~S}$ in $\mathrm{H}_{2}$ could cause significant poisoning at $750^{\circ} \mathrm{C}$. [138] While for the cermet anode of proton conducting IT-SOFC, no significant poisoning behavior was observed with the introduction of 5ppm of $\mathrm{H}_{2} \mathrm{~S}$ into humidified $\mathrm{H}_{2}$ fuel. [15] The reason for such change in poisoning behavior has not been systematically studied, especially at intermediate temperatures of $\sim 400-600^{\circ} \mathrm{C}$.

Therefore, in this study, the electrochemical behaviors of the anode for proton conducting IT-SOFC upon exposure to ppm-level $\mathrm{H}_{2} \mathrm{~S}$ as contaminants in hydrogen fuel are investigated based on both anode-supported and electrolyte-supported proton conducting SOFC (PC-SOFC) full cell, and Ni-based anode symmetrical cells using both proton conducting electrolyte (BZCYYb) and oxide-ion conducting electrolyte (YSZ). 
The aim is to gain a better understanding of the electrochemical responses of proton conducting IT-SOFC to $\mathrm{H}_{2} \mathrm{~S}$ poison and the differences in $\mathrm{H}_{2} \mathrm{~S}$ poisoning behaviors between PC-SOFC versus conventional oxide-ion conducting SOFC (OC-SOFC).

Besides that, series of chemical exposure tests on both loose Ni-BZCYYb powder and dense Ni-BZCYYb composite pellets were carried out to simulate the interaction between $\mathrm{H}_{2} \mathrm{~S}$ and the cermet anode for proton conducting IT-SOFC under various conditions followed by characterization techniques such as X-Ray Diffraction (XRD), scanning electron microscopy (SEM), energy dispersive spectroscopy (EDS) and secondary ion mass spectroscopy (SIMS).

The results from these experiments will be presented and their implications on the anode reaction mechanism and kinetics, as well as the possible electrocatalytic role PCC play in the anode reaction for proton conducting IT-SOFC will be discussed.

\subsection{Experimental}

\subsubsection{Powder Synthesis and Cell Fabrication}

In this study, $\mathrm{BaZr}_{0.1} \mathrm{Ce}_{0.7} \mathrm{Y}_{0.1} \mathrm{Yb}_{0.1} \mathrm{O}_{3-\delta}(\mathrm{BZCYYb})$ was chosen as the proton conducting ceramic (PCC) electrolyte, which was synthesized by glycine nitrate process (GNP) process. [89] Briefly, salts of $\mathrm{Ba}\left(\mathrm{NO}_{3}\right)_{2}$ (\#A11305, Alfa Aesar, 99\%), $\mathrm{ZrO}\left(\mathrm{NO}_{3}\right)_{2} \bullet x \mathrm{H}_{2} \mathrm{O}$

(\#43224, Alfa Aesar, 99.9\%), $\mathrm{Ce}\left(\mathrm{NO}_{3}\right)_{3} \cdot 6 \mathrm{H}_{2} \mathrm{O}$ (\#11329, Alfa Aesar, 99.5\%), $\mathrm{Y}\left(\mathrm{NO}_{3}\right)_{3} \cdot 6 \mathrm{H}_{2} \mathrm{O}\left(\# 12898\right.$, Alfa Aesar, 99.9\%), and $\mathrm{Yb}\left(\mathrm{NO}_{3}\right)_{3} \bullet \mathrm{xH}_{2} \mathrm{O}$ (\#12901, Alfa Aesar, 99.9\%) were dissolved in hot DI water (set at $\sim 100^{\circ} \mathrm{C}$ ) together with glycine (\#G8898, 
Sigma Aldrich, 99+\%). The molar ratio was 1: 1 between glycine and total metal ions. The solution was then heated up on a hotplate set at $\sim 540^{\circ} \mathrm{C}$. After the self-combustion process, the fine powder produced was collected and then calcined in ambient air at $1100^{\circ} \mathrm{C}$ for 5 hours to form the pure perovskite phase. The cathode material used in this study is $\mathrm{La}_{0.6} \mathrm{Sr}_{0.4} \mathrm{Co}_{0.2} \mathrm{Fe}_{0.8} \mathrm{O}_{3-\delta}$ (LSCF) and the synthesis steps are similar to that for $\mathrm{BZCYYb}$ except the starting materials were changed to $\mathrm{La}\left(\mathrm{NO}_{3}\right)_{3}$ (\#A11305, Alfa Aesar, 99\%), $\mathrm{Sr}\left(\mathrm{NO}_{3}\right)_{2}$ (\#31633, Alfa Aesar, 99\%), $\mathrm{Fe}\left(\mathrm{NO}_{3}\right)_{3} \cdot 9 \mathrm{H}_{2} \mathrm{O}$ (\#216828, Alfa Aesar, 99\%), $\mathrm{Co}\left(\mathrm{NO}_{3}\right)_{2} \cdot 6 \mathrm{H}_{2} \mathrm{O}(\# 239267$, Alfa Aesar, 99\%). After self-combustion, the powder was calcined at $1000^{\circ} \mathrm{C}$ for 2 hours in ambient air to form the pure perovskite phase. [139]

Anode-supported PC-SOFC full cells with the configuration of $\mathrm{Ni}$ BZCYYb/BZCYYb/LSCF-BZCYYb were fabricated. First, anode precursor/electrolyte bilayer was prepared via dry-pressing using $0.2 \mathrm{~g}$ NiO-BZCYYb-starch powder mixture with weight ratio of 5.5: 3.5: 1 and $10 \mathrm{mg}$ BZCYYb electrolyte powder in a $10 \mathrm{~mm}$ diameter die at a pressure of $250 \mathrm{MPa}$. The pellets of anode precursor/electrolyte bilayer were then sintered at $1400^{\circ} \mathrm{C}$ for 5 hours with heating and cooling rate of $5^{\circ} \mathrm{C} / \mathrm{min}$ (anode side facing down touching alumina crucible support while electrolyte side facing up). [89] The cathode slurry was prepared by mixing powders of LSCF and BZCYYb and polymer binder solution (containing 8wt\% polymer) with LSCF: BZCYYb: polymer binder solution weight ratio of 7: 3: 15, followed by ball-milling for 24 hours. The cathode was brushpainted onto the electrolyte side of the sintered anode/electrolyte bilayer pellets using the LSCF-BZCYYb slurry. The painted cathode area was $\sim 0.16 \mathrm{~cm}^{2}$, and it was dried in an air oven at $150^{\circ} \mathrm{C}$ and then calcined at $1100^{\circ} \mathrm{C}$ for 2 hours in ambient air with heating and 
cooling rate of $5^{\circ} \mathrm{C} / \mathrm{min}$. Finally, silver mesh and wires were attached to the electrodes using pure silver paste for current collection.

For the electrolyte-supported PC-SOFC full cells with the configuration of Ni$\mathrm{BZCYYb} / \mathrm{BZCYYb} / \mathrm{LSCF}-\mathrm{BZCYYb}$, the fabrication process is described as following: First, an electrolyte pellet was prepared via dry-pressing $0.2 \mathrm{~g} \mathrm{BZCYYb}$ powder in a 10 $\mathrm{mm}$ diameter die at a pressure of $250 \mathrm{MPa}$ followed by sintering at $1550^{\circ} \mathrm{C}$ for 5 hours in air with heating and cooling rate of $5^{\circ} \mathrm{C} / \mathrm{min}$ in a so called "protected sintering" configuration. [89] Second, the anode slurry was brushed-painted onto one side of the sintered electrolyte pellet. The anode slurry was made by mixing NiO, BZCYYb and organic binder solution (with polymer concentration of $8 \mathrm{wt} . \%$, same for below) at a weight ratio of 3: 2: 5 followed by heat treatment in air at $1400^{\circ} \mathrm{C}$ for 2 hours at a heating and cooling rate of $5^{\circ} \mathrm{C} / \mathrm{min}$. Finally, LSCF-BZCYYb cathode slurry, with a LSCF: BZCYYb : organic binder solution weight ratio of $6.5: 3.5: 10$ was brush-painted onto the other side of the pellet and then calcined at $1100^{\circ} \mathrm{C}$ for 2 hours in ambient air with a heating and cooling rate of $5^{\circ} \mathrm{C} / \mathrm{min}$. [138] Both the cathode and anode area were $\sim 0.16 \mathrm{~cm}^{2}$. For subsequent electrochemical test, silver mesh and wires were attached to the electrodes using pure silver paste for current collection.

In addition, both anode symmetrical PC-SOFC with the configuration of NiBZCYYb/BZCYYb/Ni-BZCYYb and anode symmetrical OC-SOFC with the configuration of Ni-YSZ/YSZ/Ni-YSZ were fabricated as described below. The anode symmetrical PC-SOFC were fabricated by first dry pressing $0.1 \mathrm{~g}$ of BZCYYb powder into $10 \mathrm{~mm}$ diameter pellets at a pressure of $250 \mathrm{MPa}$. The electrolyte pellets were then sintered 
at $1550^{\circ} \mathrm{C}$ for 5 hours under "protected condition" with heating and cooling rate of $5^{\circ} \mathrm{C} / \mathrm{min}$. [38] Then, the anode slurry was made by mixing NiO, BZCYYb, and polymer binder solution (polymer content of $8 \%$ ) at weight ratio of $5.5: 3.5: 9$. After that, symmetrical anodes were painted onto both sides of the sintered electrolyte pellet followed by drying in an air oven at $100^{\circ} \mathrm{C}$ and then calcination at $1400^{\circ} \mathrm{C}$ for 2 hours in ambient air with heating and cooling rate of $5^{\circ} \mathrm{C} / \mathrm{min}$. For the anode symmetrical OC-SOFC, first, $0.1 \mathrm{~g}$ of YSZ powder (\#312022, FuelCellMaterials, 8 mol. $\% \mathrm{Y}_{2} \mathrm{O}_{3}$ doping, USA) was dry pressed into a $10 \mathrm{~mm}$ diameter pellet at a pressure of $120 \mathrm{MPa}$. Then, the YSZ electrolyte pellet was sintered in air at $1550^{\circ} \mathrm{C}$ for 5 hours with a heating and cooling rate of $5^{\circ} \mathrm{C} / \mathrm{min}$. Anode slurry was made by mixing $\mathrm{NiO}, \mathrm{YSZ}$, and polymer binder solution at a weight ratio of 3 : $2: 5$. After that, symmetrical anodes were painted onto both sides of the sintered YSZ electrolyte pellet followed by drying in an air oven at $100^{\circ} \mathrm{C}$ and then calcination at $1400^{\circ} \mathrm{C}$ for 2 hours in ambient air with a heating and cooling rate of $5{ }^{\circ} \mathrm{C} / \mathrm{min}$. For both anode symmetrical cells, silver meshes were attached onto both electrodes using pure silver paste for current collection.

\subsubsection{Testing of the Effects of $\mathrm{H}_{2} \mathrm{~S}$ on Electrochemical Cells}

For electrochemical testing of PC-SOFC full cells (anode-supported and electrolytesupported), the cells were first sealed onto one end of an alumina support tube using ceramic sealant (Aremco 552, USA) and placed in the hot zone of a tube furnace. [140] Then the cell was heated up to $750^{\circ} \mathrm{C}$, during which the anode-side was purged with pure nitrogen ( $\mathrm{N}_{2}$ ) (UHP grade, Airgas, USA) while the cathode side was exposed to ambient 
air. At $750^{\circ} \mathrm{C}$, clean dry hydrogen $\left(\mathrm{H}_{2}\right)$ (UHP grade, Airgas, USA) was introduced into the anode side at a flow rate of $40 \mathrm{~mL} / \mathrm{min}$, and $\mathrm{NiO}$ in the anode was reduced to $\mathrm{Ni}$. After the anode reduction, electrochemical measurements including electrochemical impedance spectroscopy (EIS) measurements and cell voltage measurement under constant current were carried out using a potentiostat (Interface 1000, Gamry, USA). For EIS measurements, the frequency range was set from $10^{-2} \mathrm{~Hz}$ to $10^{6} \mathrm{~Hz}$ with $\mathrm{AC}$ amplitude of $0.1 \mathrm{~mA}$.

To characterize the effects of $\mathrm{H}_{2} \mathrm{~S}$ on the electrochemical responses of the anodesupported PC-SOFC, low ppm-level $\mathrm{H}_{2} \mathrm{~S}$ was introduced into the $\mathrm{H}_{2}$ fuel while keeping the total fuel flow rate the same. (In particular, 38.7-36 mL/min of $\mathrm{H}_{2}$ gas was passed through a water bubbler at room temperature and then 1.3-4 $\mathrm{mL} / \mathrm{min}$ of $100 \mathrm{ppm}_{2} \mathrm{~S}$ balanced by $\mathrm{H}_{2}$ gas mixture (Airgas, USA) was combined with the humidified $\mathrm{H}_{2}$ stream before being introduced into the anode chamber to get the corresponding concentration of $\mathrm{H}_{2} \mathrm{~S}$, All fuel gas concentrations mentioned in this study for various gas mixtures are by volume at room temperature before entering the anode chamber.) For anode-supported SOFC full cells, the change in cell voltage was monitored continuously at a constant current density of 125 $\mathrm{mA} / \mathrm{cm}^{2}$, and EIS was recorded before, after 2 hours of exposure to ppm-level $\mathrm{H}_{2} \mathrm{~S}$, and after removal of $\mathrm{H}_{2} \mathrm{~S}$ for 24 hours under both open circuit condition and biased condition of $0.7 \mathrm{~V}$. In addition, in order to reveal the impact of $\mathrm{H}_{2} \mathrm{O}$ including how $\mathrm{H}_{2} \mathrm{O}$ influences the $\mathrm{H}_{2} \mathrm{~S}$ poisoning behavior, in some cases, $\mathrm{H}_{2}$ gas was passed through a water bubbler at room temperature before being introduced into the anode chamber. 
To characterize the effects of $\mathrm{H}_{2} \mathrm{~S}$ on the electrochemical responses of the electrolytesupported $\mathrm{PC}-\mathrm{SOFC}$, at each temperature $\left(750,650,550\right.$ and $\left.450^{\circ} \mathrm{C}\right), 3-10 \mathrm{ppm}_{2} \mathrm{~S}$ was introduced into the humidified $\mathrm{H}_{2}$ fuel while keeping the total fuel flow rate the same. The changes in cell voltage under constant currents densities $\left(35,35,6\right.$ and $2 \mathrm{~mA} / \mathrm{cm}^{2}$ at testing temperatures of $750,650,550$ and $450^{\circ} \mathrm{C}$, respectively) were recorded. In addition, EIS spectra were recorded before and after 2 hours of exposure to low ppm-level $\mathrm{H}_{2} \mathrm{~S}$.

For testing of both anode-symmetrical PC-SOFC and OC-SOFC, they were placed in the hot zone inside a one-end closed ceramic tube with gas fed directly to the cell. The symmetrical cells were also heated up in $\mathrm{N}_{2}$ to $750^{\circ} \mathrm{C}$ and then reduced in pure $\mathrm{H}_{2}$ at $750^{\circ} \mathrm{C}$. EIS under open circuit condition were recorded in humidified $\mathrm{H}_{2}(\sim 3 \%$ moisture, labelled as wet $\mathrm{H}_{2}$ in this study) and in wet $\mathrm{H}_{2}$ containing $10 \mathrm{ppm}$ of $\mathrm{H}_{2} \mathrm{~S}$ at temperatures of 750 , 650 , and $550^{\circ} \mathrm{C}$. The detailed testing sequence was as following: EIS was first recorded in clean wet $\mathrm{H}_{2}$ from $750^{\circ} \mathrm{C}$ all the way to $550^{\circ} \mathrm{C}$, and the cell was then heated up to $750^{\circ} \mathrm{C}$ in wet $\mathrm{H}_{2}$. After that, $10 \mathrm{ppm} \mathrm{H}_{2} \mathrm{~S}$ was introduced into the wet $\mathrm{H}_{2}$ and EIS was recorded again after 2 hours of holding at each temperature $\left(750,650\right.$, and $\left.550^{\circ} \mathrm{C}\right)$.

\subsubsection{Stability Tests of Ni-BZCYYb Mixed Powders}

To study the chemical stability of Ni-BZCYYb cermet anode under relevant testing conditions and understand the observed electrochemical responses to $\mathrm{H}_{2} \mathrm{~S}$, a series of experiments were carried out by exposing NiO-BZCYYb loose powder mixtures (5.5: 3.5

weight ratio) after hydrogen reduction to ppm-level $\mathrm{H}_{2} \mathrm{~S}$ as fuel contaminants in both $\sim 3 \%$ 
humidified and dry $\mathrm{H}_{2}$. In each set of tests, $10 \mathrm{mg}$ of $\mathrm{NiO}-\mathrm{BZCYYb}$ powder mixture was placed in an alumina boat in a one-end closed tube with fuel gas mixture directly fed to the sample surface. As in electrochemical testing, the samples were first heated up in $\mathrm{N}_{2}$ to $750^{\circ} \mathrm{C}$. Then $\mathrm{NiO}$ in the mixture was reduced to $\mathrm{Ni}$ in dry $\mathrm{H}_{2}$ for 30 minutes. After that, the samples were cooled down to $550^{\circ} \mathrm{C}$, and $10 \mathrm{ppm}_{2} \mathrm{~S}$ was introduced into the hydrogen fuel (3\% humidified or nominal dry with $\sim 10 \mathrm{ppm} \mathrm{H}_{2} \mathrm{O}$ ) stream for 24 hours. For comparison purpose, one sample was treated in the same way without the introduction of $\mathrm{H}_{2} \mathrm{~S}$. All post-exposure samples were cooled rapidly (by quickly removing the sample tube from the furnace) in clean $\mathrm{N}_{2}$ to avoid any additional reaction. X-Ray diffraction (SIEMENS diffractometer D5000) was taken for all samples after the exposure tests for phase identification. Besides that, some samples were analyzed using energy dispersive spectroscopy (EDS) equipped on a field emission scanning electron microscope (FE-SEM, JEOL JSM 6330F) for determining the distribution of elements of interest such as $\mathrm{Ba}, \mathrm{Ni}$ and $\mathrm{S}$.

\subsubsection{SIMS Analysis on Ni-BZCYYb Pellet after $\mathrm{H}_{2} \mathrm{~S}$ Exposure}

Since the poisoning process and related mechanism for conventional oxide-ion conducting SOFC with Ni-YSZ cermet anode and YSZ electrolyte are well studied and documented in the literature, $[26,28,29,31,33,137,138]$ the focus here in this study is on the sulfuranode interaction for PC-SOFC. 
Considering the fact that sulfur is well known to adsorb strongly over Ni surface without formation of bulk nickel sulfides under these conditions with different extent of coverage depending on the exact temperature and $\mathrm{H}_{2} \mathrm{~S}$ concentration, $[25,28]$ the issue of particular interest here is the interaction between the BZCYYb PCC electrolyte and $\mathrm{H}_{2} \mathrm{~S}$ under the testing condition. SIMS is very sensitive and will be complementary to XRD and EDS for the analysis on the surface of Ni-BZCYYb.

To simulate the $\mathrm{H}_{2} \mathrm{~S}$ poisoning effect on Ni-PCC cermet anode, dense Ni-BZCYYb pellets were prepared by mixing Ni (99.8\%, -300 mesh, Alfa Aesar, USA) and BZCYYb powder with the weight ratio of $6: 4$ and pressing into a $10 \mathrm{~mm}$ diameter pellet at the pressure of $100 \mathrm{MPa}$. The pressed pellet was then sintered at $1350^{\circ} \mathrm{C}$ in $4 \% \mathrm{H}_{2}$ balanced by argon (Ar) (UHP grade, Airgas, USA) for 5 hours to avoid possible oxidation. For further characterizations, the sintered pellets were ground and polished to achieve a smooth surface. After that, the polished pellet was exposed to $10 \mathrm{ppm}(\mathrm{v}) \mathrm{H}_{2} \mathrm{~S}$ balanced by $\sim 3 \%$ humidified $\mathrm{H}_{2}$ at $550^{\circ} \mathrm{C}$ for 24 hours with subsequent rapid cooling in clean wet $\mathrm{H}_{2}$. Secondary-ion Mass Spectroscopy (SIMS) was then conducted on the post $\mathrm{H}_{2} \mathrm{~S}$-exposure sample surface using an ion time of flight (Ion TOF) - SIMS instrument utilizing Bismuth (III) cation $\left(\mathrm{Bi}^{3+}\right)$ for measurement on fields of view (FOV) between $20-100 \mu \mathrm{m}$. Barium, sulfur, nickel and their corresponding oxides and hydroxides ion species were detected under both positive and negative ion modes for elemental distribution identification and depth profiling. 


\subsection{Results}

\subsection{1 $\mathrm{H}_{2} \mathrm{~S}$ Effect on Ni-BZCYYb/BZCYYb/LSCF Anode-supported PC- SFOC Full Cell}

The impedance spectra at $750^{\circ} \mathrm{C}$ for the Ni-BZCYYb/BZCYYb/LSCF anode-supported PC-SOFC full cell under open circuit condition before and after the introduction of $5 \mathrm{ppm}$ $\mathrm{H}_{2} \mathrm{~S}$ into the $\mathrm{H}_{2}$ fuel is shown in Figure 3. 1. There is very little change in either ohmic resistance $\left(\mathrm{R}_{\mathrm{O}}\right)$ or apparent interfacial resistance $\left(\mathrm{R}_{\mathrm{a} i}\right.$, which is the difference between the high frequency and low frequency intercepts in the impedance curve) with the introduction of $5 \mathrm{ppm} \mathrm{H}_{2} \mathrm{~S}$ to the dry $\mathrm{H}_{2}$ fuel (the so-called "dry" $\mathrm{H}_{2}$ in this study was directly from UHP grade $\mathrm{H}_{2}$ cylinder with $p \mathrm{H}_{2} \mathrm{O}$ of $\sim 10 \mathrm{ppm}$ ). The addition of $3 \%$ moisture to the $\mathrm{H}_{2}$ fuel does not seem to change the overall electrochemical response with respect to introduction of $5 \mathrm{ppm} \mathrm{H}_{2} \mathrm{~S}$ poison, as shown also in Figure 3. 1.

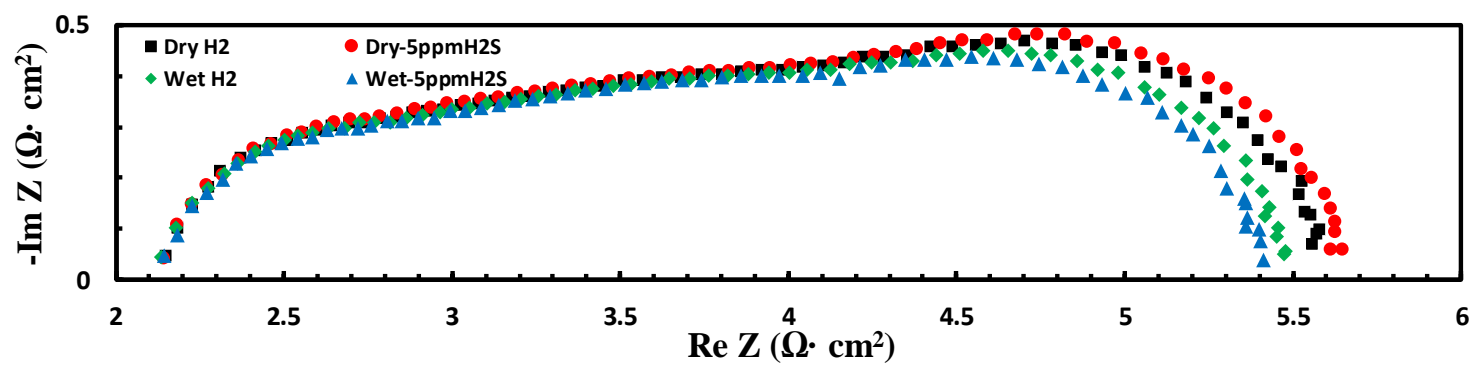

Figure 3. 1 Impedance spectra for a Ni-BZCYYb/BZCYYb/LSCF-BZCYYb anode supported proton-conducting SOFC full cell at $750^{\circ} \mathrm{C}$ showing the effect of introducing 5 ppm $\mathrm{H}_{2} \mathrm{~S}$ as fuel contaminant to the dry $\mathrm{H}_{2}$ (UHP grade $\mathrm{H}_{2}$ with $p \mathrm{H}_{2} \mathrm{O} \approx 10$ ppm; same for all subsequent figures) and 3\% humidified $\mathrm{H}_{2}$ (i.e. $~ 3 \% \mathrm{H}_{2} \mathrm{O}+97 \% \mathrm{H}_{2}$, labelled as wet $\mathrm{H}_{2}$ or simply wet in subsequent figures). 
Figure 3.2 (a) and (b) show the change of cell voltage of the anode-supported full cell under constant current at $750^{\circ} \mathrm{C}$ as a function of time when $5 \mathrm{ppm} \mathrm{H}_{2} \mathrm{~S}$ was introduced into and then later removed from the fuels of dry $\mathrm{H}_{2}$ and $3 \%$ humidified $\mathrm{H}_{2}$, respectively. The PC-SOFC with Ni-BZCYYb anode and BZCYYb electrolyte, despite the gradual degradation (probably due to non-ideal cell fabrication), appears to show no obvious poisoning by the low ppm $\mathrm{H}_{2} \mathrm{~S}$ introduced. Such tolerance to low ppm $\mathrm{H}_{2} \mathrm{~S}$ for proton conducting SOFC is consistent with earlier observations such as that by Yang et al. who reported Ni-BZCYYb/BZCYYb/LSCF anode-supported cells show sulfur tolerance up to $\sim 20 \mathrm{ppm} \mathrm{H}_{2} \mathrm{~S}$ at $750^{\circ} \mathrm{C}$ (see Figure 2. 11).[15] 

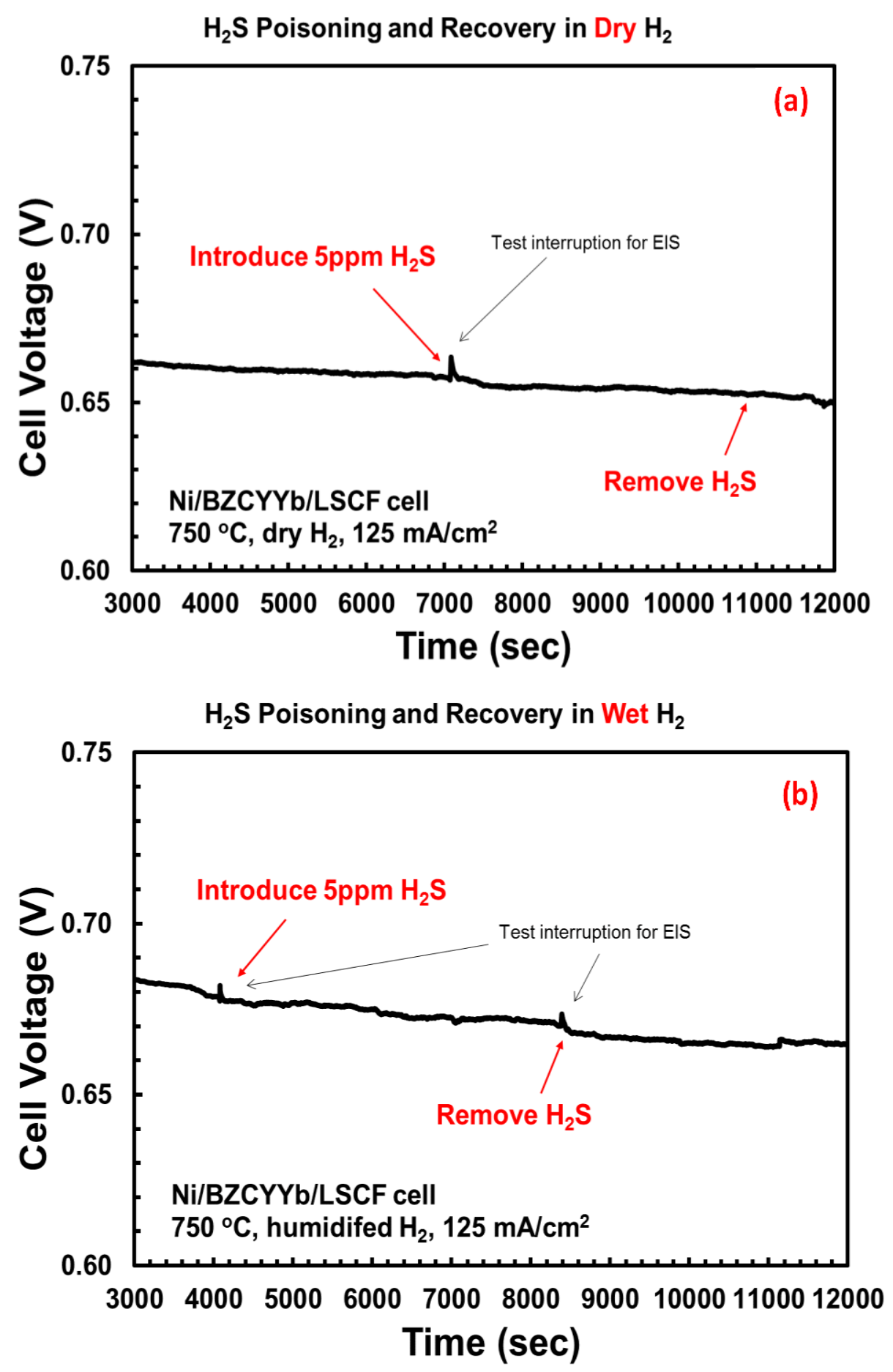

Figure 3. 2 Plots of cell voltage versus time for the Ni-BZCYYb/BZCYYb/LSCFBZCYYb anode-supported PC-SOFC full cell at $750^{\circ} \mathrm{C}$ when $5 \mathrm{ppm}$ of $\mathrm{H}_{2} \mathrm{~S}$ is introduced into and later removed from the fuel of (a) dry $\mathrm{H}_{2}\left(p \mathrm{H}_{2} \mathrm{O} \approx 10 \mathrm{ppm}\right)$ and (b) $3 \%$ humidified $\mathrm{H}_{2}$. 


\subsection{2 $\mathrm{H}_{2} \mathrm{~S}$ Effect on Ni-BZCYYb/BZCYYb/LSCF Electrolyte-supported PC- SOFC Full Cell}

The impedance spectra for the Ni-BZCYYb/BZCYYb/LSCF-BZCYYb electrolytesupported PC-SOFC full cell under open circuit condition with $10 \mathrm{mV}$ AC bias before and after the introduction of 3-10 ppm $\mathrm{H}_{2} \mathrm{~S}$ into the $3 \%$ wet $\mathrm{H}_{2}$ fuel from $750^{\circ} \mathrm{C}$ to $450^{\circ} \mathrm{C}$ are shown in Figure 3. 3. At $750^{\circ} \mathrm{C}$ (Figure 3. 3 (a)), with the introduction of $3 \mathrm{ppm}_{2} \mathrm{~S}$, a small increase (from $1.18 \Omega \cdot \mathrm{cm}^{2}$ to $1.25 \Omega \cdot \mathrm{cm}^{2}$ or $6 \%$ relative) in the total electrode apparent interfacial resistance $\left(\mathrm{R}_{\mathrm{ai}}\right)$ was observed but no change in cell ohmic resistance ( $\mathrm{R}_{\mathrm{O}}$ ), which are similar to the observations for anode-supported PC-SOFC. As $\mathrm{H}_{2} \mathrm{~S}$ concentration increased from $3 \mathrm{ppm}$ to $10 \mathrm{ppm}$, the poisoning effect got slightly more severe. Furthermore, it's noteworthy that the increase in $\mathrm{R}_{\mathrm{ai}}$ is mainly due to the increase in the middle and low frequency (MF and LF, $10^{4}$ to $10^{-2} \mathrm{~Hz}$ ) semicircles, while almost no change was observed for the high frequency $\left(\mathrm{HF}, 10^{6}\right.$ to $\left.10^{4} \mathrm{~Hz}\right)$ semicircles. 

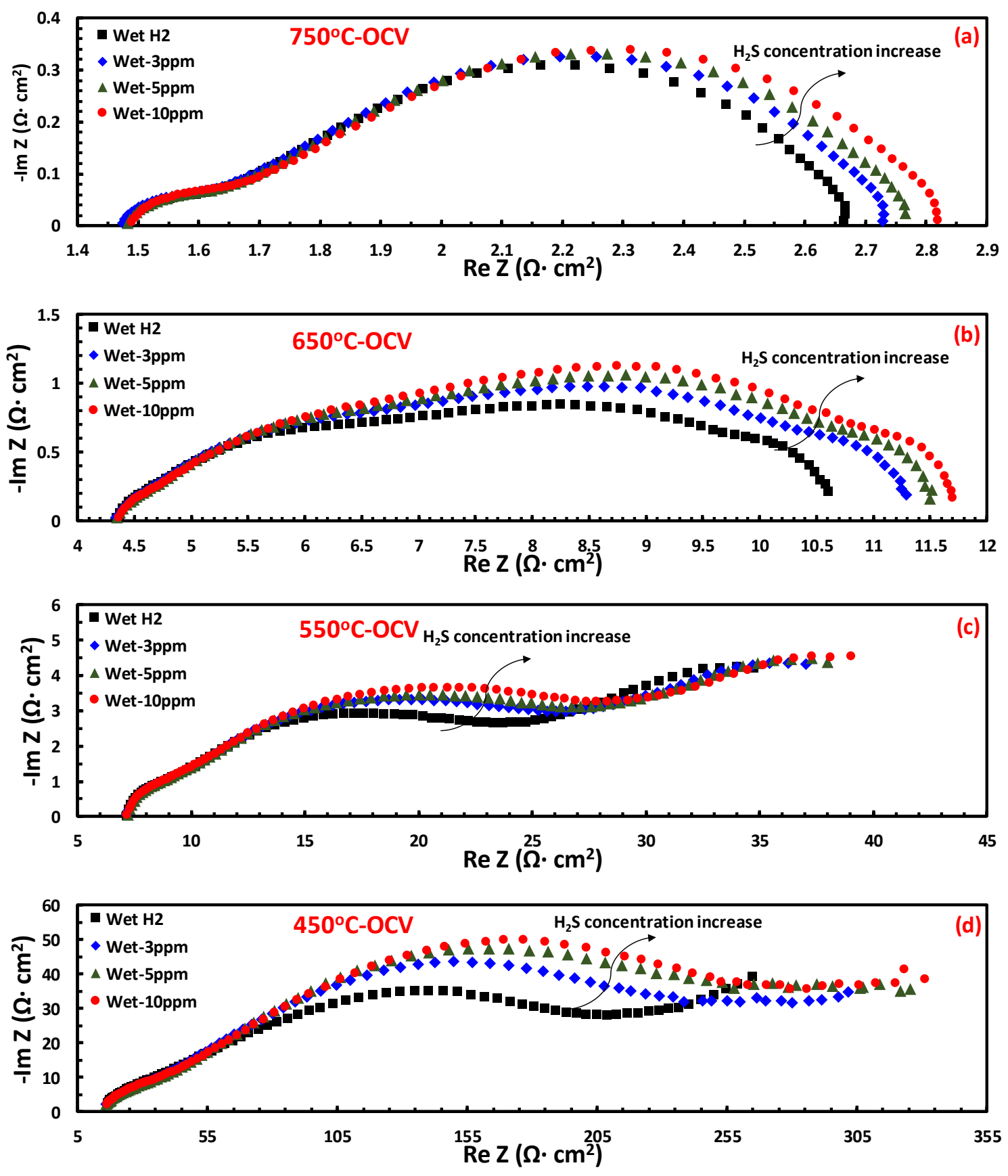

Figure 3. 3 Impedance spectra measured under open circuit condition for a NiBZCYYb/BZCYYb/LSCF-BZCYYb electrolyte-supported PC-SOFC full cell at (a) $750^{\circ} \mathrm{C}$, (b) $650^{\circ} \mathrm{C}$, (c) $550^{\circ} \mathrm{C}$, and (d) $450^{\circ} \mathrm{C}$ showing the effect of introducing $3-10 \mathrm{ppm}$ (by volume) $\mathrm{H}_{2} \mathrm{~S}$ as fuel contaminant to the $\sim 3 \%$ wet $\mathrm{H}_{2}$. 
As temperature decreased to 650,550 and $450^{\circ} \mathrm{C}$, the observed poisoning behaviors by 3-10 ppm $\mathrm{H}_{2} \mathrm{~S}$ of the electrolyte-supported PC-SOFC full cell largely remain unchanged with a small ( 10 to $20 \%)$ yet observable increase in electrode apparent interfacial resistance $\mathrm{R}_{\mathrm{ai}}$ but no change in ohmic resistance $\mathrm{R}_{\mathrm{O}}$, and the increase in $\mathrm{R}_{\mathrm{ai}}$ is limited to the MF-LF semicircles (see Figure 3. 3(b to d)).

Additionally, as shown in Figure 3. 4, the impedance spectra measured under constant current (e.g., $35 \mathrm{~mA} / \mathrm{cm}^{2}$ ) mode do not show obvious difference comparing with those measured under open circuit conditions.
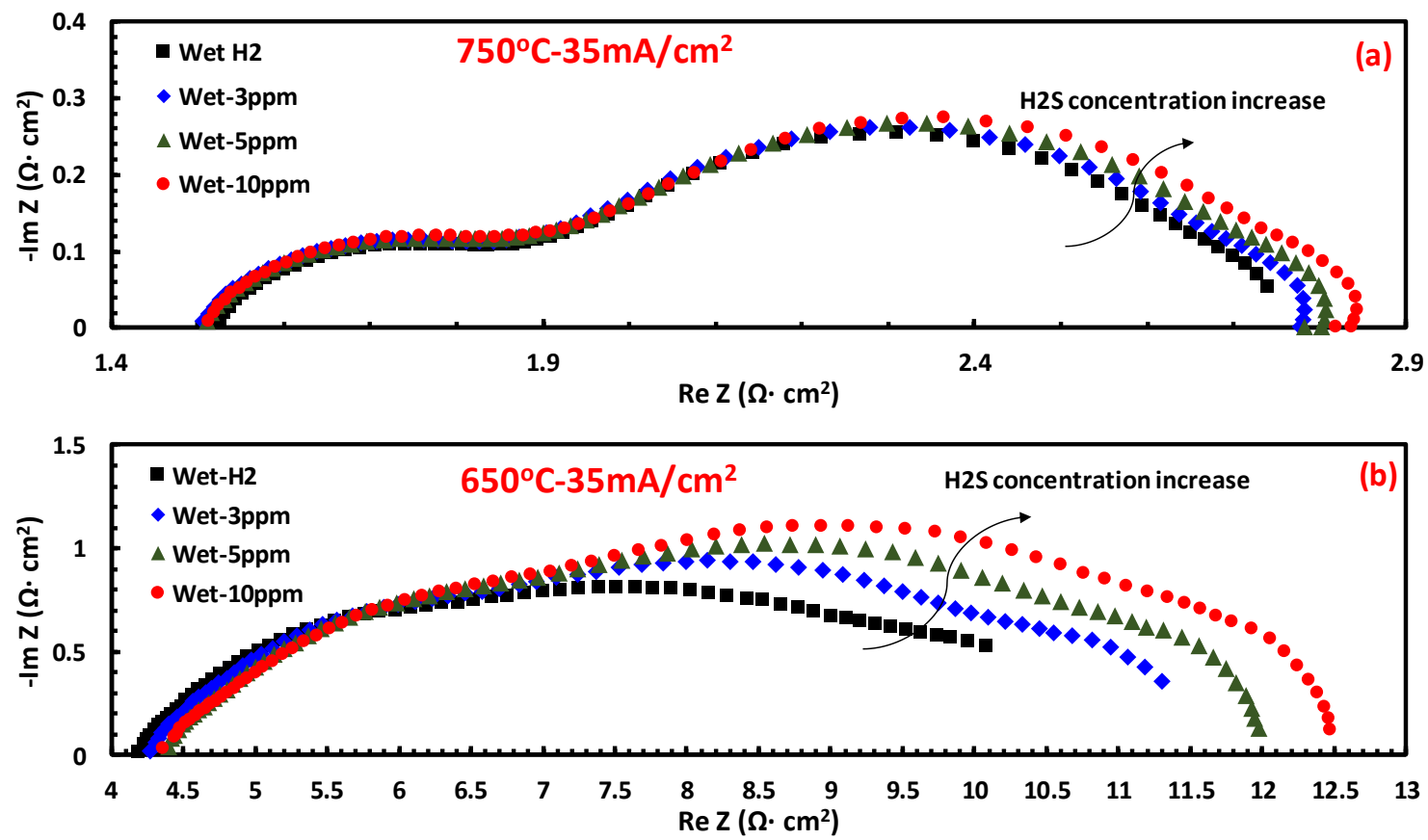

Figure 3. 4 Impedance spectra for a Ni-BZCYYb/BZCYYb/LSCF-BZCYYb electrolytesupported PC-SOFC full cell operated with constant current of $5.5 \mathrm{~mA} / \mathrm{cm}^{2}$ at (a) $750^{\circ} \mathrm{C}$ and (b) $650^{\circ} \mathrm{C}$ showing the effect of introducing 3-10 $\mathrm{ppm}_{2} \mathrm{~S}$ as fuel contaminant to the wet $\mathrm{H}_{2}$. 
Figure 3.5 shows the cell voltage for an electrolyte-supported PC-SOFC full cell under constant current before, after the introduction of 3-10 $\mathrm{ppm}_{2} \mathrm{~S}$, and after the removal of $\mathrm{H}_{2} \mathrm{~S}$ in the wet hydrogen fuel. At $750^{\circ} \mathrm{C}$, the decrease in cell voltage due to the introduction of ppm-level $\mathrm{H}_{2} \mathrm{~S}$ was almost negligible (Figure 3. 5(a)), which is in line with the observations (no change in cell voltage upon $\mathrm{H}_{2} \mathrm{~S}$ introduction to $\mathrm{H}_{2}$ ) for anode supported PC-SOFC full cell at this temperature as shown in Figure 3. 1. As temperature dropped to $650-450^{\circ} \mathrm{C}$ range, the decrease in cell voltage with the introduction of $\mathrm{H}_{2} \mathrm{~S}$ becomes more obvious. Upon the removal of $\mathrm{H}_{2} \mathrm{~S}$, cell voltage recovered slowly and also only partially at $650^{\circ} \mathrm{C}$, while at lower temperature of 550 and $450^{\circ} \mathrm{C}$, the recovery was not significant.
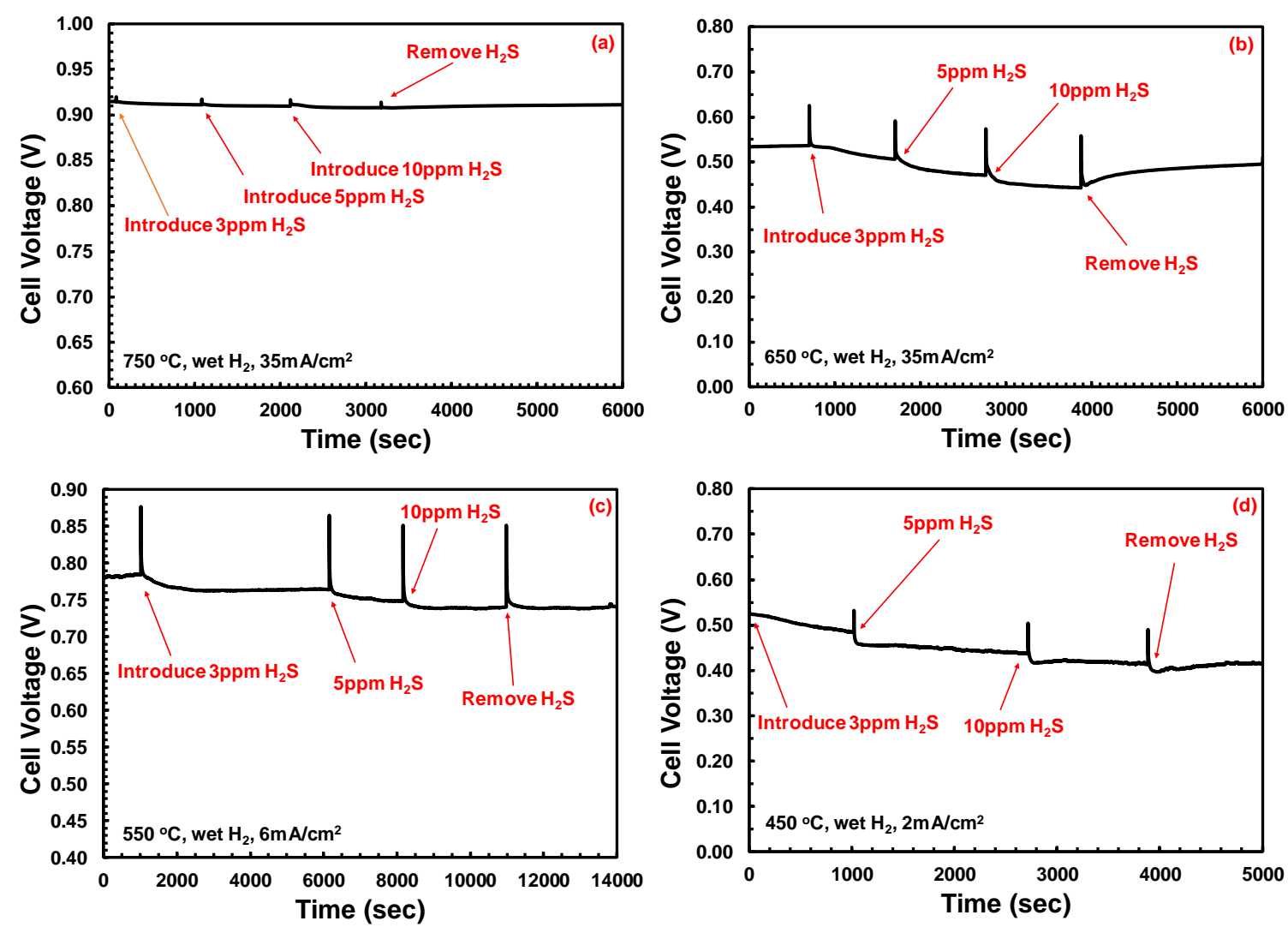

Figure 3. 5 Plots of cell voltage versus time under constant current for the NiBZCYYb/BZCYYb/LSCF-BZCYYb electrolyte-supported PC-SOFC full cell at (a) 
$750^{\circ} \mathrm{C}$, (b) $650^{\circ} \mathrm{C}$, (c) $550^{\circ} \mathrm{C}$, and (d) $450^{\circ} \mathrm{C}$ when $3-10$ ppm of $\mathrm{H}_{2} \mathrm{~S}$ is introduced into and later removed from the fuel of $3 \%$ humidified $\mathrm{H}_{2}$.

\subsection{3 $\mathrm{H}_{2} \mathrm{~S}$ Effect on Ni-BZCYYb/BZCYYb/Ni-BZCYYb Anode Symmetrical PC-SOFC}

The impedance spectra of the Ni-BZCYYb/BZCYYb/Ni-BZCYYb anode symmetrical PC-SOFC were measured at $750^{\circ} \mathrm{C}$ under open circuit condition with $10 \mathrm{mV}$ AC bias in dry $\mathrm{H}_{2}$ and $\mathrm{H}_{2}$ containing 3, 5, and $10 \mathrm{ppm}$ of $\mathrm{H}_{2} \mathrm{~S}$ are shown in Figure 3. 6 (a). Different from the anode-supported and electrolyte-supported PC-SOFC full cell, for the anode symmetrical PC-SOFC, low ppm $\mathrm{H}_{2} \mathrm{~S}$ leads to clear increase in the total electrode apparent interfacial resistance $\mathrm{R}_{\mathrm{ai}}$ but no change in cell ohmic resistance $\mathrm{R}_{\mathrm{O}}$. With increasing concentration of $\mathrm{H}_{2} \mathrm{~S}$ from 3 ppm to $5 \mathrm{ppm}$, the poisoning effect seems to get more severe. However, when $\mathrm{H}_{2} \mathrm{~S}$ concentration was further increased to $10 \mathrm{ppm}$, no further change in $\mathrm{R}_{\mathrm{ai}}$ was observed, suggesting possible saturation of the $\mathrm{H}_{2} \mathrm{~S}$ poisoning effect. Examination of the impedance spectra suggests that the increase in $\mathrm{R}_{\mathrm{ai}}$ is mainly due to the increase in the middle and low frequency (MF and LF) semicircles, while the high frequency (HF) semicircle remains largely unchanged after the introduction of 3-10 ppm of $\mathrm{H}_{2} \mathrm{~S}$.

The influence of water vapor on the $\mathrm{H}_{2} \mathrm{~S}$ poisoning effect for the anode symmetrical cell is shown in Figure 3. 6 (b). It shows similar poisoning behavior by $3-10 \mathrm{ppm}_{2} \mathrm{~S}$ in $\sim 3 \%$ humidified $\mathrm{H}_{2}$ as that in dry $\mathrm{H}_{2}$. This suggests that presence of significantly increased

concentration of water vapor from $\sim 10 \mathrm{ppm}$ in the so-called dry $\mathrm{H}_{2}$ to $\sim 3 \%$ in the $\mathrm{H}_{2}$ fuel 
does not seem to dramatically change the electrochemical response of Ni-cermet anode to low-ppm level $\mathrm{H}_{2} \mathrm{~S}$ poison for PC-SOFC.

The results of low-ppm level $\mathrm{H}_{2} \mathrm{~S}$ poisoning effect on the Ni-BZCYYb/BZCYYb/NiBZCYYb symmetrical cell at reduced temperature of $650^{\circ} \mathrm{C}$ and $550^{\circ} \mathrm{C}$ were shown in Figure 3.6 (c), (d), (e) and (f). It's obvious that, similar to $750^{\circ} \mathrm{C}$, no change in the HF semicircle or $\mathrm{R}_{\mathrm{O}}$ was observed under both dry and wet $\mathrm{H}_{2}$ conditions. On the other hand, at $650^{\circ} \mathrm{C}$ and $550^{\circ} \mathrm{C}$, the increase in $\mathrm{LF}$ loops caused by $\mathrm{H}_{2} \mathrm{~S}$ becomes more obvious than at $750^{\circ} \mathrm{C}$, while no saturation of $\mathrm{H}_{2} \mathrm{~S}$ poisoning effect was observed up to $10 \mathrm{ppm}$ of $\mathrm{H}_{2} \mathrm{~S}$ at those temperatures. 

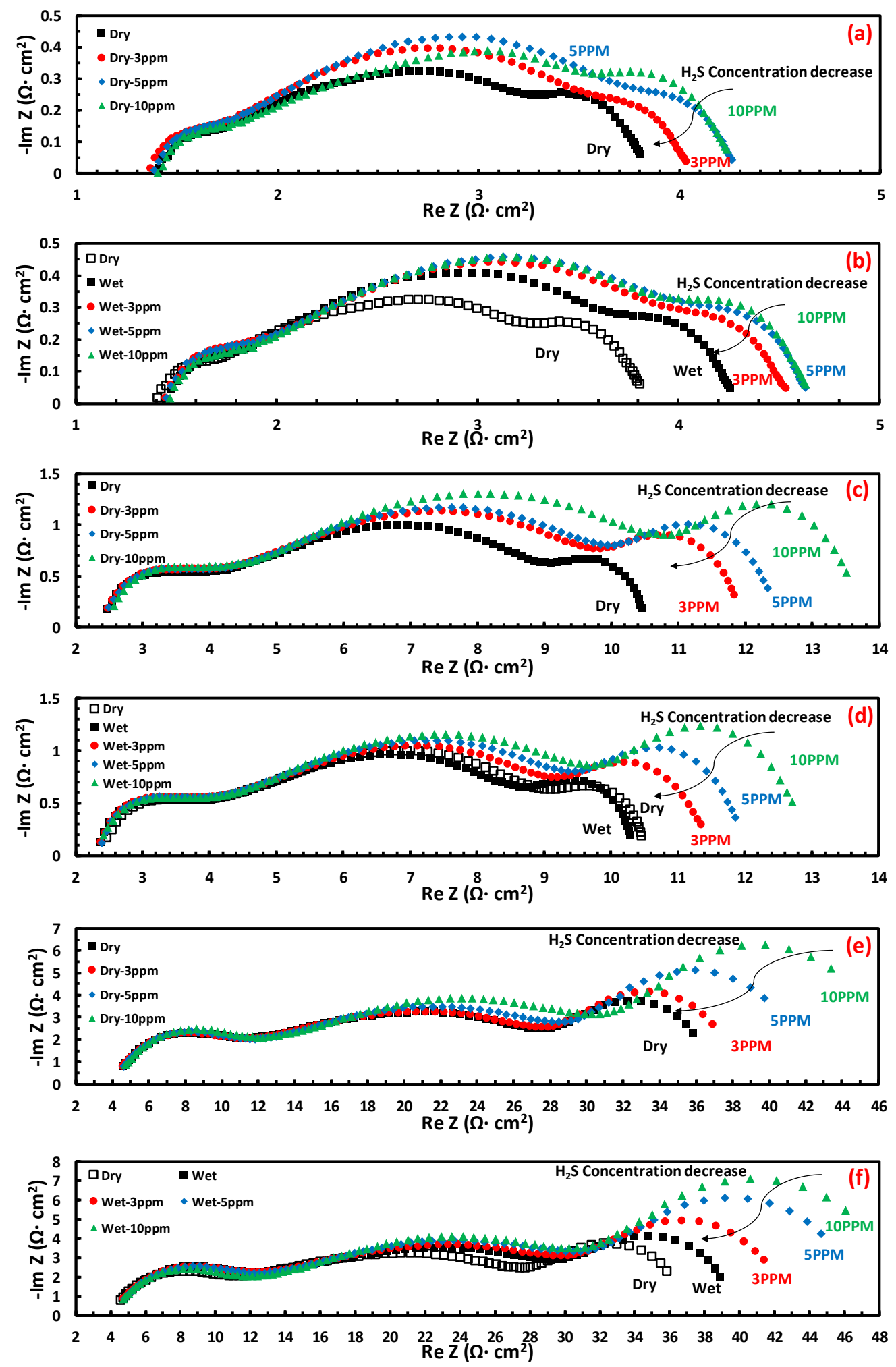
Figure 3. 6 Plots showing change of cell impedance spectra for the $\mathrm{Ni}$ BZCYYb/BZCYYb/Ni-BZCYYb anode symmetrical PC-SOFC in fuels of dry $\mathrm{H}_{2}$ (a, c, e) and $\sim 3 \%$ humidified $\mathrm{H}_{2}(\mathrm{~b}, \mathrm{~d}, \mathrm{f})$ before and after the introduction of 3, 5, and $10 \mathrm{ppm}$ of $\mathrm{H}_{2} \mathrm{~S}$ at $750^{\circ} \mathrm{C}$ (a and b), $650^{\circ} \mathrm{C}$ (c and d), and $550^{\circ} \mathrm{C}$ (e and f), respectively.

\subsection{4 $\mathrm{H}_{2} \mathrm{~S}$ Effect on Ni-YSZ/YSZ/Ni-YSZ Anode Symmetrical OC-SOFC}

Additionally, the $\mathrm{H}_{2} \mathrm{~S}$ poisoning effect on anode symmetrical OC-SOFC is also studied for comparison purposes. As shown in Figure 3.7 (a), upon the introduction of $10 \mathrm{ppm} \mathrm{H}_{2} \mathrm{~S}$ into wet $\mathrm{H}_{2}$ at $750^{\circ} \mathrm{C}, \mathrm{R}_{\mathrm{ai}}$ increases by $\sim 400 \%$ for the $\mathrm{Ni}-\mathrm{YSZ} / \mathrm{YSZ} / \mathrm{Ni}-\mathrm{YSZ}$ anode symmetrical OC-SOFC, which is much larger than the increase in $\mathrm{R}_{\mathrm{ai}}$ (only $\sim 10 \%$ ) for the Ni-BZCYYb/BZCYYb/Ni-BZCYYb anode symmetrical PC-SOFC as shown in Figure 3. 8 (a). Similar trend, i.e., the significantly smaller relative increase in $R_{a i}$ due to low ppmlevel $\mathrm{H}_{2} \mathrm{~S}$ poisoning for PC-SOFC than for conventional OC-SOFC, was also observed at lower temperatures of 650 , and $550^{\circ} \mathrm{C}$, as shown in Figure 3. 8(b to c) versus Figure 3. 7(b to $\mathrm{c})$. 

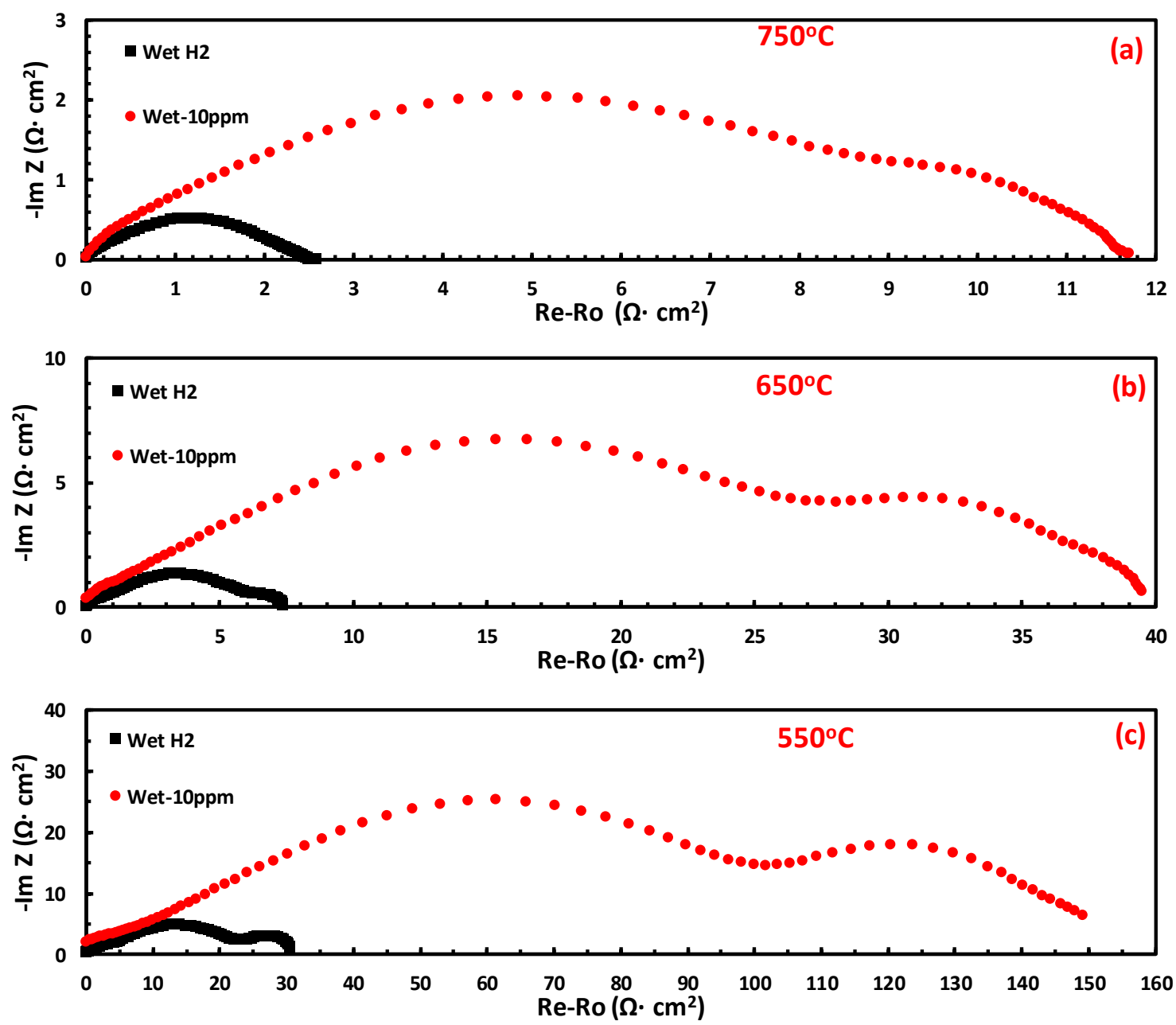

Figure 3. 7 Impedance spectra for a Ni-YSZ/YSZ/Ni-YSZ anode symmetrical OC-SOFC

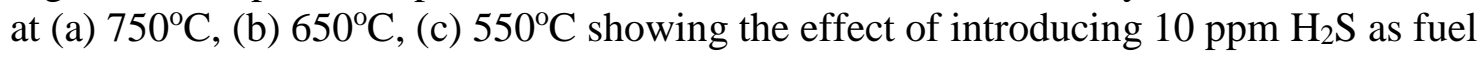
contaminant to the wet $\mathrm{H}_{2}$ (ohmic resistance subtracted) 

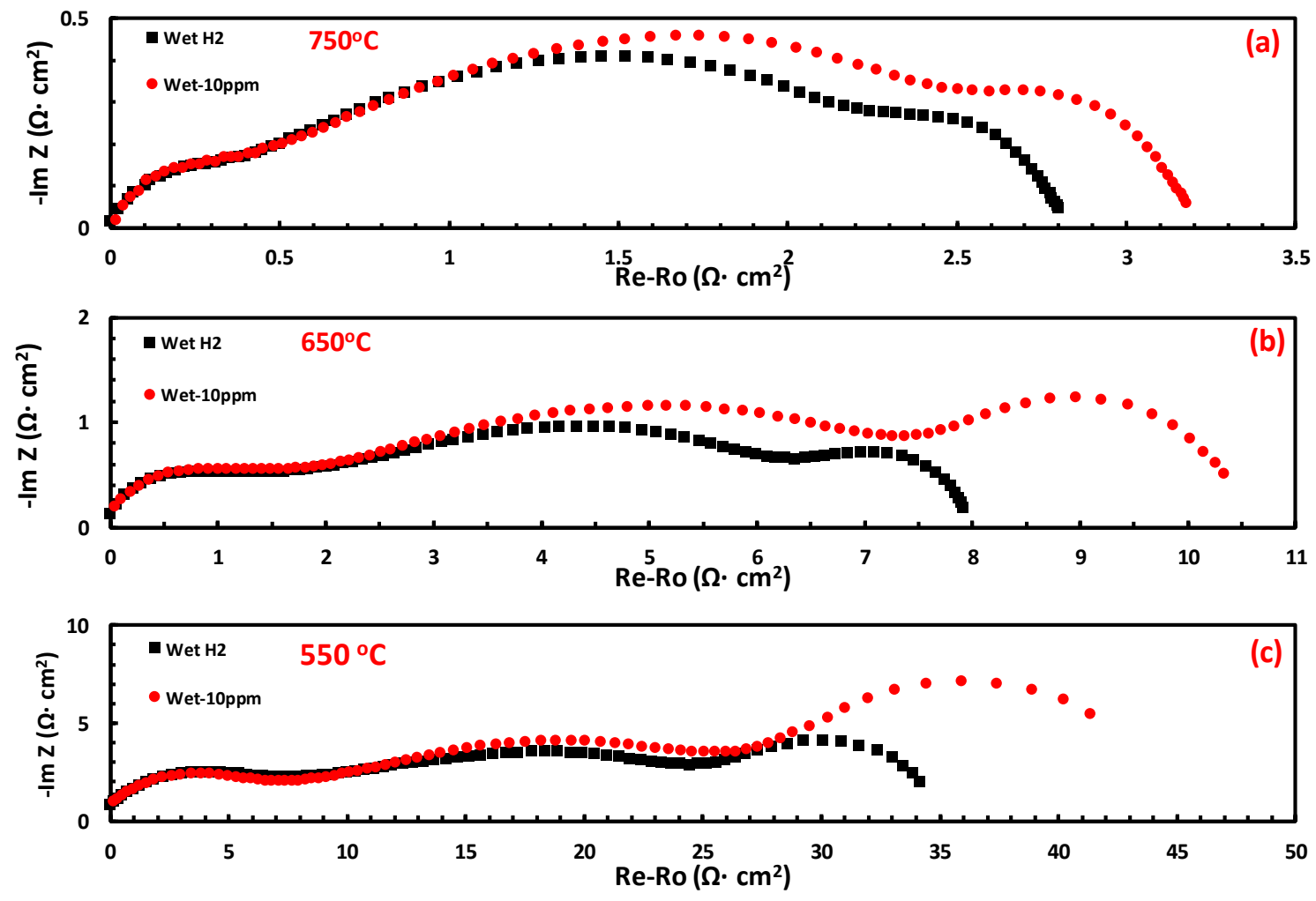

Figure 3. 8 Impedance spectra for an Ni-BZCYYb/BZCYYb/Ni-BZCYYb anode symmetrical PC-SOFC at (a) $750^{\circ} \mathrm{C}$, (b) $650^{\circ} \mathrm{C}$, and (c) $550^{\circ} \mathrm{C}$ showing the effect of introducing $10 \mathrm{ppm} \mathrm{H}_{2} \mathrm{~S}$ as fuel contaminant to the wet $\mathrm{H}_{2}$ (ohimc resistance subtracted).

\subsubsection{XRD and EDS Analysis on Ni-BZCYYb Powder Mixture after} Exposure to $\mathrm{H}_{2} \mathrm{~S}$

The XRD patterns for the Ni-BZCYYb loose powder mixture after exposure test to 10ppm $\mathrm{H}_{2} \mathrm{~S}$ in both dry and wet $\mathrm{H}_{2}$ at $550^{\circ} \mathrm{C}$ for 24 hours are shown in Figure 3. 9. There is no

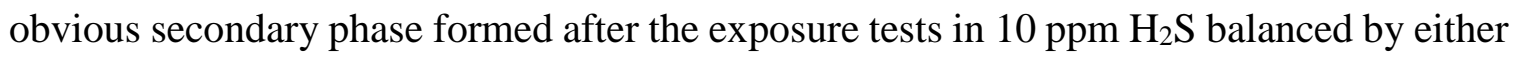
dry or wet $\mathrm{H}_{2}$ at $550^{\circ} \mathrm{C}$ for 24 hours. The EDS elemental analysis of the post $10 \mathrm{ppm}_{2} \mathrm{~S}$ exposure samples (shown in section 3.6 supplementary materials) also shows no evidence 
of sulfur accumulation in the samples. These results prove that there is no observable bulk phase reaction between $\mathrm{Ni}$ and $\mathrm{BZCYYb}$ and $10 \mathrm{ppm} \mathrm{H}_{2} \mathrm{~S}$ at $550^{\circ} \mathrm{C}$.

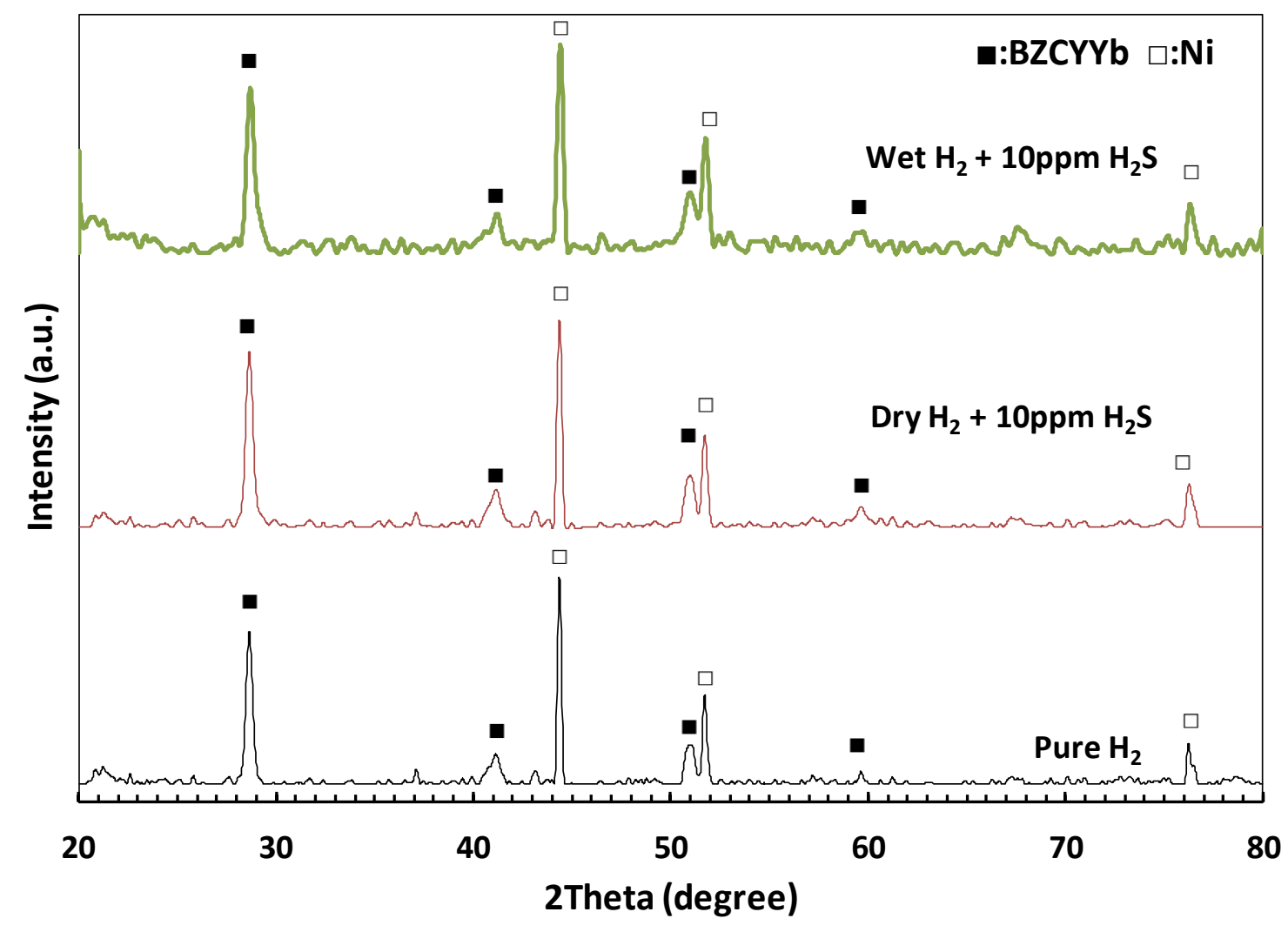

Figure 3. 9 XRD patterns for NiO-BZCYYb mixed powders after reduction in $\mathrm{H}_{2}$ at $750^{\circ} \mathrm{C}$ and then exposure tests at $550^{\circ} \mathrm{C}$ for 24 hours in pure $\mathrm{H}_{2}$ (as control sample) or fuel gas mixtures of dry $\mathrm{H}_{2}+10 \mathrm{ppm} \mathrm{H}_{2} \mathrm{~S} / \mathrm{H}_{2}$ or wet $\mathrm{H}_{2}+10 \mathrm{ppm}_{2} \mathrm{~S}$. These results prove that there is no observable bulk phase reaction between $\mathrm{Ni}$ and BZCYYb and $10 \mathrm{ppm}$ $\mathrm{H}_{2} \mathrm{~S}$ at $550^{\circ} \mathrm{C}$. 


\subsubsection{SIMS Analysis on Ni-BZCYYb Composite Pellet after Exposure to Low-ppm Level $\mathrm{H}_{2} \mathrm{~S}$}

Figure 3. 10 shows a representative optical microscope image of the Ni-BZCYYb composite pellet sample after sintering in $4 \% \mathrm{H}_{2} / \mathrm{Argon}$ (Ar) forming gas and subsequent grinding and polishing. The sample surface is reasonably smooth with easily identifiable bright and dark parts, which correspond to the $\mathrm{Ni}$ and the BZCYYb phase, respectively. The Ni regions have dimension of $\sim 10-20 \mu \mathrm{m}$, while the $\mathrm{BZCYYb}$ regions are $\sim 30-60 \mu \mathrm{m}$ in size.

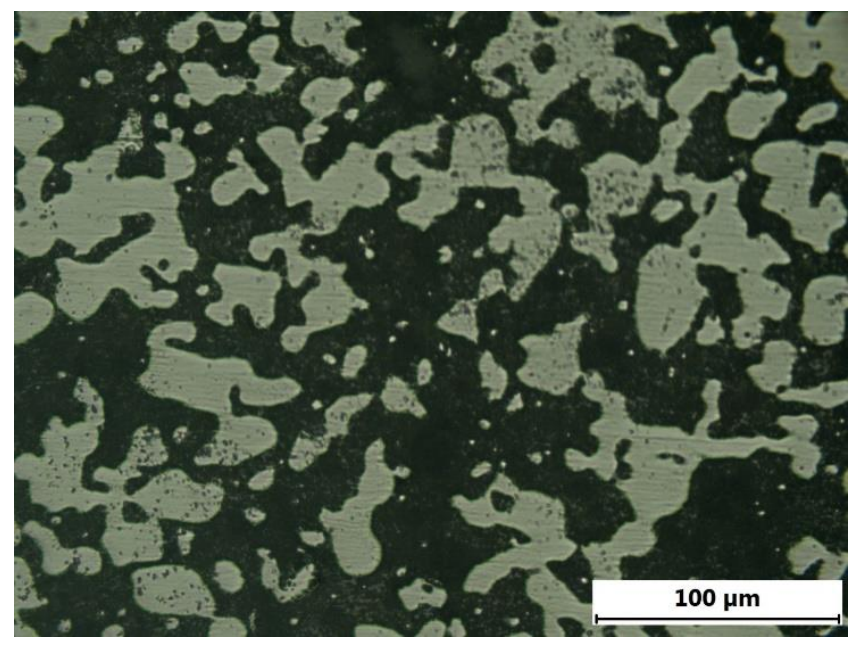

Figure 3. 10 Metallographic microscope image of the sintered and polished Ni-BZCYYb composite sample surface. The bright and dark regions correspond to the $\mathrm{Ni}$ and the BZCYYb phase, respectively

Figure 3. 11 shows a representative SIMS elemental mapping image of $\mathrm{Ni}$ and $\mathrm{Ba}$ species and $\mathrm{S}$ species from the surface of the Ni-BZCYYb dense composite pellet after it

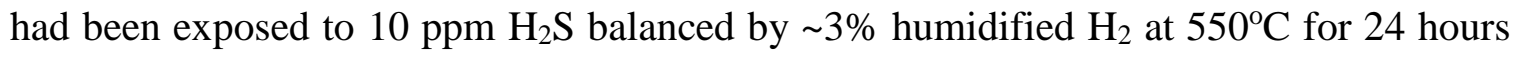


followed by rapid cooling in clean wet $\mathrm{H}_{2}$. It's observed that $\mathrm{Ba}$ and $\mathrm{S}$ species show strong association with each other, as evidence by their overlapping distribution, while the distribution of $\mathrm{Ni}$ species is complementary to $\mathrm{Ba}$ and $\mathrm{S}$ species.
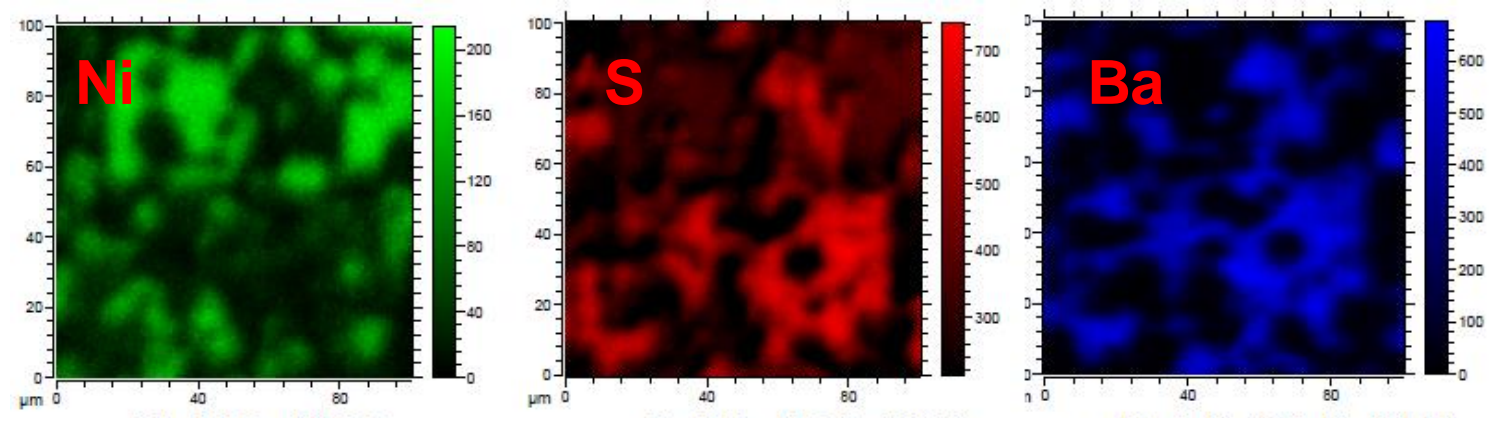

Figure 3. 11 Representative SIMS mapping results showing the distributions of $\mathrm{Ni}, \mathrm{S}$, and Ba species (including their associated oxides) as the sample was sputtered down during the analysis

\subsection{Discussion}

\subsubsection{Electrochemical Behaviors of PC-SOFC against $\mathrm{H}_{2} \mathrm{~S}$ Poisoning}

For electrolyte-supported PC-SOFC full cell and anode symmetrical cell, depending on temperature and $\mathrm{H}_{2} \mathrm{~S}$ concentration, there is an observable increase by $\sim 10-30 \%$ in the electrode apparent interfacial resistance $\mathrm{R}_{\mathrm{a}}$, which is largely confined to the ML to $\mathrm{LF}$ semicircles, while there is no obvious change in ohmic resistance Ro. (see Figure 3. 3, Figure 3. 4 and Figure 3.6) These observations indicate that typical PC-SOFC with NiPCC based cermet anodes are still subjected to poisoning by low ppm-level sulfur contaminant in the hydrogen fuel at $\sim 750$ to $550^{\circ} \mathrm{C}$. Such a conclusion is not surprising consider that the typical cermet anode for a common PC-SOFC still consists of Ni metal 
and highly basic PCC electrolyte such as BZCYYb, both of which have high affinity for sulfur adsorption and may even form bulk sulfide phases (when $\mathrm{H}_{2} \mathrm{~S}$ concentration is high in the range of hundreds of ppm or higher). [137] In addition, the results also show that as temperature drops (from $\sim 750$ to $\sim 550^{\circ} \mathrm{C}$ ), the observed poisoning by low ppm-level $\mathrm{H}_{2} \mathrm{~S}$ becomes only slightly more obvious (see Figure 3. 4, Figure 3. 5, Figure 3.6) and less reversible (Figure 3. 5), but there seems to be no fundamental change in the poisoning behavior, suggesting the underlying poisoning mechanism in that temperature range is likely to remain the same.

Comparing with earlier studies and our own study, it seems that, at elevated temperature such as $750-600^{\circ} \mathrm{C}$, the electrolyte-supported $\mathrm{PC}-\mathrm{SOFC}$ as well as proton conducting anode symmetrical cell are more sensitive to $\mathrm{H}_{2} \mathrm{~S}$ poisoning than anodesupported PC-SOFC. [15, 38, 141, 142]Since all three types of electrochemical cells have the similar Ni-PCC cermet anode with doped $\mathrm{Ba}(\mathrm{Ce}, \mathrm{Zr}) \mathrm{O}_{3}$ (e.g., BZCYYb) based PCC electrolyte, the difference in $\mathrm{H}_{2} \mathrm{~S}$ sensitivity (i.e., the relative increase in $\mathrm{R}_{\mathrm{ai}}$ due to exposure to similar low-ppm $\mathrm{H}_{2} \mathrm{~S}$ ) is attributed to the large difference in the cermet anode thickness. The anode supported PC-SOFC full cell have thick anodes on the order of $\sim 600 \mu \mathrm{m}$, while both electrolyte-supported PC-SOFC full cell and anode symmetrical PC-SOFC have relatively thin anode of $\sim 30 \mu \mathrm{m}$, which makes the electrochemical response for those later two faster and more obvious. 


\subsubsection{Comparison of Electrochemical Behaviors of Anode Symmetrical PC- SOFC versus OC-SOFC}

In this study, the electrochemical behavior against low-ppm level $\mathrm{H}_{2} \mathrm{~S}$ for the anode symmetrical PC-SOFC is also compared with anode symmetrical OC-SOFC with YSZ electrolyte and Ni-YSZ cermet anode at $\sim 750^{\circ} \mathrm{C}$ and lower temperatures. As summarized in However, there is also one major difference in the observed electrochemical behaviors against $\mathrm{H}_{2} \mathrm{~S}$ poisoning between the two types of SOFCs. For comparable $\mathrm{H}_{2} \mathrm{~S}$ concentration and temperature, the relative degradation in anode electrochemical reaction rate appears to be much smaller for a PC-SOFC comparing with a typical oxide-ion conducting SOFC. For example, for both electrolyte-supported (see Figure 3. 5) and anode-supported PCSOFC (Figure 3. 2), when temperature was $750^{\circ} \mathrm{C}$, low ppm-level $\mathrm{H}_{2} \mathrm{~S}$ causes a very small drop $(\sim 0-2 \%)$ in cell power output under constant current operation. (Note such an observation was made for low fuel utilization condition, which might change when current density or fuel utilization is high.) In comparison, numerous earlier studies clearly show a significant drop ( 10-15\%) in power output for conventional oxide-ion conducting SOFC. $[29,137]$ The results of impedance measurement under open circuit condition are also consistent with the power output measurement. For electrolyte-supported PC-SOFC full cell, as shown in Figure 3. 4, the electrode apparent interfacial resistance $R_{a i}$ increases due to $10 \mathrm{ppm} \mathrm{H}_{2} \mathrm{~S}$ is only $\sim 20 \%$ at $750^{\circ} \mathrm{C}$, while it was $\sim 80 \%$ for $8 \mathrm{ppm}(\mathrm{v}) \mathrm{H}_{2} \mathrm{~S}$ for conventional electrolyte-supported SOFC at $800^{\circ} \mathrm{C}$. [29] Such a difference is even more obvious when comparison was made on the electrode interfacial resistance change for anode symmetrical cells. The possible explanations are discussed later. 
Table 3. 1, there are several similarities. First, when low ppm level $\mathrm{H}_{2} \mathrm{~S}$ is used (i.e., without the concern of causing bulk phase reactions), [137] both OC-SOFC and PCSOFC show performance degradation as evidenced by either a drop in cell power output (e.g., cell voltage drop under constant current condition) or an increase in electrode apparent interfacial resistance $\mathrm{R}_{\mathrm{ai}}$ with little or no change in cell ohmic resistance $\mathrm{R}_{\mathrm{O}}$. Second, the extent of sulfur poisoning for both types of SOFC appears to get more significant when $\mathrm{H}_{2} \mathrm{~S}$ concentration increases or when the temperature drops. $[15,29,33$, $35,38,138]$

However, there is also one major difference in the observed electrochemical behaviors against $\mathrm{H}_{2} \mathrm{~S}$ poisoning between the two types of SOFCs. For comparable $\mathrm{H}_{2} \mathrm{~S}$ concentration and temperature, the relative degradation in anode electrochemical reaction rate appears to be much smaller for a PC-SOFC comparing with a typical oxide-ion conducting SOFC. For example, for both electrolyte-supported (see Figure 3. 5) and anode-supported PCSOFC (Figure 3. 2), when temperature was $750^{\circ} \mathrm{C}$, low ppm-level $\mathrm{H}_{2} \mathrm{~S}$ causes a very small drop $(\sim 0-2 \%)$ in cell power output under constant current operation. (Note such an observation was made for low fuel utilization condition, which might change when current density or fuel utilization is high.) In comparison, numerous earlier studies clearly show a significant drop $(\sim 10-15 \%)$ in power output for conventional oxide-ion conducting SOFC. $[29,137]$ The results of impedance measurement under open circuit condition are also consistent with the power output measurement. For electrolyte-supported PC-SOFC full cell, as shown in Figure 3. 4, the electrode apparent interfacial resistance $\mathrm{R}_{\mathrm{ai}}$ increases due to $10 \mathrm{ppm} \mathrm{H}_{2} \mathrm{~S}$ is only $\sim 20 \%$ at $750^{\circ} \mathrm{C}$, while it was $\sim 80 \%$ for $8 \mathrm{ppm}(\mathrm{v}) \mathrm{H}_{2} \mathrm{~S}$ for conventional electrolyte-supported SOFC at $800^{\circ} \mathrm{C}$. [29] Such a difference is even more obvious when comparison was made on the electrode interfacial resistance change for anode symmetrical cells. The possible explanations are discussed later. 
Table 3. 1 Summary of poisoning effect by low-ppm level $\mathrm{H}_{2} \mathrm{~S}$ on oxide-ion conducting SOFC and PC-SOFC in hydrogen-based fuel at $\sim 750^{\circ} \mathrm{C}$. For electrolyte, YSZ stands for $8 \mathrm{~mol} \%$ yttria stabilized zirconia while BZCYYb stands for $\mathrm{BaZr}_{0.1} \mathrm{Ce}_{0.7} \mathrm{Y}_{0.1} \mathrm{Yb}_{0.1} \mathrm{O}_{3-\delta}$ proton conducting ceramic (PCC) electrolyte. $\Delta R_{\mathrm{O}}$ and $\Delta R_{\mathrm{ai}}$ are the observed relative increase in cell ohmic resistance and total electrode apparent interfacial resistance, respectively, measured under open circuit condition.

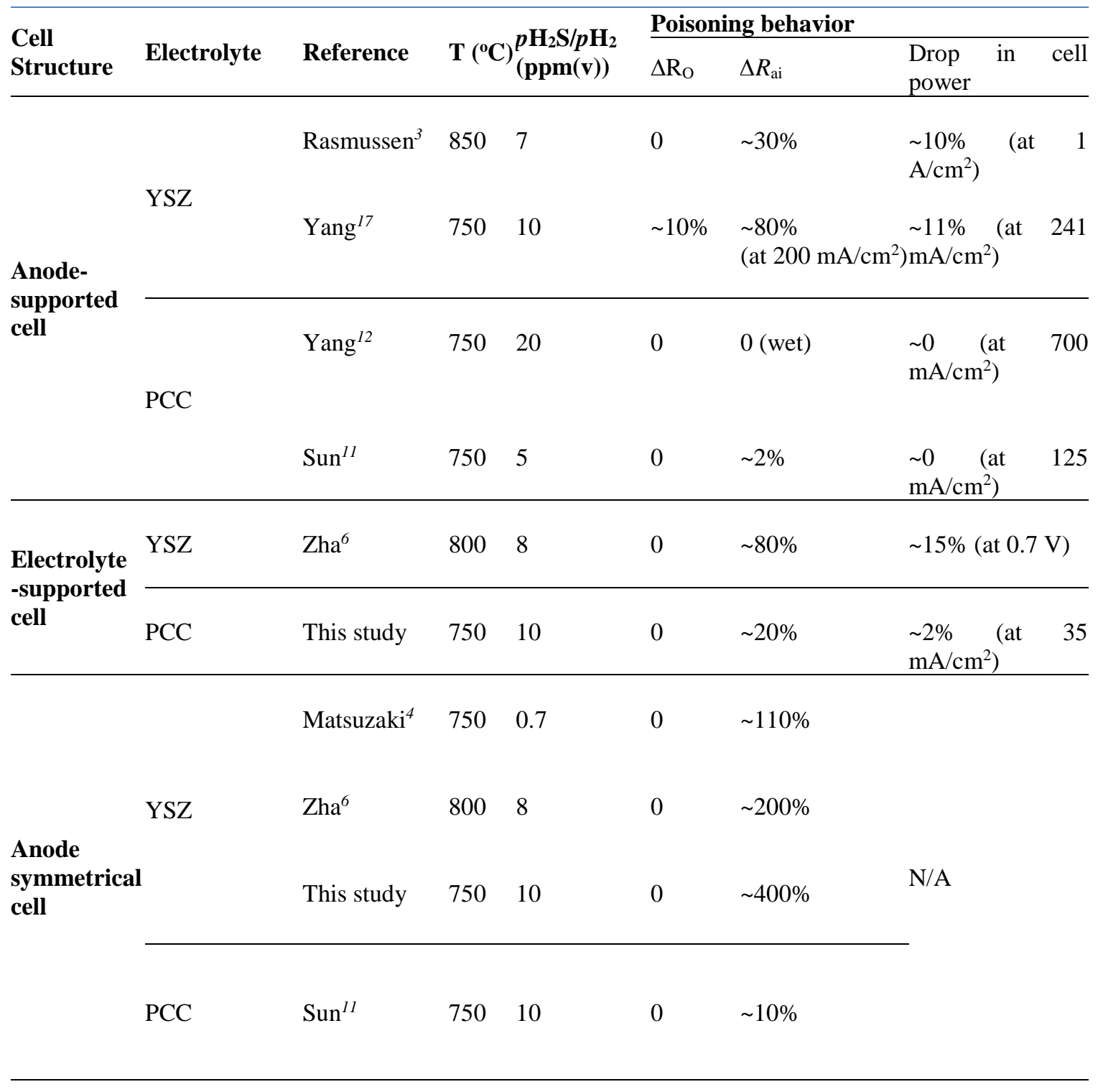

In addition, for the anode symmetrical PC-SOFC with the configuration of $\mathrm{Ni}$ BZCYYb/BZCYYb/Ni-BZCYYb, the change of activation energy for ohmic resistance $\mathrm{R}_{\mathrm{O}}$ 
and apparent interfacial resistance $\mathrm{R}_{\mathrm{ai}}$ in dry $\mathrm{H}_{2}\left(\mathrm{pH}_{2} \mathrm{O} \approx 10 \mathrm{ppm}\right.$ as mentioned) and upon introduction of various concentrations of $\mathrm{H}_{2} \mathrm{~S}$ into dry $\mathrm{H}_{2}$ is shown in Figure 3. 12 (a). The activation energy for $\mathrm{R}_{\mathrm{O}}$ was about $0.45 \mathrm{eV}$, which matches that for typical proton conducting electrolytes. [85] The activation energy for the overall anode apparent interfacial resistance $\mathrm{R}_{\mathrm{ai}}$ was about $0.92 \mathrm{eV}$, which is comparable to that for Ni-YSZ cermet $\mathrm{H}_{2}$ electrode for oxide ion SOFC. [83, 87, 143, 144] As the impedance spectra (see Figure 3. 6) could be clearly separated into at least three semi-circles, the activation energy for each of the high, middle and low frequency part of polarization resistance $\left(\mathrm{R}_{\mathrm{HF}}, \mathrm{R}_{\mathrm{MF}}, \mathrm{R}_{\mathrm{LF}}\right)$ was also analyzed. As mentioned before, with the introduction of $10 \mathrm{ppm} \mathrm{H}_{2} \mathrm{~S}$, there is no obvious change in the HF semicircle. Consistently, there also appears to be no change for the activation energy for $\mathrm{R}_{\mathrm{HF}}$. This suggests that the HF process, which is most likely attributed to the charge transfer step, is not influenced by the introduction of low ppm-level $\mathrm{H}_{2} \mathrm{~S}$ for the anode symmetrical cell based on BZCYYb proton conducting electrolyte and $\mathrm{Ni}$-BZCYYb cermet anode. In comparison, for the low frequency LF semicircle, the activation energy seems to increase with increasing $\mathrm{H}_{2} \mathrm{~S}$ concentration up to $\sim 5 \mathrm{ppm}$. This means the introduction of low ppm-level $\mathrm{H}_{2} \mathrm{~S}$ makes it more difficult for the LF process and greater activation would be required. A natural hypothesis would be that the LF process might be associated with the surface diffusion process for the hydrogen electrode reaction of PC-SOFC, and the strong adsorption of sulfur interferes with the surface diffusion of adsorbed hydrogen (atoms). The sensitivity of adsorption to different low ppm-level $\mathrm{H}_{2} \mathrm{~S}$ suggests that the surface diffusion in this anode reaction is actually more likely to be over the BZCYYb surface as nickel surface should have already been saturated by parts-per-billion ( $\mathrm{ppb}$ ) level $\mathrm{H}_{2} \mathrm{~S}$ at intermediate temperature of $550^{\circ} \mathrm{C}$ and no longer 
sensitive to variation in low ppm-level $\mathrm{H}_{2} \mathrm{~S}$. [25, 28] As to the mid frequency MF process, interestingly, although it seems to slow down, the activation energy actually does not change upon $\mathrm{H}_{2} \mathrm{~S}$ introduction. One possibility is that the poisoning at MF is related to physical blockage, i.e., reduced possibility of occupation but without change in the reaction mechanism. Therefore, the MF process may correspond to hydrogen adsorption onto the $\mathrm{BZCYYb}$ surface since at intermediate temperature such as $550^{\circ} \mathrm{C}$, Ni surface would already be completely covered by ppb-level sulfur and would not show sensitivity in low ppm-level $\mathrm{H}_{2} \mathrm{~S}$ concentration. [25, 28, 137]The $\mathrm{H}_{2} \mathrm{~S}$ poisoning behavior for proton conducting SOFC in 3\% humidified hydrogen (see Figure 3. 8 and Figure 3. 12 (b)) is similar to that in dry $\mathrm{H}_{2}$, suggesting that introduction of significantly more moisture to $\mathrm{H}_{2}$ (i.e., $3 \%$ versus $\sim 10 \mathrm{ppm}$ in the so-called dry $\mathrm{H}_{2}$ ) does not fundamentally change the sulfur poisoning behavior for Ni-proton conducting electrolyte cermet anode of PC-SOFC. 

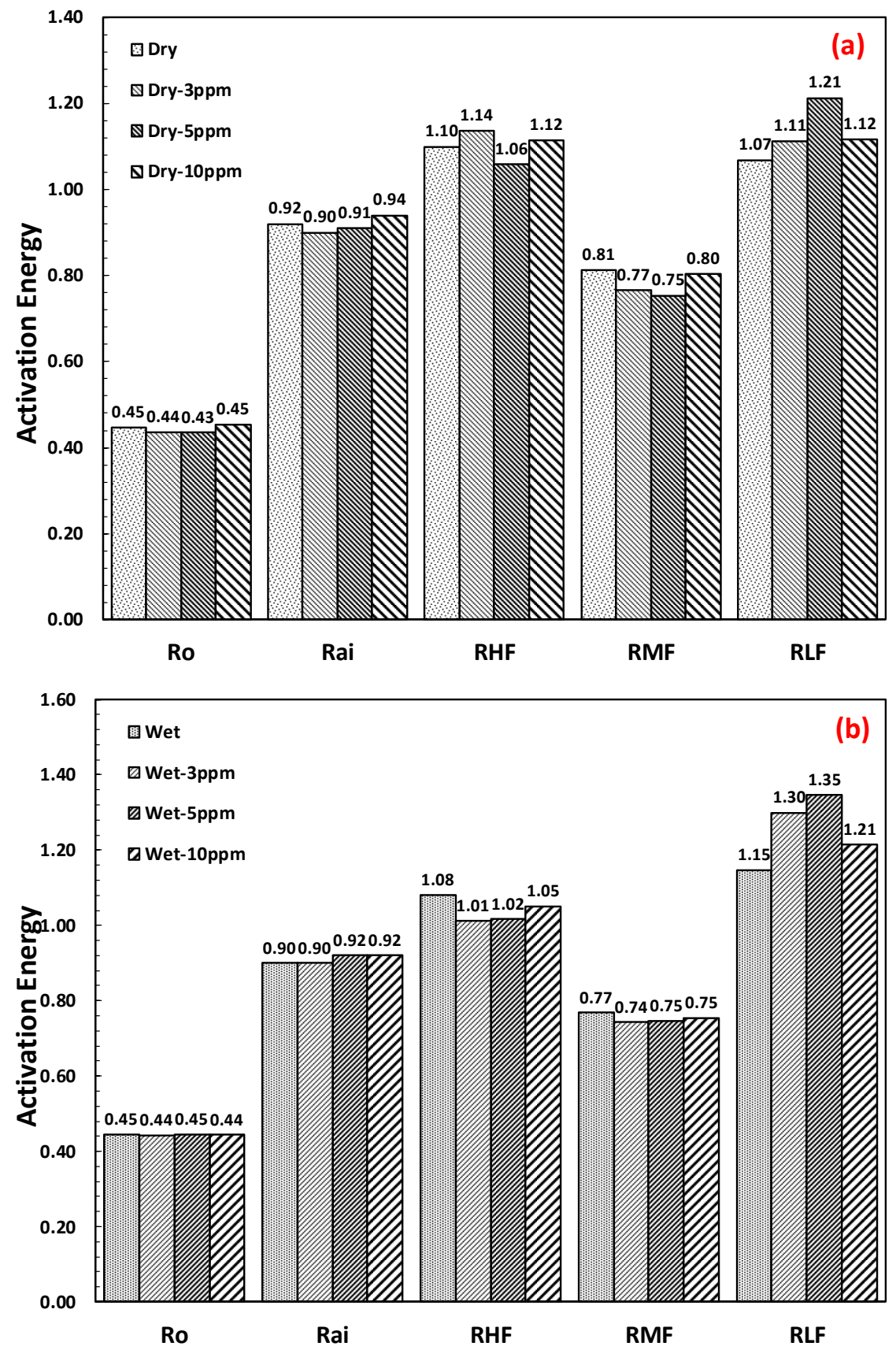

Figure 3. 12 Comparison of activation energy (calculated from $550-750^{\circ} \mathrm{C}$ ) for ohmic resistance $\mathrm{R}_{\mathrm{O}}$, total apparent interfacial resistance $\mathrm{R}_{\mathrm{ai}}$, and the different electrode processes at high frequency $R_{H F}$, mid-frequency $R_{M F}$, and low frequency $R_{L F}$ in (a) dry $\mathrm{H}_{2}\left(\mathrm{pH}_{2} \mathrm{O} \approx 10 \mathrm{ppm}\right)$ and (b) $3 \%$ humidified $\mathrm{H}_{2}$ without and with 3,5 , and $10 \mathrm{ppm}_{2} \mathrm{~S}$ poison for the Ni-BZCYYb/BZCYYb/Ni-BZCYYb anode symmetrical PC-SOFC. 


\subsubsection{Analysis of the $\mathrm{H}_{2} \mathrm{~S}$ Effect on Ni-BZCYYb Mixture}

It should be mentioned that, unlike the conventional oxide ion conducting YSZ electrolyte, the highly basic proton conducting oxides such as BZCYYb are known to have strong tendency to interact with $\mathrm{H}_{2} \mathrm{~S}$ to either form bulk metal sulfides (e.g., BaS) or strongly adsorbed surface sulfur species. In fact, it had been reported that at $750^{\circ} \mathrm{C}$, the $\mathrm{BZCYYb}$ proton conducting electrolyte would not react with $50 \mathrm{ppm} \mathrm{H}_{2} \mathrm{~S}$ in hydrogen, [15]but it does react and form bulk $\mathrm{BaS}$ when $\mathrm{H}_{2} \mathrm{~S}$ concentration was increased to $100 \mathrm{ppm}$ or when the balance gas was changed to argon. [89] In this study, as mentioned before, the bulk phase stability of the Ni-BZCYYb mixed powders against $10 \mathrm{ppm}_{2} \mathrm{~S}$ balanced by dry or wet $\mathrm{H}_{2}$ at temperature such as $550^{\circ} \mathrm{C}$ was confirmed in the exposure tests (see Figure 3. 9 (a)) showing no indication of observable bulk reaction between $\mathrm{H}_{2} \mathrm{~S}$ and $\mathrm{Ni}$ or BZCYYb. In addition, analysis using EDS did not identify the presence of bulk sulfide in the post $\mathrm{H}_{2} \mathrm{~S}$ exposure samples. On the other hand, The observed strong association between the Ba species (e.g., $\mathrm{Ba}^{+}, \mathrm{BaO}^{+}, \mathrm{BaOH}^{+}$) and $\mathrm{S}$ species (e.g., $\mathrm{S}^{-}, \mathrm{SO}^{-}, \mathrm{SO}_{2}^{-}, \mathrm{SO}_{3}^{-}$) indicates that besides the well-known sulfur adsorption on Ni metal phase, $[25,28,29,137,138] \mathrm{H}_{2} \mathrm{~S}$ also interacts with the PCC electrolyte phase (in this study, BZCYYb) to form certain sulfur-containing species on and near the surface of the cermet including near the triple phase boundary (TPB).

However, two experimental observations also need to be taken into account here. First, in our SIMS analysis, the observed association between Ba species and S species persists

even after the sample was sputtered down using ions (in this case, $\mathrm{Bi}^{3+}$ ions) for tens of microns and even deeper. Second, as mentioned before, no bulk BaS or other sulfur- 
containing bulk phases were formed in Ni-BZCYYb powder, despite extended exposure to the low-ppm level $\mathrm{H}_{2} \mathrm{~S}$ at the testing temperature including $550^{\circ} \mathrm{C}$.

Considering all the experimental observations discussed above especially XRD, EDS and SIMS analysis of the $\mathrm{H}_{2} \mathrm{~S}$ exposed samples, the implication is that the interaction between $\mathrm{H}_{2} \mathrm{~S}$ and BZCYYb PCC electrolyte under the condition studied (low ppm $\mathrm{H}_{2} \mathrm{~S}$ at $450-750^{\circ} \mathrm{C}$ ) appears to be bulk in nature but not to the extent of forming a new crystalline phase. One possibility for such a scenario is that, with the presence of low ppm-level $\mathrm{H}_{2} \mathrm{~S}$ in the gas atmosphere, some sulfur atoms may get incorporated or dissolved into the BZCYYb bulk at low concentration via displacing lattice oxygen transforming the BZCYYb material into an oxysulfide, i.e. $\mathrm{Ba}\left(\mathrm{Zr}_{0.1} \mathrm{Ce}_{0.7} \mathrm{Y}_{0.1} \mathrm{Y}_{0.1}\right) \mathrm{O}_{3-\delta-y} \mathrm{~S}_{\mathrm{y}}$ with $\mathrm{y}<<1$. This seems reasonable given that oxides such as cerium oxide $\left(\mathrm{CeO}_{2}\right)$ was observed to transform gradually to oxysulfide and eventually to sulfide depending on $\mathrm{H}_{2} \mathrm{~S}$ concentration. [141, 145-147] In comparison, no clear association between $\mathrm{Ni}$ and $\mathrm{H}_{2} \mathrm{~S}$ was detected by SIMS throughout the analysis including when the sample was sputtered down. This is consistent with the nature of sulfur adsorption over Ni surface and the limited sulfur solubility (on the order of $10 \mathrm{ppm}$ ) in solid nickel at those temperatures. [24-26, 29, 31] As the surfaceadsorbed sulfur is sputtered away during SIMS analysis, very little sulfur exists within the bulk of $\mathrm{Ni}(<\sim 10 \mathrm{ppm}(\mathrm{v}))$, and, therefore, no clear association of sulfur and $\mathrm{Ni}$ was identified. 


\subsubsection{Proposed $\mathrm{H}_{2} \mathrm{~S}$ Poisoning Mechanism for the Anode Reaction Process of PC-SOFC}

In summary, this study shows that typical PC-SOFC with Ni-PCC electrolyte cermet anode is still poisoned by low ppm-level $\mathrm{H}_{2} \mathrm{~S}$ at temperature in the range of $450-750^{\circ} \mathrm{C}$. Consistent with conventional OC- SOFC, anode sulfur poisoning of PC-SOFC is characterized by an increase in anode interfacial resistance with no change in ohmic resistance. As $\mathrm{H}_{2} \mathrm{~S}$ concentration increases or temperature decreases, the extent of sulfur poisoning (in terms of relative increase in interfacial resistance increase or drop in power output) increases, while it also becomes less reversible.

However, as stated, there is also one major difference in terms of sulfur poisoning behavior between the two types of SOFCs with different ion conducting species. The observed extent of performance degradation due to sulfur poisoning by low-ppm level $\mathrm{H}_{2} \mathrm{~S}$ for PC-SOFC is typically much less than that for conventional OC-SOFC under comparable conditions (e.g., temperature and bias condition). Such a difference is attributed primarily to the different anode reaction routes for these two types of SOFCs as shown in Figure 3. 13. In particular, as state before in section 2.2.1., the anode reaction in conventional oxide-ion conducting SOFC with YSZ electrolyte and Ni-YSZ cermet anode involves multiple steps including (1) hydrogen adsorption, (2) hydrogen dissociation and surface diffusion, (3) charge transfer and associated water $\left(\mathrm{H}_{2} \mathrm{O}\right)$ evolution, and finally (4) water desorption as shown in Figure 3. 13 (a). (It is recognized that hydrogen adsorption and dissociation over Ni surface is typically extremely fast at elevated temperature. [28, 138]) When sulfur (e.g., as $\mathrm{H}_{2} \mathrm{~S}$ ) is present in the system, it will selectively adsorb over $\mathrm{Ni}$ 
surface (and not much over YSZ surface), which inhibits the steps of (1) hydrogen gas adsorption, and (2) dissociation and surface diffusion as shown in Figure 3.13 (b). In addition, due to the relatively large size of water molecules, it is also reasonable to expect that the adsorbed sulfur over Ni near TPB would also dramatically slow down step (3) of charge transfer as it requires unoccupied sites for water generation.

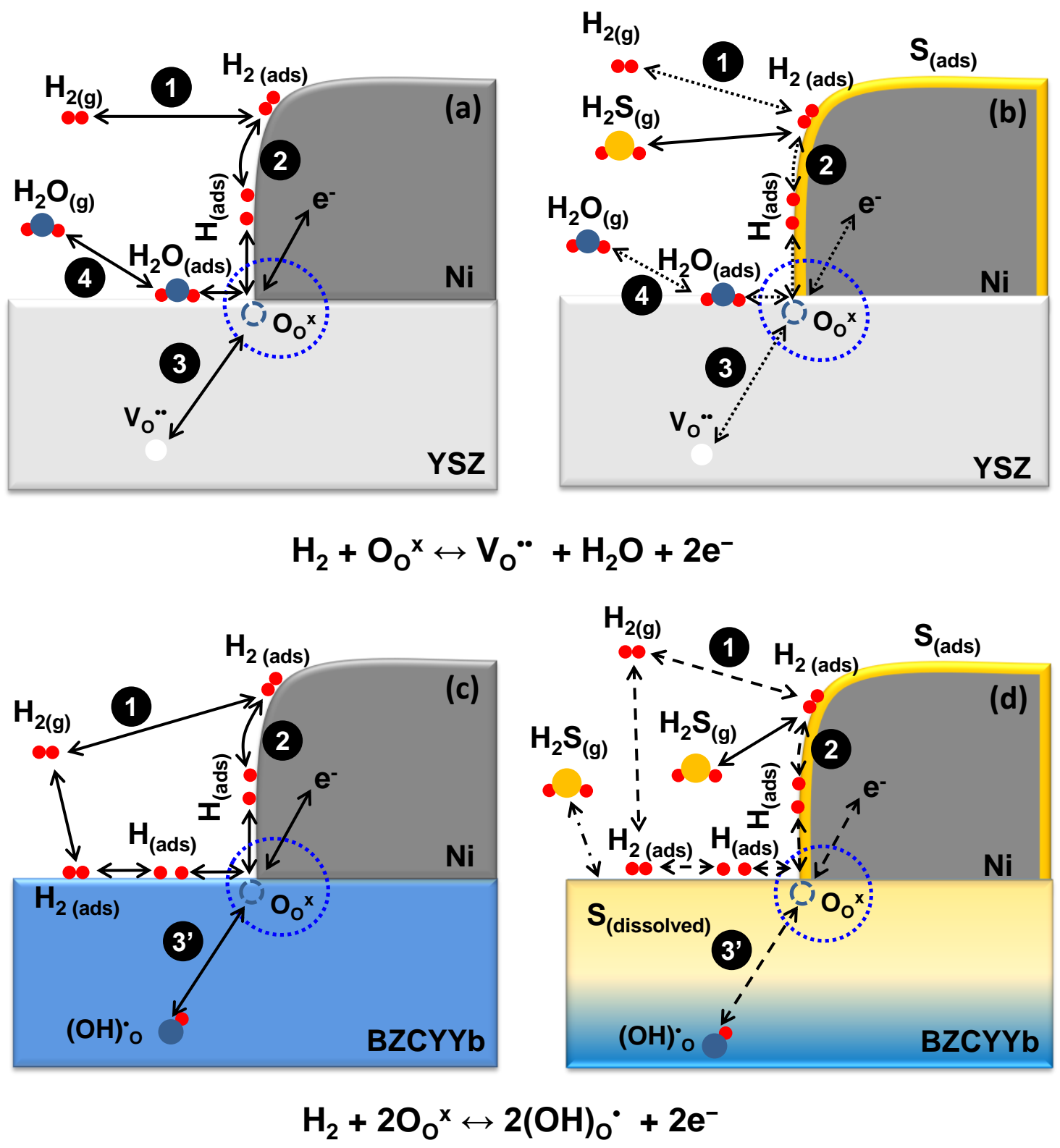


Figure 3.13 Schematics showing anode reaction steps for both conventional oxide-ion conducting SOFC ( $a$ and $b$ ) and ideal pure PC-SOFC (c and d) before ( $a, c)$ and after (b, d) sulfur poisoning by low-ppm level $\mathrm{H}_{2} \mathrm{~S}$ at intermediate temperature. Note that the anode reaction mechanism for PC-SOFC is greatly simplified and the exact process including the dominating pathway still needs to be studied. In addition, BCZYYb stands for the $\mathrm{BaZr}_{0.1} \mathrm{Ce}_{0.7} \mathrm{Y}_{0.1} \mathrm{Yb}_{0.1} \mathrm{O}_{3-\delta}$ PCC electrolyte used in this study, while $\mathrm{BZCYYbS}$ stands for BZCYYb with sulfur incorporation into the oxygen sublattice to form $\mathrm{Ba}\left(\mathrm{Zr}_{0.1} \mathrm{Ce}_{0.7} \mathrm{Y}_{0.1} \mathrm{Y}_{0.1}\right) \mathrm{O}_{3-\delta-\mathrm{y}} \mathrm{S}_{\mathrm{y}}$ oxysulfide with $\mathrm{y}<<1$.

In comparison, for a PC-SOFC especially at relatively low temperatures such as 550 or $450^{\circ} \mathrm{C}$, the system would approach ideal pure proton conduction condition. The anode hydrogen electrochemical oxidation reaction in such an ideal PC-SOFC would only involve (3') hydrogen incorporation into the proton conducting electrolyte and no water evolution as shown in Figure 3. 13 (c). $[15,38,81,88]$ (It is noted that unlike conventional OCSOFC, the exact anode reaction process for PC-SOFC, including whether it is limited to TPB or occurring over Ni or PCC surface, is not yet clear at the moment, and the schematic in Figure 3. 13 (c) is only an over-simplification of the actual processes.) Under such circumstance, if sulfur is present in the system, adsorbed sulfur would still cover both $\mathrm{Ni}$ metal as well the PCC electrolyte surface and interfere with (1) hydrogen adsorption and (2) dissociation and surface diffusion over Ni surface as shown in Figure 3. 13 (d). This naturally would slow down the overall anode reaction somewhat. However, it is hypothesized that, due to absence of water involvement in the anode reaction process for PC-SOFC and the relatively small size of hydrogen molecule/atom, the anode reaction could still proceed with less disruption than the circumstance when water is involved, as in conventional oxide-ion conducting SOFC. 
On the other hand, one additional hypothesis from the observed much less degradation for sulfur poisoning of PC-SOFC comparing with conventional OC-SOFC is that the proton conducting ceramic (PCC) electrolyte (in this case, $\mathrm{BZCYYb}$ ) might also play some (electro-)catalytic role in the anode hydrogen electrochemical oxidation reaction for PCSOFC. In other words, the PCC electrolyte surface might also be active for the adsorption and dissociation of hydrogen molecules in the hydrogen anode reaction for PC-SOFC, especially at temperature of $\sim 450-550^{\circ} \mathrm{C}$. The support for this hypothesis is that previous studies have shown that adsorbed sulfur would almost completely cover the Ni metal surface and dramatically slow down the adsorption and dissociation of hydrogen over the Ni surface under the relevant sulfur poisoning condition studied (e.g., $550{ }^{\circ} \mathrm{C}$ with $\sim 10$ $\left.\operatorname{ppm}(v) \mathrm{H}_{2} \mathrm{~S}\right) .[25,28,137]$ For a PC-SOFC with Ni-PCC cermet anode, if all catalytically active sites are limited to the $\mathrm{Ni}$ surface, the near complete coverage of Ni surface by adsorbed sulfur would lead to very large increase in anode interfacial resistance $\mathrm{R}_{\mathrm{a}}$, which might be the case for the $>400 \%$ increase in $\mathrm{R}_{\mathrm{ai}}$ for an anode symmetrical cell based on conventional oxide conducting electrolyte (see, for example, Figure 3. 7). In contrast, for a PC-SOFC, the actual observed relative increase in $\mathrm{R}_{\mathrm{ai}}$ was very moderate at $\sim 10-20 \%$ (see, for example, Figure 3. 7Figure 3. 1, Figure 3. 3, Figure 3. 4 and However, there is also one major difference in the observed electrochemical behaviors against $\mathrm{H}_{2} \mathrm{~S}$ poisoning between the two types of SOFCs. For comparable $\mathrm{H}_{2} \mathrm{~S}$ concentration and temperature, the relative degradation in anode electrochemical reaction rate appears to be much smaller for a PC-SOFC comparing with a typical oxide-ion conducting SOFC. For example, for both electrolyte-supported (see Figure 3. 5) and anode-supported PC-SOFC (Figure 3. 2), when temperature was $750^{\circ} \mathrm{C}$, low ppm-level $\mathrm{H}_{2} \mathrm{~S}$ causes a very small drop ( 0-2\%) in cell power 
output under constant current operation. (Note such an observation was made for low fuel utilization condition, which might change when current density or fuel utilization is high.) In comparison, numerous earlier studies clearly show a significant drop $(\sim 10-15 \%)$ in power output for conventional oxide-ion conducting SOFC. [29, 137] The results of impedance measurement under open circuit condition are also consistent with the power output measurement. For electrolyte-supported PC-SOFC full cell, as shown in Figure 3. 4, the electrode apparent interfacial resistance $\mathrm{R}_{\mathrm{ai}}$ increases due to $10 \mathrm{ppm}_{2} \mathrm{~S}$ is only $\sim 20 \%$ at $750^{\circ} \mathrm{C}$, while it was $\sim 80 \%$ for $8 \mathrm{ppm}(\mathrm{v}) \mathrm{H}_{2} \mathrm{~S}$ for conventional electrolytesupported SOFC at $800^{\circ} \mathrm{C}$. [29] Such a difference is even more obvious when comparison was made on the electrode interfacial resistance change for anode symmetrical cells. The possible explanations are discussed later.

Table 3. 1) even though Ni metal is still the only metal phase in the cermet anode.

Therefore, it seems likely that the surface of PCC electrolyte such as BZCYYb could also be active for hydrogen adsorption and dissociation under the condition studied, which is possible given that PCC electrolytes are known to interact with hydrogen. With the presence of low-ppm level $\mathrm{H}_{2} \mathrm{~S}$, SIMS analysis of the Ni-BZCYYb composite suggests that sulfur atoms have got incorporated into the bulk of BZCYYb electrolyte (possibly by displacing lattice oxygen), while analysis using XRD and EDS have ruled out the formation of other crystalline bulk sulfides. We hypothesize that the similar nature of sulfur and oxygen in terms of their valence states may not lead to significant change in the defect structure of the PCC electrolyte, and hydrogen surface adsorption/dissociation might still remain active despite the PCC electrolyte surface oxygen covered-over or even (partially) 
replaced by sulfur. Further detailed mechanism studies including i) analysis with more sensitive and quantitative surface analysis techniques, ii) use of patterned electrode cells with different metal electrodes that enable comparison between Ni metal and inert metal catalysts (e.g., gold or copper metal) and use of cells with different controlled microstrctures, and iii) theoretical modeling including fitting of the impedance data with better separation to equivalent circuits are all needed to test the hypotheses raised here and provide more insights about the fundamental anode reaction mechanism and sulfur poisoning processes for PC-SOFC.

\subsection{Conclusions}

The effect of $\mathrm{H}_{2} \mathrm{~S}$ as a fuel contaminant on PC-SOFC was studied. The results from proton conducting SOFC full cells and proton conducting anode symmetrical cells clearly show that PC-SOFC, similar to conventional OC-SOFC, is still poisoned by low-ppm level $\mathrm{H}_{2} \mathrm{~S}$ at temperatures in the range of 750 to $450^{\circ} \mathrm{C}$ with increase in anode interfacial resistance $\mathrm{R}_{\mathrm{ai}}$ and no change in ohmic resistance $\mathrm{R}_{\mathrm{o}}$. The sulfur poisoning for PC-SOFC gets more obvious and less reversible as $\mathrm{H}_{2} \mathrm{~S}$ concentration increases. On the other hand, the relative degradation in anode reaction rate due to sulfur poisoning (e.g., as measured by relative increase in anode interfacial resistance) is much smaller for PC-SOFC than for conventional OC-SOFC under comparable conditions. This is attributed to the fact that the anode reaction route for an ideal PC-SOFC only involves proton incorporation and no water evolution, which is different from conventional OC-SOFC. The displayed significantly less anode sulfur poisoning for a PC-SOFC also implies that proton 
conducting ceramic (PCC) electrolyte might play an important (electro-)catalytic role (i.e., promoting hydrogen adsorption/dissociation) in the anode hydrogen oxidation reaction for PC-SOFC, which helps maintain the reaction rate upon exposure to low-ppm level $\mathrm{H}_{2} \mathrm{~S}$. As no formation of bulk sulfide phases was revealed by bulk characterization techniques such as EDS and XRD for the post $\mathrm{H}_{2} \mathrm{~S}$ exposure sample, surface sensitive technique of SIMS mapping with depth profiling was carried out. The results suggest a strong association between Ba species and S species that persists into the bulk of the Ni-PCC composite, indicating the possible incorporation of sulfur into the barium containing PCC electrolyte. Further study using more quantitative surface analysis techniques, electrochemical testing involving patterned metal electrode cells with controlled geometry and/or electrode materials and cells with controlled microstructure, and theoretical modeling (including fitting to equivalent circuits) may help clarify the fundamental mechanism for the anode hydrogen reaction of PC-SOFC including the detailed sulfur poisoning mechanism. 


\subsection{Supplementary Materials}

EDS results are shown as following:

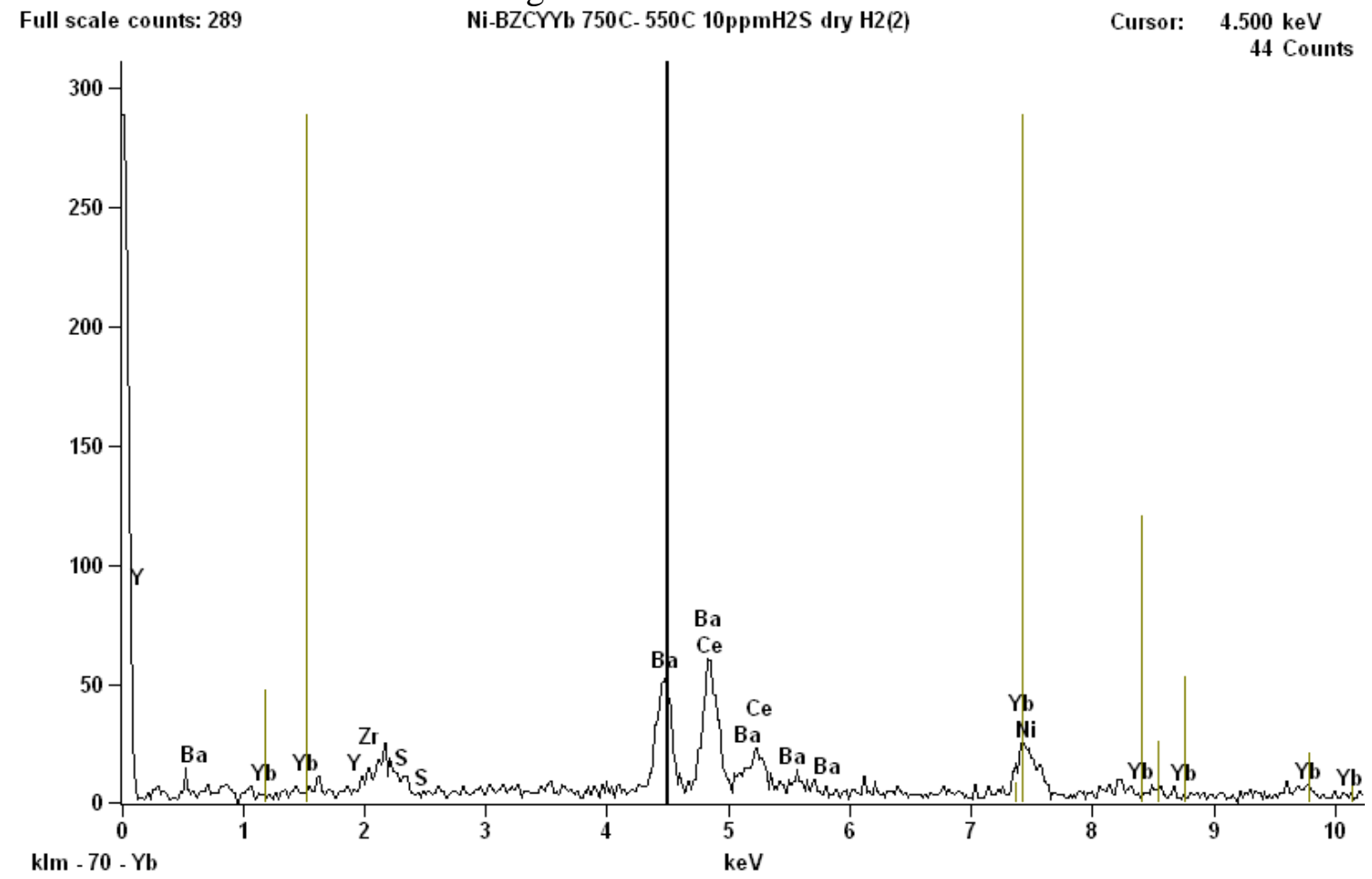

Figure S3.1 EDS map scanning of the Ni-BZCYYb mixed loose powder after exposed to 10ppm $\mathrm{H}_{2} \mathrm{~S}$ at $550^{\circ} \mathrm{C}$ in wet $\mathrm{H}_{2}$ for 24 hours test showing no evidence of sulfur existence.

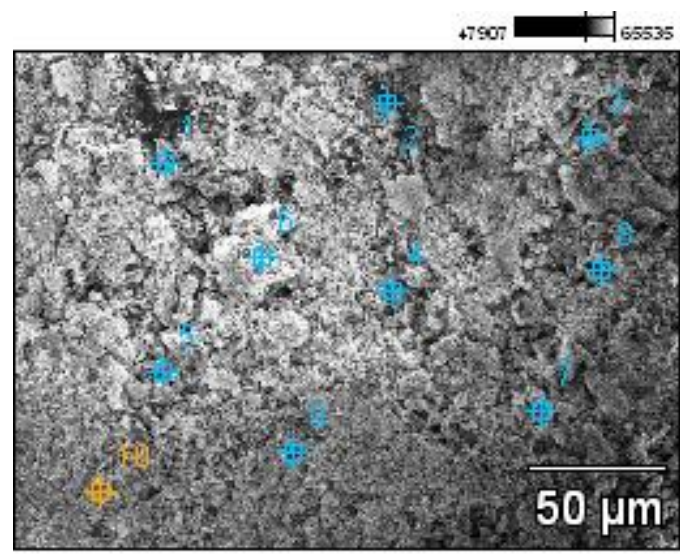

Figure S3.2 SEM image of the Points 1-10 indicating the locations for detection by EDS point scanning on the Ni-BZCYYb mixed loose powder 
Table S3.1 Elements' distribution on the surface of Ni-BZCYYb mixed loose powder after $\mathrm{H}_{2} \mathrm{~S}$ exposure test by atom quantity percentage

\begin{tabular}{lccccccc} 
& $\boldsymbol{S}-\boldsymbol{K}$ & $\boldsymbol{N i}-\boldsymbol{K}$ & $\boldsymbol{Y}-\boldsymbol{L}$ & $\mathbf{Z} \boldsymbol{r}-\boldsymbol{L}$ & $\boldsymbol{B a}-\boldsymbol{L}$ & $\boldsymbol{C e}-\boldsymbol{L}$ & $\boldsymbol{Y b}-\boldsymbol{L}$ \\
\hline $\boldsymbol{p t 1}$ & 0.00 & 25.37 & 0.00 & 0.00 & 40.82 & 32.18 & 1.64 \\
$\boldsymbol{p t 2}$ & 0.00 & 0.00 & 0.00 & 0.00 & 91.74 & 8.26 & 0.00 \\
$\boldsymbol{p t 3}$ & 0.00 & 11.41 & 0.00 & 0.00 & 47.67 & 32.32 & 8.60 \\
$\boldsymbol{p t 4}$ & 0.00 & 1.25 & 0.00 & 0.00 & 54.82 & 35.11 & 8.82 \\
$\boldsymbol{p t 5}$ & 0.00 & 22.62 & 0.00 & 1.82 & 47.12 & 28.17 & 0.27 \\
$\boldsymbol{p t 6}$ & 0.00 & 0.91 & 0.00 & 0.00 & 53.79 & 40.11 & 5.18 \\
$\boldsymbol{p t 7}$ & 0.00 & 0.00 & 0.00 & 2.33 & 55.15 & 37.21 & 5.31 \\
$\boldsymbol{p t 8}$ & 0.00 & 23.90 & 0.00 & 1.96 & 41.71 & 25.30 & 7.14 \\
$\boldsymbol{p t 9}$ & 0.00 & 7.56 & 0.00 & 0.00 & 52.93 & 33.76 & 5.75 \\
$\boldsymbol{p t 1 0}$ & 0.00 & 11.67 & 0.00 & 0.00 & 53.12 & 35.22 & \\
\hline
\end{tabular}

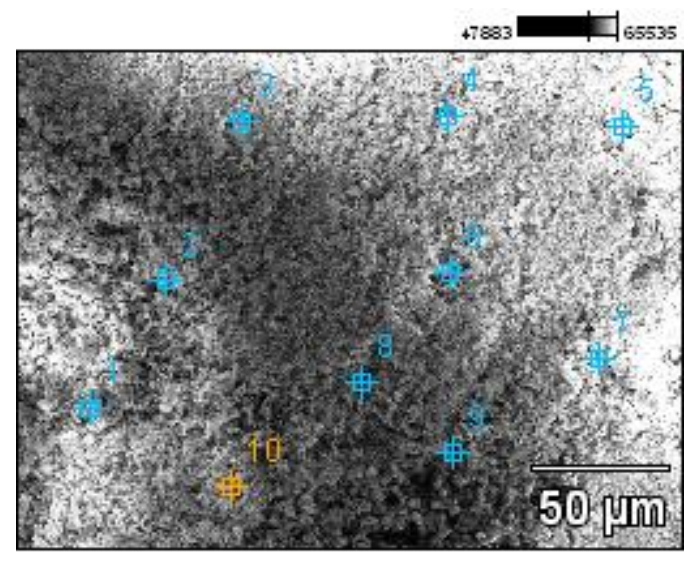

Figure S3.3 SEM image of the Points 1-10 indicating the locations for detection by EDS point scanning $\left(2^{\text {nd }}\right)$ 
Table S3.2 Elements' distribution on the surface of Ni-BZCYYb mixed loose powder after $\mathrm{H}_{2} \mathrm{~S}$ exposure test by atom quantity percentage $\left(2^{\text {nd }}\right)$

\begin{tabular}{lccccccc} 
& $\boldsymbol{S}-\boldsymbol{K}$ & $\boldsymbol{N i}-\boldsymbol{K}$ & $\boldsymbol{Y}-\boldsymbol{L}$ & $\mathbf{Z} \boldsymbol{r}-\boldsymbol{L}$ & $\boldsymbol{B a}-\boldsymbol{L}$ & $\boldsymbol{C e}-\boldsymbol{L}$ & $\boldsymbol{Y b}-\boldsymbol{L}$ \\
\hline $\boldsymbol{p t 1}$ & 0.00 & 85.43 & 0.00 & 0.00 & 8.64 & 5.93 & \\
$\boldsymbol{p t 2}$ & 0.00 & 2.83 & 3.40 & 2.07 & 54.24 & 29.06 & 8.40 \\
$\boldsymbol{p t 3}$ & 4.37 & 2.04 & 0.00 & 1.98 & 46.50 & 40.35 & 4.76 \\
$\boldsymbol{p t 4}$ & 0.45 & 0.00 & 0.00 & 0.00 & 55.29 & 39.38 & 4.88 \\
$\boldsymbol{p t 5}$ & 0.00 & 0.00 & 0.00 & 0.00 & 56.66 & 38.27 & 5.07 \\
$\boldsymbol{p t 6}$ & 0.00 & 5.72 & 0.00 & 0.00 & 60.62 & 33.66 & \\
$\boldsymbol{p t 7}$ & 0.00 & 17.50 & 0.00 & 0.00 & 44.00 & 31.06 & 7.43 \\
$\boldsymbol{p t 8}$ & 0.00 & 39.65 & 0.00 & 0.00 & 33.36 & 23.15 & 3.84 \\
$\boldsymbol{p t 9}$ & 3.06 & 26.77 & 0.00 & 0.00 & 41.63 & 27.07 & 1.47 \\
$\boldsymbol{p t 1 0}$ & 0.00 & 0.56 & 0.00 & 0.00 & 58.56 & 34.67 & 6.21 \\
\hline
\end{tabular}

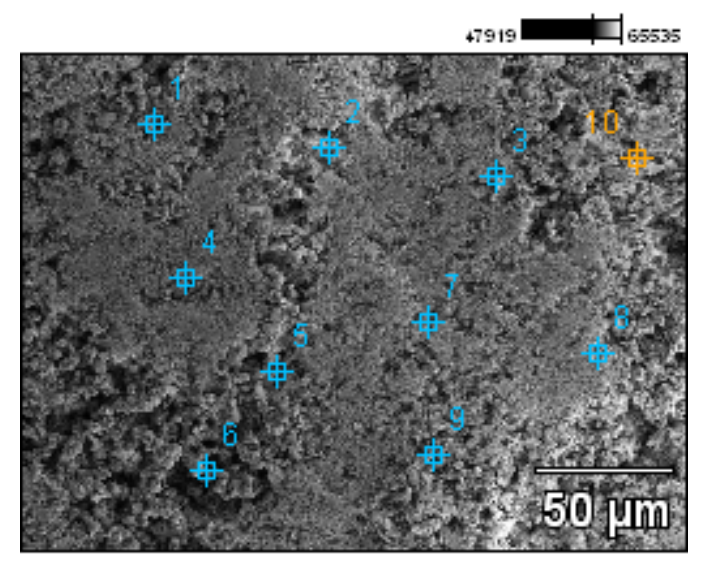

Figure S3.4 SEM image of the Points 1-10 indicating the locations for detection by EDS point scanning $\left(3^{\text {rd }}\right)$ 
Table S3.3 Elements' distribution on the surface of Ni-BZCYYb mixed loose powder after $\mathrm{H}_{2} \mathrm{~S}$ exposure test by atom quantity percentage $\left(3^{\text {rd }}\right)$

\begin{tabular}{|c|c|c|c|c|c|c|c|}
\hline & $S-K$ & $N i-K$ & $Y-L$ & $Z r-L$ & $B a-L$ & $C e-L$ & $Y b-L$ \\
\hline pt1 & 0.00 & 33.41 & 0.00 & 0.00 & 33.80 & 25.00 & 7.79 \\
\hline$p t 2$ & 0.00 & 5.48 & 0.00 & 0.00 & 58.86 & 32.77 & 2.89 \\
\hline$p t 3$ & 0.00 & 13.32 & 0.00 & 0.00 & 51.14 & 31.15 & 4.39 \\
\hline pt4 & 0.00 & 68.32 & 0.00 & 0.00 & 18.41 & 13.27 & \\
\hline$p t 5$ & 0.00 & 18.02 & 0.00 & 0.00 & 59.03 & 22.96 & \\
\hline pt6 & 0.00 & 98.26 & 0.00 & 0.00 & 0.84 & 0.91 & \\
\hline$p t 7$ & 0.00 & 13.25 & 0.00 & 5.61 & 48.31 & 27.45 & 5.37 \\
\hline pt8 & 0.00 & 18.60 & 0.00 & 0.00 & 50.83 & 28.82 & 1.75 \\
\hline$p t 9$ & 0.00 & 72.42 & 0.00 & 0.00 & 14.84 & 12.74 & \\
\hline pt10 & 0.00 & 93.60 & 0.00 & 0.00 & 6.40 & & \\
\hline
\end{tabular}

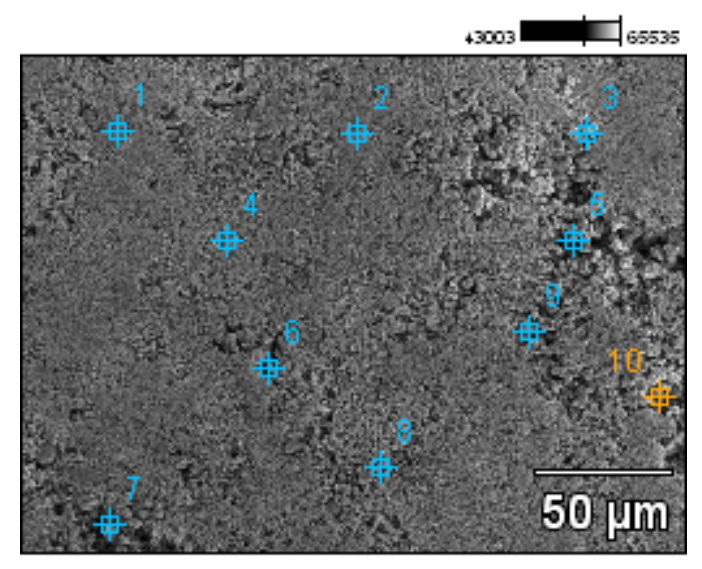

Figure S3.4 SEM image of the Points 1-10 indicating the locations for detection by EDS point scanning $\left(4^{\text {th }}\right)$ 
Table S3.4 Elements' distribution on the surface of Ni-BZCYYb mixed loose powder after $\mathrm{H}_{2} \mathrm{~S}$ exposure test by atom quantity percentage $\left(4^{\text {th }}\right)$

\begin{tabular}{|c|c|c|c|c|c|c|c|}
\hline & $S-K$ & $N i-K$ & $Y-L$ & $Z r-L$ & $B a-L$ & $C e-L$ & $Y b-L$ \\
\hline$p t 1$ & 0.00 & 0.00 & 0.00 & 0.00 & 54.64 & 36.53 & 8.83 \\
\hline$p t 2$ & 0.00 & 0.00 & 0.00 & 0.00 & 56.06 & 38.85 & 5.09 \\
\hline pt3 & 0.00 & 12.67 & 0.00 & 11.52 & 50.29 & 25.52 & \\
\hline pt4 & 0.00 & 0.00 & 0.00 & 0.00 & 56.99 & 35.68 & 7.33 \\
\hline pt5 & 0.00 & 97.61 & 0.00 & 0.00 & 1.44 & 0.95 & 0.00 \\
\hline pt6 & 0.00 & 64.09 & 0.00 & 0.00 & 21.12 & 14.80 & 0.00 \\
\hline pt7 & 0.00 & 98.66 & 0.00 & 0.00 & 0.90 & 0.45 & 0.00 \\
\hline pt8 & 0.00 & 5.74 & 0.00 & 0.00 & 94.26 & 0.00 & 0.00 \\
\hline pt9 & 0.00 & 77.55 & 0.00 & 0.00 & 12.29 & 7.13 & 3.03 \\
\hline pt10 & 0.00 & 2.23 & 0.00 & 0.00 & 64.42 & 30.04 & 3.31 \\
\hline
\end{tabular}




\section{Chapter IV: $\mathrm{CO}_{2}$ Poisoning Behavior for the Anode of Proton Conducting IT-SOFC}

This chapter details the study on the $\mathrm{CO}_{2}$ poisoning behavior for the anode of proton conducting IT-SOFC. This chapter is based on published paper by Shichen Sun, Osama Awadallah, and Zhe Cheng. Title of "Poisoning of Ni-based anode for proton conducting SOFC by $\mathrm{H} 2 \mathrm{~S}, \mathrm{CO}$ 2, and $\mathrm{H} 2 \mathrm{O}$ as fuel contaminants." in Journal of Power Sources 378 (2018): 255-263.

\subsection{Introduction}

Carbon dioxide $\left(\mathrm{CO}_{2}\right)$ is deemed harmless for the anode reaction of conventional oxideion conducting solid oxide fuel cells (SOFC). [39] However, it is known to negatively impact proton conducting ceramics (PCC), often leading to formation of carbonates or hydroxides. [89, 121, 148-150] For proton conducting intermediate temperature SOFC (ITSOFC) based on PCC as electrolyte and part of the cermet anode, it is necessary to investigate how carbon dioxide $\left(\mathrm{CO}_{2}\right)$ would impact the anode reaction. Therefore, the electrochemical behaviors of the anode for proton conducting IT-SOFC upon exposure to low percentage-level $\mathrm{CO}_{2}$ in hydrogen fuel were investigated. Studies based on both anodesupported and electrolyte-supported proton conducting IT-SOFC full cell and Ni-based anode symmetrical proton conducting SOFC were carried out, using one leading proton conducting ceramics of BZCYYb. The focus was on characterizing the severity and reversibility of poisoning, if any, as caused by $\mathrm{CO}_{2}$ as fuel contaminants including the responses in cell bulk and interfacial resistances and linking the observed electrochemical 
behaviors to the electro-catalytic activity of PCC in the anode reaction using different routes. In addition, chemical stability tests regarding the exposure to $\mathrm{CO}_{2}$ was also carried out on Ni-BZCYYb powder, followed by characterization methods such as X-Ray diffraction (XRD) and Raman spectroscopy. The implications of the observed poisoning behavior against $\mathrm{CO}_{2}$ exposure will be discussed and analyzed to establish better understanding of the anode reaction mechanism for proton conducting IT-SOFC. Beyond that, the directions for future study will be pointed out.

\subsection{Experimental}

\subsubsection{Powder Synthesis and Cell Fabrication}

In this study, $\mathrm{BaZr}_{0.1} \mathrm{Ce}_{0.7} \mathrm{Y}_{0.1} \mathrm{Yb}_{0.1} \mathrm{O}_{3-\delta}(\mathrm{BZCYYb})$ was chosen as the proton conducting ceramic (PCC) electrolyte, and it was synthesized by glycine nitrate process (GNP) followed by heat treatment to form the perovskite phase as described in 3.2.1. The cathode material used in this study is $\mathrm{La}_{0.6} \mathrm{Sr}_{0.4} \mathrm{Co}_{0.2} \mathrm{Fe}_{0.8} \mathrm{O}_{3-\delta}$ (LSCF) and the synthesis steps are also similar to that for BZCYYb as described in 3.2.1.

Anode-supported full cells with the configuration of Ni-BZCYYb/BZCYYb/LSCFBZCYYb were fabricated as described in 3.2.1. Briefly, anode precursor/electrolyte bilayer was first prepared via dry-pressing using $0.2 \mathrm{~g}$ NiO-BZCYYb-starch powder mixture with weight ratio of 5.5: $3.5: 1$ and $10 \mathrm{mg}$ BZCYYb electrolyte powder at a pressure of $250 \mathrm{MPa}$. Then the pellets of anode precursor/electrolyte bilayer were sintered at $1400^{\circ} \mathrm{C}$ for 5 hours. After that, cathode slurry of LSCF and BZCYYb and polymer binder 
solution with weight ratio of 7: 3: 15 were brush painted onto the electrolyte side of the sintered anode/electrolyte bilayer pellets with area of $\sim 0.16 \mathrm{~cm}^{2}$. The dried cathode/electrolyte/anode pellets were then calcined at $1100^{\circ} \mathrm{C}$ for 2 hours in ambient air. Finally, silver mesh and wires were attached to the electrodes using pure silver paste for current collection.

Electrolyte-supported PC-SOFC full cell with the configuration of $\mathrm{Ni}$ BZCYYb/BZCYYb/LSCF-BZCYYb were also fabricated by the steps as described in 3.2.1. Briefly, an electrolyte pellet was first prepared via dry-pressing $0.2 \mathrm{~g}$ BZCYYb powder followed by sintering at $1550^{\circ} \mathrm{C}$ for 5 in a so called "protected sintering" configuration. [89] Second, the anode slurry made by mixture of $\mathrm{NiO}, \mathrm{BZCYYb}$ and organic binder solution at a weight ratio of 3:2: 5 was brushed-painted onto one side of the sintered electrolyte pellet followed by heat treatment in air at $1400{ }^{\circ} \mathrm{C}$ for 2 hours. Finally, LSCF-BZCYYb cathode slurry, with a LSCF: BZCYYb: organic binder solution weight ratio of 6.5: 3.5: 10 was brush-painted onto the other side of the pellet and then calcined at $1100{ }^{\circ} \mathrm{C}$ for 2 hours in ambient air. Both the cathode and anode area were $\sim 0.16$ $\mathrm{cm}^{2}$. For subsequent electrochemical test, silver mesh and wires were attached to the electrodes using pure silver paste for current collection.

In addition, anode symmetrical cells with the configuration of $\mathrm{Ni}$ BZCYYb/BZCYYb/Ni-BZCYYb were fabricated as described in 3.2.1 by first dry pressing $0.1 \mathrm{~g}$ of $\mathrm{BZCYYb}$ powder into $10 \mathrm{~mm}$ diameter pellets at a pressure of $250 \mathrm{MPa}$. The electrolyte pellets were then sintered at $1550^{\circ} \mathrm{C}$ for 5 hours under "protected condition". NiO-BZCYYb slurry was made by mixing NiO, BZCYYb, and polymer binder 
solution (polymer content of $8 \%$ ) at weight ratio of 5.5: 3.5: 9. After that, symmetrical anodes were painted onto both sides of the sintered electrolyte pellet followed by drying in an air oven at $100^{\circ} \mathrm{C}$ and then calcination at $1400^{\circ} \mathrm{C}$ for 2 hours in ambient air with heating and cooling rate of $5^{\circ} \mathrm{C} / \mathrm{min}$. Silver meshes were attached onto both electrodes using pure silver paste for current collection purpose.

\subsubsection{Electrochemical Testing of the Effects of $\mathrm{CO}_{2}$ as Fuel Contaminants}

For electrochemical testing of anode-supported and electrolyte-supported PC-SOFC full cells, the steps are also same as described in 3.2.2. First, they were sealed onto one end of an alumina support tube using ceramic sealant (Aremco 552) and placed in the hot zone of a tube furnace. [140] The cell was then heated up to $750^{\circ} \mathrm{C}$ during which the anode-side was purged with pure $\mathrm{N}_{2}$ (UHP300 grade, Airgas) while the cathode side was exposed to ambient air. Then at $750^{\circ} \mathrm{C}$, dry hydrogen (UHP300 grade with $p \mathrm{H}_{2} \mathrm{O}$ of $\sim 10$ ppm, Airgas) was introduced into the anode side at a flow rate of $40 \mathrm{~mL} / \mathrm{min}$ and $\mathrm{NiO}$ in the anode was reduced to $\mathrm{Ni}$.

For anode-symmetrical cells, the steps are also similar to that described in 3.2.2. First, the cells were placed in the hot zone inside a one-end closed ceramic tube with gas fed directly to the cell to obtain a rapid response. The symmetrical cells were then heated up in $\mathrm{N}_{2}$ to $750^{\circ} \mathrm{C}$ and reduced in pure $\mathrm{H}_{2}$.

After anode reduction, electrochemical measurements for those cells, especially electrochemical impedance spectroscopy (EIS) measurements were carried out using a 
potentiostat (Interface 1000, Gamry). To characterize the effects of $\mathrm{CO}_{2}$ on the electrochemical responses of the full cells and anode symmetrical cells, $5 \% \mathrm{CO}_{2}$ was introduced into the $\mathrm{H}_{2}$ fuel while keeping the total fuel flow rate the same. For anodesupported SOFC full cells, the change in cell voltage was monitored continuously at a constant current density of $125 \mathrm{~mA} / \mathrm{cm}^{2}$, and EIS was recorded before, after 2 hours of exposure to $5 \% \mathrm{CO}_{2}$, and after removal of $\mathrm{CO}_{2}$ for 24 hours under both open circuit condition and biased condition of $0.7 \mathrm{~V}$ at $750^{\circ} \mathrm{C}$. For electrolyte-supported and anodesymmetrical cells, EIS under open circuit condition was recorded in clean dry $\mathrm{H}_{2}$ (UHP grade with $p \mathrm{H}_{2} \mathrm{O}$ of $\sim 10 \mathrm{ppm}$, labelled as $d r y$ in this study) and compared to those in $\mathrm{H}_{2}$ containing $5 \% \mathrm{CO}_{2}$ after 2 hours of exposure at temperatures of 750,650 , and $550^{\circ} \mathrm{C}$.

\subsubsection{Stability Tests of Ni-BZCYYb Mixed Powders}

To study the chemical stability of Ni-BZCYYb cermet anode under relevant testing conditions and understand the observed electrochemical responses to $\mathrm{CO}_{2}$ poisoning, a series of experiments were carried out by exposing NiO-BZCYYb powder mixtures (5.5: 3.5 weight ratio) after hydrogen reduction to low percentage-level $\mathrm{CO}_{2}$ as fuel contaminants in both $\sim 3 \%$ humidified and dry $\mathrm{H}_{2}$. Similarly, as described in 3.2.3, in each set of tests, $10 \mathrm{mg}$ of $\mathrm{NiO}-\mathrm{BZCYYb}$ powder mixture was placed in an alumina boat in a one-end closed tube with fuel gas mixture directly fed to the sample surface. As in electrochemical testing, the samples were first heated up in $\mathrm{N}_{2}$ to $750^{\circ} \mathrm{C}$. Then $\mathrm{NiO}$ in the mixture was reduced to $\mathrm{Ni}$ in dry $\mathrm{H}_{2}$ for 30 minutes. After that, the samples were cooled down to $550^{\circ} \mathrm{C}$, and $5 \% \mathrm{CO}_{2}$ was introduced into the hydrogen fuel (3\% humidified or 


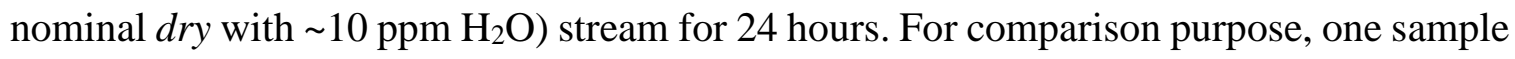
was treated in the same way without the introduction of $\mathrm{CO}_{2}$. All post-exposure samples were cooled rapidly (by quickly removing the sample tube from the furnace) in clean $\mathrm{N}_{2}$ to avoid any additional reaction. X-Ray diffraction (SIEMENS diffractometer D5000) was taken for all samples after the exposure tests for phase identification. Besides that, Raman spectra were also collected for selected samples using a spectrometer (HoloSpec f/l.8i, Kaiser Optical System) equipped with an air-cooled Ar ion laser system (Spectra Physics Model $177,514 \mathrm{~nm}, 35 \mathrm{~mW}$, spot size $10 \mu \mathrm{m}$ ) in the range of 200 to $2000 \mathrm{~cm}^{-1}$ Raman shift for additional identification of the reaction products from the stability tests.

\subsection{Results}

\subsection{1 $\mathrm{CO}_{2}$ Poisoning of Ni-BZCYYb/BZCYYb /LSCF Anode-supported PC- SOFC Full Cell}

Figure 4. 1 (a) shows the effect of $5 \% \mathrm{CO}_{2}$ on the anode-supported full cell operated at $750^{\circ} \mathrm{C}$ under constant current condition: Upon introduction of $5 \% \mathrm{CO}_{2}$, the cell voltage dropped immediately and then seemed to reach steady state. Later, when the $5 \% \mathrm{CO}_{2}$ was removed from the fuel stream, the cell voltage increased back first quickly and then slowly and eventually fully recovered to the performance before poisoning. 

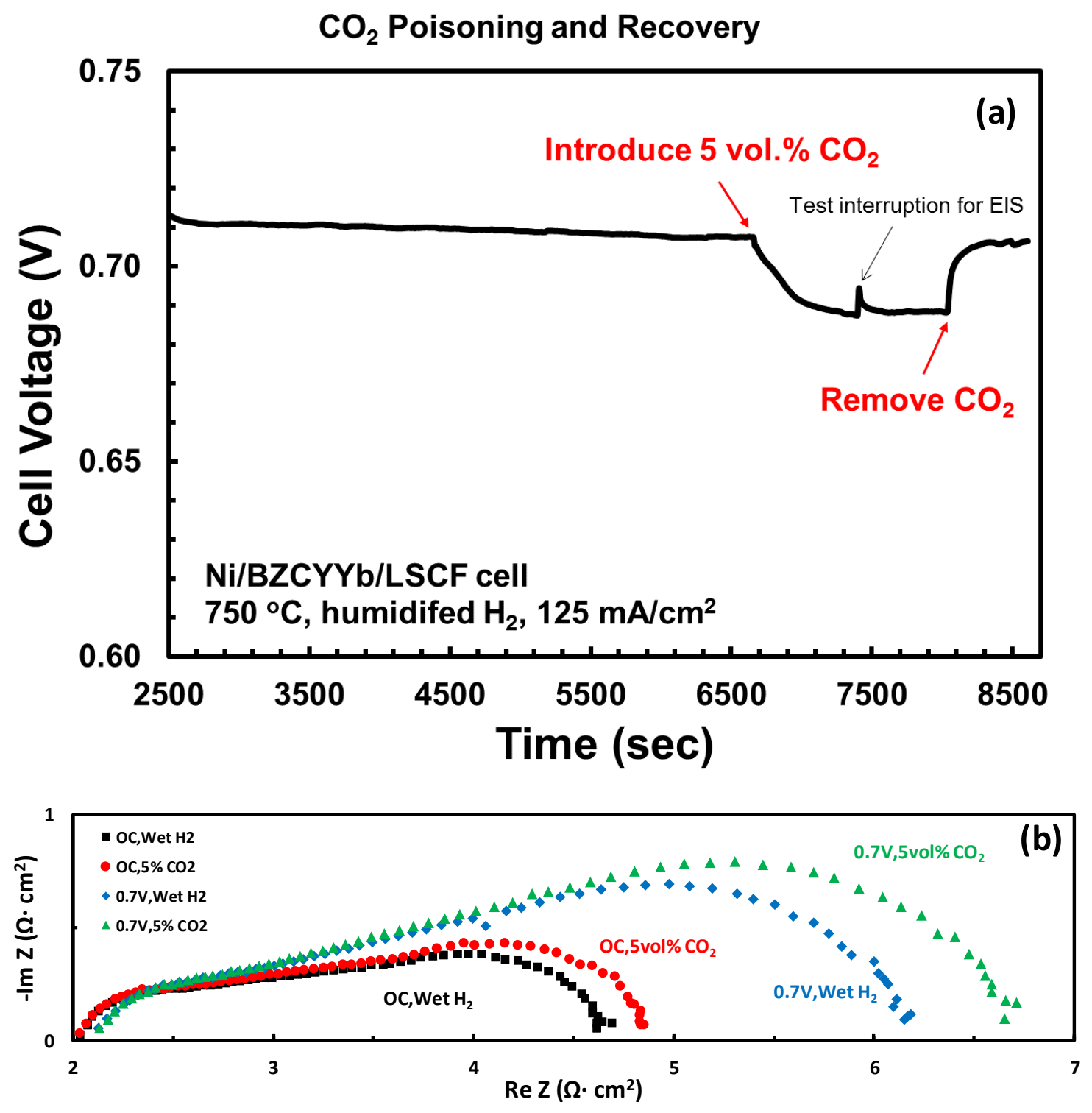

Figure 4. 1 (a) Plot of cell voltage versus time for the Ni-BZCYYb/BZCYYb/LSCFBZCYYb anode-supported proton-conducting SOFC full cell operated under constant current density of $125 \mathrm{~mA} / \mathrm{cm}^{2}$ showing the poisoning and recovery as caused by introducing $5 \% \mathrm{CO}_{2}$ to the $3 \%$ humidified $\mathrm{H}_{2}$ fuel and later remove it at $750^{\circ} \mathrm{C}$. (b) Impedance spectra for the Ni-BZCYYb/BZCYYb/LSCF anode-supported protonconducting SOFC full cell operated with $3 \%$ humidified $\mathrm{H}_{2}$ (labelled as "Wet $\mathrm{H}_{2}$ ") at $750^{\circ} \mathrm{C}$ under open circuit (OC) condition and constant cell voltage of $0.7 \mathrm{~V}$ showing the poisoning effect of $5 \% \mathrm{CO}_{2}$. 
Figure 4. 1 (b) shows the impedance for the anode-supported full cell at $750^{\circ} \mathrm{C}$ under both OCV and constant cell voltage of $0.7 \mathrm{~V}$ before and after the introduction of $5 \% \mathrm{CO}_{2}$ into the $3 \%$ humidified $\mathrm{H}_{2}$. Under both open circuit and biased conditions, cell interfacial resistance $\mathrm{R}_{\mathrm{ai}}$ increased with the introduction of $\mathrm{CO}_{2}$, especially in the MF-LF loops, while no change was observed in cell ohmic resistance $\mathrm{R}_{\mathrm{O}}$.

\subsection{2 $\mathrm{CO}_{2}$ Poisoning of Ni-BZCYYb/BZCYYb/LSCF Electrolyte-supported PC-SOFC Full Cell}

Figure 4. 2 shows the change in impedance spectra for the Ni-BZCYYb/BZCYYb/LSCF electrolyte-supported PC-SOFC full cell upon the introduction of $5 \% \mathrm{CO}_{2}$ into dry $\mathrm{H}_{2}$ fuel at $750^{\circ} \mathrm{C}, 650^{\circ} \mathrm{C}$ and $550^{\circ} \mathrm{C}$. At $750^{\circ} \mathrm{C}$, the poisoning behavior is similar to that for anodesupported cell: No change in cell ohmic resistance $\mathrm{R}_{\mathrm{O}}$ was observed, while the MF-LF semicircles show slight increase with the introduction of $5 \% \mathrm{CO}_{2}$ (see Figure 4. 2 (a)). Similar trend was observed at $650^{\circ} \mathrm{C}$, with insignificant increase in $\mathrm{R}_{\mathrm{ai}}$ which is limited in MF-LF semicircles (see Figure 4. 2 (b)). As temperature goes $550^{\circ} \mathrm{C}$, the increase in MFLF semicircles get slightly larger than that at $750^{\circ} \mathrm{C}$ and $650^{\circ} \mathrm{C}$ (see Figure 4.2 (c)). 

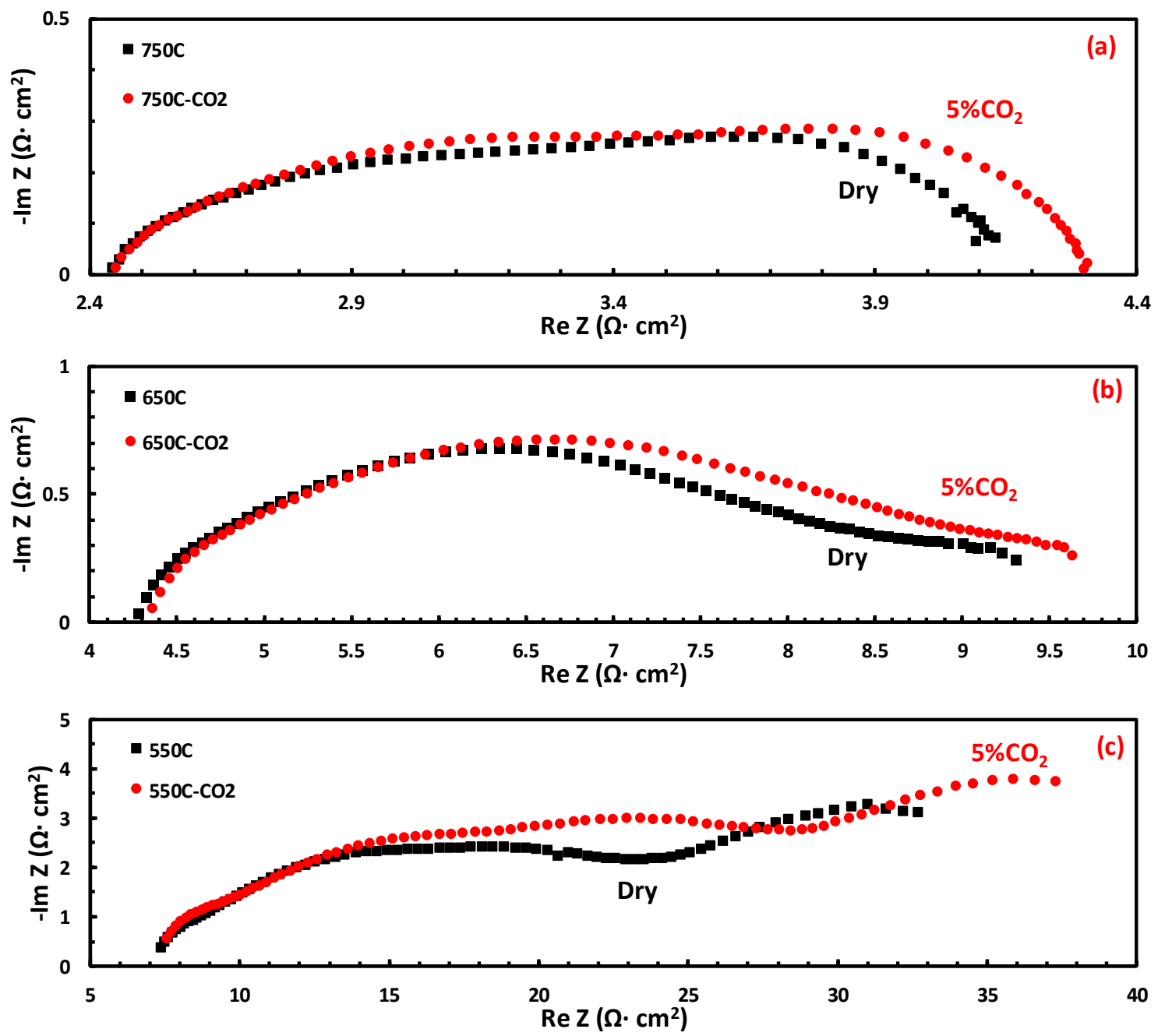

Figure 4. 2 Impedance spectra measured under open circuit condition for a $\mathrm{Ni}$ $\mathrm{BZCYYb/BZCYYb/LSCF-BZCYYb}$ electrolyte-supported proton-conducting SOFC (PC-SOFC) at (a) $750^{\circ} \mathrm{C}$, (b) $650^{\circ} \mathrm{C}$, (c) $550^{\circ} \mathrm{C}$, and showing the effect of introducing $5 \mathrm{vol} \% \mathrm{CO}_{2}$ as fuel contaminant to the dry $\mathrm{H}_{2}$. 


\subsection{3 $\mathrm{CO}_{2}$ Poisoning of Ni-BZCYYb/BZCYYb/Ni-BZCYYb Anode Symmetrical Cell}

Figure 4. 3 shows the change in impedance spectra for the Ni-BZCYYb/BZCYYb/NiBZCYYb anode symmetrical cell upon introduction of $5 \% \mathrm{CO}_{2}$ into dry $\mathrm{H}_{2}$ fuel at $750^{\circ} \mathrm{C}$, $650^{\circ} \mathrm{C}$ and $550^{\circ} \mathrm{C}$. At $750^{\circ} \mathrm{C}$ and $650^{\circ} \mathrm{C}$, the poisoning behavior is similar to that for anodesupported full cell and electrolyte-supported full cell (compare Figure 4. 3 (a) and (b) versus Figure 4. 1 (b) and Figure 4. 2 (a) and (b)): No change in the HF semicircle or ohmic resistance $\mathrm{R}_{\mathrm{O}}$ was observed, while the MF-LF semicircles show obvious increase. As temperature goes down to $550^{\circ} \mathrm{C}$, very dramatic increase in MF-LF semicircles was observed with total anode apparent interfacial resistance $\mathrm{R}_{\mathrm{ai}}$ more than doubled.
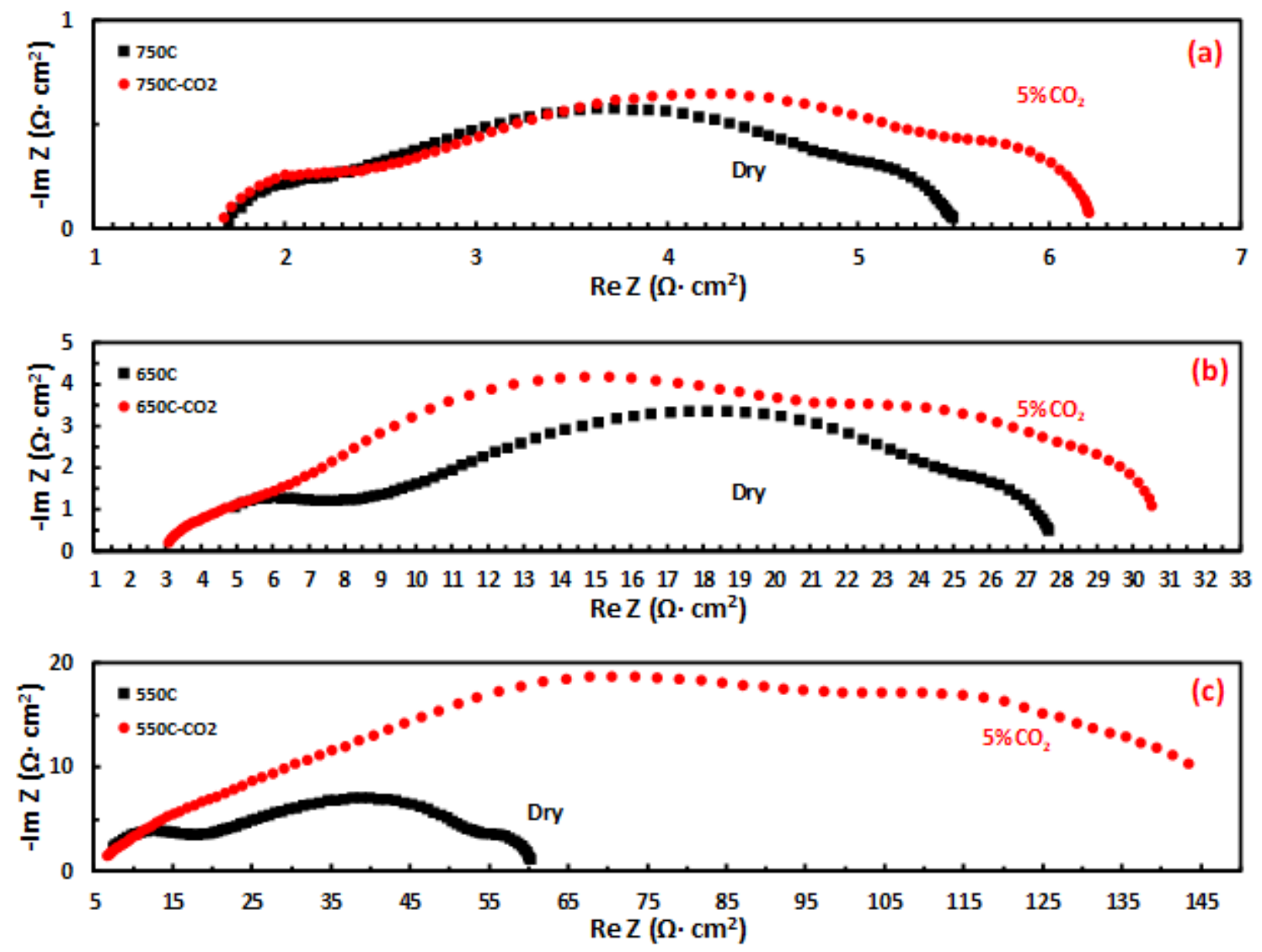
Figure 4. 3 Impedance spectra showing the effect of introducing $5 \% \mathrm{CO}_{2}$ to dry $\mathrm{H}_{2}$ fuel on the Ni-BZCYYb/BZCYYb/Ni-BZCYYb anode symmetrical cell at (a) $750^{\circ} \mathrm{C}$, (b) $650^{\circ} \mathrm{C}$ and (c) $550^{\circ} \mathrm{C}$, respectively.

\subsection{4 $\mathrm{CO}_{2}$ Exposure Tests on Ni-BZCYYb Mixed Powders}

The XRD patterns for the Ni-BZCYYb mixed powders after various exposure tests are shown in Figure 4. 4 (a). It can be found that after exposing the Ni-BZCYYb mixed powders to $5 \% \mathrm{CO}_{2}$ at $550^{\circ} \mathrm{C}$ in both dry and wet $\mathrm{H}_{2}$, the diffraction peaks for $\mathrm{BZCYYb}$ (e.g., at $2 \theta$ of $28.7^{\circ}, 41.3^{\circ}$, and $51.2^{\circ}$ ) largely disappeared while significant amounts of new phases of barium carbonate $\left(\mathrm{BaCO}_{3}\right)$ and doped ceria $\left(\mathrm{CeO}_{2}\right)$ emerged. On the other hand, it is noted that when the $\mathrm{CO}_{2}$ exposure test was carried out at $750^{\circ} \mathrm{C}$, the extent of reaction between $5 \% \mathrm{CO}_{2}$ balanced by $\mathrm{H}_{2}$ and $\mathrm{BZCYYb}$ was much less obvious with no detectable doped ceria formation, which is also consistent with earlier observation. [35] These observations were further confirmed by the corresponding Raman spectra for the post $\mathrm{CO}_{2-}$ exposure samples as shown in Figure 4.4 (b). The major peaks for BZCYYb (doublets at $\sim 350 \mathrm{~cm}^{-1}$, a small hump at $\sim 430 \mathrm{~cm}^{-1}$, and a broad peak at $\sim 640 \mathrm{~cm}^{-1}$ ) were identified in the control sample treated in dry $\mathrm{H}_{2}$, [35] while those peaks disappeared in the samples exposed to $5 \% \mathrm{CO}_{2}$ balanced by either dry or wet $\mathrm{H}_{2}$ at $550^{\circ} \mathrm{C}$ for 24 hours. On the other hand, three new major Raman peaks were identified in the $\mathrm{CO}_{2}$-exposed samples, including two peaks at 690 and $1059 \mathrm{~cm}^{-1}$, which are attributed to $\mathrm{BaCO}_{3}$ [41] and one peak at 480 $\mathrm{cm}^{-1}$, which is attributed to (doped) $\mathrm{CeO}_{2}$. [151] (It should be noted that the $\mathrm{BaCO}_{3}$ Raman peaks at $\sim 690$ and $1059 \mathrm{~cm}^{-1}$ were also observed in the control sample that was exposed to dry $\mathrm{H}_{2}$ only but with much lower intensities. One possible explanation is that, the 
synthesized BZCYYb powder via the GNP process might contain small amount of excess Barium, which converts to $\mathrm{BaCO}_{3}$ upon air exposure at room temperature.[89]) Besides that, no observable peaks for either amorphous carbon $\left(\right.$ at $\sim 1350 \mathrm{~cm}^{-1}$ ) or graphitic carbon (at $\sim 1580 \mathrm{~cm}^{-1}$ ) were detected in all the samples. [40] 

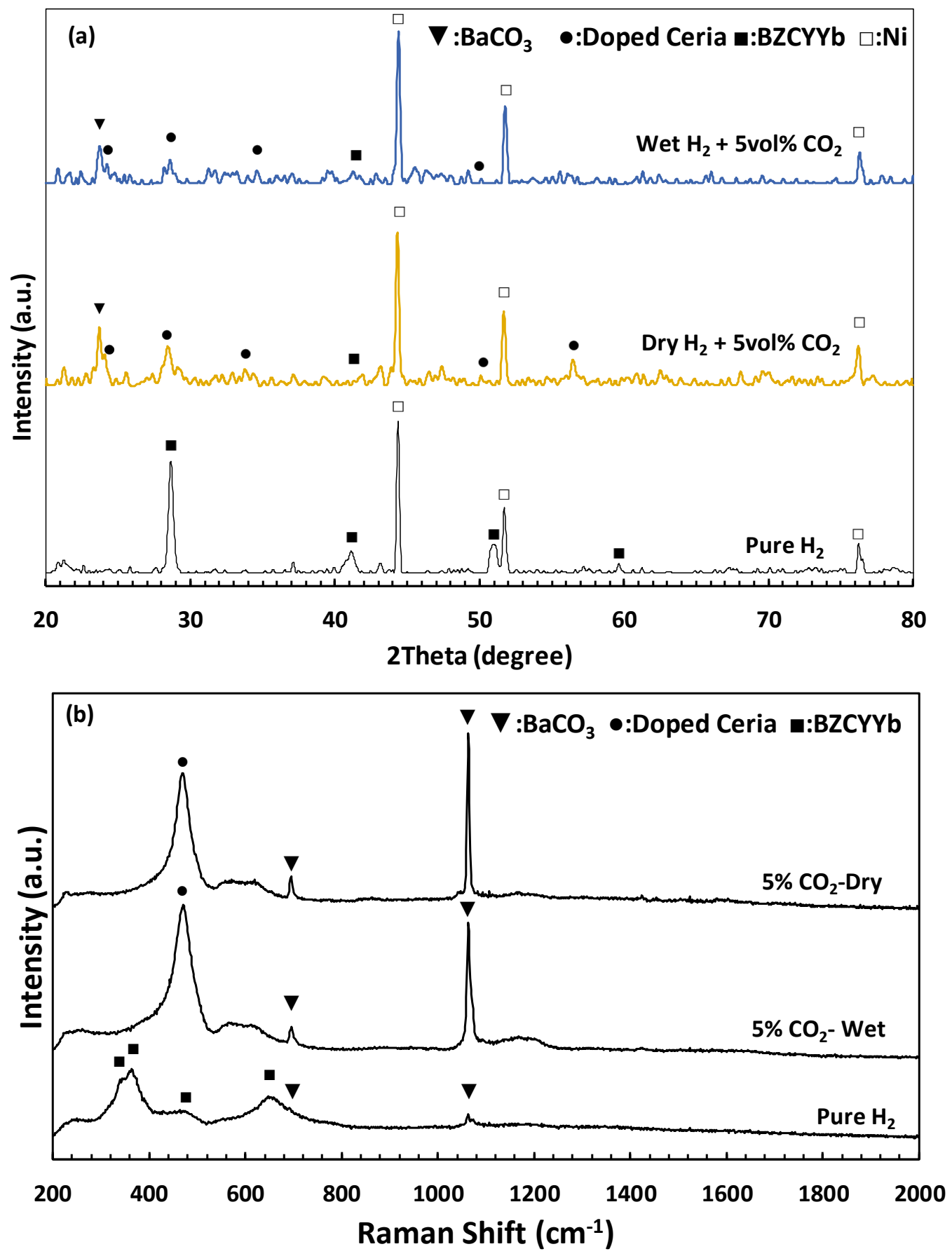

Figure 4. 4 (a) XRD patterns for NiO-BZCYYb mixed powders after reduction in $\mathrm{H}_{2}$ at $750^{\circ} \mathrm{C}$, and exposure tests at $550^{\circ} \mathrm{C}$ for 24 hours to pure $\mathrm{H}_{2}$ (as control sample) and fuel gas mixtures of dry $\mathrm{H}_{2}+5 \% \mathrm{CO}_{2}$, wet $\mathrm{H}_{2}+5 \% \mathrm{CO}_{2}$, (b) Raman spectra for samples after exposure to fuel gas mixtures of dry $\mathrm{H}_{2}+5 \% \mathrm{CO}_{2}$, wet $\mathrm{H}_{2}+5 \% \mathrm{CO}_{2}$, and pure $\mathrm{H}_{2}$ (as control sample), respectively. 


\subsection{Discussions}

The results in Figure 4. 1, Figure 4. 2 and Figure 4. 3 for all three types of PC-SOFC clearly suggest that $\mathrm{CO}_{2}$ behaves like a poison for the anode reaction process for PC-SOFC. This is different from conventional oxide ion conducting SOFC for which $\mathrm{CO}_{2}$ is usually not regarded as harmful: $\mathrm{CO}_{2}$ is often present in the anode chamber as the reforming/water-gas shift reaction (WGSR) product that would not harm the cell performance unless at extremely high concentration. The implication of the insensitivity of conventional oxide ion conducting SOFC with $\mathrm{Ni}$-cermet anode to $\mathrm{CO}_{2}$ fuel contaminant is that, unlike sulfur, in hydrogen atmosphere, $\mathrm{CO}_{2}$ would not adsorb strongly on Ni catalyst surface to block the conventional anode hydrogen electrochemical oxidation reaction under typical SOFC operating conditions.

On the other hand, it is well known that $\mathrm{CO}_{2}$ has very strong affinity to the highly basic proton conducting electrolyte such as BZCYYb and may even lead to bulk phase reaction. [89]In fact, it has been reported that $\mathrm{CO}_{2}$ would react with the current $\mathrm{BZCYYb}$ electrolyte to form $\mathrm{BaCO}_{3}$ under certain condition such as in $50 \% \mathrm{CO}_{2} / 50 \%$ Ar at $750^{\circ} \mathrm{C}$. [42, 89] In this study, as shown before in Figure 4. 3 (c), at intermediate temperature of $550^{\circ} \mathrm{C}$, the anode apparent interfacial resistance $\mathrm{R}_{\mathrm{ai}}$ increases by more than $100 \%$ upon exposure to $5 \% \mathrm{CO}_{2}$ in proton conducting anode symmetrical cell. This is attributed to the bulk phase reaction between $5 \% \mathrm{CO}_{2}$ and $\mathrm{BZCYYb}$ proton conducting electrolyte, and it is supported by the result of stability tests at $550^{\circ} \mathrm{C}$ that show disintegration of $\mathrm{BZCYYb}$ proton conducting electrolyte and accompanied formation of $\mathrm{BaCO}_{3}$ and doped $\mathrm{CeO}_{2}$ (see Figure 4. 4 (a)) upon exposure to $5 \% \mathrm{CO}_{2}$ in hydrogen (dry or $3 \%$ humidified). On the other hand, 
the much smaller increase in $\mathrm{R}_{\mathrm{ai}}$ for proton conducting electrolyte-supported cell could be possibly due to the contribution from cathode, which dominated the interfacial resistance at reduced temperature of $550^{\circ} \mathrm{C}$ and had no response to $\mathrm{CO}_{2}$ introduction in the anode side.

On the other hand, when the temperature is raised to 650 or even $750^{\circ} \mathrm{C}$, the relative increase in $\mathrm{R}_{\text {ai }}$ due to the introduction of $5 \% \mathrm{CO}_{2}$ into the $\mathrm{H}_{2}$ fuel stream was still observable (see Figure 4. 2 and Figure 4.3 (b) and (a)) but much less than that at $550^{\circ} \mathrm{C}$. The explanation for this dramatic reduction in poisoning by $5 \% \mathrm{CO}_{2}$ at higher temperature such as 650 and $750^{\circ} \mathrm{C}$ is that the same fuel mixture of $5 \% \mathrm{CO}_{2}$ in $\mathrm{H}_{2}$ at those elevated temperatures does not lead to complete bulk phase reaction and disintegration of BZCYYb proton conducting electrolyte. Instead, the exposure to the nominal $5 \% \mathrm{CO}_{2}$ balanced by $\mathrm{H}_{2}$ mixture at those temperatures might only lead to surface $\mathrm{CO}_{2}$ adsorption. Such an explanation was consistent with $\mathrm{XRD}$ for the $750^{\circ} \mathrm{C} 5 \% \mathrm{CO}_{2}$ exposed samples showing no obvious decrease in the diffraction peaks' intensity for the BZCYYb proton conducting electrolyte phase and no doped ceria formation, as typically observed when $\mathrm{BaCeO}_{3}$-based proton conducting electrolyte experiences bulk phase reaction. [42, 89]

One underlying reason for the mitigation of $\mathrm{CO}_{2}$ poisoning effect with increasing temperature to $\sim 650$ or $750^{\circ} \mathrm{C}$ is attributed to the fact that $\mathrm{CO}_{2}$ and $\mathrm{H}_{2}$ could go through reverse water gas shift (RWGS) reaction $\mathrm{CO}_{2}+\mathrm{H}_{2}=\mathrm{CO}+\mathrm{H}_{2} \mathrm{O}$ as mentioned in section 2.2.3.

The RWGS reaction shifts towards the right (i.e., forming more $\mathrm{CO}$ with less remaining $\left.\mathrm{CO}_{2}\right)$ at higher temperature. [152] Therefore, it is likely that at higher temperatures such as 
$750^{\circ} \mathrm{C}$, the actual $\mathrm{CO}_{2}$ concentration in the fuel stream could be much lower than the nominal value of 5\% as introduced due to RWGS reaction. (In fact, based on equilibrium constant data for the RWGS, the equilibrium $\mathrm{CO}_{2}$ concentration for a $5 \% \mathrm{CO}_{2} / 95 \% \mathrm{H}_{2}$ feed gas mixture will be around $0.3 \%$ at $750^{\circ} \mathrm{C}$.) As a result, $\mathrm{CO}_{2}$ poisoning was observed to be not very severe. In comparison, at a lower temperature such as $550^{\circ} \mathrm{C}$, due to both thermodynamics (i.e., equilibrium $\mathrm{CO}_{2}$ concentration will be higher of $\sim 0.7 \%$ at $550^{\circ} \mathrm{C}$ ) and slower kinetics for the RWGS, less amount of $\mathrm{CO}_{2}$ is converted to $\mathrm{CO}$, and severe poisoning would be observed due to bulk reaction between $\mathrm{CO}_{2}$ and the $\mathrm{BZCYYb}$ proton conducting electrolytes.

Finally, it is recognized that such an explanation might still be a simplification of the actual situation. For example, as CO is also produced from RWGS, it might lead to carbon deposition or coking on the Ni-based anode for proton conducting SOFC through the disproportionation reaction, especially at lower temperature:

$2 \mathrm{CO}=\mathrm{C}+\mathrm{CO}_{2}$ Equation 4.1

In fact, Ishiyama had observed carbon deposition over BZCYYb in a fuel mixture of $20 \% \mathrm{CO}_{2}$ and $80 \% \mathrm{H}_{2}$ at $500^{\circ} \mathrm{C}$. [103] However, no observable peaks for amorphous carbon or graphite were detected for the Ni-BZCYYb mixed powders after exposing to $5 \% \mathrm{CO}_{2}$ balanced by either wet or dry $\mathrm{H}_{2}$ at $550^{\circ} \mathrm{C}$ and $450^{\circ} \mathrm{C}$ by Raman, as shown in Figure 4.4 (b), suggesting formation of $\mathrm{CO}$ and related carbon deposition are probably not critical in explaining the observed $\mathrm{CO}_{2}$ poisoning behavior in this study. 


\subsection{Conclusions}

Electrochemical study on both anode-supported and electrolyte-supported PC-SOFC full cells and anode symmetrical PC-SOFC show that the anode reaction for PC-SOFC based on BZCYYb electrolyte and Ni-BZCYYb cermet anode is poisoned by low ppm-level $\mathrm{H}_{2} \mathrm{~S}$ and low percentage level of $\mathrm{CO}_{2}$. At temperature in the range of 550 to $750^{\circ} \mathrm{C}, \mathrm{CO}_{2}$ does not cause change in cell ohmic resistance Ro, but lead to observable increase in electrode interfacial resistance $\mathrm{R}_{\mathrm{ai}}$, especially in the mid-to-low frequency (MF-LF) semicircles but not in the high frequency (HF) semicircle. The observed poisoning behaviors of proton conducting SOFC by low-percentage level of $\mathrm{CO}_{2}$ is similar to that caused by low ppmlevel $\mathrm{H}_{2} \mathrm{~S}$ and can be attributed to the strong adsorption of $\mathrm{CO}_{2}$ species on the highly basic BZCYYb electrolyte surface, which interferes with the sub-steps of hydrogen adsorption and surface diffusion in the anode reaction for PC-SOFC. The great similarity of the poisoning behaviors between $\mathrm{CO}_{2}$ and $\mathrm{H}_{2} \mathrm{~S}$ despite their different affinity for the Ni-based metal catalyst suggests that the surface of proton conducting electrolyte such as BZCYYb might play a significant electrocatalytic role in the overall anode reaction for PC-SOFC and further experiments will be needed to test such a hypothesis and help reveal the fundamental anode reaction mechanism of hydrogen electrochemical reaction for proton conducting SOFCs. Finally, it should be mentioned that for $\mathrm{CO}_{2}$, when their concentration increase (e.g. $5 \mathrm{vol} \%$ to $50 \mathrm{vol} \%$ ) or when the temperature drops $\left(750^{\circ} \mathrm{C}-450^{\circ} \mathrm{C}\right)$, the interactions between those contaminants and the proton conducting electrolyte (BZCYYb in this case) may change from surface adsorption to bulk phase reaction, leading to disintegration of the proton conducting electrolyte and accompanied formation of bulk 
phases (e.g., $\mathrm{BaCO}_{3}$ and doped $\mathrm{CeO}_{2}$ ), and greater extent of poisoning would be observed accordingly. 


\section{Chapter V: Electrochemical Behaviors of Ag, LSCF and BSCF as Cathode for Proton Conducting IT-SOFC}

This chapter details the study on the electrochemical behaviors of Ag, LSCF and BSCF as cathode for proton conducting IT-SOFC. This chapter is based on published paper by Shichen Sun, and Zhe Cheng. "Electrochemical Behaviors for Ag, LSCF and BSCF as Oxygen Electrodes for Proton Conducting IT-SOFC." in Journal of The Electrochemical Society 164.10 (2017): F3104-F3113.

\subsection{Introduction}

The cathode in solid oxide fuel cells (SOFC) is often considered to be the rate-limiting factor, especially for SOFCs that operated at intermediate temperature $\left(400-700^{\circ} \mathrm{C}\right)$. $[44$, 70] Many efforts have been put into developing cathode materials that are suitable for intermediate temperature solid oxide fuel cells (IT-SOFC). [13, 70, 153, 154] However, there has been no consensus about the ideal cathode material or architecture that enables facile oxygen electrode reaction for proton conducting IT-SOFC. In this work, the electrochemical behaviors of several model cathode materials were compared at intermediate temperature of $450-650^{\circ} \mathrm{C}$. Among various cathode materials available, silver (Ag), as an electronic conductor, was chosen because it could be used to represent cells with oxygen electrode reactions confined to the triple phase boundary (TPB). $\mathrm{La}_{0.6} \mathrm{Sr}_{0.4} \mathrm{Co}_{0.2} \mathrm{Fe}_{0.8} \mathrm{O}_{3-\delta}$ (LSCF) was chosen because it is a mixed ionic and electronic conductor (MIEC) and also the state-of-the-art cathode for conventional oxide-ion conducting SOFC. [93, 155] Additionally, composite cathode made of LSCF and proton 
conducting oxide is also interesting due to the concern with LSCF's limited proton conductivity and the possibility of expanded TPB for the LSCF-based composite cathode. [121]Finally, $\mathrm{Ba}_{0.5} \mathrm{Sr}_{0.5} \mathrm{Co}_{0.8} \mathrm{Fe}_{0.2} \mathrm{O}_{3-\delta}$ (BSCF), which is regarded as one of the most active cathode materials at intermediate temperature, was also chosen because previous studies have shown BSCF displays significant weight gain and monotonic conductivity relaxation behavior in humidified atmosphere, $[20,156]$ suggesting possible mixed protonic and electronic conductivity. On the other hand, recent studies also show decreased electrode interfacial resistance with the introduction of moisture, especially in the high frequency range of $10^{6}$ to $10^{4} \mathrm{HZ}$, when used as the oxygen electrode on proton conducting electrolytes such as $\mathrm{BaCe}_{0.9} \mathrm{Y}_{0.1} \mathrm{O}_{3-\delta}(\mathrm{BCY})[20]$ and $\mathrm{BaZr}_{0.1} \mathrm{Ce}_{0.7} \mathrm{Y}_{0.1} \mathrm{Yb}_{0.1} \mathrm{O}_{3-\delta}(\mathrm{BZCYYb})$. [157] These observations suggest BSCF might enable the expansion of reaction sites to the entire BSCF surface thus providing high activity for cathode reaction. [20, 157] The electrochemical impedance for symmetrical cells with Ag, LSCF, LSCF-BZCYYb composite, and BSCF cathodes and a leading proton conducting electrolyte of BZCYYb were characterized. The focus was on revealing the responses to changing oxygen partial pressure $\left(\mathrm{pO}_{2}\right)$ and moisture $\left(\mathrm{H}_{2} \mathrm{O}\right)$ content. The implications of the experimental observations to the understanding of the cathode reaction processes will be discussed, including the roles of various electrode materials (e.g. BSCF) play and the importance of being proton conducting to the oxygen electrode reaction over a proton conducting electrolyte. Finally, the directions for future development of better cathodes for proton conducting IT-SOFC are pointed out considering all things mentioned above. 


\subsection{Experimental}

\subsubsection{Powder Synthesis and Compatibility Test}

All of the BZCYYb powder (nominal composition of $\mathrm{BaZr}_{0.1} \mathrm{Ce}_{0.7} \mathrm{Y}_{0.1} \mathrm{Yb}_{0.1} \mathrm{O}_{3-\delta}$ ), $\mathrm{BSCF}$ powder (nominal composition of $\mathrm{Ba}_{0.5} \mathrm{Sr}_{0.5} \mathrm{Co}_{0.8} \mathrm{Fe}_{0.2} \mathrm{O}_{3-\delta}$ ) and LSCF powder (nominal composition of $\left.\mathrm{La}_{0.6} \mathrm{Sr}_{0.4} \mathrm{Co}_{0.2} \mathrm{Fe}_{0.8} \mathrm{O}_{3-\delta}\right)$ were synthesized by the glycine nitrate process (GNP). [89] The metal precursors used include $\mathrm{Ba}\left(\mathrm{NO}_{3}\right)_{2}$ (\#10180117, Alfa Aesar, 99\%), $\mathrm{La}\left(\mathrm{NO}_{3}\right)_{2}$ (\#A11305, Alfa Aesar, 99\%), Sr(NO$)_{2}$ (\#SZBB0470V, Sigma-Aldrich, 99\%), $\mathrm{Co}\left(\mathrm{NO}_{3}\right)_{2} \cdot 6 \mathrm{H}_{2} \mathrm{O}$ (\#239267, Alfa Aesar, 99\%), $\mathrm{Fe}\left(\mathrm{NO}_{3}\right)_{3} \cdot 9 \mathrm{H}_{2} \mathrm{O}$ (\#216828, Alfa Aesar, 99\%), $\mathrm{ZrO}\left(\mathrm{NO}_{3}\right)_{2} \cdot \mathrm{xH}_{2} \mathrm{O}$ source (\#43224, Alfa Aesar, 99.9\%), $\mathrm{Ce}\left(\mathrm{NO}_{3}\right)_{3} \cdot \mathrm{xH}_{2} \mathrm{O}(\# 11329$, Alfa Aesar, 99.5\%), $\mathrm{Y}\left(\mathrm{NO}_{3}\right)_{3} \cdot 6 \mathrm{H}_{2} \mathrm{O}$ (\#12898, Alfa Aesar, 99.9\%), and $\mathrm{Yb}\left(\mathrm{NO}_{3}\right)_{3} \cdot \mathrm{xH}_{2} \mathrm{O}$ (\#12901, Alfa Aesar, 99.9\%). The molar ratio between glycine and total metal ions was 1:1 for BZCYYb and 7:6 for BSCF and LSCF. The mixed solutions in $1 \mathrm{~L}$ glass beaker were place directly on a hotplate set at $540^{\circ} \mathrm{C}$ and the solutions boiled and eventually selfcombust. After self-combustion, the powders were calcined at $1100^{\circ} \mathrm{C}$ for 2 hours for the $\mathrm{BZCYYb}$ and at $1000^{\circ} \mathrm{C}$ for 2 hours for the BSCF and LSCF powders in ambient air to form the pure phases. $[68,89,157,158]$ The stability and compatibility between BZCYYb and BSCF at intermediate temperature have been studied before. [157] In order to verify the chemical compatibility between LSCF and BZCYYb under fabrication condition, powders of the two materials with weight ratio of 7:3 were intimately mixed and exposed to ambient air at typical LSCF-BZCYYb cathode firing temperature of $1000^{\circ} \mathrm{C}$ for 2 hours.

To test the stability and compatibility of the LSCF and BZCYYb mixture under subsequent 
testing conditions, the powder mixtures were exposed at $750^{\circ} \mathrm{C}$ in dry simulated air, $3 \%$ humidified simulated air, and pure $\mathrm{O}_{2}$ for 24 hours with the flow rate of $50 \mathrm{cc} / \mathrm{min}$. The assynthesized samples and samples after compatibility/stability tests were all analyzed by XRay diffraction (SIEMENS diffractometer D5000) for phase identification.

\subsubsection{Cell Fabrication}

Cathode symmetrical cells with the configuration of $\mathrm{Ag} / \mathrm{BZCYYb} / \mathrm{Ag}$, LSCF/BZCYYb/LSCF, LSCF-BZCYYb/BZCYYb/LSCF-BZCYYb, and BSCF/BZCYYb/BSCF were fabricated. First, all electrolyte pellets with diameter of 10 $\mathrm{mm}$ were dry-pressed at $200 \mathrm{MPa}$ using $0.2 \mathrm{~g} \mathrm{BZCYYb}$ powder, followed by protected sintering at $1550^{\circ} \mathrm{C}$ for 5 hours. [89] Then, $4 \mathrm{~mm} * 4 \mathrm{~mm}$ cathodes were brush painted onto both sides of the sintered BZCYYb pellets with pure silver paste, LSCF paste, mixed LSCF-BZCYYb paste (LSCF : BZCYYb weight ratio of 7:3), and BSCF paste, [157] respectively. All painted samples were fully dried in an air oven at $100^{\circ} \mathrm{C}$ and then calcined at $1000^{\circ} \mathrm{C}$ for 2 hours, except for the silver symmetrical cell, which was calcined at $700^{\circ} \mathrm{C}$ for 2 hours. The heating and cooling rates were $5^{\circ} \mathrm{C} / \mathrm{min}$.

Besides that, anode-supported full cell with the configuration of BSCF/BZCYYb/NiOBZCYYb was fabricated. First, NiO-BZCYYb anode precursor/BZCYYb electrolyte bilayer was prepared via dry-pressing: 0.2g NiO-BZCYYb-starch powder mixture with weight ratio of 5.5: 3.5: 1 was pressed first gently in the $10 \mathrm{~mm}$ diameter die; then $10 \mathrm{mg}$ BZCYYb electrolyte was added onto the anode substrate and the bilayer was pressed 
together at a pressure of $200 \mathrm{MPa}$. The pellets of the anode precursor/electrolyte bilayer were then sintered at $1400^{\circ} \mathrm{C}$ for 5 hours in air with heating and cooling rate of $5^{\circ} \mathrm{C} / \mathrm{min}$. $4 \mathrm{~mm} * 4 \mathrm{~mm}$ BSCF cathode was brush-painted onto the electrolyte side of the sintered anode/electrolyte bilayer pellets using the same BSCF slurry as described above, dried at $150^{\circ} \mathrm{C}$, and then calcination at $1100^{\circ} \mathrm{C}$ for 2 hours in air with heating and cooling rate of $5^{\circ} \mathrm{C} / \mathrm{min}$. Finally, silver mesh and wires were attached to the electrodes using pure silver paste for current collection. The microstructure of both the surface and the cross-section of the fabricated cathode symmetrical cells were observed using a field emission scanning electron microscope (FE-SEM, JEOL JSM 6330F).

\subsubsection{Electrochemical Impedance Spectroscopy (EIS) Measurement}

Electrochemical Impedance Spectroscopy (EIS) measurements were carried out using a potentiostat (Gamry Interface 1000) under open circuit condition and in the frequency range of $10^{6}$ to $10^{-2} \mathrm{HZ}$ for the symmetrical cells and the anode-supported full cells. The symmetrical cells were connected with silver paste and silver mesh current collector and were placed in the hot zone inside a one-end closed alumina tube with gas fed directly to the cells to obtain a rapid response. Each sample was first tested in dry simulated air (Airgas AI UZ300, with nominal composition of $20 \% \mathrm{O}_{2} / 80 \% \mathrm{~N}_{2}$ with $<\sim 5$ parts per million or $\sim 5$ ppm of $\mathrm{H}_{2} \mathrm{O}$ and $\mathrm{CO}_{2}$ ) at a flow rate of $50 \mathrm{ml} \mathrm{min}^{-1}$ from temperature of $650^{\circ} \mathrm{C}$ to $450^{\circ} \mathrm{C}$. To test the effect of $\mathrm{pO}_{2}$ on the oxygen electrode behavior, oxygen (Airgas OX UHP300) and nitrogen (Airgas NI UHP300) were introduced to the sample testing chamber with different ratios adjusted by digital mass flow controllers. After finishing the tests in various 
$\mathrm{pO}_{2}$, water vapor with controlled concentrations (e.g., $0.6 \%, 3 \%, 10 \%$, and $20 \%$ ) was introduced into the testing chamber by passing the simulated air through a water bubbler set at different temperatures to test the effect of water vapor on the oxygen electrode behavior. For testing involving $10 \%$ and $20 \%$ water vapor, the connection tubes were heated to $\sim 100^{\circ} \mathrm{C}$ with heating tapes to prevent water condensation. In addition, for better control of the moisture content inside the chamber, the samples were heated to $750^{\circ} \mathrm{C}$ before adjusting the moisture content. For the anode-supported full cell, it was sealed onto ceramic tube fixture and heated up with the anode-side exposed to nitrogen. Then, at $750^{\circ} \mathrm{C}$, anode gas flow was switched from nitrogen to pure hydrogen to reduce the $\mathrm{NiO}$ to Ni. The impedance spectra for the various symmetrical and full cells were collected at various intermediate temperatures between 450 and $650^{\circ} \mathrm{C}$.

\subsection{Results}

\subsubsection{Stability, Compatibility, and Microstructure of the Electrodes}

The XRD patterns for the as-synthesized LSCF and BZCYYb powders and their mixtures after compatibility/stability tests are shown in Figure 5. 1. There is no obvious secondary phase formed after the compatibility test of firing at $1000^{\circ} \mathrm{C}$ for 2 hours in air and the three stability tests of exposing the fired LSCF-BZCYYb composite at $750^{\circ} \mathrm{C}$ for 24 hours in ambient air, pure $\mathrm{O}_{2}$, and $3 \%$ humidified air, suggesting no reaction occurred between LSCF and BZCYYb and their gas environment under the intended conditions. For BSCF, 
previous studies have shown that BSCF is compatible with BZCYYb electrolyte for cathode firing [157] and it is also stable under typical testing condition in air. [70, 157]

Besides that, the microstructure of fabricated Ag, LSCF, LSCF-BZCYYb, and BSCF cathode symmetrical cells, all with BZCYYb electrolytes, are shown in Figure 5. 2. The thickness of the all the electrodes was around $30 \mu \mathrm{m}$, but the microstructure is somewhat different: The Ag electrode gives relatively dense structure with grain size significantly larger than $1 \mu \mathrm{m}$; both the LSCF and the LSCF-BZCYYb composite electrodes are porous with fine grain size much smaller than $1 \mu \mathrm{m}$; the BSCF cathode is also porous but with grain size of $\sim 1 \mu \mathrm{m}$, which is between the grains size for the Ag and LSCF-based electrodes.

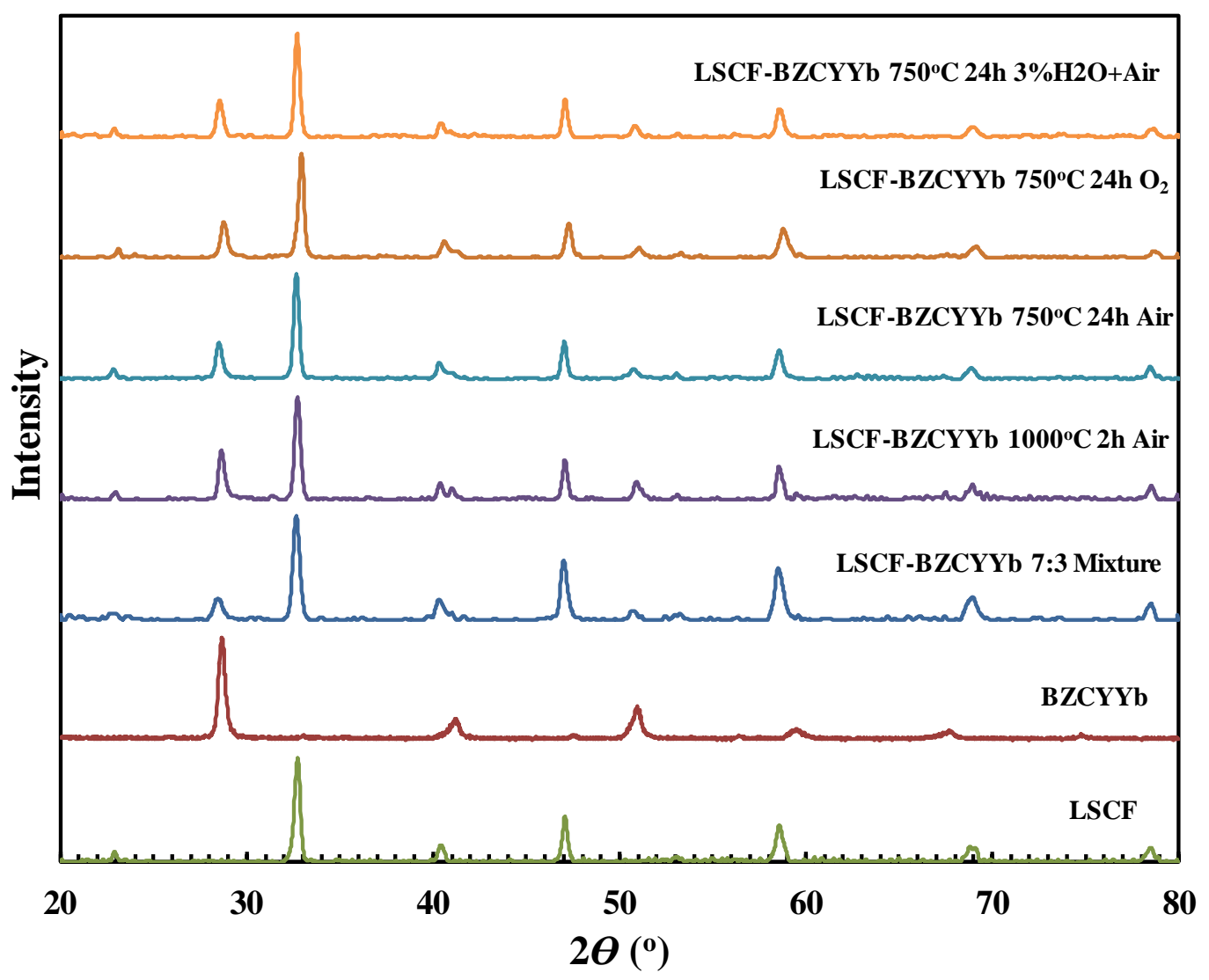


Figure 5. 1 XRD patterns of as-synthesized LSCF and BZCYYb powders and their mixtures after compatibility test of firing at $1000^{\circ} \mathrm{C}$ for 2 hours in air and the three different stability tests of exposing the fired LSCF-BZCYYb composite at $750^{\circ} \mathrm{C}$ for 24 hours in ambient air, pure $\mathrm{O}_{2}$, and $3 \%$ humidified air.

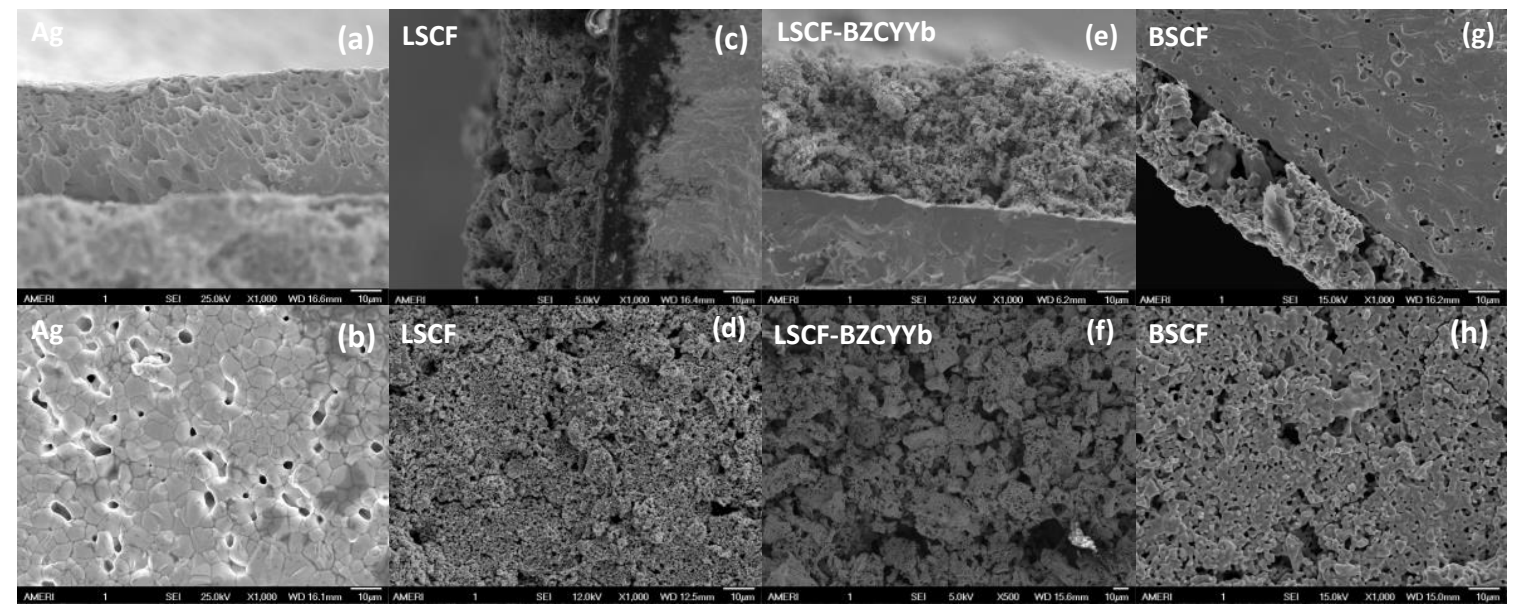

Figure 5. 2 SEM images of the cross-section and the electrode surface of the fabricated $\mathrm{Ag} / \mathrm{BZCYYb} / \mathrm{Ag}$ ( $\mathrm{a}$ and b), LSCF/BZCYYb/LSCF (c and d), LSCFBZCYYb/BZCYYb/LSCF- BZCYYb (e and f), and BSCF/BZCYYb/BSCF (g and h) cathode symmetrical cell, respectively.

\subsubsection{Electrochemical Behavior of Different Dlectrodes under Various $\mathrm{pO}_{2}$ and Moisture Content}

\subsubsection{Ag electrode}

Figure 5. 3 shows the impedance spectra for an $\mathrm{Ag} / \mathrm{BZCYYb} / \mathrm{Ag}$ symmetrical cell in dry simulated air, pure oxygen, and simulated air containing $3 \%$ moisture at 650,550 , and $450{ }^{\circ} \mathrm{C}$. Under all testing conditions, incomplete high frequency (HF) loops were observed in the impedance spectra, leading to indeterminable ohmic resistance $\left(\mathrm{R}_{\mathrm{O}}\right)$. Additionally, there are multiple, partially overlapping loops in the mid to low frequency (MF-LF) range. The estimated total apparent electrode interfacial resistance $\left(\mathrm{R}_{\mathrm{ai}}\right)$, which is the direct difference between the low frequency intercept and the high frequency 
intercept on the real axis, [159] is quite high-on the order of $\sim 50,100$, and $500 \Omega \bullet \mathrm{cm}^{2}$ at 650,550 , and $450^{\circ} \mathrm{C}$, respectively. It should be noted here that, strictly speaking, the $\mathrm{R}_{\mathrm{ai}}$ defined here is not the electrode interfacial polarization resistance $\mathrm{R}_{\mathrm{p}}$ due to the nature of mixed ionic and electronic conduction for the BZCYYb electrolyte. [159] However, due to the absence of precise ionic transference number, accurate $\mathrm{R}_{\mathrm{p}}$ number cannot be obtained readily. As a result, only the apparent interfacial resistance $\mathrm{R}_{\mathrm{ai}}$, defined as the direct difference between the low frequency intercept and the high frequency intercept on the real axis in an impedance spectrum, is used for the analysis and discussions in this study following the practice in many previous reports. [20, 157, 159] These values are much larger than the typical values for a good cathode symmetrical cell. [20, 70, 121, $153,157,160,161]$ In addition, for both the high frequency electrode resistance $R_{H F}$ and the mid-to-low frequency electrode resistance $\mathrm{R}_{\mathrm{MF}-\mathrm{LF}}$, they generally increased with decreasing $\mathrm{pO}_{2}$ or the introduction of $3 \%$ moisture. The exception is at the relatively low temperature of $450^{\circ} \mathrm{C}$ when no obvious change in $\mathrm{R}_{\mathrm{HF}}$ with decreasing $p \mathrm{O}_{2}$ was observed. 

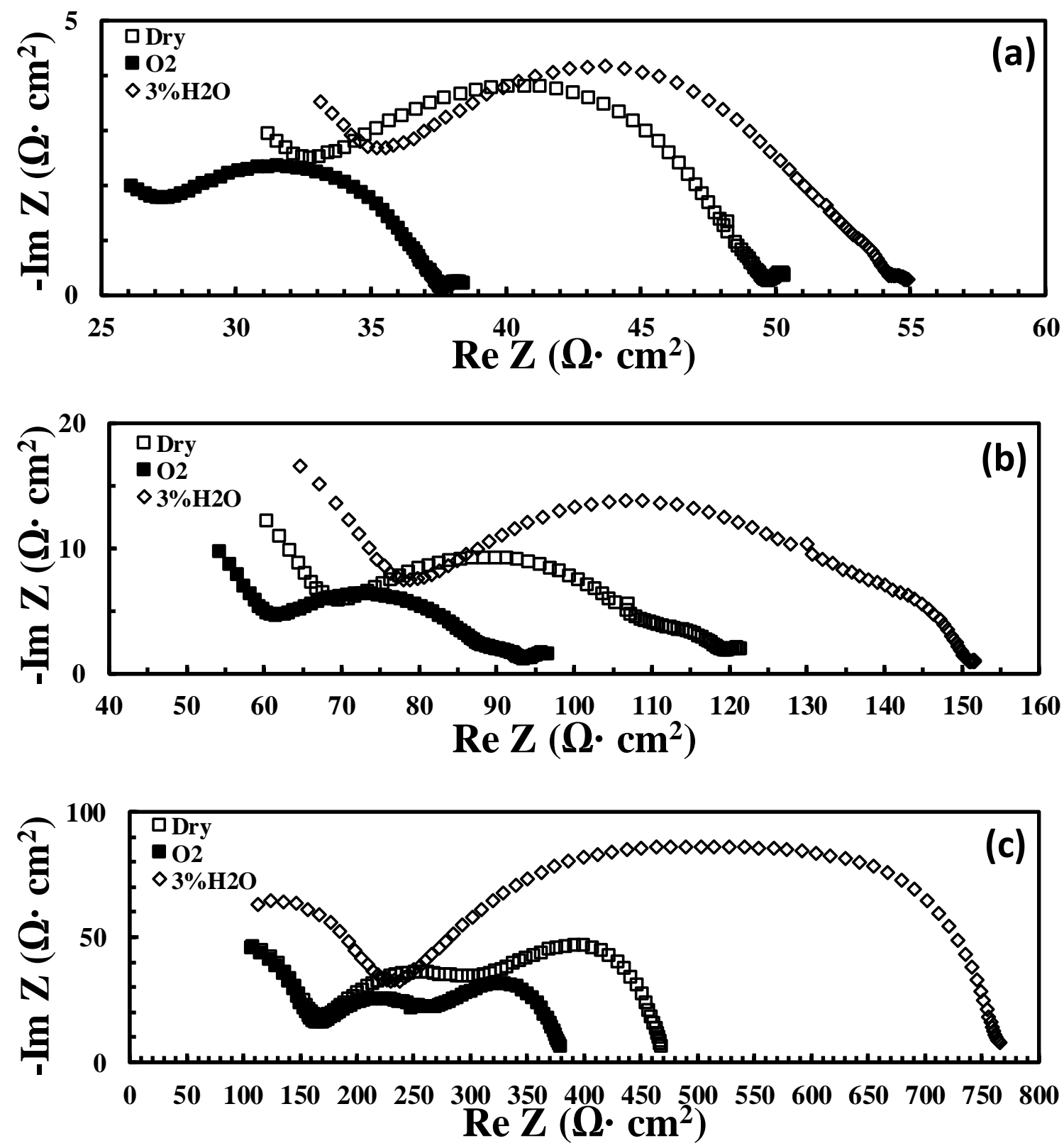

Figure 5. 3 Impedance spectra for a $\mathrm{Ag} / \mathrm{BZCYYb} / \mathrm{Ag}$ symmetrical cell in dry simulated air $\left(20 \% \mathrm{O}_{2} / 80 \% \mathrm{~N}_{2}\right.$ with $<\sim 5 \mathrm{ppm} \mathrm{H}_{2} \mathrm{O}$ and $\left.\mathrm{CO}_{2}\right)$, pure oxygen, and simulated air humidified with $3 \% \mathrm{H}_{2} \mathrm{O}$ at (a) $650^{\circ} \mathrm{C}$, (b) $550^{\circ} \mathrm{C}$, and (c) $450^{\circ} \mathrm{C}$, respectively. 


\subsubsection{LSCF Electrode}

Figure 5. 4 shows the impedance spectra for the LSCF/BZCYYb/LSCF symmetrical cell under the same conditions. The electrochemical behaviors were similar to the $\mathrm{Ag}$ symmetrical cell in several ways: Incomplete HF loops are still observed in the impedance spectra at various temperatures, leading to indeterminable Ro. The MF-LF range also contains multiple overlapping loops at all temperatures. The estimated total electrode interfacial resistance $\mathrm{R}_{\mathrm{ai}}$ appears high as well-on the order of $\sim 30,80$, and $600 \Omega \cdot \mathrm{cm}^{2}$ at 650,550 , and $450^{\circ} \mathrm{C}$, respectively. These values are one to two orders of magnitude higher than those obtained on a LSCF symmetrical cell over $\mathrm{Ce}_{0.9} \mathrm{Gd}_{0.1} \mathrm{O}_{2}$ (GDC) electrolyte at temperatures of 650 and $550^{\circ} \mathrm{C}$. [160] The $\mathrm{R}_{\mathrm{ai}}$ also generally increased with decreasing $\mathrm{pO}_{2}$ or introduction of $3 \%$ moisture. 

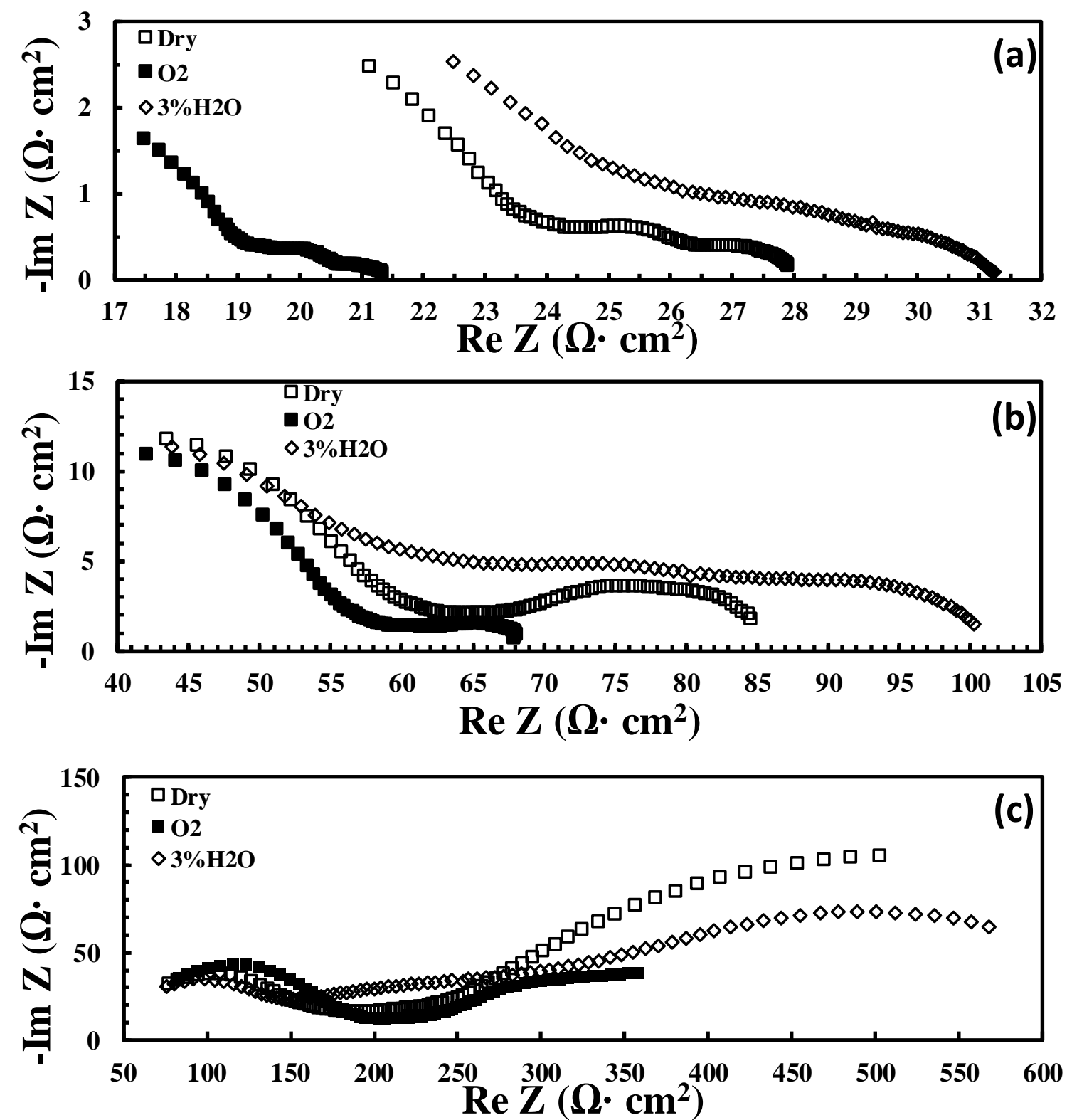

Figure 5. 4 Impedance spectra for a LSCF/BZCYYb/LSCF symmetrical cell in dry simulated air $\left(20 \% \mathrm{O}_{2} / 80 \% \mathrm{~N}_{2}\right.$ with $<\sim 5 \mathrm{ppm} \mathrm{H}_{2} \mathrm{O}$ and $\left.\mathrm{CO}_{2}\right)$, pure oxygen, and simulated air humidified with $3 \% \mathrm{H}_{2} \mathrm{O}$ at (a) $650^{\circ} \mathrm{C}$, (b) $550^{\circ} \mathrm{C}$, and (c) $450^{\circ} \mathrm{C}$, respectively.

However, comparing with the Ag electrode, there are some unique features for the LSCF electrode: In particular, temperature seems to influence the electrochemical 
responses of the symmetrical cell to gas atmosphere dramatically. For example, for LSCF, at a higher temperature of $650^{\circ} \mathrm{C}$, both the high frequency electrode resistance $\mathrm{R}_{\mathrm{HF}}$ and the mid-to-low frequency electrode resistance $\mathrm{R}_{\mathrm{MF}-\mathrm{LF}}$ increased with decreasing $\mathrm{pO}_{2}$ and the introduction of $3 \%$ moisture, which is like the Ag electrode. However, at a lower temperature of $450^{\circ} \mathrm{C}$, the electrochemical behavior becomes more complex: For $\mathrm{R}_{\mathrm{HF}}$, it decreased with decreasing $\mathrm{pO}_{2}$, and did not seem to respond to the introduction of moisture; For $\mathrm{R}_{\mathrm{MF}-\mathrm{LF}}$, it separated into multiple loops with the part at $10^{4}-10^{1} \mathrm{~Hz}$ increased upon the introduction of $3 \%$ moisture while the part at $10^{1}-10^{-2} \mathrm{~Hz}$ decreased.

\subsubsection{LSCF-BZCYYb Composite Electrode}

Figure 5. 5 shows the impedance spectra for an LSCF-BZCYYb composite electrode symmetrical cell in dry simulated air and pure oxygen at 650,550 , and $450{ }^{\circ} \mathrm{C}$. Unlike the Ag and the pure LSCF symmetrical cells, the HF loops now intercept with the real axis, enabling determination of the cell ohmic resistance $\mathrm{R}_{\mathrm{O}}$. It was observed that $\mathrm{R}_{\mathrm{O}}$ increased with decreasing $p \mathrm{O}_{2}$ at $650^{\circ} \mathrm{C}$ and $550^{\circ} \mathrm{C}$, but didn't change significantly at $450^{\circ} \mathrm{C}$. The overall apparent electrode interfacial resistance $\mathrm{R}_{\mathrm{ai}}$ also becomes much smaller-on the order of $\sim 0.7,4$, and $30 \Omega \cdot \mathrm{cm}^{2}$ in air, and it increased with decreasing $p \mathrm{O}_{2}$ at all temperatures. Both the high frequency contribution $\mathrm{R}_{\mathrm{HF}}$ and mid-to-low frequency contribution $\mathrm{R}_{\mathrm{MF}-\mathrm{LF}}$ generally followed the same trend. 

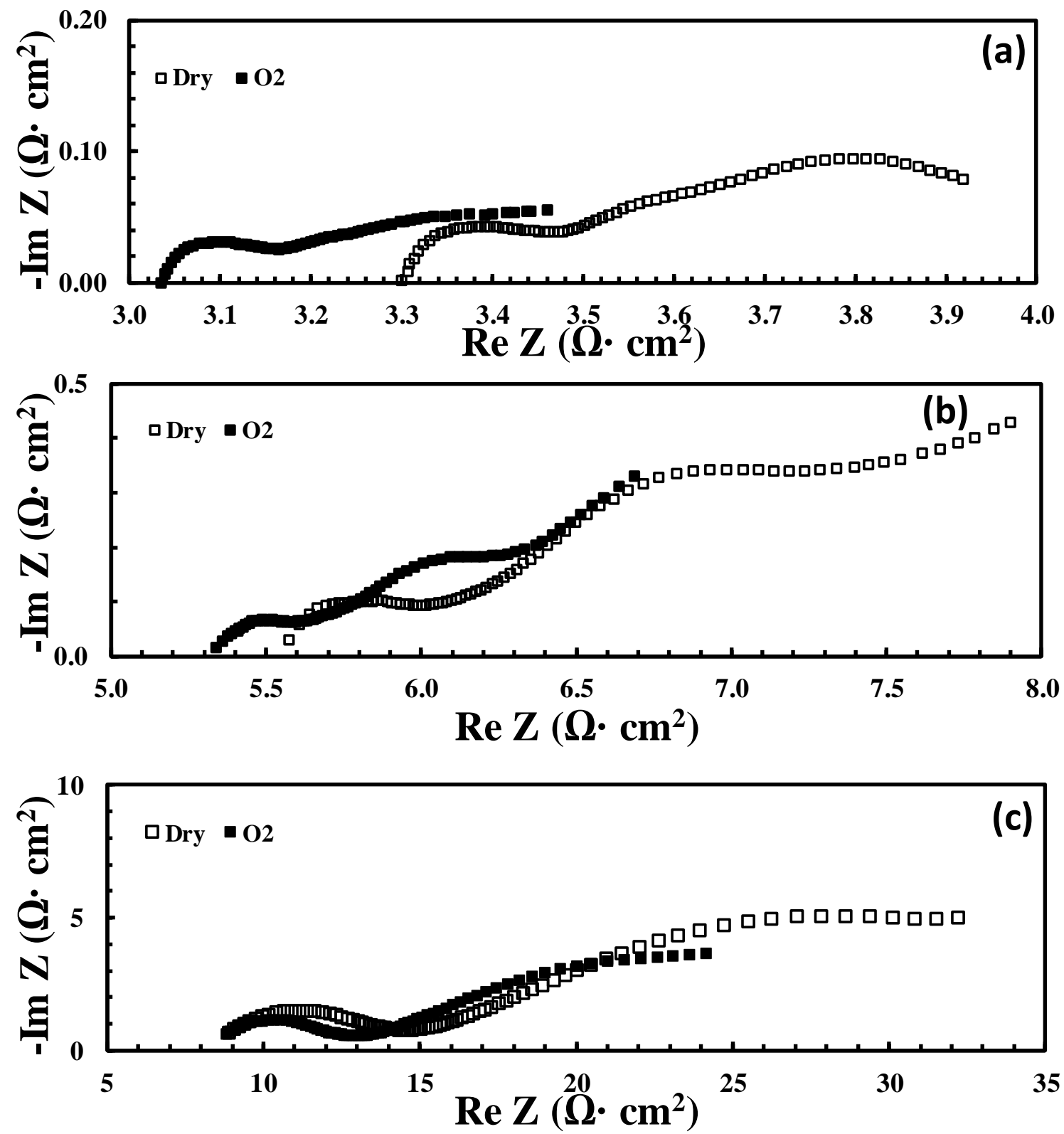

Figure 5. 5 Impedance spectra for a LSCF-BZCYYb/BZCYYb/LSCF-BZCYYb symmetrical cell in dry simulated air $\left(20 \% \mathrm{O}_{2} / 80 \% \mathrm{~N}_{2}\right.$ with $<\sim 5 \mathrm{ppm} \mathrm{H}_{2} \mathrm{O}$ and $\left.\mathrm{CO}_{2}\right)$ and pure oxygen at (a) $650^{\circ} \mathrm{C}$, (b) $550^{\circ} \mathrm{C}$, and (c) $450^{\circ} \mathrm{C}$, respectively.

Figure 5. 6 shows the impedance spectra for the same LSCF-BZCYYb composite cathode symmetrical cell in simulated air containing different moisture content. 
Surprisingly, with the introduction and continued increase of moisture content, increase in $\mathrm{R}_{\mathrm{O}}$ was observed, which was very dramatic at $650^{\circ} \mathrm{C}$ (i.e., from $3.3 \Omega \bullet \mathrm{cm}^{2}$ to $\sim 12.8, \sim 18.0$, $\sim 23.0$ and $\sim 23.1 \Omega \cdot \mathrm{cm}^{2}$ with $0.6 \%, 3 \%, 10 \%$, and $20 \% \mathrm{H}_{2} \mathrm{O}$, respectively), still significant at $550^{\circ} \mathrm{C}$ (i.e., from $5.5 \Omega \cdot \mathrm{cm}^{2}$ to $6.7,15.7, \sim 21$, and $\sim 29 \Omega \bullet \mathrm{cm}^{2}$ with $0.6 \%, 3 \%, 10 \%$, and $20 \% \mathrm{H}_{2} \mathrm{O}$, respectively), and then almost negligible at $450^{\circ} \mathrm{C}$. At the same time, the total apparent interfacial resistance $\mathrm{R}_{\mathrm{ai}}$ also increases accordingly, and the relative increase was very dramatic at higher temperature of $650^{\circ} \mathrm{C}$ and become almost negligible at lower temperature of $450^{\circ} \mathrm{C}$. 

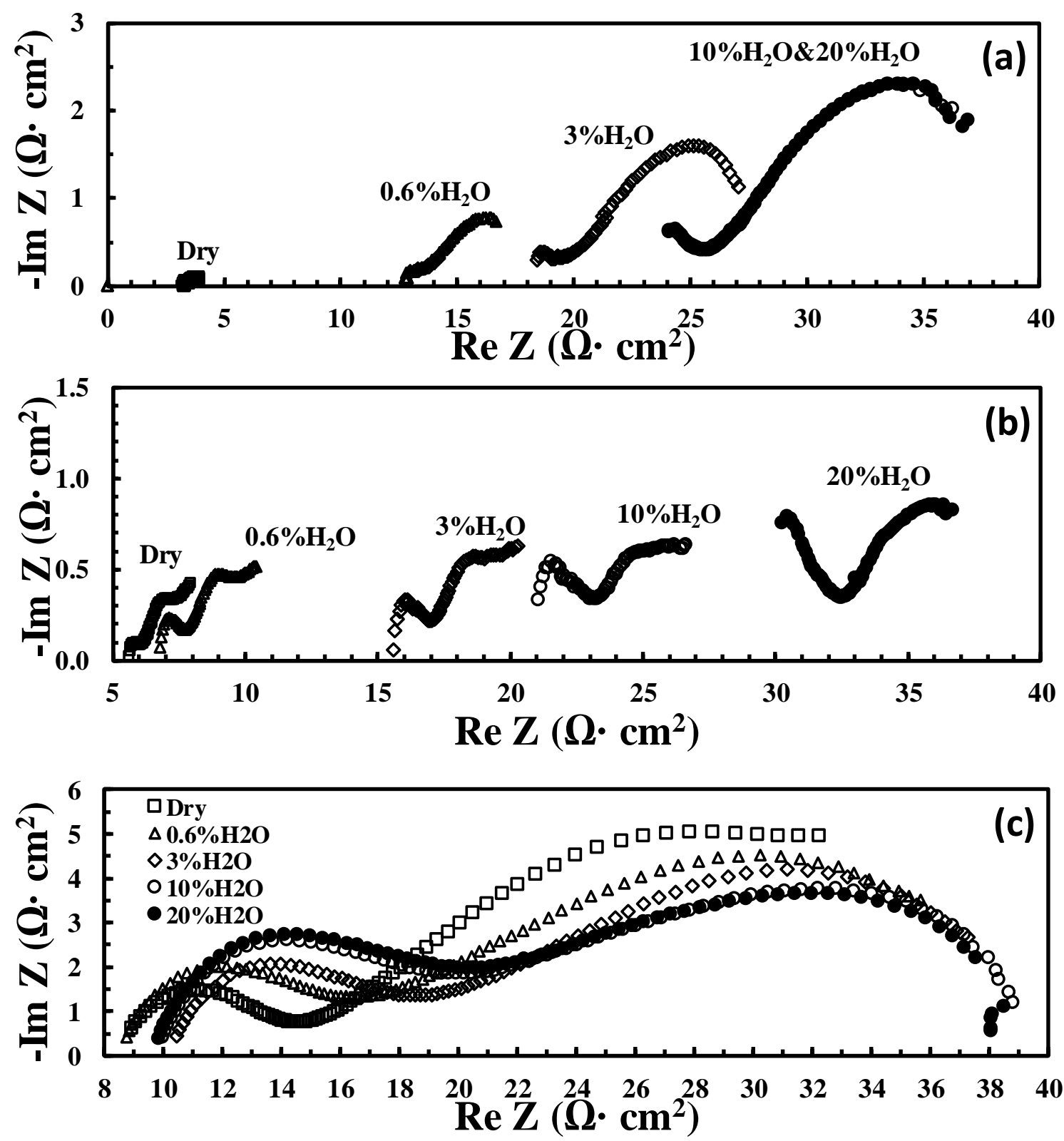

Figure 5. 6 Impedance spectra for a LSCF-BZCYYb/BZCYYb/LSCF-BZCYYb symmetrical cell in dry simulated air $\left(20 \% \mathrm{O}_{2} / 80 \% \mathrm{~N}_{2}\right.$ with $<\sim 5 \mathrm{ppm} \mathrm{H}_{2} \mathrm{O}$ and $\left.\mathrm{CO}_{2}\right)$ versus simulated air humidified with various concentrations of moisture at (a) $650^{\circ} \mathrm{C}$, (b) $550^{\circ} \mathrm{C}$, and (c) $450^{\circ} \mathrm{C}$, respectively. 


\subsubsection{BSCF Electrode}

Figure 5.7 shows the impedance spectra for the BSCF/BZCYYb/BSCF symmetrical cell in dry simulated air and dry oxygen at 650,550 , and $450^{\circ} \mathrm{C}$. Similar to the LSCF-BZCYYb composite electrode symmetrical cell, for the BSCF symmetrical cell, the HF loops still generally intercept with the real axis. Ohmic resistance $\mathrm{Ro}_{\mathrm{O}}$ increased with decreasing $\mathrm{pO}_{2}$ as well at 650 and $550^{\circ} \mathrm{C}$. (At lower temperature of $450^{\circ} \mathrm{C}, \mathrm{R}_{\mathrm{O}}$ in pure $\mathrm{O}_{2}$ did appear to be higher than that in dry simulated air.) For the total apparent electrode interfacial resistance $\mathrm{R}_{\mathrm{ai}}$ of BSCF symmetrical cell, it increased with decreasing $\mathrm{pO}_{2}$ at all temperatures under dry conditions, which is also consistent with other types of cathode symmetrical cells studied. Both the high frequency electrode resistance $R_{H F}$ and the mid-to-low frequency electrode resistance $\mathrm{R}_{\mathrm{MF}-\mathrm{LF}}$ also generally follow the same trend except for $\mathrm{R}_{\mathrm{HF}}$ at lower temperature of $450^{\circ} \mathrm{C}$ : it did not seem to change much with $\mathrm{pO}_{2}$ : Such a behavior of roughly constant $\mathrm{R}_{\mathrm{HF}}$ at $450^{\circ} \mathrm{C}$ is similar to the $\mathrm{Ag}$ symmetrical cell but different from the symmetrical cells with the LSCF or the LSCF-BZCYYb composite electrodes. 

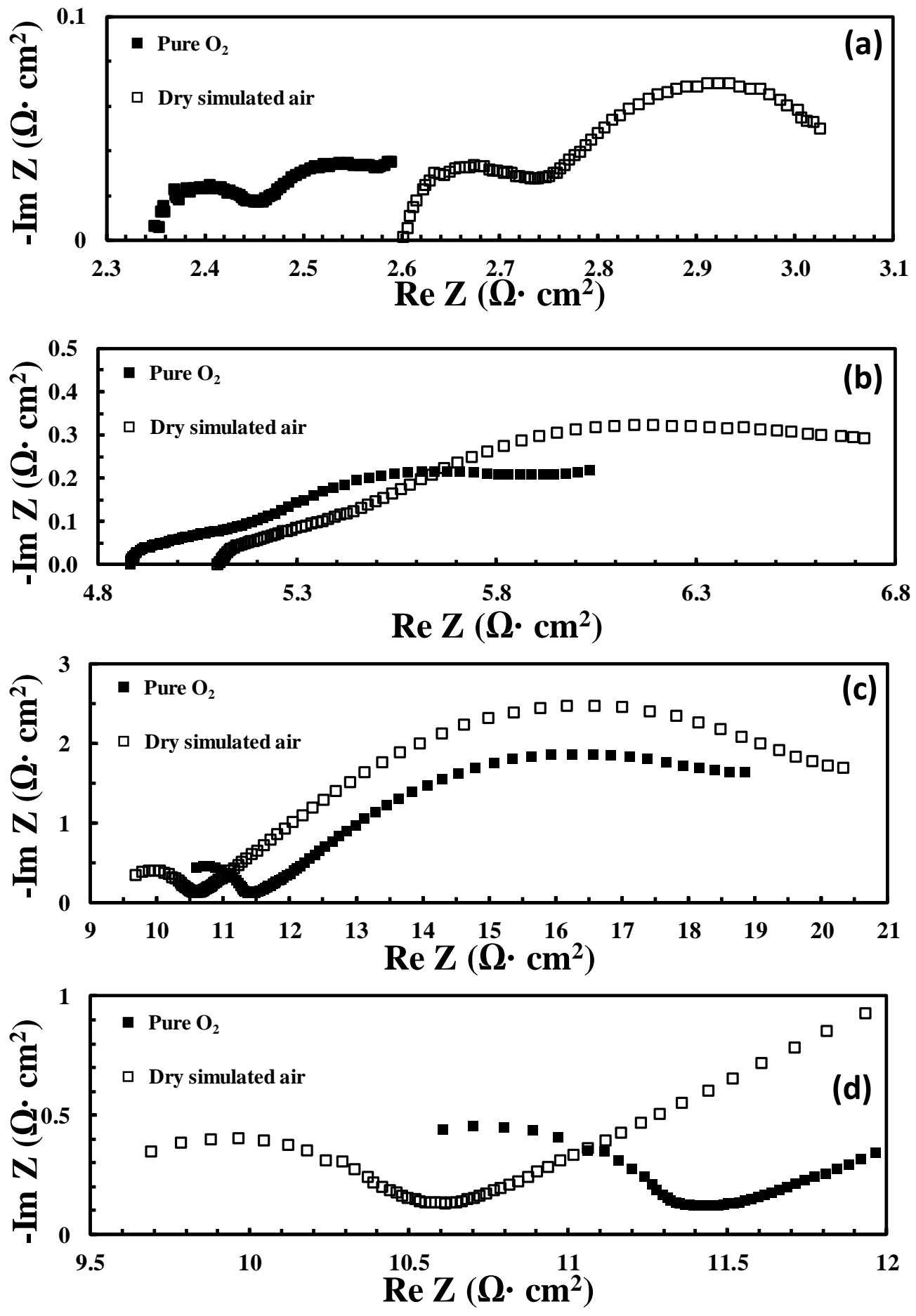

Figure 5. 7 Impedance spectra for a BSCF/BZCYYb/BSCF symmetrical cell in dry simulated air $\left(20 \% \mathrm{O}_{2} / 80 \% \mathrm{~N}_{2}\right.$ with $<\sim 5 \mathrm{ppm} \mathrm{H}_{2} \mathrm{O}$ and $\left.\mathrm{CO}_{2}\right)$ versus pure oxygen at (a) $650^{\circ} \mathrm{C}$, (b) $550^{\circ} \mathrm{C}$, (c) $450^{\circ} \mathrm{C}$, and (d) zoom-in of the impedance spectra at $450^{\circ} \mathrm{C}$ showing the high frequency (HF) part. 
Additionally, Figure 5. 8 shows the impedance spectra for the BSCF symmetrical in simulated air with different moisture content. The observations for the BSCF symmetrical cell after the introduction of moisture are as follows: Ro decreased with the introduction of moisture and further increase in moisture content. $R_{\text {ai }}$ generally first increased with the introduction of moisture and then decreased back with further increase in moisture content. Figure 5. 9 shows the same impedance curves but with ohmic resistance subtracted, and it is consistent with the authors' previous studies: [20, 157] The mid-to-low frequency part $\mathrm{R}_{\mathrm{MF}-\mathrm{LF}}$ seems to follow the same trend as $\mathrm{R}_{\mathrm{ai}}$, while the high frequency part $\mathrm{R}_{\mathrm{HF}}$ seemed to always decrease with the introduction of moisture, especially at lower temperature of $450^{\circ} \mathrm{C}$ when the $\mathrm{HF}$ loop becomes clearly separated. 

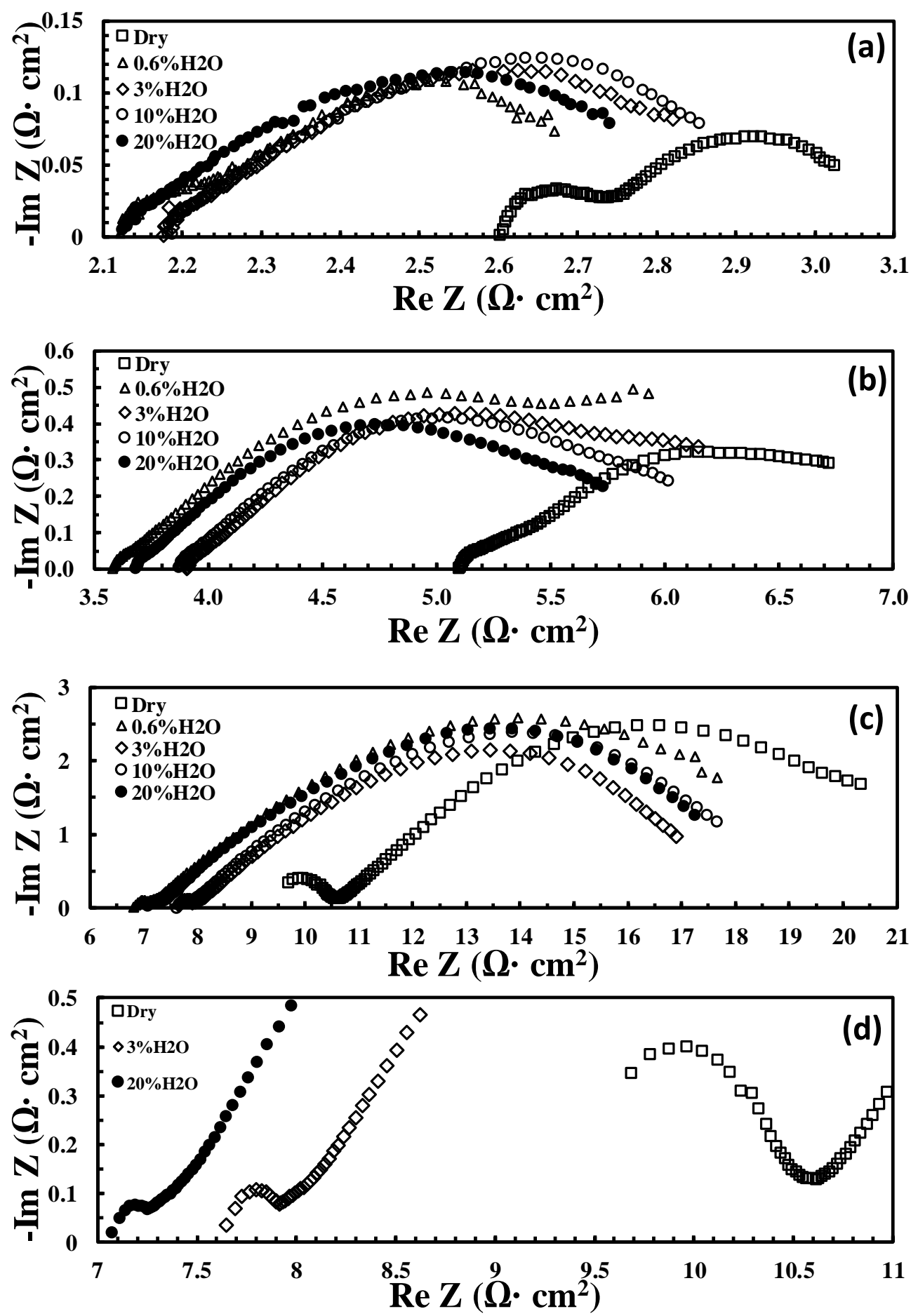

Figure 5. 8 Impedance spectra for a BSCF/BZCYYb/BSCF symmetrical cell in dry simulated air $\left(20 \% \mathrm{O}_{2} / 80 \% \mathrm{~N}_{2}\right.$ with $\left.<\sim 5 \mathrm{ppm} \mathrm{H}_{2} \mathrm{O}\right)$ versus simulated air with varying concentrations of moisture at (a) $650^{\circ} \mathrm{C}$, (b) $550^{\circ} \mathrm{C}$, (c) $450^{\circ} \mathrm{C}$, and (d) zoom-in of the impedance spectra at $450^{\circ} \mathrm{C}$ showing the high frequency (HF) part. 

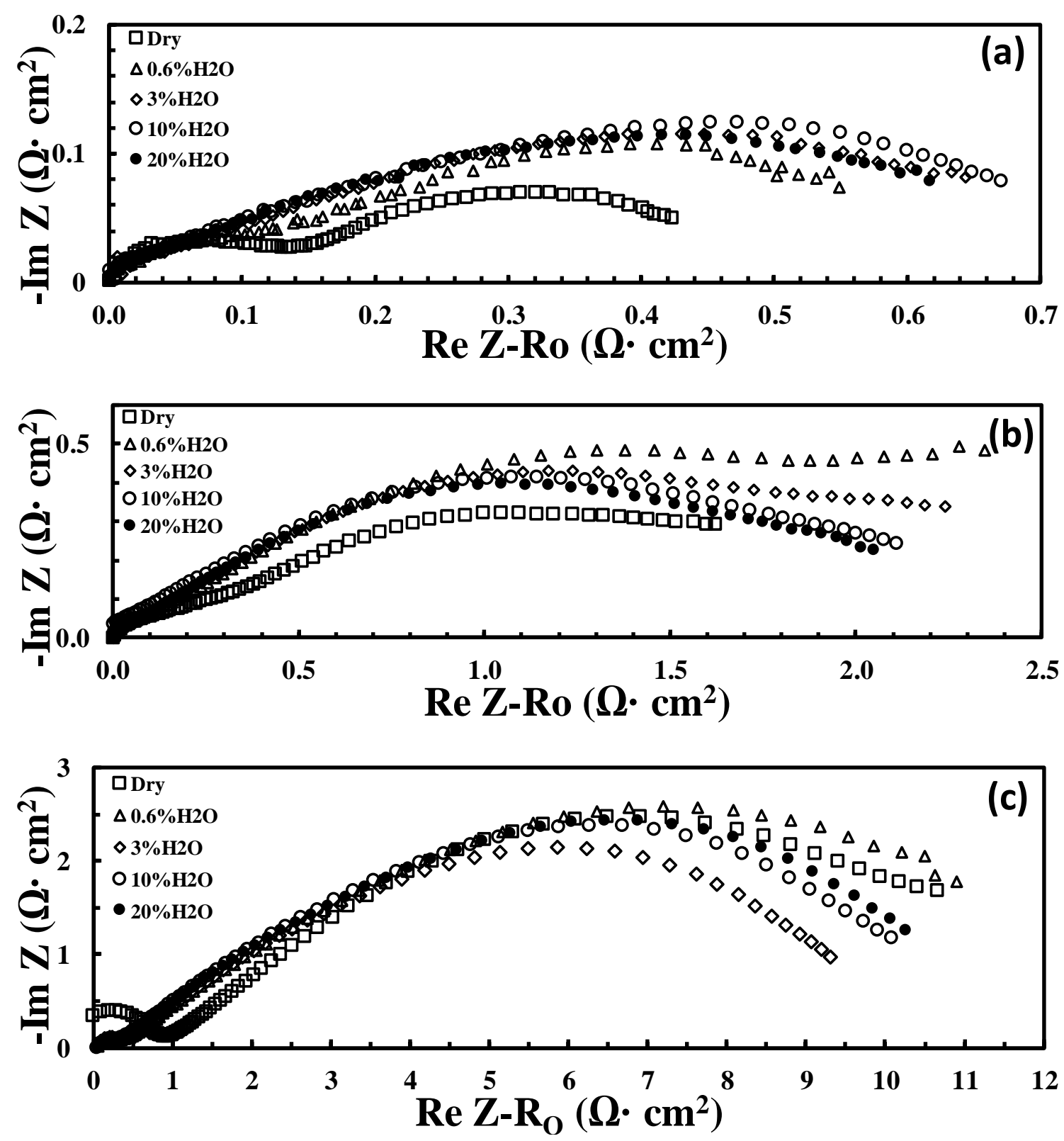

Figure 5. 9 Ohmic resistance subtracted impedance spectra for a BSCF/BZCYYb/BSCF symmetrical cell in dry simulated air $\left(20 \% \mathrm{O}_{2} / 80 \% \mathrm{~N}_{2}\right.$ with $\left.<\sim 5 \mathrm{ppm} \mathrm{H}_{2} \mathrm{O}\right)$ versus simulated air with various concentrations of moisture at (a) $650^{\circ} \mathrm{C}$, (b) $550^{\circ} \mathrm{C}$, and (c) $450^{\circ} \mathrm{C}$, respectively. 


\section{$5.4 \quad$ Discussions}

As discussed in section 1.1 and published paper, [157] the overall cathode or oxygen electrode reaction process based on a conventional oxide ion conducting electrolyte proceeds via

$\mathrm{O}_{2}+2 \mathrm{~V}_{\mathrm{O}} \ddot{*}+4 \mathrm{e}^{-} \leftrightarrow 2 \mathrm{O}^{\times}$ Equation 5.1

while the cathode reaction based on an ideal, "pure" proton conducting electrolyte proceeds via

$\mathrm{O}_{2}+4(\mathrm{OH}) \mathrm{O}^{\cdot}+4 \mathrm{e}^{-} \leftrightarrow 4 \mathrm{O}^{\times}+2 \mathrm{H}_{2} \mathrm{O}$.

Equation 5.2

The elementary steps for both reaction pathway (1) and (2) are summarized in Table 5. 1 and also illustrated in Figure 5. 10 and Figure 5. 11 for the different electrodes used.
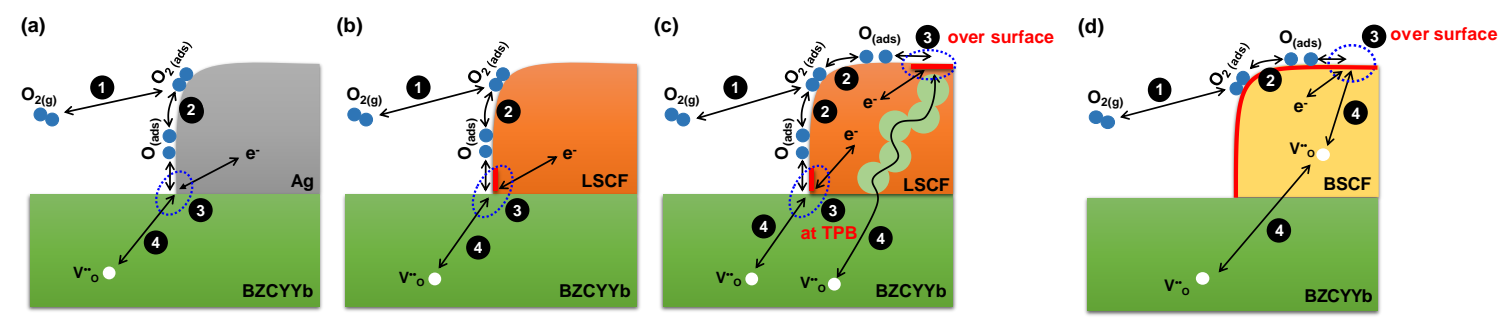

$$
\mathrm{O}_{2}+4 \mathrm{e}^{-}+2 \mathrm{~V}_{\circ} \cdot \bullet 2 \mathrm{O}^{\mathrm{x}}
$$

Figure 5. 10 Schematics showing the reaction species involved and the elementary steps (also refer to Table 5. 1) for the reversible oxygen electrode reactions for an ideal oxideion based SOFC with (a) Ag, (b) pure LSCF, (c) LSCF-BZCYYb composite, and (d) $\mathrm{BSCF}$ as the cathode (oxygen electrode) on BZCYYb electrolyte in a dry simulated air atmosphere. 

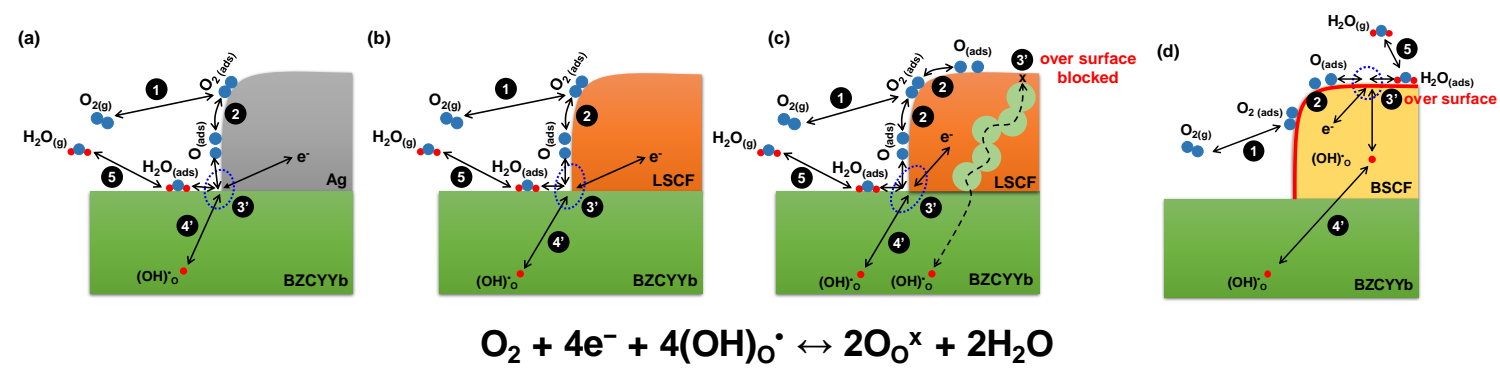

Figure 5. 11 Schematics showing the reaction species involved and the elementary steps (also refer to Table 5. 1) for the reversible oxygen electrode reactions for an ideal protonconducting electrolyte based SOFC with (a) Ag, (b) pure LSCF, and (c) LSCF-BZCYYb composite, and (d) BSCF as the cathode (oxygen electrode) on proton conducting BZCYYb electrolyte in simulated air in a humidified atmosphere assuming full hydration for the electrolyte. 
Table 5. 1 Elementary steps (and their reverse steps) of the oxygen electrode reaction for the reversible oxygen electrode reactions for ideal oxide-ion based SOFC (step 1,2,3,4) and ideal proton conducting SOFC (step 1,2,3',4',5). [157]

\begin{tabular}{|c|c|c|}
\hline Elementary Steps & & $\begin{array}{l}\text { Frequency } \\
\text { range }\end{array}$ \\
\hline $\begin{array}{l}\mathbf{1} \text { Mass transfer of } \\
\mathrm{O}_{2} \text { molecule in gas } \\
\text { phase and } \\
\text { adsorption on } \\
\text { electrode surface }\end{array}$ & $\mathrm{O}_{2}(g) \leftrightarrow \mathrm{O}_{2}($ ads $)$ & $\mathrm{LF}$ \\
\hline $\begin{array}{ll}2 \text { Adsorbed } & \mathrm{O}_{2} \\
\text { molecule } & \\
\text { dissociation } & \end{array}$ & $O_{2}(a d s) \leftrightarrow 20(a d s)$ & $\mathrm{MF}$ \\
\hline $\begin{array}{l}3 \text { Charge transfer } \\
\text { for ideal oxide ion } \\
\text { electrolyte }\end{array}$ & $O(a d s)+V_{O}^{\ddot{ }}+2 e^{-} \leftrightarrow O_{O}^{X}$ & $\mathrm{HF}$ \\
\hline $\begin{array}{l}\text { 3' Charge transfer } \\
\text { for ideal pure } \\
\text { proton electrolyte }\end{array}$ & $O(a d s)+2 e^{-}+2 O H_{O} \leftrightarrow H_{2} O(a d s)+2 O_{O}^{X}$ & $\mathrm{HF}$ \\
\hline $\begin{array}{l}4 \text { Mass transfer of } \\
\text { oxide ion in the } \\
\text { bulk of electrode } \\
\text { and/or electrolyte }\end{array}$ & $V_{O(\text { electrode })}^{*} \leftrightarrow V_{O}^{*}($ electrolyte $)$ & $\begin{array}{l}\text { Very HF } \\
\left(>>10^{6} \mathrm{~Hz}\right)\end{array}$ \\
\hline $\begin{array}{l}\text { 4' Mass transfer of } \\
\text { proton in the bulk } \\
\text { of electrode and/or } \\
\text { electrolyte }\end{array}$ & $O H_{O(\text { electrode })}^{\cdot} \leftrightarrow O H_{O(\text { electrolyte })}^{\cdot}$ & $\begin{array}{l}\text { Very HF } \\
\left(>>10^{6} \mathrm{~Hz}\right)\end{array}$ \\
\hline $\begin{array}{ll}\mathbf{5}\left(\text { or } \mathbf{5}^{\prime}\right) & \mathrm{H}_{2} \mathrm{O} \\
\text { transport } & \text { and } \\
\text { desorption } & \\
\end{array}$ & $\mathrm{H}_{2} \mathrm{O}(\mathrm{ads}) \leftrightarrow 2 \mathrm{H}_{2} \mathrm{O}(\mathrm{g})$ & $\mathrm{LF}$ \\
\hline
\end{tabular}

Among those processes, the steps of oxygen adsorption (step 1) and dissociation (step 2) always exist no matter whether the atmosphere contains water or not. For the charge transfer step, for a proton conducting electrolyte such as BZCYYb used in this study, if the atmosphere is dry and the temperature is high $\left(>\sim 700^{\circ} \mathrm{C}\right)$, it is expected to proceed primarily via the oxide ion (or $\mathrm{V}_{\mathrm{O}}{ }^{*}$ ) route as shown in step 3; (19) On the other hand, if the atmosphere is humidified and the temperature is relatively low $\left(\sim 450^{\circ} \mathrm{C}\right)$, most if not all 
oxygen vacancy can be assumed to be protonated, and the charge transfer step is expected to proceed primarily via the proton $\left((\mathrm{OH})_{\circ}^{\circ}\right)$ route as shown in step 3'. Consequently, depending on the atmosphere as well as temperature, the bulk phase ion transport step, in the electrode and/or the electrolyte, would proceed either via oxide ion (step 4) or proton (step 4'). Finally, if the charge transfer step is based on proton, there must also be the additional step of water desorption (or adsorption for the reverse reaction) (step 5'). With this in mind, the electrochemical behaviors of different oxygen electrodes over the BZCYYb proton conducting electrolyte are discussed here below.

\subsubsection{Ag Electrode}

Based on the observations above, Ag, as an electron conducting cathode, behaves rather poorly on the proton conducting BZCYYb electrolyte, giving very large apparent interfacial resistance $\mathrm{R}_{\mathrm{ai}}$ at intermediate temperature of 450 to $650^{\circ} \mathrm{C}$. This is understandable from two aspects: First, $\mathrm{Ag}$ is not expected to be an effective oxide-ion or proton conductor, which would limit the cathode oxygen electrochemical reaction to the triple-phase boundary (TPB) region, and the electrode process on the Ag electrode over an ideal oxide ion conducting electrolyte in air is represented in the schematic in Figure 5. 10 (a). Second, the fired Ag electrode has relatively coarse microstructure, as shown in the SEM images of Figure 5.2 (a) and (b), which would severely limit the total length of triplephase boundary (TPB). In fact, it is probably for these two reasons that the oxygen electrode process becomes so sluggish that high frequency loop does not even intercept with the real axis. 
Nevertheless, for the Ag electrode, the displayed increase of $R_{a i}$ with respect to reducing $\mathrm{pO}_{2}$ under dry atmosphere appears reasonable: With reduction of $p \mathrm{O}_{2}$ from $100 \%$ to $20 \%$, the oxygen gas phase transport [48] as well as surface adsorption and dissociation processes are expected to slow down significantly. Due to the complexity of the cathode process, the exact interpretation of the various overlapping semi-circles observed (e.g., as many of 4 semi-circles from high frequency to low frequency were observed at $550^{\circ} \mathrm{C}$ ) is not straightforward except at the lower temperature of $450^{\circ} \mathrm{C}$ when the reduction of $p \mathrm{O}_{2}$ does not seem to impact the HF semi-circle (see Figure 5.3 (c)), suggesting that, at $450^{\circ} \mathrm{C}$, the HF semi-circle most likely represents the charge transfer step, while the MF-to-LF semicircles should represent the various processes including gas phase transport, oxygen molecule adsorption and dissociation, and surface diffusion.

With respect to the moisture effect on the Ag electrode, the process is conceptually illustrated in Figure 5. 11 (a). Due to very sluggish electrode process, the ohmic resistance Ro cannot be accurately determined in this study in the temperature range of 450 to $650^{\circ} \mathrm{C}$. Nevertheless, an earlier study on a $\mathrm{Pt} / \mathrm{BaCe}_{0.8} \mathrm{Gd}_{0.2} \mathrm{O}_{3}(\mathrm{BCG}) / \mathrm{Pt}$ symmetrical cell at $722^{\circ} \mathrm{C}$ clearly showed decrease in Ro upon introduction of 3\% moisture. [159] In addition, as mentioned before and will be discussed later, similar reduction in $\mathrm{R}_{\mathrm{O}}$ upon the introduction of moisture for BZCYYb proton conducting electrolyte was clearly observed for the BSCF cathode symmetrical cell (see Figure 5. 8), indicating the change of ion conducting species from oxide ion to proton and the acceleration of the bulk transport process. As to the oxygen electrode reaction process, Figure 5.3 suggests that all HF and MF-LF loops seem to increase upon the introduction of 3\% moisture into dry air at temperatures from 650 to 
$450^{\circ} \mathrm{C}$. Such an observation is consistent with the previous study on the $\mathrm{Pt} / \mathrm{BCG} / \mathrm{Pt}$ symmetrical cell. [162] Part of the increase could be attributed to the strong adsorption of water molecules over the BZCYYb electrolyte surface including near the TPB, which would interfere with the processes of oxygen adsorption (step 1) and dissociation and surface diffusion (step 2). These steps, as stated before for $450^{\circ} \mathrm{C}$, are represented by the mid-to-low frequency loops. As to the charge transfer step at the TPB, with the introduction of moisture to the testing chamber, the ion conducting species is expected to change from oxygen vacancy to proton, and the charge transfer step would change from the oxide ion route (step 3) to the proton route (step 3'). The observed increase in $\mathrm{R}_{\mathrm{HF}}$ upon moisture introduction to dry air for the Ag electrode seems to suggest that, for the Ag electrode (and the Pt electrode as in the earlier study), the charge transfer step via the proton route appears to be slower than via the oxide ion route. One possible explanation for this is that the very strongly adsorbed water molecules at the TPB reduces the concentration of adsorbed oxygen, which slows down the overall charge transfer step despite the acceleration of ion transport in the bulk phase(s). Another possibity is that the proton conducting electrolytes (e.g. BZCYYb in this study and BCG [121] in the earilier study) have certain electronic conductivity in dry atmospheres, which means the measured impedance would be subjected to shortage effect, leading to underestimation of the apparent electrode interfacial resistance $\mathrm{R}_{\mathrm{ai}}$ under dry condition. [163] With the introdution of moisture, the electronic conduction would get suppressed for the proton conducting electrolyte. As a result, the measured $R_{a i}$ would suffer less from the shortage effect and appear to be larger comparing with the dry condition. Further study is needed to clarify the exact origin for 
this phenomenon (i.e., the reduction of $\mathrm{R}_{\mathrm{HF}}$ for $\mathrm{Ag}$ or Pt electrode over proton conducting electrolyte when moisture is introduced into dry air).

\subsubsection{Pure LSCF Electrode}

For the pure LSCF cathode, the observation of very large total apparent electrode interfacial resistance $\mathrm{R}_{\mathrm{ai}}$ on the order of $\sim 30 \Omega \bullet \mathrm{cm}^{2}$ at $650^{\circ} \mathrm{C}$ and $\sim 80 \Omega \bullet \mathrm{cm}^{2}$ at $550^{\circ} \mathrm{C}$ in dry simulated air or dry oxygen was rather surprising. Given that LSCF is known to be a very good mixed oxide ion and electron conductor (MIEC), $[68,74]$ and the BZCYYb electrolyte should also conduct primarily oxide ion with high conductivity in dry atmosphere, the expectation was that such an LSCF/BZCYYb/LSCF symmetrical cell should give much better interfacial resistance in dry atmosphere. In fact, as mentioned before, for pure LSCF cathode symmetrical cells over oxide ion conducting electrolyte (e.g., yttria stabilized zirconia YSZ or GDC), the interfacial resistance reported was measured to be only $\sim 0.4-1 \Omega \cdot \mathrm{cm}^{2}$ at $650^{\circ} \mathrm{C}$ and $\sim 3-10 \Omega \bullet \mathrm{cm}^{2}$ at $550^{\circ} \mathrm{C}$ in air. $[69,160$, 164] Nevertheless, the experimental observation of LSCF electrode over proton conducting electrolyte (e.g., BZCYYb) giving much larger interfacial resistance in dry atmosphere similar to the Ag electrode suggests that there is certain complexity involved when matching the pure LSCF cathode with the BZCYYb electrolyte: The LSCF behaves as if oxide ion could not effectively transport between the BZCYYb electrolyte and the LSCF cathode and, as a result, LSCF behaves more like an electronic conductor as Ag or La $\mathrm{A}_{1-}$ ${ }_{x} \mathrm{Sr}_{\mathrm{x}} \mathrm{MnO}_{3}$ (LSM). Thus, as illustrated in Figure 5.10 (b), the active reaction sites become limited to the LSCF-BZCYYb-air TPB and its very vicinity region, while most of the surface of the LSCF electrode is not active unlike in typical oxide ion SOFCs with LSCF 
cathode. Related to this, at a lower temperature of $450^{\circ} \mathrm{C}$, despite that the high frequency semi-circle seems to intercept with the real axis at $\sim 50 \Omega \cdot \mathrm{cm}^{2}$, this value is unlikely to represent the actual electrolyte ohmic resistance but is attributed to the very sluggish electrode process due to limited TPB and active LSCF surface.

As to the $p \mathrm{O}_{2}$ and moisture effects on the LSCF cathode, despite the complex shapes of the impedance spectra, the responses are also similar to the Ag electrode: With the introduction of moisture, $R_{\text {ai }}$ generally increases. This is understandable because strong adsorption of water molecules on the BZCYYb surface is expected to slow down the oxygen adsorption and dissociation and, maybe, the charge transfer step, as illustrated in Figure 5. 11 (b). The situation is expected to be somewhat similar with decreasing $p \mathrm{O}_{2}$. It is worth noting that, as mentioned before, for the LSCF cathode at $450^{\circ} \mathrm{C}$ (see Figure 5. 4 (c)), the high frequency loop seems to decrease with both decreasing $p \mathrm{O}_{2}$ and increasing $p \mathrm{H}_{2} \mathrm{O}$. Although the exact reason for such behaviors is not clear, one possible explanation is that this HF loop may not represent the charge transfer step as for the Ag electrode. Instead, it may represent $\mathrm{O}_{2}$ and $\mathrm{H}_{2} \mathrm{O}$ gas diffusion through the highly porous electrode with pore size $<\sim 1 \mu \mathrm{m}$ at that temperature to access the TPB sites right at the interface of the LSCF electrode and BZCYYb electrolyte. This seems possible given that the LSCF over BZCYYb electrolyte here behaves more like the Ag electrode with electrode reaction confined at the electrode/electrolyte interface, which is buried deeply beneath a cathode with very fine pores. As a result, the gas phase transport limitation may show up. Further study is needed to verify such a hypothesis. 


\subsubsection{LSCF-BZCYYb Composite Electrode}

When mixing LSCF with BZCYYb to make a composite electrode, as shown before in Figure 5. 5 and Figure 5. 6, such an electrode is much more active comparing with the pure LSCF electrode: The high frequency semicircle now intercepts with the real axis, giving good estimate of the ohmic resistance $R_{O}$ that would reflect the conductivity of the BZCYYb electrolyte materials: For example, considering electrolyte thickness of $\sim 600 \mu \mathrm{m}$, the estimated conductivity in dry simulated air is $\sim 0.03 \mathrm{~S} / \mathrm{cm}$ at $650^{\circ} \mathrm{C}, \sim 0.016 \mathrm{~S} / \mathrm{cm}$ at $550^{\circ} \mathrm{C}$ and $\sim 0.01 \mathrm{~S} / \mathrm{cm}$ at $450^{\circ} \mathrm{C}$, which matches well with previous results. [88]

In addition, the overall apparent electrode interfacial resistance $\mathrm{R}_{\mathrm{ai}}$ in dry air as well as pure oxygen decreases by ten times or even more comparing with the pure LSCF cathode. This dramatic improvement of electrode activity provides additional support to the earlier hypothesis that LSCF behaves more like an electronic conductor with very limited oxide ion conductivity when it is matched with a proton conducting electrolyte such as BZCYYb in the dry atmosphere. As depicted in Figure 5. 10 (c), when making a LSCF-BZCYYb composite electrode, the TPB in the LSCF-BZCYYb composite is expanded comparing with the pure LSCF cathode due to fine mixing of submicron-scale (see Figure 5. 11Figure 5. 10 (e) and (f)) ion conducting BZCYYb electrolyte phase and the LSCF phase, which only conducts electrons here. On the other hand, by providing a porous BZCYYb network in close contact with LSCF, the oxide-ions from the BZCYYb electrolyte could transport through the BZCYYb network over much of the composite cathode to larger regions with LSCF surface close to the LSCF/BZCYYb two phase boundary. The result is that more surface area of the LSCF now also becomes active for oxygen electrode reaction. The 
added TPB and expanded surface area of LSCF that become active together help accelerate the oxygen electrode processes, which are illustrated in Figure 5.10 (c). As a result of the greatly accelerated electrode reaction, the obtained Ro from impedance spectra reduce dramatically reflecting the actual conductivity of the BZCYYb electrolyte used.

On the other hand, as stated, Figure 5. 9 shows that when such an LSCF-BZCYYb composite electrode symmetrical cell over BZCYYb electrolyte is subject to humidified air, dramatic increase in $\mathrm{R}_{\mathrm{O}}$ (by almost 6 times in 3\% moisture!) with the introduction of moisture was observed at $650^{\circ} \mathrm{C}$ and, to a less extent, $550^{\circ} \mathrm{C}$. Such a behavior is attributed to the reduction of reaction sites upon humidification for the composite cathode. As stated before and shown in Figure 5. 10 (c), electrode reaction in the LSCF-BZCYYb composite cathode symmetrical cell under $d r y$ condition can occur at the TPB sites as well as over LSCF surface where BZCYYb network is close enough to deliver oxide-ions (see the schematic in Figure 5. 10 (c)). However, after the introduction of moisture, the electrode reaction for the composite cathode again becomes limited only to the TPB sites presumably due to the inability of LSCF to conduct protons when the major ionic species changes from oxide-ion to proton: This effectively blocks the reactions going through the LSCF surface near the BZCYYb network, making processes 3', 4' and 5' almost impossible to happen. In addition, this explanation could be supported by the observation that the $\mathrm{R}_{O}$ for the LSCF-BZCYYb composite symmetrical cell seems to increase to values comparable to those for the pure LSCF cathode symmetrical cell after the introduction of moisture at $650^{\circ} \mathrm{C}$ and $550^{\circ} \mathrm{C}$ (see Figure 5. 4), suggesting dramatically slowed down oxygen electrode reaction with moisture introduction. 
In comparison, at lower temperature such $450^{\circ} \mathrm{C}$, such "blocking effect" or the increases in $\mathrm{R}_{\mathrm{ai}}$ as well as $\mathrm{R}_{\mathrm{O}}$ due to moisture introduction to air for the LSCF-BZCYYb composite cathode symmetrical cell is much smaller. This might be because that although moisture still covers the BZCYYb surface and TPB at lower temperature, due to faster bulk ionic transport for proton (step 4') compared to the ionic transport via oxygen vacancy route (step 4) and the fact that moisture is now part of the charge transfer step (step $3^{\prime}$ ): despite certain parts of the oxygen electrode reaction (e.g., $\mathrm{O}_{2}$ adsorption (step 1) and dissociation (step 2)) got hindered, other part may actually accelerate (e.g., $\mathrm{H}_{2} \mathrm{O}$ splitting over the electrode surface (step 3')), and the net effect is no longer obvious. Another factor, which might be more important, is that for the BZCYYb electrolyte, both the reaction route via oxide-ion (reaction (1)) and via proton (reaction (2)) would co-exist and compete with each other. At a higher temperature such as $650^{\circ} \mathrm{C}$, the difference in the actual extent of BZCYYb hydration is large between "dry simulated air" and the 3\% humidified air. This means in "dry" air, most of the reaction would go through the oxide ion route. Then, after $3 \%$ moisture is introduced, a significant portion of the oxide ion route is blocked due to hydration of the BZCYYb electrolyte and shut off the route over LSCF surface near BZCYYb and confinement of the active region to strictly TPB. In comparison, at a lower temperature of $450^{\circ} \mathrm{C}$, due to strong bonding of the $\mathrm{BZCYYb}$ electrolyte with moisture at that temperature, even for the so-called "dry" condition, very significant portion of the electrode reaction already goes through the proton route. As a result, when $3 \%$ moisture is introduced, the actual difference in impedance spectra between "dry simulated air" and $3 \%$ humidified air appear to be much less dramatic. [88] Further study is needed to verify this. 


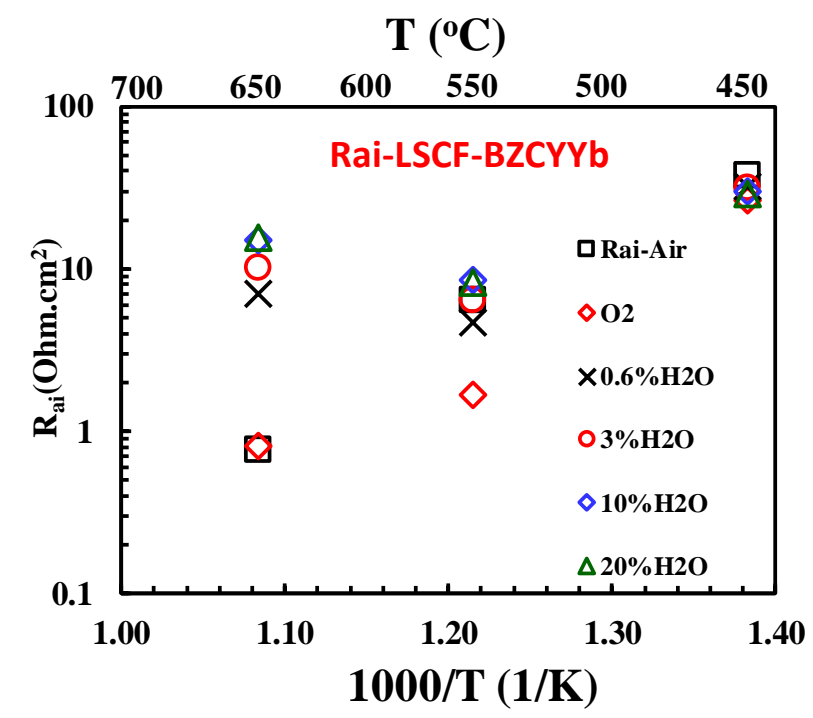

Figure 5. 12 Total apparent electrode interfacial resistance $\mathrm{R}_{\mathrm{ai}}$ in dry simulated air, pure oxygen and simulated air containing up to $20 \%$ moisture for LSCF-BZCYYb composite electrode symmetrical cells at temperatures from 650 to $450^{\circ} \mathrm{C}$.

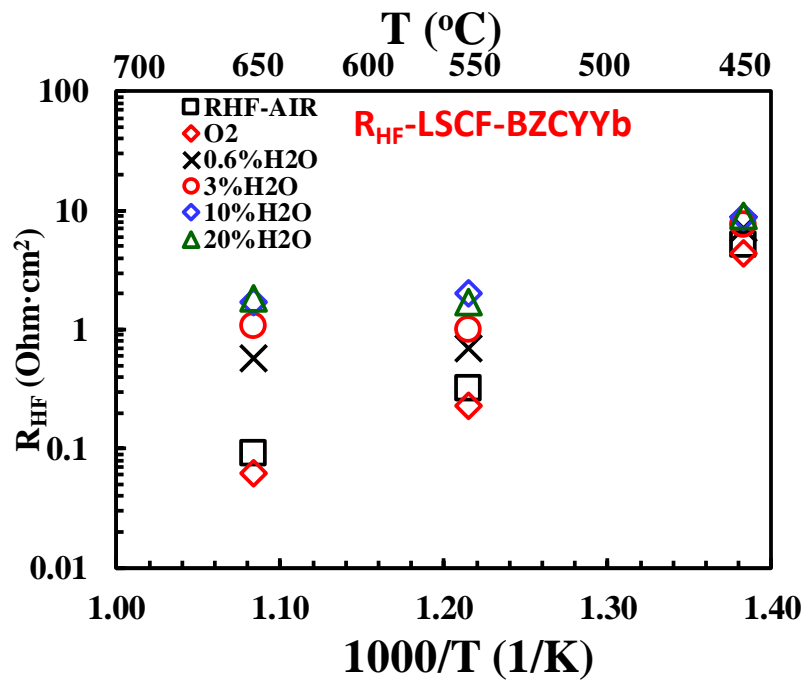

Figure 5. 13 High frequency resistance $\mathrm{R}_{\mathrm{HF}}$ in dry simulated air, pure oxygen and simulated air containing up to $20 \%$ moisture for LSCF-BZCYYb composite electrode symmetrical cells at temperatures from 650 to $450^{\circ} \mathrm{C}$. 
Finally, for the LSCF-BZCYYb symmetrical cell, equivalent circuit fitting was carried out to roughly evaluate the total apparent electrode interfacial resistance $\mathrm{R}_{\mathrm{ai}}$ and the high frequency resistance $R_{H F}$, and the values are plotted against inverse temperature (1/T), as in Figure 5. 12 and Figure 5. 13. Besides, the ASR vs. $p \mathrm{H}_{2} \mathrm{O}$ dependence of the LSCFBZCYYb symmetric cell cathode response was also examined (not shown here). It is observed that, between $650^{\circ} \mathrm{C}$ and $550^{\circ} \mathrm{C}$, both $\mathrm{R}_{\mathrm{ai}}$ and $\mathrm{R}_{\mathrm{HF}}$ decrease with decreasing temperature under humidified condition; in comparison, under dry condition, both $\mathrm{R}_{\mathrm{ai}}$ and $\mathrm{R}_{\mathrm{HF}}$ increase with decreasing temperature. This may also be related to the explanation before about the large difference in moisture response with respect to temperature for the LSCF-BZCYYb composite electrode. However, no more definitive insight into the cathode reaction process could be extracted so far as no consistent trend in behavior based on the ASR vs. $p \mathrm{H}_{2} \mathrm{O}$ dependence was observed at various temperatures.

\subsubsection{BSCF Electrode}

Comparing with the Ag, pure LSCF, and also LSCF-BZCYYb composite electrodes, the impedance data in Figure 5. 7 shows that BSCF behaves like a good MIEC electrode in a symmetrical cell with BZCYYb electrolyte: The overall $\mathrm{R}_{\mathrm{ai}}$ was the lowest among all those electrodes tested under both dry and humidified conditions. The decrease in $\mathrm{R}_{\mathrm{O}}$ with increasing $p \mathrm{O}_{2}$ is attributed to the increased electronic conduction, especially at higher temperature of $650^{\circ} \mathrm{C}$, which matches that reported in literature. [165] The decrease in Ro with the introduction of moisture is expected and can be attributed to faster mass transfer process via proton (step 4') than via oxide ion (step 4) at all temperatures, which is 
consistent with previous studies. $[12,72,157,166]$ In addition, as discussed elsewhere, the high frequency semicircle in the impedance spectra for the BSCF symmetrical cell has been attributed to the charge transfer process. [157] Such an assignment is rational as $R_{H F}$ does not seem to change with changing $p \mathrm{O}_{2}$, yet it decreases continuously with introduction and increasing moisture content, and it was particularly obvious at lower temperature. This has been attributed to faster charge transfer step via the proton route (step 3') than via the oxide ion route (step 3), especially at lower temperature of $450^{\circ} \mathrm{C}$, because $\mathrm{BSCF}$ seems to behave like a MIEC with the entire BSCF surface as well as TPB active for oxygen electrode reactions, which is not expected to be severely limited by available sites for oxygen adsorption/dissociation and charge transfer.

Besides that, the observation of the increase in RMF-LF with decreasing $p \mathrm{O}_{2}$ (see Figure 5. 14) or the introduction of $\mathrm{H}_{2} \mathrm{O}$ (see Figure 5.8 and Figure 5. 9), which is more obvious at higher temperature of $650^{\circ} \mathrm{C}$ and $550^{\circ} \mathrm{C}$, but less so at low temperature of $450^{\circ} \mathrm{C}$, suggests that these parts of resistance can be attributed to the adsorption/desorption (step 1) and dissociation/association (step 2), both which are limited by reduced surface area due to adsorption of water molecules. Moreover, the increase in RMF-LF with the introduction and increase of moisture content is generally consistent with most other types of symmetrical cells, suggesting such an increase does not seem to depend on the specific oxygen electrode material but more reflects the intrinsic strong water adsorption property of the BZCYYb electrolyte. 


\subsubsection{Electrochemical Behavior of BSCF Anode-supported Full Cell at $450^{\circ} \mathrm{C}$}

The comparison of these different electrodes suggests that, despite the higher ionic conductivity of the proton conducting electrolyte like BZCYYb, simply borrowing a good MIEC material (e.g., LSCF) for an oxide ion conducting SOFC does not guarantee excellent performance when it is used as the cathode for a proton conducting IT-SOFC. In fact, this has been confirmed by previous studies. For example, Yang et al. compared the performance for the pure LSCF cathode versus the LSCF-BZCYYb composite cathode at $750^{\circ} \mathrm{C}$ and arrived at the same conclusion that the composite cathode delivers significantly higher activity than the pure LSCF cathode. [121]

On the other hand, cathode material of BSCF does behave like a good MIEC both in dry atmosphere and in humidified atmosphere. Given that BSCF is a good oxide ion conductor and has been shown to be able to take up significant amount of moisture, [20] the result here strongly suggests the possibility that BSCF is a mixed proton-oxide ionelectron triple conducting oxide in humidified atmosphere at lower temperature and would serve as a good cathode for proton conducting IT-SOFC. This can also be supported by comparison of $\mathrm{R}_{\mathrm{ai}}$ between the BSCF symmetrical cell versus the LSCF-BZCYYb composite symmetrical cell, showing significantly lower values for the BSCF electrode, especially under humidified condition. Another piece of evidence comes from the comparison with data for an $\mathrm{LSCF}-\mathrm{Ba}\left(\mathrm{Zr}_{0.1} \mathrm{Ce}_{0.7} \mathrm{Y}_{0.2}\right) \mathrm{O}_{3-\delta}$ (BZCY) composite cathode/BZCY electrolyte/NiO-BZCY anode-supported full cell reported in a previous study: [121] At $450^{\circ} \mathrm{C}$, that cell was expected to yield total electrode interfacial resistance as high as $\sim 10 \Omega \cdot \mathrm{cm}^{2}$, while a BSCF/BZCYYb/NiO-BZCYYb anode supported cell in this 
study gave a much lower value of $\sim 2.7 \Omega \bullet \mathrm{cm}^{2}$, as shown in Figure 5. 15. Additionally, the $\mathrm{R}_{\mathrm{O}}$ and $\mathrm{R}_{\mathrm{ai}}$ values obtained in this study for the anode-supported cell is $\sim 1.5 \Omega \bullet \mathrm{cm}^{2}$ and $\sim 2.7 \Omega \bullet \mathrm{cm}^{2}$ at $450^{\circ} \mathrm{C}$, respectively. These values are consistent with those obtained for a BSCF cathode/ $\mathrm{BaCe}_{0.9} \mathrm{Y}_{0.1} \mathrm{O}_{2.95}(\mathrm{BCY})$ electrolyte anode-supported full cell giving $\mathrm{R}_{\mathrm{O}}$ and $\mathrm{R}_{\text {ai }}$ values of $\sim 0.75 \Omega \bullet \mathrm{cm}^{2}$ and $\sim 0.4 \Omega \bullet \mathrm{cm}^{2}$ at $500^{\circ} \mathrm{C}$. [72]

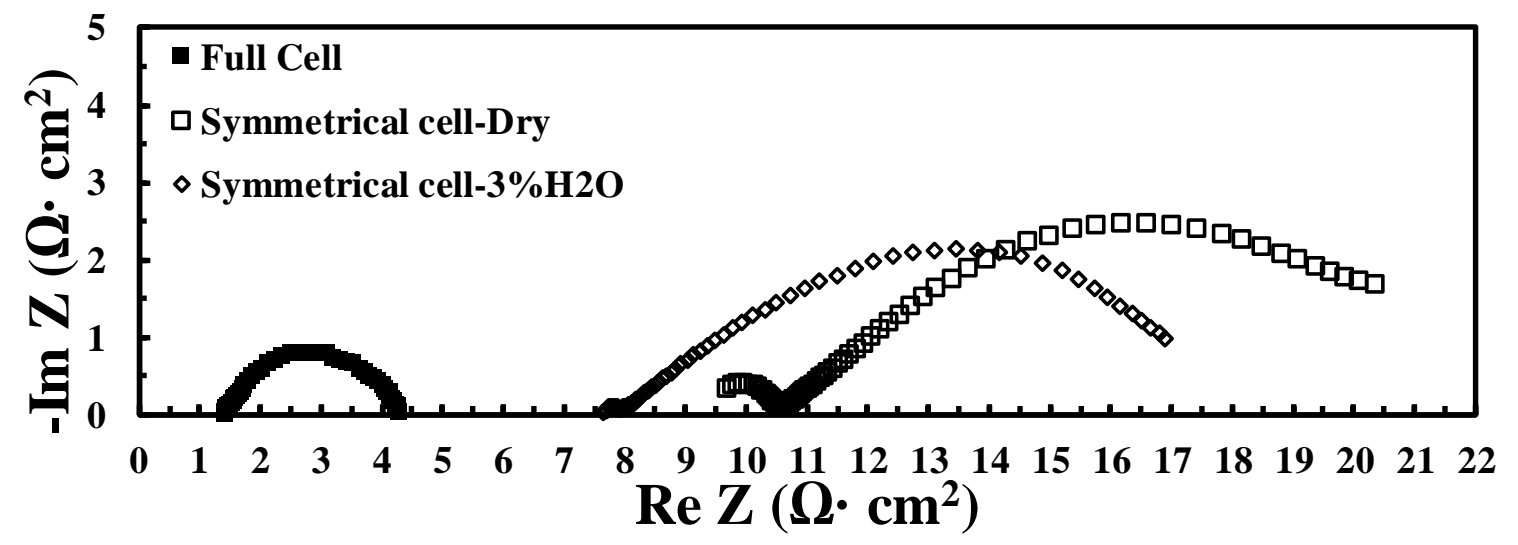

Figure 5. 15 Impedance spectra for a BSCF/BZCYYb/BSCF symmetrical cell in dry simulated air $\left(20 \% \mathrm{O}_{2} / 80 \% \mathrm{~N}_{2}\right.$ with $\left.<\sim 5 \mathrm{ppm} \mathrm{H}_{2} \mathrm{O}\right)$ and simulated air with $3 \% \mathrm{H} 2 \mathrm{O}$ versus $\mathrm{BSCF} / \mathrm{BZCYYb} / \mathrm{Ni}-\mathrm{BZCYYb}$ full cell at $450^{\circ} \mathrm{C}$

Considering that the BSCF cathode microstructure prepared in this study was by convention printing and firing approach, leading to rather coarse microstructures (Figure 5.2 (g) and (h)) comparing with the LSCF-based electrodes (see Figure 5.2 (c to f)), it seems there is still significant room for improvement in terms of optimizing the microstructure of the BSCF electrode. For example, the BSCF cathode microstructure might be optimized with better tuning of the firing process and/or introduction of nanostructured catalysts into the BSCF cathode via methods such as infiltration. [160] These would help further increase electrode active surface area and may significantly improve the cathode performance for proton conducting IT-SOFC, and will be studied in 
future. In addition, it is noted that BSCF was still developed as a "traditional" SOFC cathode materials for conventional oxide-ion conducting SOFC, while some proton-oxide ion-electron "triple conducting" cathode materials have been specifically developed recently for proton-conducting SOFCs and seem to show dramatically improved proton conductivity and electrochemical activity over BSCF. For example, $\mathrm{Ba}_{0.5} \mathrm{Sr}_{0.5} \mathrm{Fe}_{0.8} \mathrm{Zn}_{0.2} \mathrm{O}_{3-\delta}$ (BCFZ) showed proton conductivity of 0.9 to $3 \times 10^{4} \mathrm{~S} \mathrm{~cm}^{-1}$ at 600 to $350^{\circ} \mathrm{C}$; [122] $\mathrm{NdBa}_{0.5} \mathrm{Sr}_{0.5} \mathrm{Co}_{1.5} \mathrm{Fe}_{0.5} \mathrm{O}_{5+\delta}$ (NBSCF) achieved outstanding maximum power densities of $1.71,1.37,1.05$, and $0.69 \mathrm{~W} \mathrm{~cm}^{2}$ over BZCYYb electrolyte at $750,700,650$, and $600^{\circ} \mathrm{C}$; [127] $\mathrm{BaCo}_{0.4} \mathrm{Fe}_{0.4} \mathrm{Zr}_{0.2-\mathrm{x}} \mathrm{Y}_{\mathrm{x}} \mathrm{O}_{3-\delta} \quad$ (BCFZY) exhibited significantly reduced cathode interfacial resistance of only $0.12 \Omega \cdot \mathrm{cm}^{2}$ at $500^{\circ} \mathrm{C}$ over BZCYYb electrolyte. [167] These studies suggest that partial doping or substituting for the A or B site elements in BSCF could be another way to further tailor the properties for improved cathode performance for proton conducting IT-SOFC.

Finally, it should be noted that for the BSCF electrode, there appears to be a very large difference between the impedance measured in anode-supported full cell configuration versus in a cathode symmetrical cell configuration. To illustrate this, the impedance for the impedance spectra for the BSCF/BZCYYb/BSCF symmetrical cell in both dry air and $3 \%$ humidified air are also plotted together with that of the BSCF/BZCYYb/Ni-BZCYYb anode-supported full cell, as in Figure 5. 15. It can be observed that the $\mathrm{R}_{\mathrm{ai}}$ for the anodesupported full cell, which include contributions from both the Ni-BZCYYb cermet anode and the BSCF cathode, is only about one tenth (1/10) of the value from the cathode symmetrical cell! Such a large difference was not observed when BSCF was matched with the samaria-doped ceria (SDC) electrolyte with the oxygen electrode interfacial resistance 
giving the same value in full cell and in cathode symmetrical cell. [70] The underlying reason for this large discrepancy is not clear at this moment. According to the previous study by Merkle et al, [163] for the apparent cathode interfacial resistance from a cathode symmetrical cell with proton conducting electrolyte should be smaller than that when measured from a full cell due to the electronic shortage in relatively thick electrolyte for the symmetric cell. However, this prediction seems to be opposite to the current observation that the apparent cathode interfacial resistance as determined from the symmetrical cell with proton conducting electrolyte is much larger than from an anodesupported full cell. The underlying reason for this observation and the discrepancy from prediction is not clear. One hypothesis is related to the possible difference in the actual extent of hydration within the BZCYYb electrolyte: In the anode-supported cell configuration, due to the thin electrolyte $(\sim 20 \mu \mathrm{m})$ and anode side hydrogen supply, the $\mathrm{BZCYYb}$ electrolyte is presumably better hydrolyzed, which might ensure full proton conduction at intermediate temperature. In comparison, for the cathode symmetrical cell in humidified air, due to the thick electrolyte $(\sim 600 \mu \mathrm{m})$ used, the electrolyte may not stay fully hydrated in impedance measurement, especially for the cathodic part (water evolution size) due to slow diffusion of proton. Further studies will be needed to test such a hypothesis and understand the origin for the discrepancy when BSCF cathode is used over a proton conducting electrolyte. 


\subsection{Conclusions}

In summary, different oxygen electrodes of Ag, LSCF, LSCF-BZCYYb composite, and BSCF have been evaluated using cathode symmetrical cells based on BZCYYb proton conducting electrolyte. Generally, most cells show increased electrode interfacial resistance with decreasing $p \mathrm{O}_{2}$ or introduction of moisture. Pure LSCF does not behave like a good MIEC but more like Ag over the BZCYYb electrolyte, giving very high interfacial resistance and high ohmic resistance, suggesting very sluggish electrode reaction in both dry and humidified conditions. This indicates that the oxide-ion transfer between LSCF and BZCYYb electrolyte is not very ineffective even in dry atmosphere, but the underlying reason is not clear at the moment. Nevertheless, when LSCF was mixed with BZCYYb electrolyte to make a composite electrode, its activity becomes much better under dry conditions, which might be attributed to the extended TPB area and BZCYYb networks in the electrode that transfer oxide-ion to places near the LSCF surface. In comparison, BSCF electrode behaves like a MIEC giving low interfacial resistance and ohmic resistance than the other electrode materials studied under both dry and humidified conditions. The high frequency resistance $\mathrm{R}_{\mathrm{HF}}$ of BSCF does not change with $\mathrm{pO}_{2}$ but decreases with increasing $p \mathrm{H}_{2} \mathrm{O}$, which is attributed to intrinsically faster charge transfer step for the oxygen electrode reaction via the proton route than the oxide ion route. Full cell impedance data confirms that BSCF appears to be a better cathode for IT-proton conducting SOFC than the LSCF-BZCYYb composite cathode. Further study aimed at refining the cathode microstructure via techniques such as firing optimization and infiltration [168] into the BSCF cathode as well as proper doping to enhance the proton- 
oxide ion-electron triple conduction appears attractive to obtain high performance cathode for proton conducting IT-SOFCs. Finally, study also needs to be carried out to understand the large difference in BSCF cathode interfacial resistance measured in full cell versus cathode symmetrical cell configuration when using a proton conducting electrolyte and also reconcile the difference with theoretical predictions in the literature. 


\section{Chapter VI: Effects of $\mathrm{H}_{2} \mathrm{O}$ and $\mathrm{CO}_{2}$ on Electrochemical Behaviors of BSCF Cathode for Proton Conducting IT-SOFC}

This chapter details the study on the electrochemical behaviors of Ag, LSCF and BSCF as cathode for proton conducting IT-SOFC. This chapter is based on published paper by Shichen Sun, and Zhe Cheng. Title of "Effects of $\mathrm{H} 2 \mathrm{O}$ and $\mathrm{CO} 2$ on electrochemical behaviors of BSCF cathode for proton conducting IT-SOFC." in Journal of The Electrochemical Society 164.2 (2017): F81-F88.

\subsection{Introduction}

In recent years, intermediate temperature $\left(400-700^{\circ} \mathrm{C}\right)$ solid oxide fuel cells (IT-SOFC) have drawn increasing interest due to the possibility of achieving slower degradation during long-term operation, cheaper sealing and interconnect material choices, as well as higher overall thermodynamic efficiency compared to conventional high temperature $(\geq$ $\sim 750^{\circ} \mathrm{C}$ ) solid oxide fuel cells (HT-SOFC). $[12,94]$ For IT-SOFC, conventional oxide ion electrolyte of yttria-stabilized zirconia (YSZ) suffers from low ionic conductivity,[78, 81] which dictates unreasonably thin electrolyte and high cost,[169, 170] while alternative oxide ion electrolytes, such as gadolinium doped ceria (GDC) or samarium doped ceria (SDC), suffer from high electronic transport number, which lowers open circuit voltage (OCV) and system efficiency despites their significantly improved ionic conductivity at intermediate temperature.[21, 171, 172] In comparison, proton conducting oxides, many of which are perovskite-structured, offer higher ionic conductivity with low electronic transport number as well as lower activation energy at intermediate temperature.[15, 79, 
$82,86,89,173,174]$ As a result, they are regarded as the preferred electrolyte for ITSOFC.[175]

For IT-SOFC, cathode process is generally regarded as the rate-limiting step due to its high activation energy compared to the electrolyte. In particular, for proton conducting ITSOFC, there have been a number of perovskite oxides employed as potential cathodes such as $\mathrm{La}_{0.6} \mathrm{Sr}_{0.4} \mathrm{Co}_{0.2} \mathrm{Fe}_{0.8} \mathrm{O}_{3-\delta}$ (LSCF), $\mathrm{Sm}_{0.5} \mathrm{Sr}_{0.5} \mathrm{CoO}_{3-\delta}$ (SSC), and $\mathrm{BaCo}_{0.4} \mathrm{Fe}_{0.4} \mathrm{Zr}_{0.1} \mathrm{Y}_{0.1} \mathrm{O}_{3-\delta}$ (BCFZY).[121, 167, 176-178] $\mathrm{Ba}_{0.5} \mathrm{Sr}_{0.5} \mathrm{Co}_{0.8} \mathrm{Fe}_{0.2} \mathrm{O}_{3-\delta}(\mathrm{BSCF})$, which is considered to be one of the most active cathode materials for oxide ion conducting IT-SOFC, [70] could also be a promising cathode material for proton conducting IT-SOFC because of its capability of undertaking significant amount of water and becoming proton conductive at intermediate temperature of $\sim 600^{\circ} \mathrm{C}$ and below.[20, 72, 156, 179] In fact, various researchers have already explored BSCF as the cathode for proton conducting IT-SOFC and obtained varying degrees of success. $[163,166,176,177,180]$ However, there are still many unknown aspects left. For example, the exact influence of water vapor on the cathodic process for such proton conducting SOFC, especially at even lower temperatures of $\sim 400-500^{\circ} \mathrm{C}$ is still not clear. On the other hand, the influence of carbon dioxide $\left(\mathrm{CO}_{2}\right)$, which is always present in air, on the cathode electrochemical behavior for such proton conducting IT-SOFC is also uncertain despite evidence showing questionable stability of BSCF against $\mathrm{CO}_{2}$ in SOFC operation at intermediate temperature.[21] In addition, how would the co-presence of $\mathrm{H}_{2} \mathrm{O}$ and $\mathrm{CO}_{2}$, which is a more realistic situation for practical SOFC operation, influence the electrochemical behavior for proton conducting SOFC with BSCF cathode has never been studied to the best of the authors' knowledge.[22, 23] 
In this work, the chemical stability and compatibility of the BSCF cathode with one of the leading proton conducting electrolytes $\mathrm{BaZr}_{0.1} \mathrm{Ce}_{0.7} \mathrm{Y}_{0.1} \mathrm{Yb}_{0.1} \mathrm{O}_{3-\delta}(\mathrm{BZCYYb})[79,82$, 86, 89] under various conditions were studied. More importantly, BSCF/BZCYYb/BSCF cathode symmetrical cells were used to investigate the influence of water vapor and $\mathrm{CO}_{2}$ on the electrochemical behaviors for the proton conducting IT-SOFC at various temperatures ranging from $650^{\circ} \mathrm{C}$ to $400^{\circ} \mathrm{C}$. The implication of the experimental observations on the underlying oxygen electrode reaction mechanism for proton conducting IT-SOFC versus conventional oxide ion conducting SOFC is discussed, and the direction for future research on designing better cathode for proton conducting ITSOFC is pointed out.

\subsection{Experimental}

\subsubsection{Powder Synthesis}

Both BZCYYb powder with nominal composition of $\mathrm{BaZr}_{0.1} \mathrm{Ce}_{0.7} \mathrm{Y}_{0.1} \mathrm{Yb}_{0.1} \mathrm{O}_{3-\delta}$ and $\mathrm{BSCF}$ powder with nominal composition of $\mathrm{Ba}_{0.5} \mathrm{Sr}_{0.5} \mathrm{Co}_{0.8} \mathrm{Fe}_{0.2} \mathrm{O}_{3-\delta}$ were synthesized by glycine nitrate process (GNP).(33) For BZCYYb, stoichiometry amounts of $\mathrm{Ba}\left(\mathrm{NO}_{3}\right)_{2}(\# \mathrm{~A} 11305$, Alfa Aesar, 99\%), $\mathrm{ZrO}\left(\mathrm{NO}_{3}\right)_{2} \bullet \mathrm{xH}_{2} \mathrm{O}$ (\#43224, Alfa Aesar, 99.9\%), $\mathrm{Ce}\left(\mathrm{NO}_{3}\right)_{3} \bullet 6 \mathrm{H}_{2} \mathrm{O}$ (\#11329, Alfa Aesar, 99.5\%), $\mathrm{Y}\left(\mathrm{NO}_{3}\right)_{3} \cdot 6 \mathrm{H}_{2} \mathrm{O}$ (\#12898, Alfa Aesar, 99.9\%), and $\mathrm{Yb}\left(\mathrm{NO}_{3}\right)_{3} \bullet \mathrm{xH}_{2} \mathrm{O}(\# 12901$, Alfa Aesar, 99.9\%) powders were dissolved in DI water. Then glycine (\#G8898, Sigma Aldrich, 99+ \%) was added to the solution with molar ratio between glycine and total metal ions of 1:1. The solution was stirred for about 30 minutes 
in a 2-liter beaker on a hot plate at $\sim 100^{\circ} \mathrm{C}$ in order to dissolve the various salts completely. The obtained transparent solution was then heated up on the hot plate set at $\sim 540^{\circ} \mathrm{C}$. Rapid self-combustion process occurred after water was evaporated, and the very fine white powder generated after combustion was collected and calcined in ambient air at $1100^{\circ} \mathrm{C}$ for 5 hours to form pure BZCYYb perovskite phase. (It is noted that right after combustion, the powder obtained was not $\mathrm{BZCYYb}$, but doped $\mathrm{CeO}_{2}$ and amorphous phases, as reported elsewhere. [89]) In the case of BSCF powder, the major steps for powder synthesis are similar to that for BZCYYb, except the starting materials now also include $\mathrm{Fe}\left(\mathrm{NO}_{3}\right)_{3} \cdot 9 \mathrm{H}_{2} \mathrm{O}\left(\# 216828\right.$, Alfa Aesar, 99\%) and $\mathrm{Co}\left(\mathrm{NO}_{3}\right)_{2} \cdot 6 \mathrm{H}_{2} \mathrm{O}$ (\#239267, Alfa Aesar, 99\%), while the molar ratio between glycine and total metal ions was changed to 7:6 for complete combustion. After self-combustion, the powder was calcined at $1000^{\circ} \mathrm{C}$ for 2 hours in ambient air to form the pure phase. [180]

\subsubsection{Chemical Compatibility and Stability Test}

For chemical compatibility test between BSCF and BZCYYb in typical cell fabrication process, intimately mixed powders of the two materials with weight ratio of 1:1 were exposed to ambient air at typical BSCF cathode firing temperature of $1000^{\circ} \mathrm{C}$ for 5 hours. To test the stability and compatibility of the BSCF and BZCYYb mixture under typical ITSOFC operation conditions, the powder mixtures were exposed at $450^{\circ} \mathrm{C}$ in ambient air, humidified nitrogen with nominal composition of $3 \% \mathrm{H}_{2} \mathrm{O} / 97 \% \mathrm{~N}_{2}$ (gas compositions are all by volume in this study), and gas mixture of $\sim 1 \% \mathrm{CO}_{2} / 99 \% \mathrm{~N}_{2}$ for various time from 24 to 72 hours. Furthermore, the chemical stability of the BZCYYb electrolyte against 
$1 \% \mathrm{CO}_{2} / 99 \% \mathrm{~N}_{2}$ was also investigated at $750^{\circ} \mathrm{C}$ by exposing $\mathrm{BZCYYb}$ powder to that gas mixture for 24 hours. The samples after various chemical stability/compatibility tests were analyzed by X-Ray diffraction (SIEMENS diffractometer D5000) for phase identification.

\subsubsection{BSCF/BZCYYb/BSCF Symmetrical Cells Fabrication}

Cathode symmetrical cells with the configuration of BSCF/BZCYYb/BSCF were fabricated. First, electrolyte pellets with diameter of $10 \mathrm{~mm}$ were dry-pressed at $200 \mathrm{MPa}$ using $0.2 \mathrm{~g} \mathrm{BZCYYb}$ powder followed by protected sintering at $1550^{\circ} \mathrm{C}$ for 5 hours. [89] Then, the BSCF slurry was prepared by mixing BSCF powder with alpha-terpineol (\#16285, Alfa Aesar, 96\%) solvent and organic binder at weight ratio of 65: 34: 1, and ball-milled for 24 hours. $4 \times 4 \mathrm{~mm}^{2}$ BSCF electrodes were brush painted onto both sides of the sintered electrolyte pellets using the prepared slurry, fully dried in an air oven at $100^{\circ} \mathrm{C}$, and calcined at $1000^{\circ} \mathrm{C}$ for 2 hours in ambient air with heating and cooling rate of $5^{\circ} \mathrm{C} / \mathrm{min}$. (It is noticed that the $\mathrm{BSCF}$ cathode fired at $900^{\circ} \mathrm{C}$ showed weak bonding to the electrolyte, while the cathode fired at $1000^{\circ} \mathrm{C}$ showed better bonding to the electrolyte. Thus, only symmetrical cells with cathode firing temperature of $1000^{\circ} \mathrm{C}$ were used for electrochemical testing in this study.) The microstructure of the cross-section in the fabricated symmetrical cell was observed using a field emission scanning electron microscope (FE-SEM, JEOL JSM 6330F). 


\subsubsection{Electrochemical Impedance Spectroscopy (EIS) Measurements}

Electrochemical Impedance Spectroscopy (EIS) measurements were carried out using a potentiostat (Gamry Interface 1000) under open circuit condition for the symmetrical cells. The symmetrical cell with silver paste and silver mesh current collector was placed in the hot zone of a sealed quartz tube furnace. Dry simulated air (with the composition of $20 \%$ $\mathrm{O}_{2} / 80 \% \mathrm{~N}_{2}$ with $<\sim 5$ parts per million or $\sim 5 \mathrm{ppm}$ of $\mathrm{CO}_{2}$ or $\mathrm{H}_{2} \mathrm{O}$ ) at a flow rate of $200 \mathrm{ml}$ $\min ^{-1}$ was used as the baseline. To test the effect of water vapor on the oxygen electrode behavior, $3 \%, 10 \%$, and $20 \%$ water vapor was introduced into the test chamber by passing the dry simulated air through a water bubbler set at different temperatures. And the connection tubes were heated to $\sim 100^{\circ} \mathrm{C}$ to prevent condensation. Before the tests, the symmetrical cell was heated to $750^{\circ} \mathrm{C}$ in dry simulated air and held for 24 hours to stabilize it. The sequence of the electrochemical experiments for evaluating the moisture effect is described as following: i) The cell was cooled from $750^{\circ} \mathrm{C}$ to the testing temperature (e.g., $650^{\circ} \mathrm{C}$ ) in dry simulated air, held for 12 hours and then the impedance spectrum was collected. ii) After that, moisture was introduced into the simulated air first at $3 \%$ then increased to $10 \%$ and finally to $20 \%$, and the impedance spectrum for each level of humidity was collected 2 hours after the adjustment of the moisture content. iii) The cell was then heated back up to $750^{\circ} \mathrm{C}$ in dry simulated air and held for 12 hours or longer to fully dehydrate the system (including both the cell and testing chamber). This sequence of step i) to ii) and then iii) was repeated for each testing temperature such as $650^{\circ} \mathrm{C}, 550^{\circ} \mathrm{C}$, and $450^{\circ} \mathrm{C}$ to obtain electrochemical responses of the cell to different atmospheres. Similarly, to test the influence of $\mathrm{CO}_{2}$ on the oxygen electrode behavior, $1 \% \mathrm{CO}_{2}$ was 
introduced into the simulated air through a mass flow controller and the impedance spectra for the cell were collected at a given temperature before and after 2 hours of the introduction of $1 \% \mathrm{CO}_{2}$, as well as after the removal of $\mathrm{CO}_{2}$ for 24 hours. Before changing to a different testing temperature for $\mathrm{CO}_{2}$ response, the sample was always recovered in the dry simulated air (with $<5 \mathrm{ppm} \mathrm{CO}_{2}$ as mentioned before) at $750{ }^{\circ} \mathrm{C}$ for 24 hours to ensure a complete recovery and a clean surface of both the electrode and the electrolyte.

To test the behaviors when the electrode is exposed to both $\mathrm{H}_{2} \mathrm{O}$ and $\mathrm{CO}_{2}$, which is a more realistic situation for fuel cell operation, the simulated air was passed through the water bubbler at room temperature and then mixed with $\mathrm{CO}_{2}$ to give a gas mixture with nominal composition of $\sim 1 \% \mathrm{CO}_{2} / 3 \% \mathrm{H}_{2} \mathrm{O} / 20 \% \mathrm{O}_{2} / 76 \% \mathrm{~N}_{2}$, and the sequence of these tests was similar to that for tests in $1 \% \mathrm{CO}_{2}$ alone. All impedance data were collected with zero DC bias and AC amplitude of $0.1 \mathrm{~mA}$.

\subsection{Results}

\subsubsection{Compatibility and Stability of BSCF and BZCYYb in Various Atmospheres}

The XRD patterns for the as synthesized BSCF and BZCYYb powders and their mixtures after various compatibility/stability tests are summarized in Figure 6. 1. (It's noted that the synthesized BSCF contains some minor unidentified secondary phase as evidenced by the extra peak at $31^{\circ}$.) The chemical compatibility between BSCF and BZCYYb was verified with XRD, showing no change for both BSCF and BZCYYb materials after heat treatment 
at $1000{ }^{\circ} \mathrm{C}$ for 5 hours. (Similar result was also obtained for compatibility test at $900^{\circ} \mathrm{C}$.) In addition, as shown in Figure 6. 1, the chemical stability of the BSCF-BZCYYb powder mixture in both ambient air (i.e., containing $\sim 1-3 \% \mathrm{H}_{2} \mathrm{O}$ and $\sim 400 \mathrm{ppm} \mathrm{CO}_{2}$ ) and in $\mathrm{N}_{2}$ containing up to $3 \% \mathrm{H}_{2} \mathrm{O}$ and $1 \% \mathrm{CO}_{2}$ at targeted IT-SOFC operating temperature of $450^{\circ} \mathrm{C}$ was also demonstrated, which is supported by the absence of impurity peaks in the XRD patterns after long time exposure to the various gas mixtures for $24-72$ hours. It is worth mentioning that when the BZCYYb electrolyte with $\mathrm{Zr}$ doping at 0.1 level was exposed to the gas mixture of $1 \% \mathrm{CO}_{2} / 99 \% \mathrm{~N}_{2}$ at $750{ }^{\circ} \mathrm{C}$ for 24 hours, some $\mathrm{BaCO}_{3}$ did form, as shown in Figure 6. 1.

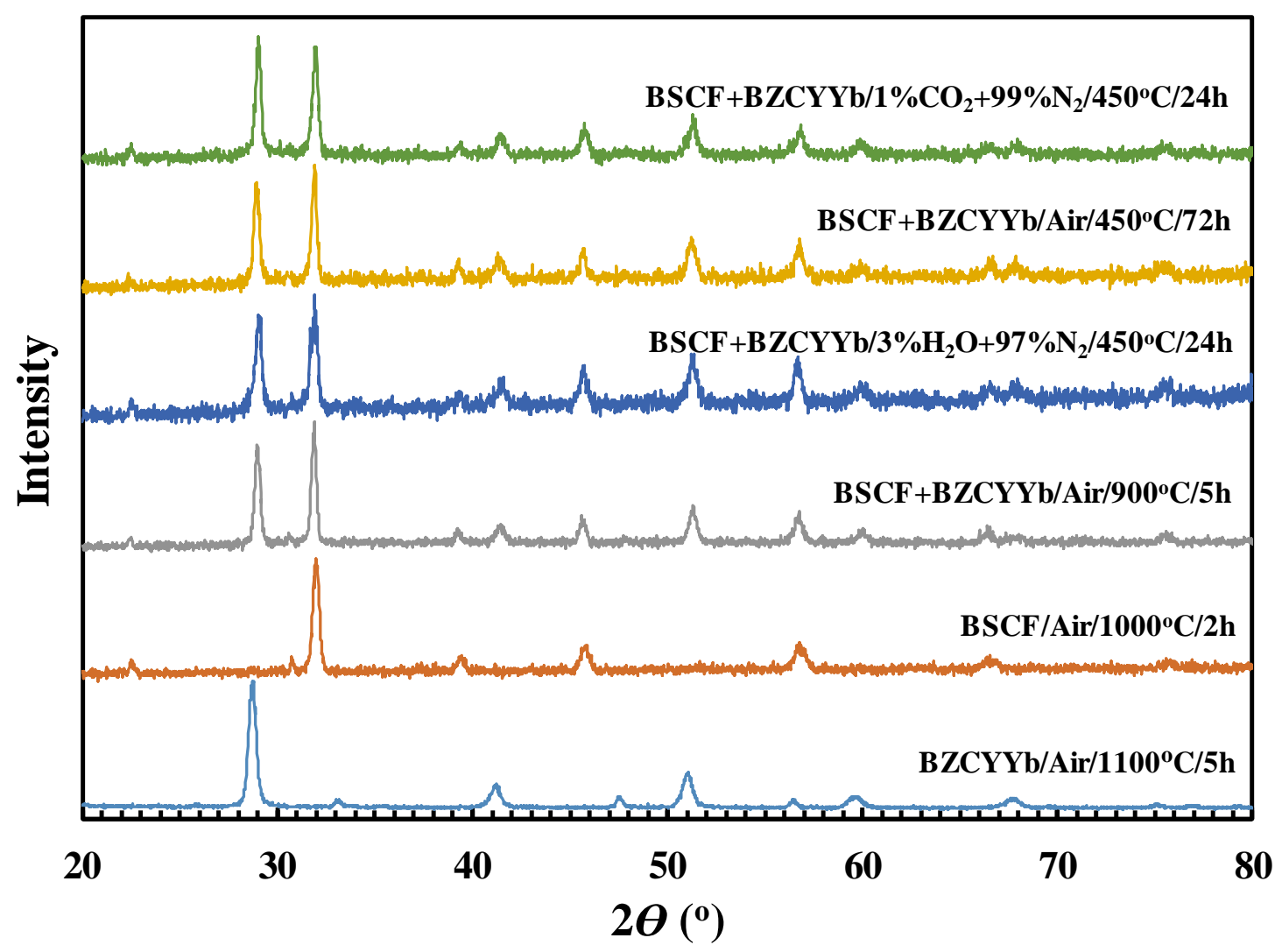

Figure 6. 1 XRD patterns of as synthesized BSCF and BZCYYb powders and their mixtures after different compatibility/stability tests. 
Apart from testing for the compatibility and stability of the materials, the microstructure of a fabricated BSCF/BZCYYb/BSCF cathode symmetrical cell is shown in Figure 6. 2. The thickness of the BSCF electrode layer was around $30 \mu \mathrm{m}$. Relatively large particle size of $\sim 1-3 \mu \mathrm{m}$ for the BSCF electrode was observed, which may be attributed to the high surface energy of BSCF and the strong tendency to coarsen.[70, 162, 181] The porosity of the BSCF electrode was estimated to be $\sim 22 \%$ based on the analysis of SEM image using the software of ImageJ (version 1.50i).

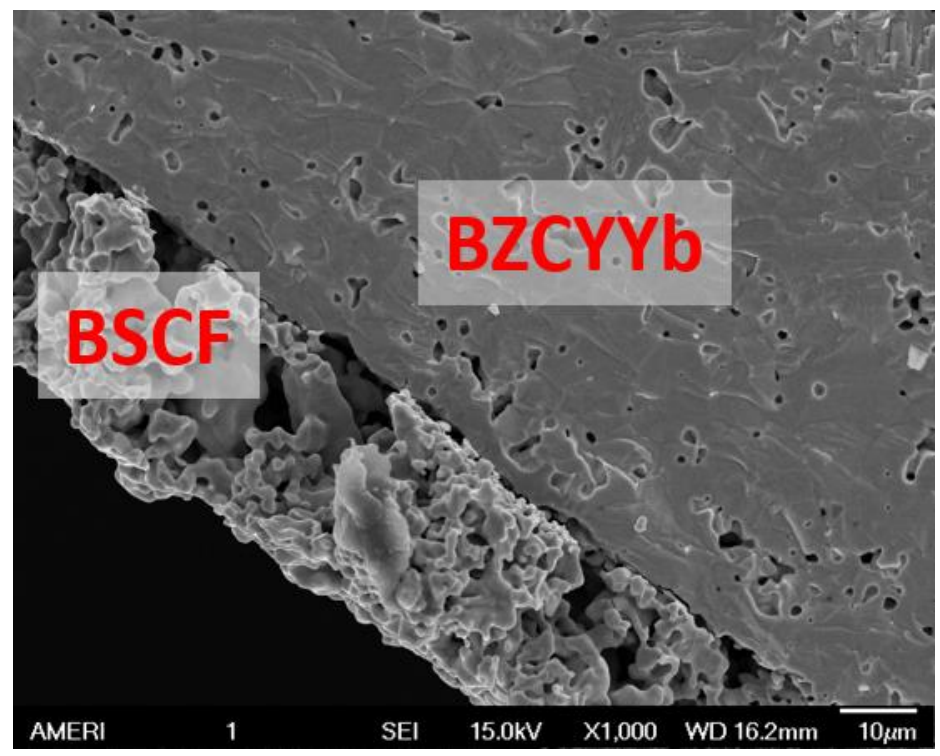

Figure 6. 2 SEM image of cross-section of fabricated BSCF/BZCYYb/BSCF symmetrical cell.

\subsubsection{Effect of Moisture on BSCF Cathode Electrochemical Behavior}

Figure 6. 3 (a), (b), and (c) show the impedance spectra for the BSCF/BZCYYb/BSCF cathode symmetrical cell in the dry simulated air (as explained, it is a gas mixture of $20 \%$ $\mathrm{O}_{2}$ and $80 \% \mathrm{~N}_{2}$ with < 5ppm $\mathrm{H}_{2} \mathrm{O}$ and $\mathrm{CO}_{2}$ as supplied from Airgas) and simulated air 
humidified with $\sim 3 \%, \sim 10 \%$, and $\sim 20 \%$ of moisture at $650^{\circ} \mathrm{C}, 550^{\circ} \mathrm{C}$, and $450^{\circ} \mathrm{C}$, respectively. At $650^{\circ} \mathrm{C}$, as shown in Figure 6.3 (a), with the introduction of $3 \% \mathrm{H}_{2} \mathrm{O}$, the ohmic resistance Ro decreases from $2.11 \mathrm{Ohm} \bullet \mathrm{cm}^{2}$ to $2.04 \mathrm{Ohm} \bullet \mathrm{cm}^{2}$. As the moisture content increases further to $10 \%$ and $20 \%$, a continued decreasing of Ro was observed. On the other hand, for the electrode interfacical polarization resistance $R_{p}$, due to the nature of mixed ionic and electronic conduction for the BZCYYb electrolyte and the absence of precise ionic transference number, [88] accurate $R_{p}$ number cannot be obtained readily. As a result, only the apparent interfacial resistance $\mathrm{R}_{\mathrm{ai}}$, which is the direct difference between the low frequency intercept and the high frequency intercept on the real axis in an impedance spectrum, is used for the analysis and discussions in this study as in many previous reports. [20,159] It can be seen from Figure 6.3 (a) that comparing with dry simulated air, $\mathrm{R}_{\mathrm{ai}}$ increases from $\sim 0.6 \mathrm{Ohm} \bullet \mathrm{cm}^{2}$ to $\sim 0.7 \mathrm{Ohm} \bullet \mathrm{cm}^{2}$ with the introduction of $3 \%$ moisture. However, with further increase of $\mathrm{H}_{2} \mathrm{O}$ concentration to $10 \%$ and beyond, $\mathrm{R}_{\mathrm{ai}}$ starts to decrease back to $\sim 0.64 \mathrm{Ohm} \bullet \mathrm{cm}^{2}$ and stabilizes. It is noted that the observation of the decrease of $\mathrm{R}_{\mathrm{ai}}$ with increasing moisture content beyond $3 \% \mathrm{H}_{2} \mathrm{O}$ for BSCF cathode over $\mathrm{BaCe}_{0.9} \mathrm{Y}_{0.1} \mathrm{O}_{3-\delta}(\mathrm{BCY} 10)$ proton conducting electrolyte had been reported before. [20] Nevertheless, to the best of the authors' knowledge, the initial increase in $R_{a i}$ from dry simulated air to $3 \%$ humidified air for proton conducting IT-SOFC with BSCF cathode has not been reported before, and such an observation implies that the introduction of moisture seems to slow down at least certain part(s) of the oxygen electrode reaction for the BSCF/BZCYYb/BSCF cathode symmetrical cell. 
At reduced temperature of $550^{\circ} \mathrm{C}$, which is shown in Figure 6.3 (b), when $3 \%$ moisture was introduced, $\mathrm{R}_{\mathrm{O}}$ still decreases; however, no continued decreasing of $\mathrm{R}_{\mathrm{O}}$ was observed with the further increase in moisture content beyond 3\%, suggesting saturation of the hydration effect by $3 \%$ of moisture at that temperature. On the other hand, an increase in $\mathrm{R}_{\mathrm{ai}}$ was observed with the introduction of $3 \%$ moisture compared with dry simulated air, and, in contrast to the observations at $650^{\circ} \mathrm{C}$, total $\mathrm{R}_{\mathrm{ai}}$ does not show a decrease when moisture concentration was further increased to $10 \%$ and beyond.

When the temperature was further reduced to $450^{\circ} \mathrm{C}$, the overall impedance spectra (shown in Figure 6. 3 (c)) clearly separate into one semicircle at the high frequency (HF, $10^{6} \sim 10^{4} \mathrm{~Hz}$ ) range and one large depressed semicircle, which most likely represents two overlapped arcs-one at the middle frequency $\left(\mathrm{MF}, \sim 10^{4}\right.$ to $\left.\sim 10^{0} \mathrm{~Hz}\right)$ range and the other at the low frequency ( $\mathrm{LF}, \sim 10^{0}$ to $10^{-2} \mathrm{~Hz}$ ) range. At this temperature, when $3 \%$ moisture was introduced, the change in $\mathrm{R}_{\mathrm{O}}$ becomes negligible. On the other hand, for $\mathrm{R}_{\mathrm{p}}$, the HF part decreases significantly, while the MF and LF parts show an obvious increase with the introduction of moisture. In addition, the effect of moisture seems to reach saturation at $3 \%$, as further increase in moisture content does not produce significant differences at $450^{\circ} \mathrm{C}$. 

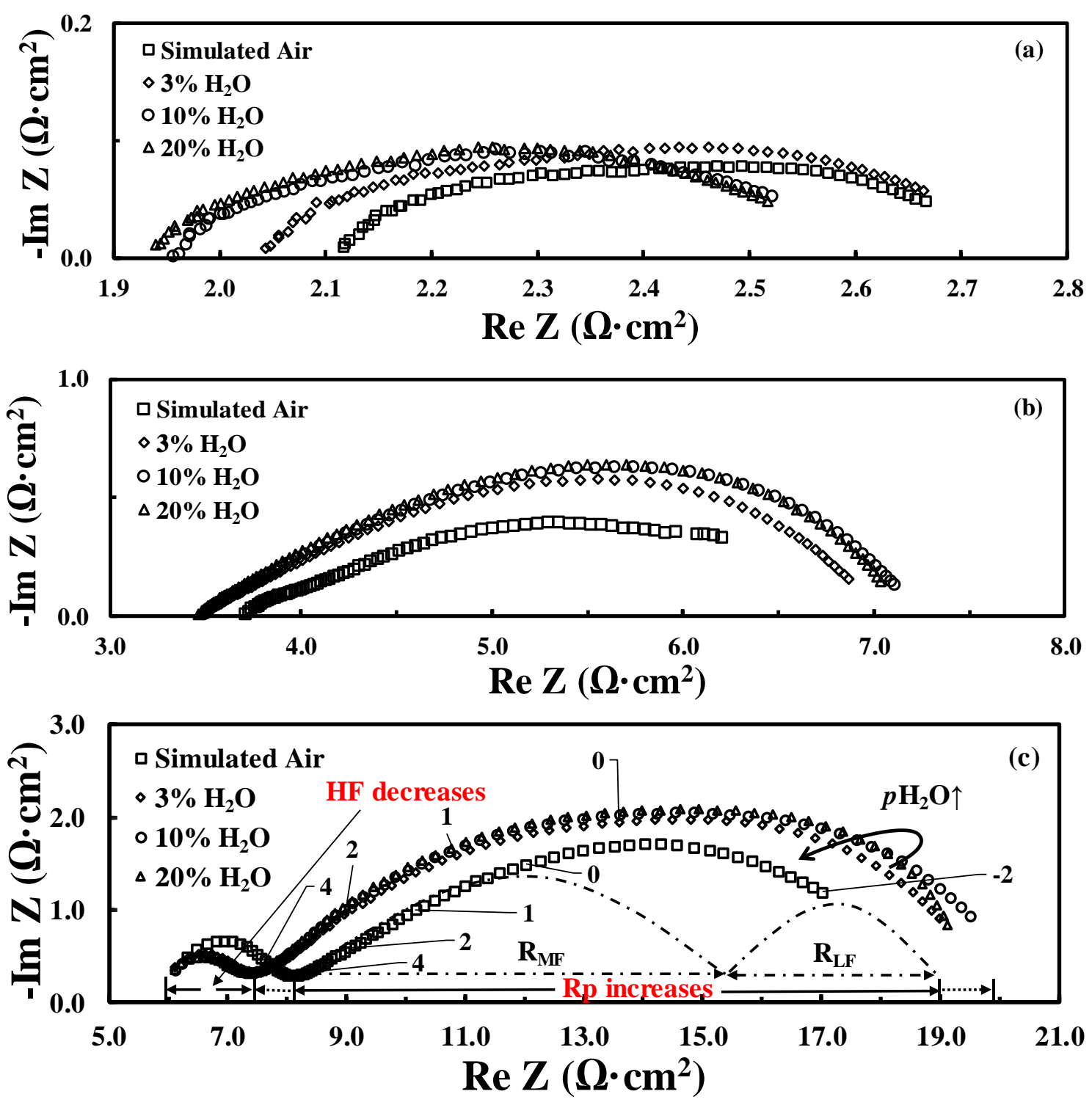

Figure 6. 3 Impedance spectra for a BSCF/BZCYYb/BSCF symmetrical cell in simulated air $\left(20 \% \mathrm{O}_{2} / 80 \% \mathrm{~N}_{2}\right.$ without $\mathrm{H}_{2} \mathrm{O}$ or $\left.\mathrm{CO}_{2}\right)$ versus simulated air humidified with various $\mathrm{pH}_{2} \mathrm{O}$ at (a) $650^{\circ} \mathrm{C}$, (b) $550^{\circ} \mathrm{C}$, and (c) $450^{\circ} \mathrm{C}$, respectively.

Additional EIS measurements were conducted at $500-400^{\circ} \mathrm{C}$ because of the clear separation of impedance spectra into two semicircles (HF and MF-LF) in that temperature range. Gradual decrease in the HF semicircle was observed with increasing concentration 
of moisture as shown, for example, in Figure 6.4 for $475^{\circ} \mathrm{C}$. For comparison, impedance spectra for another symmetrical cell in both pure $\mathrm{O}_{2}$ and dry simulated air at $450^{\circ} \mathrm{C}$ are given in Figure 6. 5 (a), which shows almost no difference in the size of the HF semicircle, while a significant increase was observed in the MF-LF semicircle in dry simulated air versus in pure $\mathrm{O}_{2}$. On the other hand, as in Figure 6.5 (b), when moisture content was increased in $\mathrm{O}_{2}$, the HF semicircle shows the similar gradual decrease.
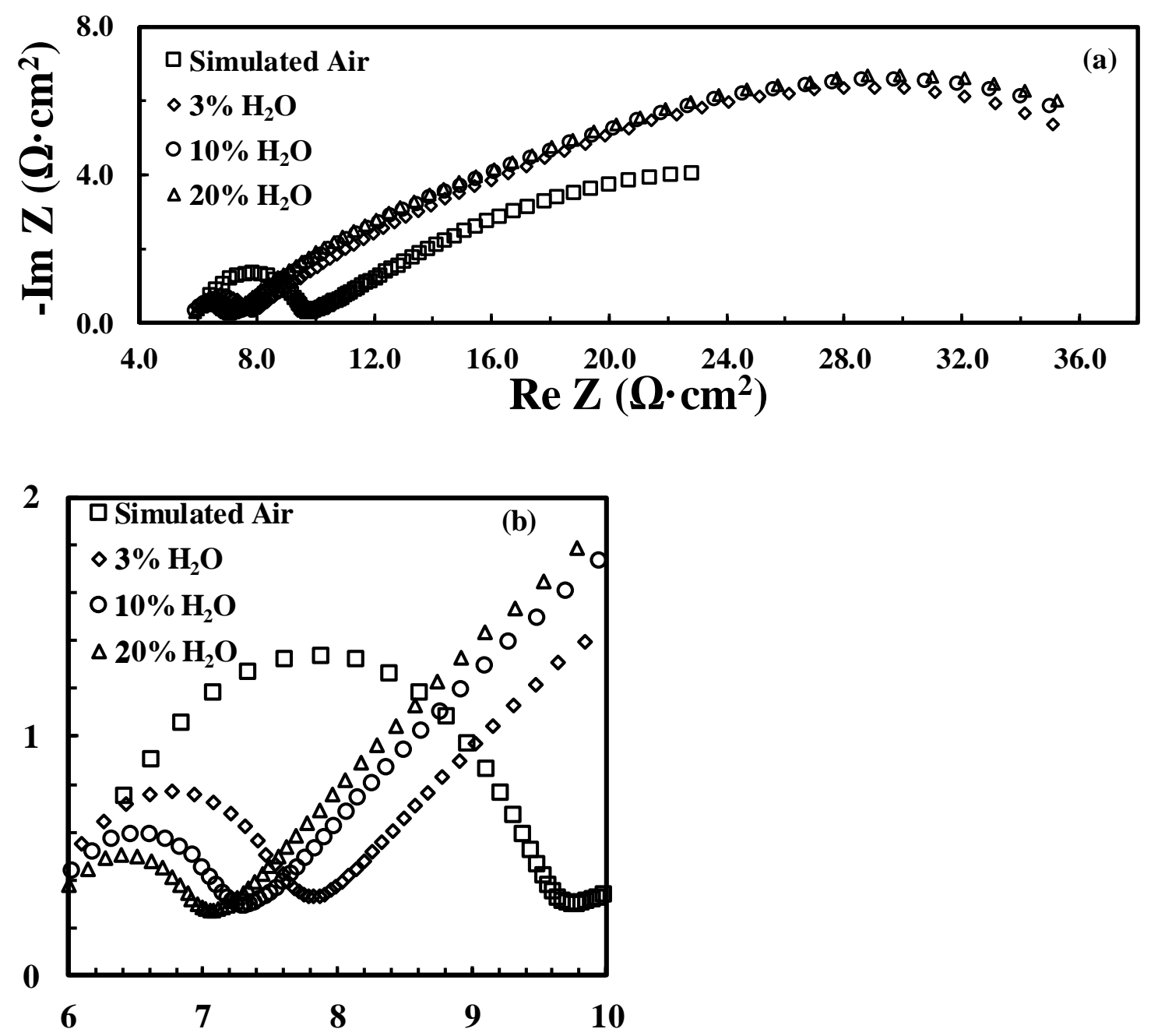

Figure 6. 4 Impedance spectra for BSCF/BZCYYb/BSCF symmetrical cell at $475^{\circ} \mathrm{C}$ in dry and wet (with various $\mathrm{pH}_{2} \mathrm{O}$ ) "simulated air" (a) the full impedance spectra, (b) zoom in to show the changes at the high frequency (HF) portion. 

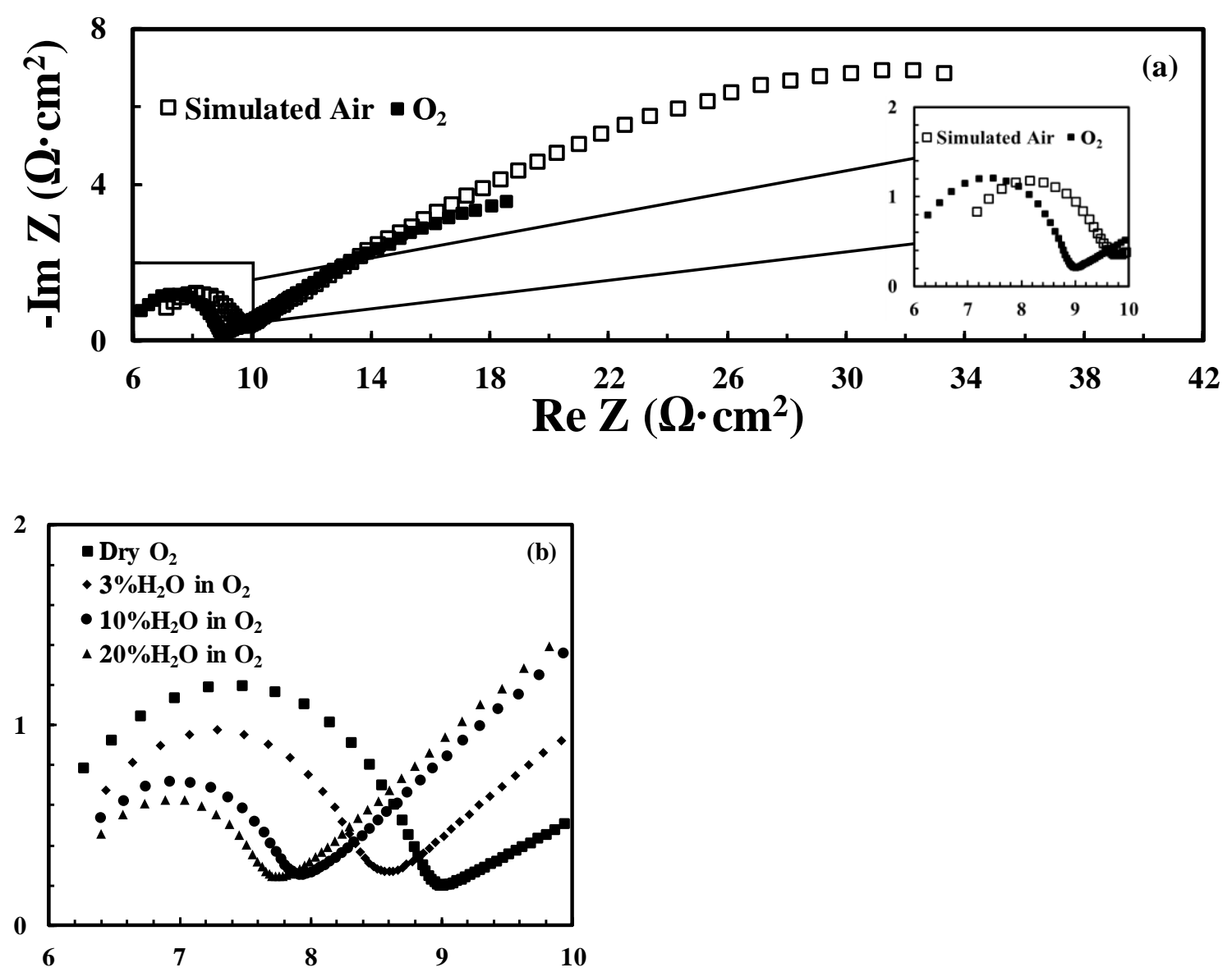

Figure 6. 5 Comparison of the impedance spectra for BSCF/BZCYYb/BSCF symmetrical cell at $450^{\circ} \mathrm{C}$ (a) entire impedance spectra comparing dry "simulated air" and dry pure $\mathrm{O}_{2}$ and zoom-in of the high frequency (HF) part, (b) zoom-in of pure $\mathrm{O}_{2}$ with different concentration of moisture at the high frequency $(\mathrm{HF})$ part.

\subsubsection{Effect of $\mathrm{CO}_{2}$ on BSCF Cathode Electrochemical Behavior}

The effect of $\mathrm{CO}_{2}$ alone (i.e., without the presence of moisture) on the $\mathrm{BSCF} / \mathrm{BZCYYb} / \mathrm{BSCF}$ symmetrical cell at $650^{\circ} \mathrm{C}, 550^{\circ} \mathrm{C}$, and $450^{\circ} \mathrm{C}$ is shown in Figure 6.

6. At $650^{\circ} \mathrm{C}$, as shown in Figure 6. 6 (a), increase in $R_{0}$ from $2.21 \mathrm{ohm} \cdot \mathrm{cm}^{2}$ to 2.39 
$\mathrm{ohm} \cdot \mathrm{cm}^{2}$ and in $\mathrm{R}_{\mathrm{ai}}$ from $0.49 \mathrm{ohm} \cdot \mathrm{cm}^{2}$ to $0.72 \mathrm{ohm} \cdot \mathrm{cm}^{2}$, respectively, were observed after the introduction of $1 \% \mathrm{CO}_{2}$ into the dry simulated air for 2 hours. After the removal of $\mathrm{CO}_{2}$ for 24 hours, almost complete recovery in both $\mathrm{Ro}_{\mathrm{O}}$ and $\mathrm{R}_{\mathrm{ai}}$ was observed. At $550^{\circ} \mathrm{C}$, as shown in Figure 6.6 (b), both $\mathrm{R}_{\mathrm{O}}$ and $\mathrm{R}_{\mathrm{ai}}$ increased after the introduction of $1 \% \mathrm{CO}_{2}$, and the relative increase in $\mathrm{R}_{\mathrm{ai}}$ due to $\mathrm{CO}_{2}$ poisoning becomes larger comparing with $650^{\circ} \mathrm{C}$. Also, only incomplete recovery was observed with the removal of $\mathrm{CO}_{2}$ even after 24 hours. At further reduced temperature of $450^{\circ} \mathrm{C}$, little change in $\mathrm{R}_{\mathrm{O}}$ was observed with the introduction of $1 \% \mathrm{CO}_{2}$, while large increase in $\mathrm{R}_{\mathrm{ai}}$ was still observed. In addition, because of the clear separation of the impedance spectra into one semicircle at the HF range and another at the MF-LF range, the increase in $\mathrm{R}_{\mathrm{ai}}$ due to $\mathrm{CO}_{2}$ at $450^{\circ} \mathrm{C}$ occurs almost exclusively to the MF-LF part. At this temperature, very little recovery was observed after the removal of $\mathrm{CO}_{2}$ for 24 hours. 

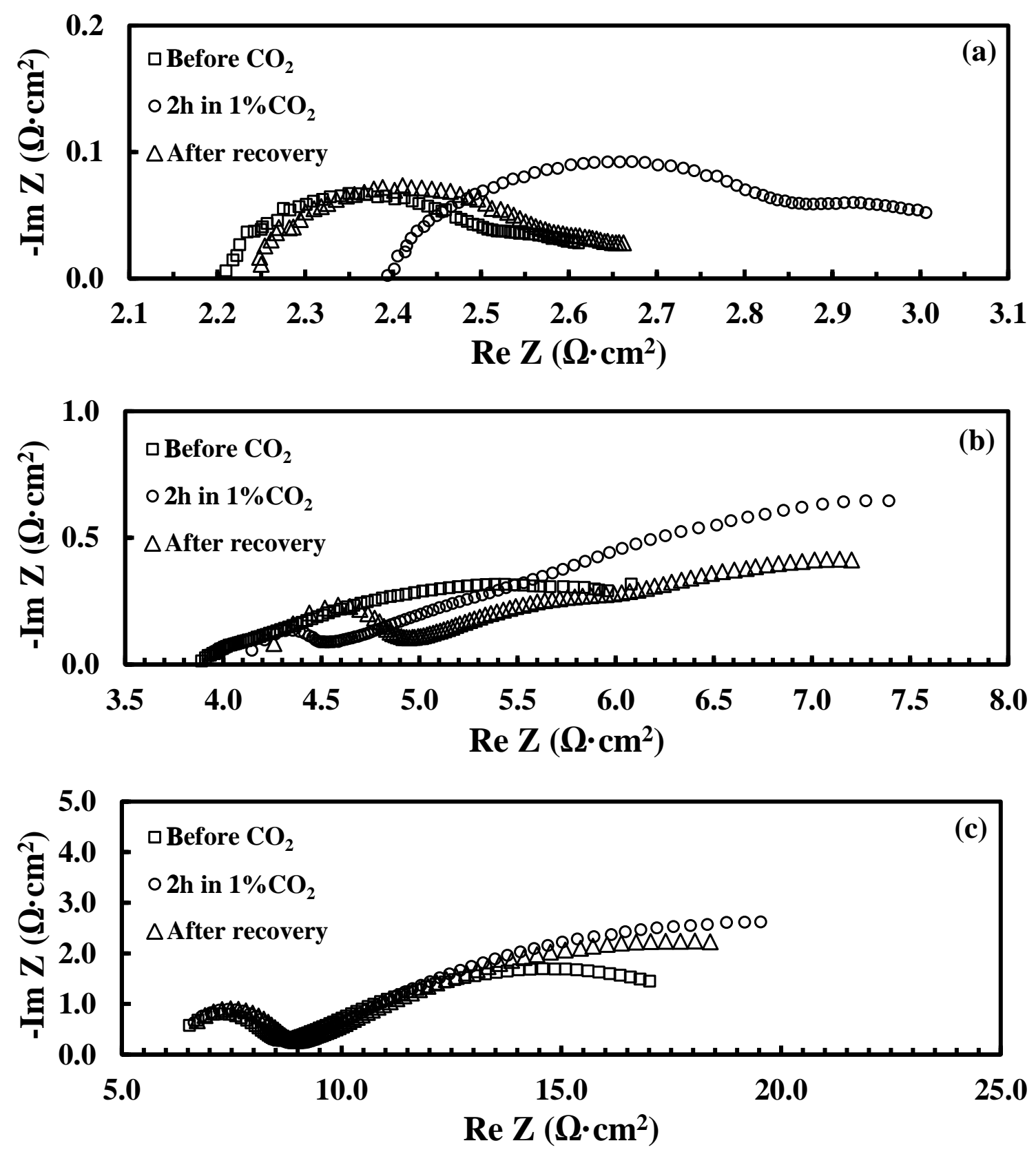

Figure 6. 6 Plots showing the change in impedance spectra for $\mathrm{BSCF} / \mathrm{BZCYYb} / \mathrm{BSCF}$ symmetrical cell in dry "simulated air" $\left(20 \% \mathrm{O}_{2} / 80 \% \mathrm{~N}_{2}\right)$ before exposure to $\mathrm{CO}_{2}$, after exposure to $1 \% \mathrm{CO}_{2}$ for $2 \mathrm{~h}$, and after recovery (i.e., removal of $1 \% \mathrm{CO}_{2}$ ) for 24 hours at (a) $650^{\circ} \mathrm{C}$, (b) $550^{\circ} \mathrm{C}$ and (c) $450^{\circ} \mathrm{C}$, respectively. 
In comparison, the effect of $1 \% \mathrm{CO}_{2}$ for $3 \%$ humidified simulated air on the BSCF/BZCYYb/BSCF symmetrical cell at 650,550 , and $450^{\circ} \mathrm{C}$ is shown in Figure 6. 7. At $650^{\circ} \mathrm{C}$, almost the same behavior was observed as both $\mathrm{R}_{\mathrm{O}}$ and $\mathrm{R}_{\mathrm{ai}}$ increase with the introduction of $1 \% \mathrm{CO}_{2}$, and they are largely recoverable with the removal of $\mathrm{CO}_{2}$. However, at lower temperatures of 550 and $450^{\circ} \mathrm{C}$, it is seen that the presence of moisture significantly improves the reversibility for $\mathrm{CO}_{2}$ poisoning. In fact, at $450^{\circ} \mathrm{C}$, the presence of $3 \%$ moisture makes the cathode much less sensitive to $1 \% \mathrm{CO}_{2}$. To illustrate the results better, based on the collected impedance spectra (as shown in Figure 6. 6 and Figure 6. ), the estimated value of $\mathrm{R}_{\mathrm{O}}$ and $\mathrm{R}_{\mathrm{ai}}$ are summarized in Table 6. 1, as well as their relative changes after being poisoned for 2 hours and after the recovery by removing $1 \% \mathrm{CO}_{2}$ for 24 hours in both dry and 3\% humidified simulated air. 

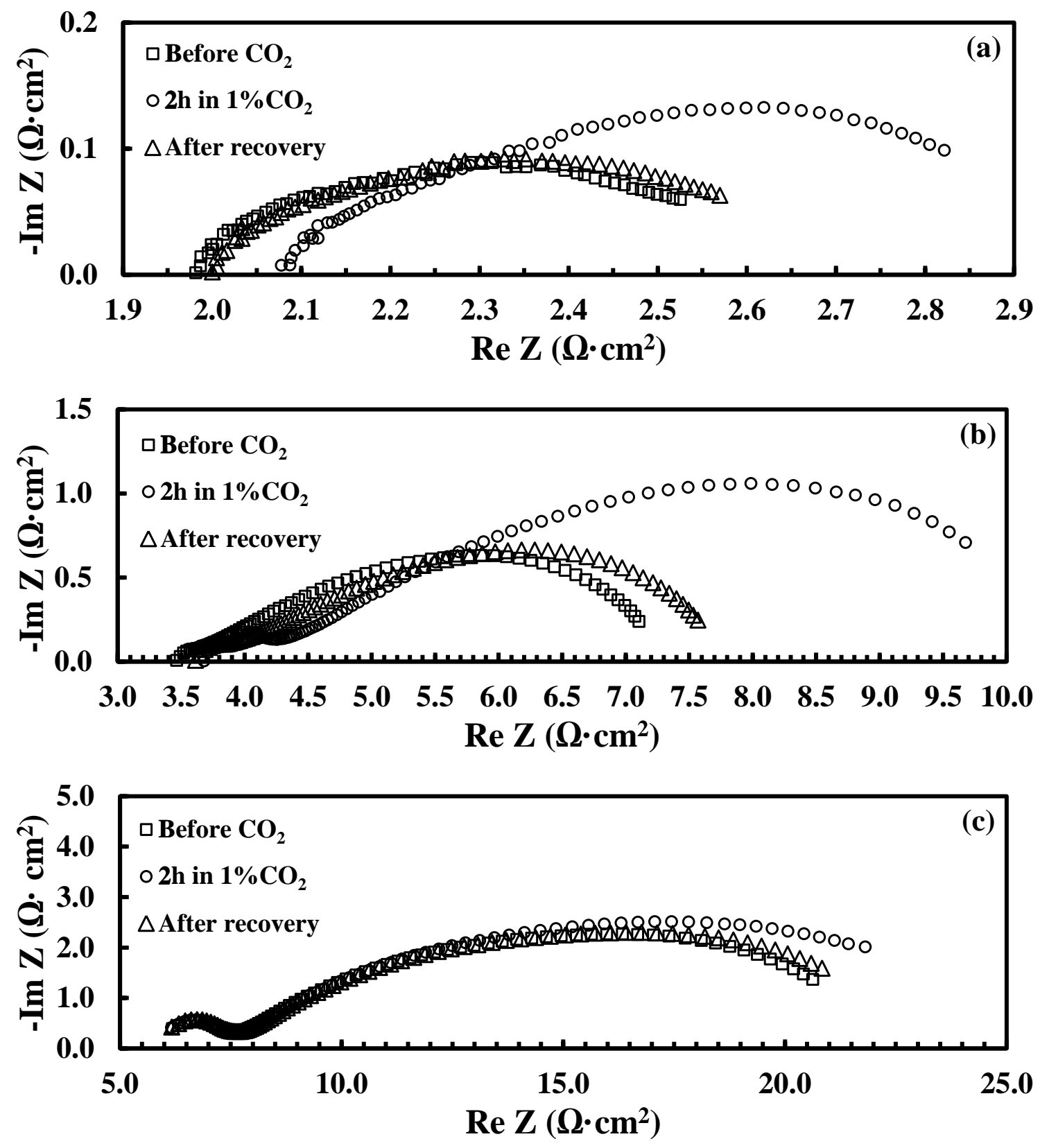

Figure 6. 7 Impedance curve for BSCF/BZCYYb/BSCF symmetrical cell in humidified simulated air $\left(3 \% \mathrm{H}_{2} \mathrm{O} / 20 \% \mathrm{O}_{2} / 77 \% \mathrm{~N}_{2}\right.$ ) before exposure, after exposure to $1 \% \mathrm{CO}_{2}$ for 2 hours, and after recovery (i.e., removal of $1 \% \mathrm{CO}_{2}$ ) for 24 hours at (a) $650^{\circ} \mathrm{C}$, (b) $550^{\circ} \mathrm{C}$ and (c) $450^{\circ} \mathrm{C}$, respectively. 
Table 6. 1 Elementary steps of the oxygen electrode reaction for BSCF electrode over BZCYYb electrolyte without the presence of $\mathrm{H}_{2} \mathrm{O}$ under ideal oxide ion conduction condition and under ideal, fully hydrated condition which only conduct proton and not oxide ion.

\begin{tabular}{|c|c|c|}
\hline Elementary Steps & Elemental step & $\begin{array}{l}\text { Frequenc } \\
\mathrm{y} \\
\text { range }\end{array}$ \\
\hline $\begin{array}{l}1 \text { Mass transfer of } \mathrm{O}_{2} \\
\text { molecule in gas phase and } \\
\text { adsorption and desorption } \\
\text { on electrode surface }\end{array}$ & $\mathrm{O}_{2}(\mathrm{~g}) \leftrightarrow \mathrm{O}_{2}$ (ads) & $\mathrm{LF}$ \\
\hline $\begin{array}{l}2 \text { Adsorbed } \mathrm{O}_{2} \text { molecule } \\
\text { dissociation/association }\end{array}$ & $\mathrm{O}_{2}$ (ads) $\leftrightarrow 20$ (ads) & $\mathrm{MF}$ \\
\hline $\begin{array}{l}3 \text { Charge transfer for pure } \\
\text { oxide ion electrolyte }\end{array}$ & $\mathrm{O}(\mathrm{ads})+\mathrm{V}_{\mathrm{O}}^{*}+2 e^{-} \leftrightarrow \mathrm{O}_{\mathrm{O}}^{\mathrm{X}}$ & $\mathrm{HF}$ \\
\hline $\begin{array}{l}\text { 3' Charge transfer for pure } \\
\text { proton electrolyte }\end{array}$ & $\begin{aligned} \mathrm{O}(\text { ads })+2 e^{-} & +2 \mathrm{OH}_{\mathrm{O}}^{-} \\
& \leftrightarrow \mathrm{H}_{2} \mathrm{O} \text { (ads) }+2 \mathrm{O}_{\mathrm{O}}^{\mathrm{X}}\end{aligned}$ & $\mathrm{HF}$ \\
\hline $\begin{array}{l}4 \text { Mass transfer of oxide ion } \\
\text { in bulk of electrode and } \\
\text { electrolyte }\end{array}$ & $\mathrm{V}_{\mathrm{O}(\text { electrode })}^{*} \leftrightarrow \mathrm{V}_{\mathrm{O}(\text { electrolyte })}^{*}$ & $\begin{array}{ll}\text { Very } & \mathrm{HF} \\
(>> & 10^{6} \\
\mathrm{~Hz}) & \end{array}$ \\
\hline $\begin{array}{l}\text { 4' Mass transfer of proton } \\
\text { in bulk of electrode and } \\
\text { electrolyte }\end{array}$ & $\mathrm{OH}_{\mathrm{O}(\text { electrode })} \leftrightarrow \mathrm{OH}_{\mathrm{O}(\text { electrolyte })}$ & $\begin{array}{ll}\text { Very } & \mathrm{HF} \\
(>> & 10^{6} \\
\mathrm{~Hz}) & \\
\end{array}$ \\
\hline $\begin{array}{lcc}5 & \mathrm{H}_{2} \mathrm{O} \text { transport } & \text { and } \\
\text { adsorption/desorption }\end{array}$ & $\mathrm{H}_{2} \mathrm{O}(\mathrm{ads}) \leftrightarrow 2 \mathrm{H}_{2} \mathrm{O}(\mathrm{g})$ & $\mathrm{LF}$ \\
\hline
\end{tabular}

\subsection{Discussions}

The results from compatibility and chemical exposure tests show that at the targeted proton conducting IT-SOFC operating temperature of $\sim 450{ }^{\circ} \mathrm{C}$, the combination of BSCF cathode and BZCYYb electrolyte has demonstrated the desired compatibility in processing and stability to practical air. However, the observation of reactivity of BZCYYb electrolyte to $1 \% \mathrm{CO}_{2} / 99 \% \mathrm{~N}_{2}$ to form $\mathrm{BaCO}_{3}$ seems to contradict the earlier study showing stability of BZCYYb against a gas mixture of $50 \% \mathrm{CO}_{2} / 50 \% \mathrm{H}_{2}$ at $750{ }^{\circ} \mathrm{C}$. [121] Whether such a discrepancy is due to the different balance gas $\left(\mathrm{N}_{2}\right.$ versus $\left.\mathrm{H}_{2}\right)$ used, or the variation in 
sample stoichiometry (e.g., Ba to $(\mathrm{Ce}+\mathrm{Zr}+\mathrm{Y}+\mathrm{Yb})$ molar ratio), or other factors is not clear at the moment.

Besides that, in order to understand the various observed phenomena concerning the effects of moisture and $\mathrm{CO}_{2}$ on the electrochemical behaviors for the BSCF/BZCYYb/BSCF symmetrical cell, fundamental oxygen electrode reaction processes are first summarized. Shown in Figure 6. (a) is the conventional cathode reaction pathway for an ideal oxide ion based SOFC with a mixed ionic and electronic conductor (MIEC) electrode. In comparison, shown in Figure 6. (b) is the ideal cathode reaction pathway for a "pure" proton conducting SOFC with MIEC electrode, which means electrolyte is fully hydrated and conducts only proton while the electrode conducts electron (hole) and proton upon hydration. The elementary steps corresponding to the illustrated pathways are summarized in Table 6. 2 .

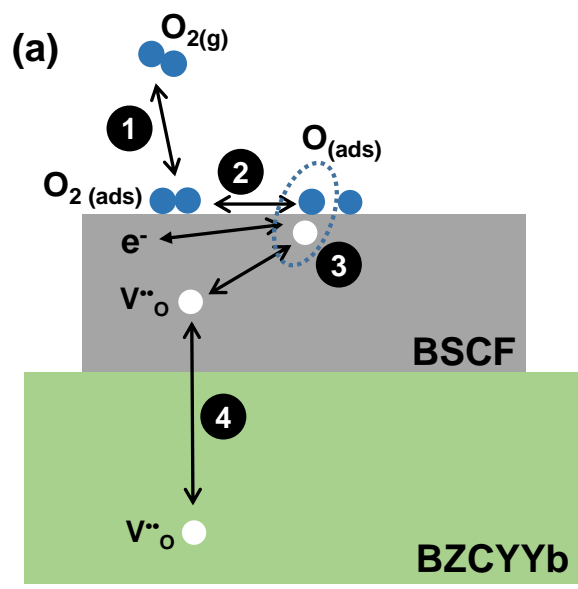

$$
\mathrm{O}_{2}+4 \mathrm{e}^{-}+2 \mathrm{~V}_{\mathrm{O}} \cdot \bullet 2 \mathrm{O}_{0} \mathrm{x}
$$

(b)

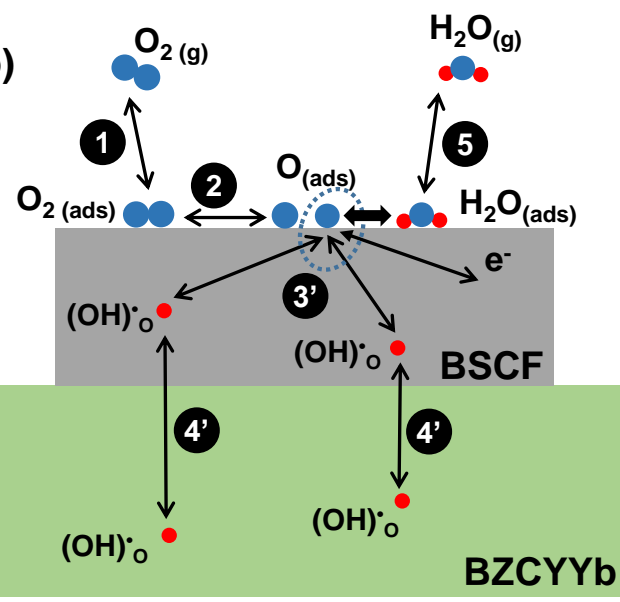

$\mathrm{O}_{2}+4 \mathrm{e}^{-}+4(\mathrm{OH})_{0} \cdot \leftrightarrow 2 \mathrm{O}_{0}^{\mathrm{x}}+2 \mathrm{H}_{2} \mathrm{O}$

Figure 6. 8 Schematics showing the reaction species involved and the elementary steps (also refer to Table 5.1) for the reversible oxygen electrode reaction for (a) ideal pure oxide-ion based SOFC and (b) ideal pure proton conducting SOFC. 
Table 6. 2 Relative change of Ohmic resistance $\mathrm{R}_{\mathrm{O}}$ and interface polarization resistance $\mathrm{R}_{\mathrm{p}}$ for the $\mathrm{BSCF} / \mathrm{BZCYYb/BSCF}$ cathode symmetrical cell after being poisoned by $1 \%$ $\mathrm{CO}_{2}$ for 2 hours and the recovery by then removing $1 \% \mathrm{CO}_{2}$ for 24 hours in both dry and $3 \% \mathrm{H}_{2} \mathrm{O}$ humidified simulated air

\begin{tabular}{|c|c|c|c|c|c|c|c|}
\hline & \multirow{2}{*}{$\begin{array}{l}\text { Temperature } \\
\text { Condition }\end{array}$} & \multirow{2}{*}{$\begin{array}{l}650^{\circ} \mathrm{C} \\
\text { Dry }\end{array}$} & \multicolumn{3}{|c|}{$550^{\circ} \mathrm{C}$} & \multicolumn{2}{|c|}{$450^{\circ} \mathrm{C}$} \\
\hline & & & $3 \% \mathrm{H}_{2} \mathrm{O}$ & Dry & $3 \% \mathrm{H}_{2} \mathrm{O}$ & Dry & $3 \% \mathrm{H}_{2} \mathrm{O}$ \\
\hline \multirow[t]{2}{*}{$\Delta \mathrm{Ro}_{\mathrm{O}} / \mathrm{R}_{\mathrm{O}}$} & After $\mathrm{CO}_{2}$ poisoning & $7.3 \%$ & $3.2 \%$ & $8.4 \%$ & $10.3 \%$ & $1.7 \%$ & $-0.3 \%$ \\
\hline & After recovery & $1.9 \%$ & $0.6 \%$ & $13.5 \%$ & $5.4 \%$ & $2.7 \%$ & $-0.2 \%$ \\
\hline \multirow[t]{2}{*}{$\Delta \mathrm{R}_{\mathrm{p}} / \mathrm{R}_{\mathrm{p}}$} & After $\mathrm{CO}_{2}$ poisoning & $69.1 \%$ & $48.3 \%$ & $61.8 \%$ & $102 \%$ & $68.4 \%$ & $15.9 \%$ \\
\hline & After recovery & $5.0 \%$ & $-7.6 \%$ & $83.8 \%$ & $5.6 \%$ & $46.1 \%$ & $8.3 \%$ \\
\hline
\end{tabular}

For the conventional ideal oxide ion based SOFC, the overall oxygen electrode reaction follows:

$\mathrm{O}_{2}+4 \mathrm{e}^{-}+2 \mathrm{~V}_{\mathrm{O}} \cdot \bullet 2 \mathrm{O}^{\mathrm{x}}$ Equation 6.1

When the electrode is MIEC, the overall oxygen electrode reaction consists of elementary steps (and their reverse steps) of 1) mass transport of $\mathrm{O}_{2}$ molecule in the gas phase and adsorption on the electrode surface; 2) dissociation of adsorbed $\mathrm{O}_{2}$ molecule into adsorbed oxygen atoms; 3) charge transfer and combining of lattice oxygen vacancy with surface adsorbed oxygen atom and electrons to form lattice oxygen; and 4) mass transport of oxide ion (oxygen vacancy) in the bulk of electrode and electrolyte.

In comparison, for the ideal pure proton conducting SOFC, in principle, the oxygen electrode reaction would follow a different pathway:

$\mathrm{O}_{2}+4 \mathrm{e}^{-}+4(\mathrm{OH})_{\mathrm{O}} \cdot 44 \mathrm{O}_{\mathrm{O}}^{\mathrm{x}}+2 \mathrm{H}_{2} \mathrm{O}$

Equation 6.2 
When the electrode is MIEC with proton as the sole ionic charge carrier, apart from the common elementary steps of $\mathrm{O}_{2}$ molecules gas phase transport and adsorption (step 1) and adsorbed $\mathrm{O}_{2}$ molecule dissociation (step 2), alternative elementary steps of 3') charge transfer and combining of proton with adsorbed oxygen atom and electrons to form water, and 4') mass transport of proton in the bulk of electrode and electrolyte, as well as 5) water molecule transport in the gas phase and adsorption/desorption on the electrode surface also need to be taken into consideration.

The actual system considered here would approach the ideal oxide-ion based system (Figure 6. (a)) in dry condition. On the other hand, when significant concentration of moisture is present, proton is generated in the BZCYYb electrolyte as following:

$\mathrm{H}_{2} \mathrm{O}+\mathrm{V}_{\mathrm{O}} \ddot{*}+\mathrm{OO}^{\mathrm{x}} \leftrightarrow 2(\mathrm{OH})_{\mathrm{O}}$

Equation 6.3

The system would then approach the ideal "pure" proton-based system (Figure 6. (b)) in humidified condition especially when the moisture content is high $(\geq 3 \%)$ and at lower temperature (e.g., $\sim 450^{\circ} \mathrm{C}$ and below) when the $\mathrm{BZCYYb}$ electrolyte and the $\mathrm{BSCF}$ electrode become fully hydrated with oxygen vacancy $\mathrm{V}_{\mathrm{O}}^{*}$ replaced by proton $\mathrm{OH}_{\mathrm{O}}$.

As shown in Figure 6. 3 (a) and (b), the decrease in $R_{O}$ at 650 and $550^{\circ} \mathrm{C}$ with the introduction of moisture into the simulated air could be attributed to the hydration of the BZCYYb electrolyte and the change of conducting species from oxide ion to proton yielding higher ionic conductivity.[88, 121] However, at temperature below $\sim 500^{\circ} \mathrm{C}$, almost negligible reduction in Ro was observed (see Figure 6.3 (c) and Figure 6. 4). Such a phenomenon could be attributed to the enhanced affinity of proton conducting oxide 
electrolyte (BZCYYb here) for water below the temperature of $\sim 450^{\circ} \mathrm{C},[84,182]$ which is supported by the TGA from previous reports suggesting that the dehydration of proton conducting oxides and associated weight loss only occur significantly at temperature above $\sim 450^{\circ} \mathrm{C}$. [20] The implication is that despite the dry simulated air used, which is supposed to give moisture content of only $\sim 5 \mathrm{ppm}$, the actual moisture content in the system due to various leakage might be sufficient to hydrate the electrolyte and make it proton conductive at temperature of $\sim 450^{\circ} \mathrm{C}$ and below. Therefore, strictly speaking, the so-called "dry simulated air" is only a loosely used term to indicate that the moisture content is, qualitatively, much lower than the 3\% used for comparison. Though the difference in actual moisture content between the so-called "dry simulated air" and 3\% humidified air may not be large enough to influence the Ohmic resistance at $\sim 450^{\circ} \mathrm{C}$ and below, it is, however, adequate to significantly impact the oxygen electrode processes, as discussed below.

For the apparent interfacial resistance $\mathrm{R}_{\mathrm{a}}$, in the temperature range of $650^{\circ} \mathrm{C}$ to $450^{\circ} \mathrm{C}$, as shown in Figure 6. 3 and Figure 6. 4, the overall $R_{a i}$ seems to increase with the introduction of moisture, especially for the middle to low frequency (MF-LF) semicircle. Generally, the MF-LF semicircle is believed to be associated with the mass transport process of oxygen molecules and the oxygen adsorption/dissociation process on the BSCF electrode. [183] The observed increase in that part upon moisture introduction could be attributed to the strong adsorption of $\mathrm{H}_{2} \mathrm{O}$ on the surface of $\mathrm{BSCF}$ electrode and the BZCYYb electrolyte, both of which have high affinity for water. This would result in the reduced number of active sites for the adsorption/dissociation of oxygen molecules. In addition, strongly adsorbed water molecules on the BSCF surface could also greatly 
impede the transport (or diffusion) of oxygen species on the electrode surface. Both effects would slow down the overall cathode reaction process, leading to the increased $\mathrm{R}_{\mathrm{ai}}$, especially in the MF-LF range.

On the other hand, as shown in Figure 6. 3 (c) and Figure 6. 4, an opposite trend with respect to the moisture effect was observed in the high frequency (HF) part of the impedance spectra. Figure 6. summarizes the $\mathrm{HF}$ resistances obtained from $500^{\circ} \mathrm{C}$ to $400^{\circ} \mathrm{C}$ for a symmetrical cell in both dry simulated air and humidified air with different moisture content. It is observed that the decrease in HF resistance due to the introduction of moisture is more significant at higher temperature (e.g., 500 and $475^{\circ} \mathrm{C}$ ) than at lower temperature (e.g., $450^{\circ} \mathrm{C}$ or below). Such results suggest that the activation energy for the HF resistance is significantly different in dry simulated air from those in humidified air. (It is noted that there appears to be a deviation at $475^{\circ} \mathrm{C}$ in Figure 6. . Whether it is due to experimental error or other factors is not clear at this moment and will be investigated in the future.) Therefore the HF semicircle is attributed to the resistance from the charge transfer step and not the grain boundary (GB), because previous study suggests that the activation energy for the GB resistance remains almost the same in humidified versus dry atmosphere.[184] Such assignment of the $\mathrm{HF}$ semicircle at temperature below $\sim 500^{\circ} \mathrm{C}$ to the charge transfer step is also consistent with literature.[20, 183]

It should be noted that similar behavior of decrease in HF semicircle with increase of moisture content from 3,10, and $20 \%$ in simulated air had been reported before for the system of $\mathrm{Sm}_{0.5} \mathrm{Sr}_{0.5} \mathrm{CoO}_{3-\delta}$ (SSC)- $\mathrm{BaCe}_{0.8} \mathrm{Sm}_{0.2} \mathrm{O}_{3-\delta}$ (BCS) composite cathode over BCS proton conducting electrolyte at $500^{\circ} \mathrm{C},[185]$ while in another study on the system of $\mathrm{BSCF}$ 
over $\mathrm{BaCe}_{0.9} \mathrm{Y}_{0.1} \mathrm{O}_{3-\delta}(\mathrm{BCY} 10)$ electrolyte at $600^{\circ} \mathrm{C}$, [20] the total apparent interfacial resistance decreases with increasing moisture content from $3 \%$ to $30 \%$. Nevertheless, to the best of the authors' knowledge, no previous study has systematically compared the cathode behavior over proton conducting electrolyte between dry and humified conditions, as reported here. The significant decrease in the HF semicircle for the oxygen electrode upon the introduction of moisture in the current study is hypothesized to be due to i) the intrinsically faster kinetics for the charge transfer step 3') via proton (Figure 6. (b)) comparing with the conventional charge transfer step 3) via oxide ion (Figure 6. (a)) and/or ii) the greater concentration of $\mathrm{H}_{2} \mathrm{O}_{(\text {ads })}$ reactant for the reverse reaction of step 3'). Both explanations are consistent with the observation of a continued decrease of high frequency resistance $\mathrm{R}_{\mathrm{HF}}$ with increasing concentration of $\mathrm{H}_{2} \mathrm{O}$, especially at temperatures of $475^{\circ} \mathrm{C}$ and $500{ }^{\circ} \mathrm{C}$ (see Figure 6. 4 (b) and Figure 6. ): As moisture content increases, the BSCF electrode and the BZCYYb electrolyte can become more and more hydrated, leading to the continued increase in proton conduction and decrease in oxide ion conduction. On the other hand, the concentration of surface $\mathrm{H}_{2} \mathrm{O}_{(\text {ads })}$ would increase as well. Either way, the overall charge transfer process 3') would become faster with greater moisture content. Further study will be needed to clarify the exact origin for such a phenomenon.

Furthermore, such explanations could also be supported by the comparison of the impedance spectra obtained in simulated air versus in pure $\mathrm{O}_{2}$ at $450^{\circ} \mathrm{C}$, as shown in Figure 6. 5 (a). The HF semicircles in simulated air and in pure $\mathrm{O}_{2}$ are essentially the same, which suggests that they are not sensitive to the amount of $\mathrm{O}_{2}$ available and should represent the charge transfer step of the electrode reaction. On the other hand, the MF-LF semicircle is 
significantly smaller in pure $\mathrm{O}_{2}$ comparing with that in dry simulated air, which is consistent with the attribution of the MF-LF semicircle to the oxygen adsorption/mass transport of oxygen molecules in the gas phase. With the introduction of moisture to $\mathrm{O}_{2}$, $\mathrm{R}_{\mathrm{HF}}$ becomes smaller and smaller with increasing moisture content, as shown in Figure 6. 5 (b), while the MF-LF semicircle becomes significantly larger, which is similar to the behavior in simulated air. In addition, as shown in Figure 6.5 (c), the impedance spectra in $3 \%$ humidified air and in humidified $\mathrm{O}_{2}$ are very similar including the MF-LF part, and this can be understood as significant surface sites over BSCF electrode are now occupied by adsorbed water, which leads to limited reaction sites for $\mathrm{O}_{2}$ adsorption, making the overall electrode reaction less sensitive to the oxygen gas concentration.

For the effect of $\mathrm{CO}_{2}$ on the cathode electrochemical behavior, adding $\mathrm{CO}_{2}$ to the dry simulated air obviously poison the BSCF electrode as evidenced by the increase in $\mathrm{R}_{\mathrm{ai}}$ (shown in Figure 6. 6 and Table 6. 1). In addition, $1 \% \mathrm{CO}_{2}$ also seems to cause increase in $\mathrm{R}_{\mathrm{O}}$ for the $\mathrm{BZCYYb}$ electrolyte at higher temperature such as $650^{\circ} \mathrm{C}$ and $550^{\circ} \mathrm{C}$ (as shown in Table 6. 1). This is most likely due to the bulk reaction between $\mathrm{CO}_{2}$ and the BZCYYb electrolyte, as evidenced by the XRD pattern in Figure 6. 1 showing the existence of $\mathrm{BaCO}_{3}$ impurity after the exposure of the $\mathrm{BZCYYb}$ powder to $1 \% \mathrm{CO}_{2} / 99 \% \mathrm{~N}_{2}$ at $750^{\circ} \mathrm{C}$ for 24 hours. In comparison, at lower temperature of $450^{\circ} \mathrm{C}$, no obvious change in $\mathrm{R}_{\mathrm{O}}$ was observed, which is consistent with the XRD pattern for the BSCF+BZCYYb powder mixture after 24 hours of exposure to $1 \% \mathrm{CO}_{2} / 99 \% \mathrm{~N}_{2}$ in Figure 6. 1, suggesting sufficient chemical stability against $1 \% \mathrm{CO}_{2}$ for the $\mathrm{BSCF}$ electrode and $\mathrm{BZCYYb}$ electrolyte at that temperature. 


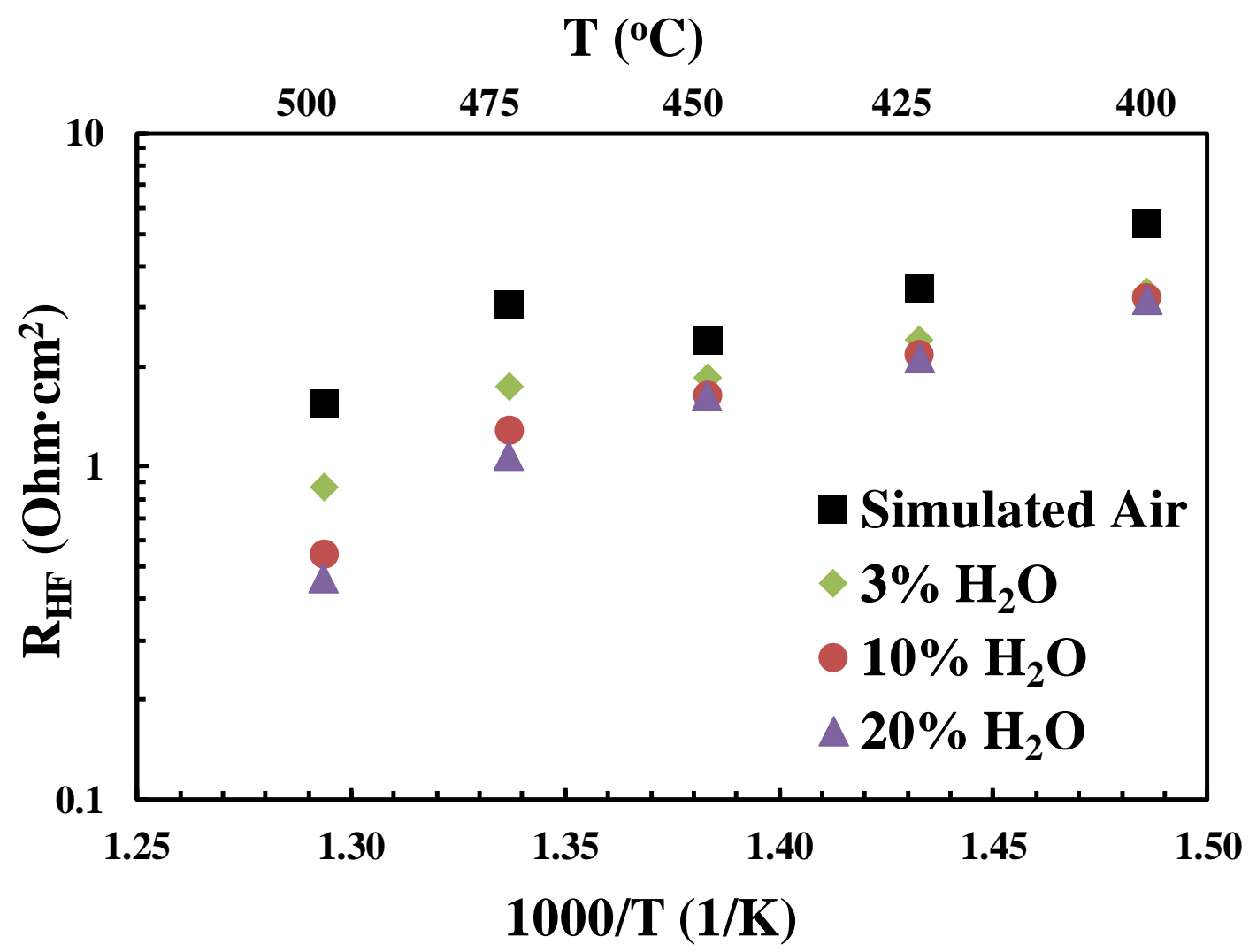

Figure 6. 9 High frequency resistance $\mathrm{R}_{\mathrm{HF}}$ in dry simulated air versus that contains up to $20 \%$ moisture at temperatures from 500 to $400^{\circ} \mathrm{C}$.

In addition, the increase of $\mathrm{R}_{\mathrm{ai}}$ upon the introduction of $1 \% \mathrm{CO}_{2}$ into the dry simulated air, especially for the MF-LF semicircle (shown in Figure 6. 6 (b) and (c)) could be attributed to the adsorption of $\mathrm{CO}_{2}$ on the $\mathrm{BSCF}$ and $\mathrm{BZCYYb}$ surfaces, which would substantially occupy the active surface sites for oxygen adsorption and slow down the overall reaction. On the other hand, when the oxygen electrode process shows clear separation into $\mathrm{HF}$ and MF-LF semicircles at lower temperature such as $450^{\circ} \mathrm{C}$, the $\mathrm{HF}$ semicircle does not appear to be influenced much by the adsorption of $\mathrm{CO}_{2}$ (Figure 6. 6 (c)). This is also consistent with the attribution that the HF semicircle represents the charge 
transfer process. Furthermore, as summarized in Table 6.2, the $\mathrm{CO}_{2}$ poisoning is largely recoverable upon the removal of $1 \% \mathrm{CO}_{2}$ in the dry simulated air at $650^{\circ} \mathrm{C}$, but it gets less reversible at lower temperature of $550^{\circ} \mathrm{C}$ and $450^{\circ} \mathrm{C}$. This is likely due to the relative strong adsorption and high desorption temperature $\left(>600^{\circ} \mathrm{C}\right)$ for $\mathrm{CO}_{2}$ on $\mathrm{BSCF}$ surface as reported before.[21-23]

With the presence of $3 \%$ moisture, the extent of poisoning caused by $1 \% \mathrm{CO}_{2}$ reduces and the recovery becomes much more complete, especially at lower temperature of $550^{\circ} \mathrm{C}$ and $450^{\circ} \mathrm{C}$, as shown in Figure 6. and in Table 6. 1. The less extent of $\mathrm{CO}_{2}$ poisoning, faster and more complete recovery in the presence of moisture comparing with dry condition could be attributed to the strong adsorption of moisture on the BSCF and BZCYYb surfaces, especially at lower temperature of $550^{\circ} \mathrm{C}$ and $450^{\circ} \mathrm{C}$, which leads to the formation of adsorbed surface bicarbonate species (i.e., adsorbed $-\mathrm{HCO}_{3}$ ) apart from typical surface carbonate (adsorbed $-\mathrm{CO}_{2}$ ) on the electrode and electrolyte. According to Yan et al., the surface bicarbonate species have weaker bonding and much lower desorption temperature of $\sim 400^{\circ} \mathrm{C}$ comparing with the desorption temperature of $\sim 600^{\circ} \mathrm{C}$ for surface carbonate species. [22]

Finally, considering that the $\mathrm{CO}_{2}$ concentration in ambient air is much lower than the $1 \%$ used in this study and there will always be some moisture in air, the results observed suggest that proton conducting IT-SOFC with BSCF cathode might be insensitive to typical $\mathrm{CO}_{2}$ poisoning for operation at reduced temperature of $\sim 450^{\circ} \mathrm{C}$. On the other hand, the observed apparent interfacial resistance on the order of $10-15 \Omega \cdot \mathrm{cm}^{2}$ at this temperature is still much higher than ideal. Therefore, alternative SOFC cathodes that have relatively 
lower affinity for water adsorption, high activity for oxygen dissociative adsorption, as well as high proton conductivity would be promising candidates for proton conducting ITSOFC.

\subsection{Conclusions}

BSCF cathode demonstrates chemical compatibility with BZCYYb proton conducting electrolyte up to $1000^{\circ} \mathrm{C}$ and stability at $450^{\circ} \mathrm{C}$ in air containing $3 \% \mathrm{H}_{2} \mathrm{O}$ and $1 \% \mathrm{CO}_{2}$. For a BSCF/BZCYYb/BSCF symmetrical cell, ohmic resistance $\mathrm{R}_{\mathrm{O}}$ decreases with the introduction of moisture, which is consistent with typical hydration behavior of the $\mathrm{BZCYYb}$ proton conducting electrolyte. For the apparent interfacial resistance $\mathrm{R}_{\mathrm{a}}$, the middle and low frequency (MF-LF) semicircle increases with the introduction of moisture. $[20,118,185]$ Such an increase is attributed to the occupation of the BSCF electrode surface active sites by water molecules that inhibit oxygen adsorption/dissociation and surface diffusion. On the other hand, the high frequency (HF) semicircle, which corresponds to the charge transfer process in the oxygen electrode reaction, could be clearly separated at $\leq \sim 500^{\circ} \mathrm{C}$ and it shows significant reduction with the introduction of moisture. Such a phenomenon is hypothesized to be related to the intrinsically faster charge transfer process involving proton vs the conventional pathway involving only oxide ion and/or the greater availability of reactant, in particular adsorbed water $\mathrm{H}_{2} \mathrm{O}_{\text {(ads) }}$, for the reverse reaction of the charge transfer step in the oxygen electrode reaction over the proton conducting electrolyte. On the other hand, introducing $1 \% \mathrm{CO}_{2}$ to simulated air causes obvious poisoning for the $\mathrm{BSCF} / \mathrm{BZCYYb} / \mathrm{BSCF}$ symmetrical cell. While $\mathrm{CO}_{2}$ poisoning 
becomes less reversible at lower temperature, the presence of moisture helps reduce the extent of $\mathrm{CO}_{2}$ poisoning and improves the reversibility especially at reduced temperatures of $450^{\circ} \mathrm{C}$. This is attributed to the co-adsorption of $\mathrm{H}_{2} \mathrm{O}$ and $\mathrm{CO}_{2}$ on BSCF and $\mathrm{BZCYYb}$ surfaces, as well as the formation of bicarbonates on surfaces, which tend to bond weaker and desorb at lower temperature comparing with surface carbonate species. Considering water molecules adsorb strongly on $\mathrm{BSCF}$ at $\sim 450^{\circ} \mathrm{C}$ and below, which tends to interfere with the oxygen adsorption as shown in this study, designing alternative cathodes with reduced tendency for water adsorption while maintaining fast oxygen adsorption and high proton conductivity appears to be a promising direction in the future development of cathodes for proton conducting IT-SOFC. 


\section{Chapter VII: Summary}

\subsection{Anode for Proton Conducing IT-SOFC}

The present study investigated the $\mathrm{H}_{2} \mathrm{~S}$ and $\mathrm{CO}_{2}$ poisoning effects on the $\mathrm{Ni}-\mathrm{BZCYYb}$ cermet anode of proton conducting IT-SOFC, and the major conclusions are listed below:

- PC-SOFC, especially the electrolyte-supported full cell and anode symmetrical cell with thin anode, show small but observable poisoning effect with increase in interfacial resistance $\mathrm{R}_{\mathrm{ai}}$ and no change in ohmic resistance $\mathrm{R}_{\mathrm{O}}$ upon the introduction of low-ppm level $\mathrm{H}_{2} \mathrm{~S}$ to $\mathrm{H}_{2}$ in the range of 750 to $450^{\circ} \mathrm{C}$

- The extent of anode $\mathrm{H}_{2} \mathrm{~S}$ poisoning is much smaller for PC-SOFC compared to conventional OC-SOFC, and this is attributed to the fact that the anode reaction route for PC-SOFC involves only proton incorporation and no water evolution, which is very different from conventional OC-SOFC

- The displayed significantly less anode sulfur poisoning for PC-SOFC also implies that proton conducting ceramic (PCC) electrolyte might play an important (electro-) catalytic role in the anode reaction for PC-SOFC, and helps maintain the reaction rate upon exposure to low-ppm level $\mathrm{H}_{2} \mathrm{~S}$

- No bulk sulfide phases was revealed by characterization techniques such as XRD and EDS for the post low ppm-level $\mathrm{H}_{2} \mathrm{~S}$ exposure sample, while surface sensitive technique of SIMS suggests a strong association between Ba species and

$\mathrm{S}$ species that persists into the bulk of the Ni-BZCYYb mixture, indicating the possible incorporation or dissolution of sulfur into the $\mathrm{BZCYYb}$ 
- Low-percentage level $\mathrm{CO}_{2}$ shows similar poisoning effect as low-ppm level $\mathrm{H}_{2} \mathrm{~S}$ on all three types of $\mathrm{PC}-\mathrm{SOFC}$ at temperature in the range of 550 to $750^{\circ} \mathrm{C}$, with no change in electrolyte ohmic resistance $\mathrm{R}_{O}$ while observable increase in electrode interfacial resistance $\mathrm{R}_{\mathrm{ai}}$ was limited to the mid-to-low frequency (MFLF) semicircles.

- The observed poisoning behaviors of proton conducting SOFC by lowpercentage level of $\mathrm{CO}_{2}$ at higher temperature can be attributed to the strong adsorption of $\mathrm{CO}_{2}$ species on the highly basic $\mathrm{BZCYYb}$ electrolyte surface, which interferes with the sub-steps of hydrogen adsorption and surface diffusion in the anode reaction for PC-SOFC. On the other hand, with decrease in temperature, the same low percentage-level $\mathrm{CO}_{2}$ would cause bulk phase reaction with the $\mathrm{BZCYYb}$ electrolyte and greater poisoning effect.

- The great similarity of the electrochemical behaviors of proton conducting SOFC upon exposure to $\mathrm{H}_{2} \mathrm{~S}$ and $\mathrm{CO}_{2}$ fuel contaminants, despite their different affinity to Ni catalyst, suggest PCC (BZCYYb in this study) might play an electrocatalytic role ed in the anode reaction for PC-SOFC

- Future studies using different tools such as anode patterned electrode cells and more in-depth materials characterizations will be needed to fully reveal the $\mathrm{H}_{2} \mathrm{~S}$ and $\mathrm{CO}_{2}$ poisoning mechanism and the exact roles of $\mathrm{PCC}$ for proton conducting SOFC. 


\subsection{Cathode for Proton Conducting IT-SOFC}

Ag, LSCF, LSCF-BZCYYb composite, and BSCF were evaluated as cathodes for PCSOFC using cathode symmetrical cells under various $p \mathrm{O}_{2}$ and $p \mathrm{H}_{2} \mathrm{O}$ at $650-450^{\circ} \mathrm{C}$. In addition, the $\mathrm{H}_{2} \mathrm{O}$ and $\mathrm{CO}_{2}$ effect on the BSCF cathode was also studied based on PCSOFC cathode symmetrical cells. The major conclusions are listed below:

- For Ag, LSCF, LSCF-BZCYYb, and BSCF cathode symmetrical cells based on $\mathrm{BZCYYb}$ proton conducting ceramic electrolyte, electrode interfacial resistance $\mathrm{R}_{\mathrm{ai}}$ increased with decreasing $p \mathrm{O}_{2}$ or introduction of moisture.

- Pure LSCF does not behave like a good MIEC but more like an electronic conductor as $\mathrm{Ag}$ over the BZCYYb electrolyte, giving very high $\mathrm{R}_{\mathrm{ai}}$ and $\mathrm{R}_{\mathrm{o}}$, suggesting sluggish cathode reaction in both dry and humidified conditions. This indicates that the oxide-ion transfer between LSCF and BZCYYb electrolyte is not very effective even in dry atmosphere.

- LSCF-BZCYYb composite cathode shows much lower interfacial resistance under dry conditions, which is attributed to the extended TPB area and BZCYYb networks in the electrode that transfer oxide-ion to places near the LSCF surface. However, the interfacial resistance of LSCF-BZCYYb composite cathode increased dramatically with the introduction of moisture

- BSCF electrode behaves like a good cathode in proton conducting IT-SOFC showing low $\mathrm{R}_{\mathrm{ai}}$ and $\mathrm{R}_{\mathrm{o}}$ under both dry and humidified conditions. The high frequency resistance $\mathrm{R}_{\mathrm{HF}}$ of $\mathrm{BSCF}$ does not change with $p \mathrm{O}_{2}$ but decreases with increasing $p \mathrm{H}_{2} \mathrm{O}$, which is attributed to the intrinsically faster charge transfer step for the oxygen electrode 
reaction via the proton route than the oxide ion route. On the other hand, the overall $R_{a i}$, especially the MF-LF semicircles increase with the introduction of moisture. Such increase was attributed to the occupation of the BSCF electrode surface active sites by water molecules that inhibit oxygen adsorption/dissociation and surface diffusion steps in cathode reaction

- BSCF cathode shows obvious poisoning effect upon the introduction of $1 \% \mathrm{CO}_{2}$ and the poisoning effect becomes less reversible at lower temperature. On the other hand, the presence of moisture helps reduce the extent of $\mathrm{CO}_{2}$ poisoning and improves the reversibility, which is attributed to the co-adsorption of $\mathrm{H}_{2} \mathrm{O}$ and $\mathrm{CO}_{2}$ on BSCF and BZCYYb surfaces, as well as the formation of bicarbonates on surfaces that tends to bond weaker and desorb at lower temperature

- Future work focusing on improving cathode microstructure for the proton conducting cathode is needed. On the other hand, research aimed at designing of cathodes with reduced tendency for water adsorption while maintaining fast oxygen adsorption and high proton conductivity should be carried out. 


\section{References}

1. Badwal, S.P.S. and K. Foger, Solid oxide electrolyte fuel cell review. Ceramics International, 1996. 22(3): p. 257-265.

2. Hammou, A. and J. Guindet, Solid oxide fuel cells. The CRC Handbook of Solid State Electrochemistry, 1997: p. 407.

3. Singhal, S.C., Advances in solid oxide fuel cell technology. Solid State Ionics, 2000. 135(1-4): p. 305-313.

4. Yamamoto, O., Solid oxide fuel cells: fundamental aspects and prospects. Electrochimica Acta, 2000. 45(15-16): p. 2423-2435.

5. Singhal, S.C., Solid oxide fuel cells for stationary, mobile, and military applications. Solid State Ionics, 2002. 152: p. 405-410.

6. Stambouli, A.B. and E. Traversa, Solid oxide fuel cells (SOFCs): a review of an environmentally clean and efficient source of energy. Renewable and sustainable energy reviews, 2002. 6(5): p. 433-455.

7. Ormerod, R.M., Solid oxide fuel cells. Chemical Society Reviews, 2003. 32(1): p. 17-28.

8. Minh, N.Q., Solid oxide fuel cell technology-features and applications. Solid State Ionics, 2004. 174(1-4): p. 271-277.

9. Mahato, N., et al., Progress in material selection for solid oxide fuel cell technology: A review. Progress in Materials Science, 2015. 72: p. 141-337.

10. $\quad$ Fergus, J., et al., Solid oxide fuel cells: materials properties and performance. 2016: CRC press.

11. Singhal, S.C. and K. Kendall, High-temperature solid oxide fuel cells: fundamentals, design and applications. 2003: Elsevier.

12. Wachsman, E.D. and K.T. Lee, Lowering the temperature of solid oxide fuel cells. Science (New York, N.Y.), 2011. 334(6058): p. 935-939.

13. Brett, D.J.L., et al., Intermediate temperature solid oxide fuel cells. Chemical Society Reviews, 2008. 37(8): p. 1568-1578.

14. Jacobson, A.J., Materials for solid oxide fuel cells. Chemistry of Materials, 2009. 22(3): p. 660-674. 
15. Yang, L., et al., Enhanced sulfur and coking tolerance of a mixed ion conductor for SOFCs: $B a Z r(0.1) C e(0.7) Y(0.2-x) Y b(x) O(3$-delta). Science (New York, N.Y.), 2009. 326(5949): p. 126-129.

16. Hirabayashi, D., et al., Solid oxide fuel cells operating without using an anode material. Solid State Ionics, 2004. 168(1-2): p. 23-29.

17. Tomita, A., et al., Chemical and redox stabilities of a solid oxide fuel cell with BaCe0. 8Y0. 2O3- $\alpha$ functioning as an electrolyte and as an anode. Solid State Ionics, 2006. 177(33-34): p. 2951-2956.

18. Goodenough, J.B. and Y.-H. Huang, Alternative anode materials for solid oxide fuel cells. Journal of Power Sources, 2007. 173(1): p. 1-10.

19. Li, M., et al., BaZr0. 1Ce0. 7Y0. $1 Y b 0.1 O 3-\delta$ as highly active and carbon tolerant anode for direct hydrocarbon solid oxide fuel cells. International Journal of Hydrogen Energy, 2014. 39(28): p. 15975-15981.

20. Grimaud, A., et al., Hydration properties and rate determining steps of the oxygen reduction reaction of perovskite-related oxides as $H$-SOFC cathodes. Journal of the Electrochemical Society, 2012. 159(6): p. B694.

21. Yan, A., et al., Investigation of a $\mathrm{Ba} 0.5 \mathrm{Sr} 0.5 \mathrm{Co} 0.8 \mathrm{Fe} 0.2 \mathrm{O} 3-\delta$ based cathode IT-SOFC: I. The effect of CO2 on the cell performance. Applied Catalysis B: Environmental, 2006. 66(1): p. 64-71.

22. Yan, A., et al., Investigation of a $\mathrm{Ba} 0.5 \mathrm{Sr} 0.5 \mathrm{Co} 0.8 \mathrm{Fe} 0.2 \mathrm{O} 3-\delta$ based cathode SOFC: II. The effect of CO2 on the chemical stability. Applied Catalysis B: Environmental, 2007. 76(3): p. 320-327.

23. Yan, A., et al., A temperature programmed desorption investigation on the interaction of $\mathrm{Ba} 0.5 \mathrm{Sr} 0.5 \mathrm{Co} 0.8 \mathrm{Fe} 0.2 \mathrm{O} 3-\delta$ perovskite oxides with $\mathrm{CO} 2$ in the absence and presence of $H 2 O$ and $O$ 2. Applied Catalysis B: Environmental, 2008. 80(1): p. 24-31.

24. Brigham, R.J., H. Neumayer, and J.S. Kirkaldy, Solubility limit for sulphur in nickel between 637 and 1400 C. Canadian Metallurgical Quarterly, 1970. 9(4): p. 525529.

25. Bartholomew, C.H., P.K. Agrawal, and J.R. Katzer, Sulfur poisoning of metals. Advances in catalysis, 1982. 31: p. 135-242.

26. Sasaki, K., et al., H2S poisoning of solid oxide fuel cells. Journal of the Electrochemical Society, 2006. 153(11): p. A2029.

27. Cheng, Z., S. Zha, and M. Liu, Influence of cell voltage and current on sulfur poisoning behavior of solid oxide fuel cells. Journal of Power Sources, 2007. 172(2): p. 688-693. 
28. Wang, J.-H. and M. Liu, Computational study of sulfur-nickel interactions: A new S-Ni phase diagram. Electrochemistry Communications, 2007. 9(9): p. 2212-2217.

29. Zha, S., Z. Cheng, and M. Liu, Sulfur poisoning and regeneration of Ni-based anodes in solid oxide fuel cells. Journal of the Electrochemical Society, 2007. 154(2): p. B206.

30. Hansen, J.B.g., Correlating sulfur poisoning of SOFC nickel anodes by a Temkin isotherm. Electrochemical and Solid-State Letters, 2008. 11(10): p. B180.

31. Lussier, A., et al., Mechanism for SOFC anode degradation from hydrogen sulfide exposure. International Journal of Hydrogen Energy, 2008. 33(14): p. 3945-3951.

32. Offer, G.J., et al., Thermodynamics and kinetics of the interaction of carbon and sulfur with solid oxide fuel cell anodes. Journal of the American Ceramic Society, 2009. 92(4): p. 763-780.

33. Rasmussen, J.F.B. and A. Hagen, The effect of H2S on the performance of Ni-YSZ anodes in solid oxide fuel cells. Journal of Power Sources, 2009. 191(2): p. 534541.

34. Rasmussen, J.F.B. and A. Hagen, The effect of H2S on the performance of SOFCs using methane containing fuel. Fuel Cells, 2010. 10(6): p. 1135-1142.

35. Yang, L., et al., New insights into sulfur poisoning behavior of Ni-YSZ anode from long-term operation of anode-supported SOFCs. Energy \& Environmental Science, 2010. 3(11): p. 1804-1809.

36. Papurello, D., et al., Sulfur poisoning in Ni-anode solid oxide fuel cells (SOFCs): deactivation in single cells and a stack. Chemical Engineering Journal, 2016. 283: p. 1224-1233.

37. Papurello, D. and A. Lanzini, SOFC single cells fed by biogas: Experimental tests with trace contaminants. Waste Management, 2018. 72: p. 306-312.

38. Sun, S., O. Awadallah, and Z. Cheng, Poisoning of Ni-Based anode for proton conducting SOFC by $\mathrm{H} 2 \mathrm{~S}, \mathrm{CO} 2$, and $\mathrm{H} 2 \mathrm{O}$ as fuel contaminants. Journal of Power Sources, 2018. 378: p. 255-263.

39. Abudula, A., et al., Oxidation mechanism and effective anode thickness of SOFC for dry methane fuel. Solid State Ionics, 1996. 86: p. 1203-1209.

40. Ferrari, A.C. and J. Robertson, Interpretation of Raman spectra of disordered and amorphous carbon. Physical review B, 2000. 61(20): p. 14095.

41. Tu, C.S., et al., Thermal stability of $B a(\operatorname{Zr} 0.8-x$ Ce $x$ Y 0.2) $O 2.9$ ceramics in carbon dioxide. Journal of Applied Physics, 2009. 105(10): p. 103504. 
42. Ishiyama, T., et al., Decomposition reaction of BaZr0. 1Ce0. 7Y0. 1Yb0. 1O3- $\delta$ in carbon dioxide atmosphere with nickel sintering aid. Journal of the Ceramic Society of Japan, 2017. 125(4): p. 247-251.

43. Badwal, S. Materials for solid oxide fuel cells. in Materials Forum. 1997.

44. Brandon, N.P., S. Skinner, and B.C.H. Steele, Recent advances in materials for fuel cells. Annual Review of Materials Research, 2003. 33(1): p. 183-213.

45. Zhu, W.Z. and S.C. Deevi, Development of interconnect materials for solid oxide fuel cells. Materials Science and Engineering: A, 2003. 348(1-2): p. 227-243.

46. Fergus, J.W., Lanthanum chromite-based materials for solid oxide fuel cell interconnects. Solid State Ionics, 2004. 171(1-2): p. 1-15.

47. Minh, N.Q., Ceramic fuel cells. Journal of the American Ceramic Society, 1993. 76(3): p. 563-588.

48. Tsai, T. and S.A. Barnett, Effect of LSM-YSZ cathode on thin-electrolyte solid oxide fuel cell performance. Solid State Ionics, 1997. 93(3-4): p. 207-217.

49. Yokokawa, H., et al., Fundamental mechanisms limiting solid oxide fuel cell durability. Journal of Power Sources, 2008. 182(2): p. 400-412.

50. Lefebvre-Joud, F., G. Gauthier, and J. Mougin, Current status of proton-conducting solid oxide fuel cells development. Journal of Applied Electrochemistry, 2009. 39(4): p. 535-543.

51. Männer, R., et al., CHARACTERISATION OF YSZ ELECTROLYTE MATERIALS WITH VARIOUS YTTRIA CONTENTS. 1991. 3: p. 2085-2089.

52. Minh, N.Q. and T. Takahashi, Science and technology of ceramic fuel cells. 1995: Elsevier.

53. Baumard, J. and P.i. Abelard, Defect structure and transport properties of ZrO 2based solid electrolytes, in Science and technology of zirconia II. 1983.

54. Rühle, M., N. Claussen, and A.H. Heuer, Science and technology of zirconia II. Vol. 12. 1984: American Ceramic Society.

55. Murakami, S., et al. A study on Composite Anode of Solid Oxide Fuel Cells. in Proc. of the International Symposium on Solid Oxide Fuel Cells, Science House, Tokyo, Japan. 1990.

56. Easler, T., et al., Electrode Development for Monolithic Fuel Cells. 1986: p. 72-5.

57. MAJUMDAR, S., T. CLAAR, and B.J.J.o.t.A.C.S. FLANDERMEYER, Stress and fracture behavior of monolithic fuel cell tapes. 1986. 69(8): p. 628-633. 
58. Dees, D., et al., Conductivity of Porous Ni/ZrO2 - Y 2 O 3 Cermets. 1987. 134(9): p. 2141-2146.

59. Yamamoto, O., et al., Perovskite-type oxides as oxygen electrodes for high temperature oxide fuel cells. 1987. 22(2-3): p. 241-246.

60. Inoue, T., et al., Cathode and anode materials and the reaction kinetics for the solid oxide fuel cell. 1990. 40: p. 407-410.

61. Princivalle, A. and E. Djurado, Nanostructured LSM/YSZ composite cathodes for IT-SOFC: A comprehensive microstructural study by electrostatic spray deposition. Solid State Ionics, 2008. 179(33-34): p. 1921-1928.

62. Hammouche, A., E. Schouler, and M.J.S.S.I. Henault, Electrical and thermal properties of Sr-doped lanthanum manganites. 1988. 28: p. 1205-1207.

63. KATAYAMA, K., et al., Sintering and Electrical Conductivity of La1-XSrXMnO3. 1989. 97(1131): p. 1327-1333.

64. Hashimoto, T., et al., Electrical resistivity and Seebeck coefficient of La 1-xMx MnO 3 ( $M=$ Ca, Sr) single crystals. 1988. 23(3): p. 1102-1105.

65. Kertesz, M., et al., Structure and electrical conductivity of LaO. 84SrO. 16MnO3. 1982. 42(2): p. 125-129.

66. Kuo, J., H. Anderson, and D.J.J.o.s.s.c. Sparlin, Oxidation-reduction behavior of undoped and Sr-doped LaMnO3: Defect structure, electrical conductivity, and thermoelectric power. 1990. 87(1): p. 55-63.

67. Hwang, H.J., et al., Electrochemical performance of LSCF-based composite cathodes for intermediate temperature SOFCs. Journal of Power Sources, 2005. 145(2): p. 243-248.

68. Tietz, F., et al., Performance of LSCF cathodes in cell tests. Journal of Power Sources, 2006. 156(1): p. 20-22.

69. Liu, M., et al., Enhanced performance of LSCF cathode through surface modification. International Journal of Hydrogen Energy, 2012. 37(10): p. 86138620.

70. Shao, Z. and S.M. Haile, A high-performance cathode for the next generation of solid-oxide fuel cells. Nature, 2004. 431(7005): p. 170-173.

71. Lee, S., et al., Ba 0.5 Sr 0.5 Co 0.8 Fe $0.2 \mathrm{O} 3-\delta$ (BSCF) and La $0.6 \mathrm{Ba} 0.4$ Co 0.2 $\mathrm{Fe} 0.8 \mathrm{O} 3-\delta(\mathrm{LBCF})$ cathodes prepared by combined citrate-EDTA method for IT-SOFCs. Journal of Power Sources, 2006. 157(2): p. 848-854. 
72. Lin, Y., et al., Evaluation of Ba $0.5 \mathrm{Sr} 0.5 \mathrm{Co} 0.8 \mathrm{Fe} 0.2 \mathrm{O} 3-\delta$ as a potential cathode for an anode-supported proton-conducting solid-oxide fuel cell. Journal of Power Sources, 2008. 180(1): p. 15-22.

73. Zhao, H., et al., Preparation and properties of $\mathrm{Ba} x \mathrm{Sr} 1-x \mathrm{Co}$ y $\mathrm{Fe} 1-y \mathrm{O} 3-\delta$ cathode material for intermediate temperature solid oxide fuel cells. Journal of Power Sources, 2008. 182(2): p. 503-509.

74. Zhou, W., et al., Evaluation of A-site cation-deficient (BaO. 5SrO. 5) $1-x \mathrm{CoO}$. 8Fe0. $203-\delta(x>0)$ perovskite as a solid-oxide fuel cell cathode. Journal of Power Sources, 2008. 182(1): p. 24-31.

75. Zhu, B., et al., Intermediate-temperature proton-conducting fuel cells-present experience and future opportunities. Solid State Ionics, 1999. 125(1-4): p. 439-446.

76. Iwahara, H., Technological challenges in the application of proton conducting ceramics. Solid State Ionics, 1995. 77: p. 289-298.

77. Iwahara, H., Proton conducting ceramics and their applications. Solid State Ionics, 1996. 86: p. 9-15.

78. Kreuer, K.D., On the development of proton conducting materials for technological applications. Solid State Ionics, 1997. 97(1-4): p. 1-15.

79. Katahira, K., et al., Protonic conduction in Zr-substituted BaCeO 3. Solid State Ionics, 2000. 138(1): p. 91-98.

80. Hassan, D., S. Janes, and R. Clasen, Proton-conducting ceramics as electrodelelectrolyte materials for SOFC's—part I: preparation, mechanical and thermal properties of sintered bodies. Journal of the European Ceramic Society, 2003. 23(2): p. 221-228.

81. Kreuer, K.D., Proton-conducting oxides. Annual Review of Materials Research, 2003. 33(1): p. 333-359.

82. Fergus, J.W., Electrolytes for solid oxide fuel cells. Journal of Power Sources, 2006. 162(1): p. 30-40.

83. Ding, H., Y. Xie, and X. Xue, Electrochemical performance of BaZr 0.1 Ce $0.7 \mathrm{Y}$ $0.1 \mathrm{Yb} 0.1 \mathrm{O} 3-\delta$ electrolyte based proton-conducting SOFC solid oxide fuel cell with layered perovskite PrBaCo 2 O $5 \delta$ cathode. Journal of Power Sources, 2011. 196(5): p. 2602-2607.

84. Tauer, T., R. O'Hayre, and J.W. Medlin, A theoretical study of the influence of dopant concentration on the hydration properties of yttrium-doped barium cerate. Solid State Ionics, 2011. 204: p. 27-34. 
85. Nguyen, N.T.Q. and H.H. Yoon, Preparation and evaluation of BaZr 0.1 Ce 0.7 Y $0.1 \mathrm{Yb} 0.1 \mathrm{O} 3-\delta(B Z C Y Y b)$ electrolyte and BZCYYb-based solid oxide fuel cells. Journal of Power Sources, 2013. 231: p. 213-218.

86. Yoo, Y. and N. Lim, Performance and stability of proton conducting solid oxide fuel cells based on yttrium-doped barium cerate-zirconate thin-film electrolyte. Journal of Power Sources, 2013. 229: p. 48-57.

87. Zhou, X., et al., Ionic conductivity, sintering and thermal expansion behaviors of mixed ion conductor BaZr 0.1 Ce 0.7 Y 0.1 Yb 0.1 O 3- $\delta$ prepared by ethylene diamine tetraacetic acid assisted glycine nitrate process. Journal of Power Sources, 2011. 196(11): p. 5000-5006.

88. Rainwater, B.H., Electrical properties of BaZr0. 1Ce0. 7Y0. 1Yb0. 1O3- $\delta$ and its application in intermediate temperature solid oxide fuel cells. 2012.

89. VahidMohammadi, A. and Z. Cheng, Fundamentals of Synthesis, Sintering Issues, and Chemical Stability of BaZr0. 1Ce0. 7Y0. 1Yb0. 1O3- $\delta$ Proton Conducting Electrolyte for SOFCs. Journal of the Electrochemical Society, 2015. 162(8): p. F811.

90. Dahl, P.I., et al., Synthesis, densification and electrical properties of strontium cerate ceramics. Journal of the European Ceramic Society, 2007. 27(16): p. 44614471 .

91. Münch, W., et al., A quantum molecular dynamics study of proton conduction phenomena in BaCeO3. Solid State Ionics, 1996. 86: p. 647-652.

92. Zhou, W. and Z.J.N.E. Shao, Fuel cells: hydrogen induced insulation. 2016. 1(6): p. 16078 .

93. Fabbri, E., et al., Composite cathodes for proton conducting electrolytes. 2009. 9(2): p. 128-138.

94. Kilner, J.A. and M. Burriel, Materials for intermediate-temperature solid-oxide fuel cells. Annual Review of Materials Research, 2014. 44: p. 365-393.

95. Jiang, S.P. and S.P.S. Badwal, Hydrogen oxidation at the nickel and platinum electrodes on yttria - tetragonal zirconia electrolyte. Journal of the Electrochemical Society, 1997. 144(11): p. 3777-3784.

96. Jiang, S.P. and S.P.S. Badwal, An electrode kinetics study of $\mathrm{H} 2$ oxidation on $\mathrm{Ni} / \mathrm{Y}$ 2 O 3-ZrO 2 cermet electrode of the solid oxide fuel cell. Solid State Ionics, 1999. 123(1): p. 209-224.

97. Holtappels, P., L.G.J. De Haart, and U. Stimming, Reaction of Hydrogen/Water Mixtures on Nickel - Zirconia Cermet Electrodes: I. DC Polarization 
Characteristics. Journal of the Electrochemical Society, 1999. 146(5): p. 16201625.

98. Holtappels, P., et al., Reaction of Hydrogen/Water Mixtures on Nickel -Zirconia Cermet Electrodes: II. AC Polarization Characteristics. Journal of the Electrochemical Society, 1999. 146(8): p. 2976-2982.

99. Norby, T., et al., Hydrogen in oxides. Dalton transactions, 2004(19): p. 3012-3018.

100. Fang, S., et al., Chemical stability and hydrogen permeation performance of $\mathrm{Ni}-$ BaZr0. 1Ce0. 7Y0. 2O3- $\delta$ in an H2S-containing atmosphere. Journal of Power Sources, 2008. 183(1): p. 126-132.

101. Fang, S., et al., H2S poisoning and regeneration of $\mathrm{Ni}-\mathrm{BaZrO}$. $1 \mathrm{CeO} .7 Y 0.2 \mathrm{O}-\delta$ at intermediate temperature. 2009. 475(1-2): p. 935-939.

102. Li, J., et al., Chemical stability of $Y$-doped $\mathrm{Ba}(\mathrm{Ce}, \mathrm{Zr})$ O3 perovskites in H2Scontaining H2. 2008. 53(10): p. 3701-3707.

103. Wang, J.-H., M. Liu, and Z. Cheng, Anodes, in Solid Oxide Fuel Cells: Materials Properties and Performance. 2008, CRC Press. p. 73-129.

104. Wang, S.-G., et al., Chemisorption of $\mathrm{CO} 2$ on nickel surfaces. The Journal of Physical Chemistry B, 2005. 109(40): p. 18956-18963.

105. Zuo, C., et al., Hydrogen Permeation and Chemical Stability of Cermet [Ni-Ba (ZrO. 8-x Cex Y0. 2) O3] Membranes. 2005. 8(12): p. J35-J37.

106. Zuo, C., et al., Effect of Zr-doping on the chemical stability and hydrogen permeation of the Ni-BaCe0. 8Y0. 2O3-a mixed protonic-electronic conductor. 2006. 18(19): p. 4647-4650.

107. Fang, S., et al., Unprecedented CO2-Promoted Hydrogen Permeation in Ni-BaZrO. 1Ce0. 7 Y0. 1Yb0. 1O3- $\delta$ Membrane. 2013. 6(1): p. 725-730.

108. Fang, S., K.S. Brinkman, and F.J.J.o.M.S. Chen, Hydrogen permeability and chemical stability of $\mathrm{Ni}-\mathrm{BaZrO}$. $1 \mathrm{CeO}$. 7YO. 1YbO. 1O3- $\delta$ membrane in concentrated $\mathrm{H} 2 \mathrm{O}$ and $\mathrm{CO} 2$. 2014. 467: p. 85-92.

109. Lee, H.Y., et al., Active reaction sites for oxygen reduction in LaO. 9SrO. 1MnO3/YSZ electrodes. Journal of the Electrochemical Society, 1995. 142(8): p. 2659-2664.

110. Siebert, E., A. Hammouche, and M. Kleitz, Impedance spectroscopy analysis of La1- xSritxMnO3-yttria-stabilized zirconia electrode kinetics. Electrochimica Acta, 1995. 40(11): p. 1741-1753. 
111. Adler, S.B., J.A. Lane, and B.C.H. Steele, Electrode kinetics of porous mixed conducting oxygen electrodes. Journal of the Electrochemical Society, 1996. 143(11): p. 3554-3564.

112. Mizusaki, J., T. Saito, and H. Tagawa, A Chemical Diffusion - Controlled Electrode Reaction at the Compact La 1-x Sr x MnO3/Stabilized Zirconia Interface in Oxygen Atmospheres. Journal of the Electrochemical Society, 1996. 143(10): p. 3065-3073.

113. Sasaki, K., et al., Microstructure - property relations of solid oxide fuel cell cathodes and current collectors cathodic polarization and ohmic resistance. Journal of the Electrochemical Society, 1996. 143(2): p. 530-543.

114. Tanner, C.W., K.Z. Fung, and A.V. Virkar, The effect of porous composite electrode structure on solid oxide fuel cell performance I. Theoretical analysis. Journal of the Electrochemical Society, 1997. 144(1): p. 21-30.

115. Van Heuveln, F.H. and H.J.M. Bouwmeester, Electrode Properties of Sr - Doped LaMnO3 on Yttria - Stabilized Zirconia II. Electrode Kinetics. Journal of the Electrochemical Society, 1997. 144(1): p. 134-140.

116. Van Heuveln, F.H., H.J.M. Bouwmeester, and F.F. van Berkel, Electrode Properties of Sr - Doped LaMnO3 on Yttria - Stabilized Zirconia I. Three - Phase Boundary Area. Journal of the Electrochemical Society, 1997. 144(1): p. 126-133.

117. Horita, T., et al., Active Sites Imaging for Oxygen Reduction at the LaO. 9SrO. $1 \mathrm{MnO3}-x /$ Yttria - Stabilized Zirconia Interface by Secondary - Ion Mass Spectrometry. Journal of the Electrochemical Society, 1998. 145(9): p. 3196-3202.

118. Peng, R., et al., Cathode processes and materials for solid oxide fuel cells with proton conductors as electrolytes. Journal of Materials Chemistry, 2010. 20(30): p. 6218-6225.

119. Sun, C., R. Hui, and J. Roller, Cathode materials for solid oxide fuel cells: a review. Journal of Solid State Electrochemistry, 2010. 14(7): p. 1125-1144.

120. Choi, Y., M.e.C. Lin, and M. Liu, Computational study on the catalytic mechanism of oxygen reduction on LaO. 5SrO. 5MnO3 in solid oxide fuel cells. Angewandte Chemie International Edition, 2007. 46(38): p. 7214-7219.

121. Yang, L., et al., A mixed proton, oxygen ion, and electron conducting cathode for SOFCs based on oxide proton conductors. Journal of Power Sources, 2010. 195(2): p. 471-474.

122. Poetzsch, D., R. Merkle, and J. Maier, Proton conductivity in mixed-conducting BSFZ perovskite from thermogravimetric relaxation. Physical Chemistry Chemical Physics, 2014. 16(31): p. 16446-16453. 
123. $\mathrm{Hu}, \mathrm{H}$. and M. Liu, Interfacial studies of solid-state cells based on electrolytes of mixed ionic-electronic conductors. Solid State Ionics, 1998. 109(3): p. 259-272.

124. Fleig, J., Solid oxide fuel cell cathodes: Polarization mechanisms and modeling of the electrochemical performance. Annual Review of Materials Research, 2003. 33(1): p. 361-382.

125. Zhao, H., et al., New cathode materials for ITSOFC: phase stability, oxygen exchange and cathode properties of La2- xNiO4 $\delta$. Solid State Ionics, 2008. 179(35-36): p. 2000-2005.

126. Hibino, T., et al., A solid oxide fuel cell using Y-doped BaCeO3 with Pd-loaded $\mathrm{FeO}$ anode and $\mathrm{BaO}$. 5PrO. $5 \mathrm{CoO} 3$ cathode at low temperatures. Journal of the Electrochemical Society, 2002. 149(11): p. A1508.

127. Kim, J., et al., Triple - conducting layered perovskites as cathode materials for proton - conducting solid oxide fuel cells. ChemSusChem, 2014. 7(10): p. 28112815 .

128. Taherparvar, H., et al., Effect of humidification at anode and cathode in protonconducting SOFCs. 2003. 162: p. 297-303.

129. Potter, A. and R.J.S.S.I. Baker, Impedance studies on Pt $\mid$ SrCe0. 95Yb0. 05O3|Pt under dried and humidified air, argon and hydrogen. 2006. 177(19-25): p. 19171924.

130. Akimune, Y., et al., Nano-Ag particles for electrodes in a yttria-doped BaCeO3 protonic conductor. 2007. 178(7-10): p. 575-579.

131. Lim, D.-K., et al., Performance of proton-conducting ceramic-electrolyte fuel cell with BZCY40 electrolyte and BSCF5582 cathode. 2016. 42(3): p. 3776-3785.

132. Shang, M., J. Tong, and R.J.R.A. O'Hayre, A promising cathode for intermediate temperature protonic ceramic fuel cells: BaCo $0.4 \mathrm{Fe} 0.4 \mathrm{Zr} 0.2 \mathrm{O} 3-\delta .2013$. 3(36): p. 15769-15775.

133. Duan, C., et al., Readily processed protonic ceramic fuel cells with high performance at low temperatures. Science, 2015. 349(6254): p. 1321-1326.

134. Sammells, A.F., et al., Rational selection of advanced solid electrolytes for intermediate temperature fuel cells. Solid State Ionics, 1992. 52(1-3): p. 111-123.

135. Park, S., J.M. Vohs, and R.J. Gorte, Direct oxidation of hydrocarbons in a solidoxide fuel cell. Nature, 2000. 404(6775): p. 265-267.

136. Steele, B.C.H., Appraisal of Ce $1-y$ Gd y O 2-y/2 electrolytes for IT-SOFC operation at 500 C. Solid State Ionics, 2000. 129(1): p. 95-110. 
137. Cheng, Z., et al., From Ni-YSZ to sulfur-tolerant anode materials for SOFCs: electrochemical behavior, in situ characterization, modeling, and future perspectives. Energy \& Environmental Science, 2011. 4(11): p. 4380-4409.

138. Matsuzaki, Y. and I. Yasuda, The poisoning effect of sulfur-containing impurity gas on a SOFC anode: Part I. Dependence on temperature, time, and impurity concentration. Solid State Ionics, 2000. 132(3): p. 261-269.

139. Zhou, W., et al., LSCF Nanopowder from Cellulose - Glycine - Nitrate Process and its Application in Intermediate - Temperature Solid - Oxide Fuel Cells. Journal of the American Ceramic Society, 2008. 91(4): p. 1155-1162.

140. Cheng, Z., No title. Investigations into the interactions between sulfur and anodes for solid oxide fuel cells, 2008.

141. He, H., R.J. Gorte, and J.M. Vohs, Highly sulfur tolerant Cu-ceria anodes for SOFCs. Electrochemical and Solid-State Letters, 2005. 8(6): p. A280.

142. Duan, C., et al., Highly durable, coking and sulfur tolerant, fuel-flexible protonic ceramic fuel cells. Nature, 2018. 557(7704): p. 217.

143. Xia, C., F. Chen, and M. Liu, Reduced-temperature solid oxide fuel cells fabricated by screen printing. Electrochemical and Solid-State Letters, 2001. 4(5): p. A54.

144. Leng, Y.J., et al., Low-temperature SOFC with thin film GDC electrolyte prepared in situ by solid-state reaction. Solid State Ionics, 2004. 170(1): p. 9-15.

145. Gorte, R.J., H. Kim, and J.M. Vohs, Novel SOFC anodes for the direct electrochemical oxidation of hydrocarbon. Journal of Power Sources, 2002. 106(1): p. $10-15$.

146. Devianto, H., et al., The effect of a ceria coating on the H2S tolerance of a molten carbonate fuel cell. Journal of Power Sources, 2006. 159(2): p. 1147-1152.

147. Gong, M., et al., Sulfur-tolerant anode materials for solid oxide fuel cell application. Journal of Power Sources, 2007. 168(2): p. 289-298.

148. Jiang, S.P. and S.H. Chan, A review of anode materials development in solid oxide fuel cells. Journal of Materials Science, 2004. 39(14): p. 4405-4439.

149. McIntosh, S. and R.J. Gorte, Direct hydrocarbon solid oxide fuel cells. Chemical reviews, 2004. 104(10): p. 4845-4866.

150. Zuo, C., et al., Ba (ZrO. 1CeO. 7YO. 2) O3 - $\delta$ as an Electrolyte for Low Temperature Solid - Oxide Fuel Cells. Advanced Materials, 2006. 18(24): p. 33183320. 
151. Weber, W.H., K.C. Hass, and J.R. McBride, Raman study of CeO 2: second-order scattering, lattice dynamics, and particle-size effects. Physical Review B, 1993. 48(1): p. 178.

152. Ratnasamy, C. and J.P. Wagner, Water gas shift catalysis. Catalysis Reviews, 2009. 51(3): p. 325-440.

153. Dusastre, V. and J.A. Kilner, Optimisation of composite cathodes for intermediate temperature SOFC applications. Solid State Ionics, 1999. 126(1-2): p. 163-174.

154. Zhou, W., R. Ran, and Z. Shao, Progress in understanding and development of Ba $0.5 \mathrm{Sr} 0.5 \mathrm{Co} 0.8 \mathrm{Fe} 0.2 \mathrm{O} 3-\delta$-based cathodes for intermediate-temperature solidoxide fuel cells: a review. Journal of Power Sources, 2009. 192(2): p. 231-246.

155. Bi, L., et al., Proton-conducting solid oxide fuel cells prepared by a single step cofiring process. 2009. 191(2): p. 428-432.

156. Lim, D.-K., et al., Study of Hydration/Dehydration Kinetics of SOFC Cathode Material BaO. 5SrO. 5CoO. 8Fe0. 203- $\delta$ by Electrical Conductivity Relaxation Technique. Journal of the Electrochemical Society, 2013. 160(8): p. F768.

157. Sun, S. and Z. Cheng, Effects of H2O and CO2 on Electrochemical Behaviors of BSCF Cathode for Proton Conducting IT-SOFC. Journal of the Electrochemical Society, 2017. 164(2): p. F88.

158. Chick, L., Novel Glycine-Nitrate Process Produces Ultrafine Oxide Ceramic Powders. Materials and Processing Report, 1990. 5(8): p. 1-3.

159. $\mathrm{Hu}, \mathrm{H}$. and M. Liu, Interfacial Polarization Characteristics of Pt $\mid \mathrm{BaCe}$. 8Gd0. 2 O 3| Pt Cells at Intermediate Temperatures. Journal of the Electrochemical Society, 1997. 144(10): p. 3561-3567.

160. Lou, X., et al., Improving La 0.6 Sr 0.4 Co $0.2 \mathrm{Fe} 0.8 \mathrm{O} 3-\delta$ cathode performance by infiltration of a Sm $0.5 \mathrm{Sr} 0.5 \mathrm{CoO} 3-\delta$ coating. Solid State Ionics, 2009. 180(23): p. 1285-1289.

161. Nie, L., et al., La 0.6 Sr 0.4 Co $0.2 \mathrm{Fe} 0.8$ O 3- $\delta$ cathodes infiltrated with samarium-doped cerium oxide for solid oxide fuel cells. Journal of Power Sources, 2010. 195(15): p. 4704-4708.

162. Baumann, S., et al., Influence of sintering conditions on microstructure and oxygen permeation of $\mathrm{Ba} 0.5 \mathrm{Sr} 0.5 \mathrm{Co} 0.8 \mathrm{Fe} 0.2 \mathrm{O} \mathrm{3}-\delta$ (BSCF) oxygen transport membranes. Journal of Membrane Science, 2010. 359(1): p. 102-109.

163. Poetzsch, D., R. Merkle, and J. Maier, Oxygen Reduction at Dense Thin-Film Microelectrodes on a Proton-Conducting Electrolyte I. Considerations on Reaction Mechanism and Electronic Leakage Effects. Journal of the Electrochemical Society, 2015. 162(9): p. F950. 
164. Jamale, A.P., C.H. Bhosale, and L.D. Jadhav, Electrochemical behavior of LSCF/GDC interface in symmetric cell: An application in solid oxide fuel cells. Journal of Alloys and Compounds, 2015. 623: p. 136-139.

165. Virkar, A.N. and H.S. Maiti, Oxygen ion conduction in pure and yttria-doped barium cerate. Journal of Power Sources, 1985. 14(4): p. 295-303.

166. Ranran, P., et al., Electrochemical properties of intermediate-temperature SOFCs based on proton conducting Sm-doped $\mathrm{BaCeO} 3$ electrolyte thin film. Solid State Ionics, 2006. 177(3): p. 389-393.

167. Duan, C., et al., Readily processed protonic ceramic fuel cells with high performance at low temperatures. Science (New York, N.Y.), 2015. 349(6254): p. 1321-1326.

168. Ding, D., et al., Enhancing SOFC cathode performance by surface modification through infiltration. Energy \& Environmental Science, 2014. 7(2): p. 552-575.

169. Leng, Y.J., et al., Performance evaluation of anode-supported solid oxide fuel cells with thin film YSZ electrolyte. International Journal of Hydrogen Energy, 2004. 29(10): p. 1025-1033.

170. Moon, H., et al., Development of IT-SOFC unit cells with anode-supported thin electrolytes via tape casting and co-firing. International Journal of Hydrogen Energy, 2008. 33(6): p. 1758-1768.

171. Matsui, T., et al., Effects of mixed conduction on the open-circuit voltage of intermediate-temperature SOFCs based on Sm-doped ceria electrolytes. Solid State Ionics, 2005. 176(7): p. 663-668.

172. Chiodelli, G. and L. Malavasi, Electrochemical open circuit voltage (OCV) characterization of SOFC materials. Ionics, 2013. 19(8): p. 1135-1144.

173. Ling, Y., et al., A cobalt-free $\mathrm{Sm} 0.5 \mathrm{Sr} 0.5 \mathrm{Fe} 0.8 \mathrm{Cu} 0.2 \mathrm{O} 3-\delta$-Ce $0.8 \mathrm{Sm} 0.2 \mathrm{O}$ $2-\delta$ composite cathode for proton-conducting solid oxide fuel cells. Journal of Power Sources, 2011. 196(5): p. 2631-2634.

174. Zhao, F., et al., Fabrication and characterization of anode-supported microtubular solid oxide fuel cell based on BaZr 0.1 Ce 0.7 Y 0.1 Yb $0.103-\delta$ electrolyte. Journal of Power Sources, 2011. 196(2): p. 688-691.

175. Malavasi, L., C.A.J. Fisher, and M.S. Islam, Oxide-ion and proton conducting electrolyte materials for clean energy applications: structural and mechanistic features. Chemical Society Reviews, 2010. 39(11): p. 4370-4387.

176. Dailly, J., et al., Perovskite and A 2 MO 4-type oxides as new cathode materials for protonic solid oxide fuel cells. Electrochimica Acta, 2010. 55(20): p. 5847-5853. 
177. Fabbri, E., et al., Electrode materials: a challenge for the exploitation of protonic solid oxide fuel cells. 2010. 11(4): p. 044301.

178. Fabbri, E., et al., Towards the Next Generation of Solid Oxide Fuel Cells Operating Below $600^{\circ} C$ with Chemically Stable Proton - Conducting Electrolytes. Advanced Materials, 2012. 24(2): p. 195-208.

179. Jeon, S.-Y., et al., Effectiveness of Protonic Conduction in BaO. 5SrO. 5CoO. 8Fe0. $203-\delta$ Cathode in Intermediate Temperature Proton-Conducting CeramicElectrolyte Fuel Cell. Journal of the Electrochemical Society, 2014. 161(6): p. F760.

180. Liu, B. and Y. Zhang, Ba $0.5 \mathrm{Sr} 0.5$ Co $0.8 \mathrm{Fe} 0.2 \mathrm{O} 3$ nanopowders prepared by glycine-nitrate process for solid oxide fuel cell cathode. Journal of Alloys and Compounds, 2008. 453(1): p. 418-422.

181. Zhou, W., et al., A novel efficient oxide electrode for electrocatalytic oxygen reduction at 400-600 C. Chemical Communications, 2008(44): p. 5791-5793.

182. Andersson, A.K.E., et al., Chemical Expansion Due to Hydration of Proton Conducting Perovskite Oxide Ceramics. Journal of the American Ceramic Society, 2014. 97(8): p. 2654-2661.

183. Mauvy, F., et al., Electrode properties of Ln2NiO4 $\delta$ ( $L n=L a, N d, P r) A C$ impedance and DC polarization studies. Journal of the Electrochemical Society, 2006. 153(8): p. A1553.

184. Ryu, K.H. and S.M. Haile, Chemical stability and proton conductivity of doped $\mathrm{BaCeO}$ 3-BaZrO 3 solid solutions. Solid State Ionics, 1999. 125(1): p. 355-367.

185. He, F., et al., Cathode reaction models and performance analysis of Sm $0.5 \mathrm{Sr} 0.5$ $\mathrm{CoO} 3-\delta-\mathrm{BaCe} 0.8 \mathrm{Sm} 0.2 \mathrm{O} 3-\delta$ composite cathode for solid oxide fuel cells with proton conducting electrolyte. Journal of Power Sources, 2009. 194(1): p. 263268. 
VITA

\section{SHICHEN SUN}

2007-2011

B.S., Materials Physics

Fudan University

Shanghai, China

2011-2014

Physics editor

Wangxiangsiwei Publication Coporation

Beijing, China

2014-2018

Research Assistant

Florida International University

Miami, Florida

\section{PUBLICATIONS}

1. Sun, Shichen; Cheng, Zhe. "H2S poisoning of proton conducting solid oxide fuel cell and comparison with conventional oxide-ion conducting solid oxide fuel cell," Journal of the Electrochemical Society (2018), 165 (10), F836-F844. DOI: 10.1149/2.0841810jes

2. Sun, Shichen; Awadallah, Osama; Cheng, Zhe. "Poisoning of Nickel-Based Anode for Proton Conducting SOFC by H2S, CO2, and $\mathrm{H} 2 \mathrm{O}$ as Fuel Contaminants," Journal of Power Sources (2018), 378, 255-263. DOI:10.1016/j.jpowsour.2017.12.056

3. Sun, Shichen; Cheng, Zhe. "Electrochemical Behaviors for Ag, LSCF and BSCF as Oxygen Electrodes for Proton Conducting IT-SOFC," Journal of the Electrochemical Society (2017), 164(10), F3104-F3113. DOI:10.1149/2.0121710jes

4. Sun, Shichen; Cheng, Zhe. "Effects of $\mathrm{H} 2 \mathrm{O}$ and $\mathrm{CO} 2$ on Electrochemical Behaviors of BSCF Cathode for Proton Conducting IT-SOFC," Journal of the Electrochemical Society (2017), 164(2), F81-F88. DOI:10.1149/2.0611702jes. 